\title{
Expectations in financial markets
}

Citation for published version (APA):

Jongen, R. (2007). Expectations in financial markets. [Doctoral Thesis, Maastricht University]. Maastricht University. https://doi.org/10.26481/dis.20071206rj

Document status and date:

Published: 01/01/2007

DOI:

10.26481/dis.20071206rj

Document Version:

Publisher's PDF, also known as Version of record

\section{Please check the document version of this publication:}

- A submitted manuscript is the version of the article upon submission and before peer-review. There can be important differences between the submitted version and the official published version of record.

People interested in the research are advised to contact the author for the final version of the publication, or visit the DOI to the publisher's website.

- The final author version and the galley proof are versions of the publication after peer review.

- The final published version features the final layout of the paper including the volume, issue and page numbers.

Link to publication

\footnotetext{
General rights rights.

- You may freely distribute the URL identifying the publication in the public portal. please follow below link for the End User Agreement:

www.umlib.nl/taverne-license

Take down policy

If you believe that this document breaches copyright please contact us at:

repository@maastrichtuniversity.nl

providing details and we will investigate your claim.
}

Copyright and moral rights for the publications made accessible in the public portal are retained by the authors and/or other copyright owners and it is a condition of accessing publications that users recognise and abide by the legal requirements associated with these

- Users may download and print one copy of any publication from the public portal for the purpose of private study or research.

- You may not further distribute the material or use it for any profit-making activity or commercial gain

If the publication is distributed under the terms of Article $25 \mathrm{fa}$ of the Dutch Copyright Act, indicated by the "Taverne" license above, 
Expectations in Financial Markets 



\title{
Expectations in Financial Markets
}

\author{
PROEFSCHRIFT
}

ter verkrijging van de graad van doctor aan de Universiteit Maastricht, op gezag van de Rector Magnificus, Prof. mr. G.P.M.F. Mols, volgens het besluit van het College van Decanen, in het openbaar te verdedigen op donderdag 6 december 2007 om 16.00 uur

door

R.B.M. Jongen 


\section{Promotores:}

Prof. dr. C.C.P. Wolff

Prof. dr. W.F.C. Verschoor (Radboud Universiteit Nijmegen)

\section{Beoordelingscommissie:}

Prof. dr. J.M.E. Pennings (Voorzitter)

Prof. dr. R.M.M.J. Bauer

Prof. dr. E. de Jong (Radboud Universiteit Nijmegen)

(C) 2007 Ron Jongen

ISBN 978-90-5278-682-7

Cover design: Ilja Maas 


\section{Preface}

This dissertation is about expectations in financial markets. The purpose of this research is to examine what one can learn from expectations, what they tell us about individual participants in financial markets, about the future, about periods of financial turmoil, and about the way market participants form their beliefs. In this research, I use survey data as a proxy for expectations of market participants. Survey data are obtained through sending questionnaires to key players in financial markets, to ask these market participants what they think will happen in the future with a particular economic variable. In this study, I focus on expectations of future exchange rates and future interest rates.

Looking back over the four years I worked on this research I have to admit that it was a tremendously interesting and fun experience. The many useful discussions I had with my colleagues and experts in the field, the many business trips I made abroad, and the many things I have learned during this time have certainly given shape to this dissertation and to me as a person. I am grateful to many people who have made this experience particularly enjoyable.

My first words of gratitude go to my supervisor Christian Wolff. I would like to thank him for the many things I have learned from him and for the confidence he always expressed in me and my work. He has allowed me much independence in how I conducted my research, but at the same time he was close by to provide meaningful advice and constructive criticism. His role as a mentor has extended far beyond that concerning the content of this dissertation alone. Over the years I have also become impressed by his personality and attitude towards life, and I look back at a very pleasant cooperation.

My other supervisor, Willem Verschoor, has also been a great motivating force behind this dissertation. Despite the physical distance between Nijmegen and Maastricht, I always felt his presence and encouragement. The most apparent example of this is that he envisaged the final version of an article and the academic journal in which this article should be published long before the first letter was ever written! The conversations we had about my work, but also about holidays, family and his boat, have always been very enjoyable to me.

Aline and Remco definitely deserve thank-you's! Our cooperation on some of the work in this dissertation has been a wonderful experience and the articles we wrote together look very promising! I sincerely hope that we will continue our cooperation in the future. I am also grateful to Ilja and Hetty for helping me so much with the 
design and format of this book.

I owe a special word of gratitude to Dennis and Chris, my two 'paranimfen' They have always supported me greatly and have provided me with much valuable advice during the last stages of finishing this dissertation. But more than that, both of them, each in their own way, have been two very important persons to me during the years I worked on this dissertation. I hope that our friendship will all but grow for the years ahead.

They say that caring parents are always proud of their children. I am fortunate to concur with this! I learned much from my parents' sense of perspective and the need for reflection. Their unconditional support, care, advice, and pride, I will always cherish and they have greatly shaped me as a person. Many of my achievements, however small they may be, are also theirs. To them I can only say: I am very proud of you too!

My last words are for the person who has been standing at my side for all these years ... Loes. She made me feel proud of my work, and I made her share in the excitement of my research, mostly by attending opera performances in La Scala, eating Wiener Schnitzels in Vienna, experiencing the culinary discoveries in the Zeughauskeller in Zürich, running from one highlight to the other to see as much as possible from yet another city during the free hours we had on a conference trip, and many other experiences. To me it feels she wrote two dissertations: her own in terms of content and at the same time mine in terms of encouragement, reflection, and understanding. Her wonderful personality, intelligence, and the bravery in the choices she makes in her life can only make me feel all but exceptionally proud of her. I am grateful that we have been on such a long journey together with many wonderful roads still ahead.

Ron Jongen

Maastricht, Fall 2007 


\section{Contents}

1 Introduction 1

1.1 Expectations in Financial Markets . . . . . . . . . . . . . . . . 1

1.2 A Survey Data Approach . . . . . . . . . . . . . . . . . . 3

1.3 Aims and Outline of the Dissertation . . . . . . . . . . . . . 4

2 Perspectives on Foreign Exchange Rate Expectations 9

2.1 Introduction . . . . . . . . . . . . . . . . . . 9

2.2 The Forward Premium Puzzle . . . . . . . . . . . . . . . . . . 11

2.3 Modeling Risk Premiums . . . . . . . . . . . . . . . . . 17

2.4 Foreign Exchange Forecasting Performance . . . . . . . . . . . . . 20

2.5 Market Microstructure and Heterogeneity . . . . . . . . . . . . . 22

2.6 Noise Trading, Chartism, and the Role of Fundamentals . . . . . . . 26

2.7 Conclusions . . . . . . . . . . . . . . 28

3 On the Rationality of Interest Rate Expectations 31

3.1 Introduction . . . . . . . . . . . . . . . . . . 31

3.2 Survey Data and Standard Propositions Regarding Expectations . . 33

3.3 The Rationality of Interest Rate Expectations . . . . . . . . . . . . . 36

3.4 Models of Expectations Formation . . . . . . . . . . . . . . . 45

3.5 Conclusions . . . . . . . . . . . . . . . . . 53

4 Time-Variation in Term Premia $\quad 55$

4.1 Introduction . . . . . . . . . . . . . . . . . 55

4.2 The Expectations Hypothesis of the Term Structure . . . . . . . . 58

4.3 Survey Data and Standard Propositions Regarding Expectations . . 59

4.4 Rational Expectations and Time-Varying Term Premia . . . . . . . . 67

4.5 Time Series Behavior of the Term Premia . . . . . . . . . . . . . 73

4.6 Determinants of the Time-Variation Present in the Term Premium . 74

4.7 Conclusions . . . . . . . . . . . . . . . . . 79

5 Dispersion of Beliefs in Foreign Exchange $\quad 81$

5.1 Introduction . . . . . . . . . . . . . . . . . 81

5.2 Dispersion of Beliefs in Foreign Exchange . . . . . . . . . . . . . . 84

5.3 Data ......................... 87 
5.4 Are the Beliefs of Foreign Exchange Forecasters Dispersed? . . . . . 89

5.5 Asymmetric Information with Individual and Idiosyncratic Effects . 96

5.6 Dispersion of Beliefs and Market Conditions . . . . . . . . . . . . . 101

5.7 Conclusions . . . . . . . . . . . . . . . . 106

6 The Use of Fundamentalist and Chartist Techniques in Forecasting $\begin{array}{ll}\text { Foreign Exchange } & 109\end{array}$

6.1 Introduction . . . . . . . . . . . . . . . . . . . 109

6.2 Methodological Background . . . . . . . . . . . . . . 111

6.3 The Forecasting Rules . . . . . . . . . . . . . . . . . . . . 112

6.3.1 Purchasing Power Parity . . . . . . . . . . . . . . . . 114

6.3.2 Monetary Model . . . . . . . . . . . . . . . . 115

6.4 Data . . . . . . . . . . . . . . . . . 116

6.4.1 Unit Root Test Results . . . . . . . . . . . . . . . 117

6.4.2 Cointegration Results ................. 120

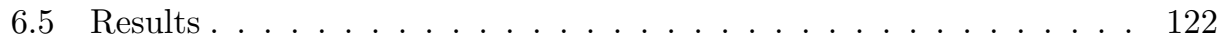

6.5.1 Linear Model . . . . . . . . . . . . . . . . . . . . . . . 122

6.5.2 Heterogeneous Agent Model . . . . . . . . . . . . . . . 125

6.5.3 State Space Model . . . . . . . . . . . . . . . . . 128

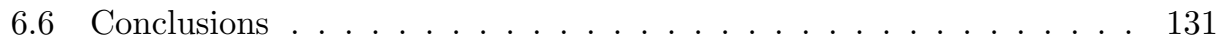

7 Using Survey Data to Test Propositions Regarding Exchange Risk $\begin{array}{lc}\text { Exposure } & 133\end{array}$

7.1 Introduction . . . . . . . . . . . . . . . . . 133

7.2 Background and Motivation . . . . . . . . . . . . . . 135

7.3 Sample Selection of U.S. Multinationals and Survey Data . . . . . . 138

7.3.1 U.S. Multinational Firms . . . . . . . . . . . . . . . . 138

7.3.2 Exchange Risk Factors . . . . . . . . . . . . . . . . . 139

7.4 Empirical Design . . . . . . . . . . . . . . . . . . . . . . . . . . . . . . . . . . . 143

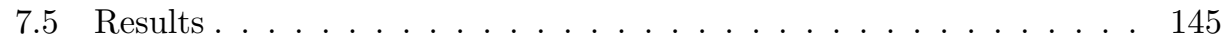

7.6 Conclusions . . . . . . . . . . . . . . . . . . . . . . . . . 149

8 Conclusions $\quad 151$

8.1 Expectations in Financial Markets . . . . . . . . . . . . . . . . 151

8.2 Summary . . . . . . . . . . . . . . . . . 151

8.3 Lessons from Expectations and Suggestions for Future Research . . . 155

$\begin{array}{lr}\text { Bibliography } & 159\end{array}$

$\begin{array}{ll}\text { Nederlandse Samenvatting } & 173\end{array}$

$\begin{array}{ll}\text { Curriculum Vitae } & 179\end{array}$ 


\section{List of Tables}

3.1 Summary Statistics of the Survey-Based Forecast Error . . . . . . . 35

3.2 Pooled Test of Forward Rate Unbiasedness . . . . . . . . . . . . . . 37

3.3 Individual Test of Forward Rate Unbiasedness . . . . . . . . . . . . . 39

3.4 Unbiasedness Test of Survey-Based Expectations . . . . . . . . . . . 41

3.5 Multivariate Orthogonality Test (3-month forecast horizon) . . . . . 43

3.6 Multivariate Orthogonality Test (12-month forecast horizon) . . . . 44

3.7 Test of Error Orthogonality to Forward Premiums . . . . . . . . . . 46

3.8 Extrapolative Expectations Model . . . . . . . . . . . . . . . 48

3.9 Adaptive Expectations Model . . . . . . . . . . . . . . . 50

3.10 Mixed Expectations Model (3-month forecast horizon) . . . . . . . . 51

3.11 Mixed Expectations Model (12-month forecast horizon) . . . . . . . 52

4.1 Forecast Performance . . . . . . . . . . . . . . . . 61

4.2 Summary Statistics of the Realized and Expected Interest Rates . . 62

4.3 Summary Statistics of the Term Premia . . . . . . . . . . . . 63

4.4 Unit Root Test Results . . . . . . . . . . . . . . . . . . . 66

4.5 Forward Rate Unbiasedness . . . . . . . . . . . . . . . 68

4.6 Error Orthogonality to Forward Premia . . . . . . . . . . . . . . 71

4.7 Time-Variation in Term Premia . . . . . . . . . . . . . . . 72

4.8 ARMA Specifications for the Term Premia . . . . . . . . . . . . 75

4.9 Linear Model of the Term Premium . . . . . . . . . . . . . . . 77

4.10 A GARCH-in-Mean Model of the Term Premium . . . . . . . . . . . 78

5.1 Data Summary . . . . . . . . . . . . . . . . . 88

5.2 Distributional Summary Statistics of the Deviations (pooled sample) 93

5.3 Hill Estimates (pooled sample) . . . . . . . . . . . . . . . 95

5.4 Percentages Agents with Individual or Idiosyncratic Effects . . . . . 98

5.5 Percentages Agents with Individual or Idiosyncratic Effects (combined) 100

5.6 Combinations of Effects . . . . . . . . . . . . . . . . . 101

5.7 Dispersion and Market Characteristics . . . . . . . . . . . . . 103

5.8 Granger Causality Tests . . . . . . . . . . . . . . . 105 
6.1 Unit Root Test Results (individual series) . . . . . . . . . . . . . 118

6.2 Unit Root Test Results (relative to U.S. series) . . . . . . . . . . . 119

6.3 Cointegration Test Results (full sample) . . . . . . . . . . . . . . 121

6.4 Linear Model (3 month forecast horizon) . . . . . . . . . . . . . . . . 123

6.5 Linear Model (12 month forecast horizon) . . . . . . . . . . . . . . . 124

6.6 Heterogeneous Agent Model (3 month forecast horizon) . . . . . . . 126

6.7 Heterogeneous Agent Model (12 month forecast horizon) . . . . . . . 127

6.8 State Space Model (3 month forecast horizon) . . . . . . . . . . . . . 129

6.9 State Space Model (12 month forecast horizon) … . . . . . . 130

7.1 Summary Statistics of Sample of U.S. Multinational Firms . . . . . . 139

7.2 Geographic Dispersion of the Foreign Activities of U.S. Firms . . . . 140

7.3 Summary Statistics of Realized and Unexpected Exchange Rate Change142

7.4 Exposure to Realized Exchange Rate Changes . . . . . . . . . . . . . 146

7.5 Exposure to Unanticipated Exchange Rate Changes . . . . . . . . 147 


\section{Chapter 1}

\section{Introduction}

\subsection{Expectations in Financial Markets}

Expectations play a very important role in all aspects of life. Everyone has his or her own expectations about specific events or about the outcome of these events in the future, for instance the status of the weather, the result of a football match, or even the life expectancy of oneself. These expectations are usually very subjective. At times we can have the same expectation as other people, while at other times the expectations are not in line.

The expectations we have guide, to a large extent, the actions we perform at the present time. If we have a certain expectation about an event in the future, we plan our actions in such a way that we can benefit the most from the event in the future. Expectations may be the result of sheer guess and intuition, but can also be the result of experience, learning, and other skillful use of all the information we possess that may have anything to do with the future event for which we have a particular expectation.

In financial markets expectations play an equally important role. The behavior of what we observe now in these markets is often driven by what we expect will happen in the future. An expected political uproar or civil war in oil producing countries, for instance, will increase the price of crude oil and an expected increase in United States (U.S.) interest rates will raise the rate of return on U.S. dollars above the rate of return on euros, leading investors to shift investments to U.S. assets, which results in an increase in the U.S. dollar / Euro exchange rate (i.e., an appreciation of the U.S. dollar and a depreciation of the Euro).

In fact, many theoretical models in the financial economics literature assume a relationship between the current value of a financial instrument and the expectations about the future value of that instrument. An example hereof is the dividend discount model, that states that the price of a certain stock at present is the discounted value of all expected future dividend payments. Another example is the expectations hypothesis of the term structure of interest rates, of which one version states that the return on a long term bond contract is equal to the weighted average 
of the expected future return on short term contracts.

Yet, one of the most critical aspects of expectations is that they are unobservable. One cannot measure what 'the' expectation is of, say, the future exchange rate. For that reason, we cannot verify the correctness of many of the models that have been devised in the financial economics literature. Financial policy makers and academics have therefore used several attempts to approximate these expectations. The two mainstream approaches that have always been used is 1) to try to model the expectations using economic theory and other variables and 2) to make assumptions about the way the expectations are formed.

One of the most frequently used assumption about expectations is that of rationality, which, in a nutshell, states that expectations are made by an agent who is representative for all agents, who'se expectations are not biased, and who uses all information that is available to him in an optimal manner. Among the reasons of the popularity of the rational expectations assumption is the relative ease of (mathematical) modeling and, especially in empirical work, the lack of alternatives. For these reasons the rational expectations assumption has become one of the major workhorses in the financial economics literature. For instance, Lucas (1972, 1976), Sargent and Wallace (1975), and Barro (1976) demonstrate that the assumption of rationality of agents' expectations in the Muth (1961) sense has strong implications for economic behavior and policy, but, at the same time make the assumption that the rational expectations hypothesis remains upheld. In later empirical work by Friedman (1979, 1980), Fama (1984a,b) and Wolff (1987a) the rational expectations hypothesis remained the principal tool with which the expectations generating process was characterized.

Yet, the assumption of rational expectations is not a solution to many of the questions and debates that remain in the literature. For instance, in a world where expectations are generated in a rational way and where market participants are expected to behave all in the same, rational manner, we cannot explain some of the so called 'anomalies' (or: puzzles) that exist in the literature. An example of such an anomaly is the finding that the amount of foreign exchange that is currently traded on a daily basis is far in excess of the amount that is required for the trade of goods and services. Frankel and Froot (1990b), MacDonald and Marsh (1996), and Chionis and MacDonald (1997) claim that this is the result of the interaction between highly different and irrational market participants. Similarly, in the foreign exchange risk exposure literature, pioneered by the work of Adler and Dumas (1984) and Jorion (1990), expectations were also assumed to be formed in a rational manner. But the result of this assumption is that although there should be, from a theoretical perspective, a strong argument in favor of the claim that the return on companies' stocks are affected by the fluctuations in exchange rates, there is much less empirical proof hereof.

From these examples it is clear that the way we think about how expectations are generated and how typical market participants behave, needs to be re-examined. One promising alternative to the approaches in the previous section is the use of survey data. The next section will introduce this approach. 


\subsection{A Survey Data Approach}

In a typical survey representative market participants are questioned about their subjective forecasts about the future value of a particular financial instrument or the path a certain instrument will follow in the future. The participants in the survey can be questioned for point forecasts of the price of a certain stock, exchange rate, or macroeconomic variable, or simply be asked whether the value of an instrument will increase or decrease over a certain time period.

Among the advantages of using survey data is that financial policy makers and academics do not have to make any assumptions anymore about the way expectations are formed. Furthermore, no modeling of expectations is required, as the expectations formation process is left over to the individual survey participants. Although of course all survey participants can use different expectations generating techniques, any aggregate measure of these individual expectations should give a reasonable proxy for 'the' market's expectation.

Typical concerns when using survey data in any setting are whether this data reflects the true market's expectations, whether the expectations are biased because of strategic behavior from the panelists, or whether forecasts from surveys are of any good in an out-of-sample forecast setting - a criteria that has often been put forward to evaluate the quality of survey expectations. It should be noted that for survey data in the present setting it is only important that the survey forecasts reflect the market's sentiment at the time they are formed, that is, the survey data should reflect expectations, nothing more than that. There may be reasons for panelists not to reveal their true beliefs, though. One motive may be that agents do not want to expose their (private) information to other market participants. This effect can be mitigated by the reputation effect that surveys can have. When the names of the forecasters are given in the survey publication, which is more often the case nowadays, panelists have an incentive to perform well in order to attract customers.

Also, while it is not the primary concern that the expectations outperform other forecasting techniques, there is general consensus that expectations from surveys in general perform no worse than any other forecast technique. Ang et al. (2007), for instance, provide recent evidence that expectations from various surveys on inflation consistently deliver better forecasts than time-series models, models based on the yield curve, and forecasts based on the Phillips curve, which highlights the usefulness of survey measures of expectations. Elliott and Ito (1999) find that in the foreign exchange market portfolio's based on survey expectations produce small, but positive, profits.

The use of survey data is not uncommon in the finance literature and increasingly the use of surveys in various areas of the finance literature is observed. Early work predominantly focused on macro-economic forecasts. For example, Friedman (1979, 1980), Froot (1989) and MacDonald and Macmillan (1994) have used interest survey data in tests for identifying term premiums and examining the rationality of expectations of future interest rates and concluded that forecasts were biased and respondents did not efficiently exploit the information contained in past interest movements. Similarly, Dokko and Edelstein (1989) reviewed the usefulness of the 
Livingston forecasts of stock market rates of return and find evidence of adaptive behavior in the forecasts. Keane and Runkle (1990) use survey forecasts of the GNP deflator and find that expectations are rational, and MacDonald and Torrance (1988b) used survey data on expected changes in money aggregates with U.K. data and find that these survey measures of expectations are extremely useful, for, unlike statistical methods for generating estimates, they are truly exogenous.

In the last years the use of survey data has become more common in many other field in the (financial) economics literature, for instance in equity markets (Strong and $\mathrm{Xu}, 2003$ ), inflation (Branch, 2004, 2007), labor market (Di Tella and MacCulloch, 2005), trade policy (Porto, 2006), manufacturing (Mitchell, 2007), and consumer characteristics (Bhattacharya, 2007; Fernandez-Villaverde and Krueger, 2007). The use of survey-based measures of expectations has by now become a firmly-established tool in many areas of (financial) economics.

In the foreign exchange and interest rate literature in particular, Dominguez (1986), Frankel and Froot (1987b), Froot (1989), Hafer et al. (1992), Cavaglia et al. (1993b, 1994), and MacDonald and Macmillan (1994) have addressed several important topics using survey-based measures of expectations, namely whether expectations are formed in a rational manner and whether time-varying risk premiums exist in the expectations of market participants. Yet, several important issues still remain unanswered. It is the goal of this research to fill these gaps. We will outline these gaps in particular.

\subsection{Aims and Outline of the Dissertation}

The aim of this research is to get new insights in the role of expectations in financial markets. In this study we focus in particular on the foreign exchange and interest rate markets. We address several topics that have previously not been examined before. These topics are 1) whether expectations in interest rate markets are formed in a rational manner or whether any other expectations generating technique better characterizes expectations, 2) whether term premia that are inherently present in interest rates vary over time and what the source of this time-variation is, 3) whether expectations in foreign exchange markets are dispersed and what the source of this dispersion is, 4) whether market participants use different tools over time to forecast future and foreign exchange, and 5) whether we can prove that foreign exchange risk exposure is understated when not specifically measuring exposure in terms of unanticipated exchange rate exposure.

All these topics will be examined empirically and the use of survey-based measures of expectations will play a central role in each of them. It should be noted that we do not address several other important topics in the field, such as the role of expectations of stock prices, inflation rates, and other macroeconomic variables. Although much can still be learned from these fields, it is beyond the scope of this research. It should also be noted that this study does not look at the forecasting role of expectations, rather, we look at which lessons can be learned from the expectations and what the expectations say about the behavior of market participants. 
In chapter 2 we start with an exploratory study of the role of survey-based measures of expectations in the foreign exchange market. The chapter gives an overview of the theoretical and empirical work that is done in five areas of foreign exchange research, where in all the five areas the use of survey-based measures of expectations has a central role. First, the chapter analyzes the evidence on the failure of the forward exchange rate as an unbiased predictor of future spot exchange rates and in particular looks at whether the failure is primarily attributable to time-varying risk premiums, to the failure of the rationality assumption, or to a combination of both. Second, the chapter reviews the various attempts to model the time-variation in the risk premium in foreign exchange and investigates whether the use of survey-based measures of expectations adds in this modeling. Third, the chapter looks at the performance of market participants when forecasting future exchange rates and tries to ascertain whether individual market participants can outperform a simple random walk forecast. Fourth, the chapter looks at the role of heterogeneity in survey-based forecasts and how this heterogeneity can shed new light on some of the puzzles in the foreign exchange market, like the excess volume of foreign exchange trade. Fifth, the chapter reviews the literature on fundamentalistversus chartist-type of forecast techniques and how the interaction between these two techniques has changed over the years.

In chapter 3 we apply some of the lessons from the field of foreign exchange to the area of interest rates. We try to shed new light on one of the areas in the field of interest rates expectations and the term structure of interest rates that has received quite some attention in the literature, namely whether expectations of future interest rates are made in a rational manner. The chapter begins with one of the well-documented anomalies in the field, namely that implied forward interest rates are biased estimates of future interest rates. This is the so-called forward premium puzzle. We define what we mean by 'rational' and start the analysis by replicating 'traditional' ways by which the forward premium puzzle has been examined. We then introduce a unique data set of survey-based interest rate forecast for a large set of international interest rates, where forecasts are made for several periods of different length in the future. The survey data allows us to perform two additional tests, namely one in which we examine whether the expectations by market participants are biased and another that examines whether market participants use all information that is available to them in an optimal manner. These two tests together assist in answering the question whether interest rate expectations are formed in a rational manner and thus whether the failure of the forward rate as an unbiased predictor of future interest rates is attributable to irrational behavior. Finally, the chapter tries to find alternative approaches to the rational expectations model and investigates whether survey-based expectations are better characterized by learning behavior or mean-reversion behavior.

In chapter 4 we extend the analysis from chapter 3 and investigate an alternative explanation for the forward premium puzzle, namely whether the premium that market participants require for investing at a certain horizon changes over time. We call this premium the time-varying term premium. We provide a theoretical decomposition of the forward premium puzzle into one part that can be attributable 
to irrational expectations (as investigated in chapter 3) and one part that can be attributable to time-varying term premia. We apply the analysis on the same data set as in the previous chapter to keep the results comparable. Unit root tests for the stationarity of the spot and expected interest rate series are provided as a first step in examining the relationship between term premia and the forward premium puzzle. We then turn to a test that examines the time-variation and look at the role of serial correlation and volatility clustering. Next, we turn to a novel field, namely that of trying to explain the time-variation in the premia by means of survey-measures of expectations. First, we examine various time-series models, then we introduce a linear model, and finally use a GARCH-type model that considers the conditional variance of the premia.

In chapter 5 we make two switches in research. First, we jump to the field of exchange rates and second we introduce the role of heterogeneity in the expectations of market participants. Chapter 5 looks at the role of the difference between the expectations of one market participant versus those of another. We call this difference the 'dispersion of beliefs'. The chapter begins with a theoretical discussion of what dispersion of beliefs is and why it is important in asset pricing. We discuss three important reasons why dispersion of beliefs arises. Using a unique data set of survey-based exchange rate expectations, the chapter tries to address three important questions. First, it attempts to get an answer on how dispersion of beliefs can be discovered in a statistically meaningful manner. This is done by looking at the distribution of the individual differences in beliefs. We use tools from Extreme Value Theory. Second, the chapter tries to get an answer as to what the sources of the dispersion are, by looking at whether market participants have private information on which they build their individual beliefs, whether they simply interpret information in a different way, or a combination of both. Third, we try to answer the question whether the dispersion of beliefs, which is not constant over time, has an effect on the volatility of the market. We examine the (causality) relationship between dispersion, volatility and fatness of tails.

Chapter 6 builds upon the previous chapter and looks at whether dispersion of beliefs occurs because market participants use different types of rules to forecast future foreign exchange. We make the distinction between fundamentalist and chartist rules, where the former relies on various (macroeconomic) variables and the latter exclusively on the own history of the exchange rate. We develop a theoretical framework where the expected change by a particular market participant is a time-varying weighted average of a fundamentalist and chartist rule. We construct several forecast rules that are both easy to construct and for which we know that all market participants have access to. These rules are a purchasing power parity-based rule, a rule that relies on a version of the monetary model, an extrapolative expectations rule, and a moving average rule. These rules are then implemented in thee different models. The first model is a linear one where the weights of the various forecast techniques are assumed to be constant during the entire forecast period. The second model is a heterogeneous agent model that allows for switching between the chartist and fundamentalist techniques, where switching is based on the relative success of each rule in the previous period. The last model is a state-space model where the 
weights are assumed to follow a simple, low order time-series process.

Chapter 7 brings together two areas of research in international finance, namely that of survey-based exchange rate expectations and that of foreign exchange risk exposure. In the chapter we introduce a sample of 935 U.S. multinational companies that have operations abroad. We investigate whether the domestic-currency returns of these companies are exposed to foreign exchange risk by specifically modeling the 'unanticipated' changes in the exchange rates to which individual companies should be exposed. The use of survey-based measures of exchange rate expectations allow us to ascertain the claim that standard exposure studies underestimate the extent of exposure because they use 'realized' changes in the exchange rate instead of 'unanticipated' changes. This approach is revolutionary in the literature. The study also generates company-specific exchange risk factors, by exposing the individual companies' returns only to those areas in the world in which it has foreign operations. The chapter provides tests both for the case where 'realized' exchange rate changes are used to proxy the foreign exchange risk factors and the case where 'unanticipated' (based on the survey-based expectations) changes are used.

Finally, chapter 8 takes the evidence from all these studies together and presents general conclusions. Future directions for research are provided as well. 



\section{Chapter 2}

\section{Perspectives on Foreign Exchange Rate Expectations*}

\section{$2.1 \quad$ Introduction}

In the last decades we have seen an increase in the number of studies that attempt to explain various anomalies in the foreign exchange market. The academic interest in this market does not come as a surprise, because the foreign exchange market has grown to be the largest market worldwide in terms of volume and trade. For instance, the amount of foreign exchange that is traded worldwide is far in excess of what is required for trade in goods and services. It therefore seems that the foreign exchange market is a market 'on its own' and that this market, because of its large volume, is highly liquid and efficient (Froot and Thaler, 1990). For this reason, market participants are said to have equal access to information and form their expectations about future events in a uniform, rational manner.

However, with the rise of several anomalies in the foreign exchange literature, such as the forward premium puzzle or the excess trade volume, the notion of rational expectations is losing more and more ground. Instead, the focus is shifting in the direction of bounded rationality, and the accompanying heterogeneity of agents' expectations. New insight in how market participants form their expectations is therefore warranted.

Over the last decades, an interesting and promising new literature has emerged, relying on survey measures of exchange rate expectations. Instead of making assumptions about the way expectations are formed, or relying on some underlying model for these expectations, these studies try to measure expectations by use of a market panel. Pioneered by the work of, inter alia, Blake et al. (1986), Dominguez (1986), and Frankel and Froot (1987b), many studies since have employed some form of survey measures of expectations in explaining some of the anomalies in the foreign

* Part of this chapter is forthcoming in the Journal of Economic Surveys as joint work with Willem F.C. Verschoor and Christian C.P. Wolff. 
exchange market.

In this chapter we will give an overview of the work that was conducted in five areas of foreign exchange research, all of which have received considerable attention over the past few decades. The emphasis in these five areas is on the role of expectations about future exchange rates. First, we will discuss the failure of the forward rate as an unbiased estimate for future spot exchange rates, and in particular look at whether the failure is attributable to the role of time-varying risk premiums, or due to the failure of the assumption of rational expectations. Second, we look at attempts to model the time-variation in the term premium using either fundamentals-based models or time-series models. Third, we look at the performance of market participants when forecasting future exchange rates and try to ascertain whether individual agents can outperform a simple benchmark like a random walk forecast. Fourth, we look at a relatively new field within the foreign exchange literature: market microstructure and the role of heterogeneous expectations. Finally, we review some of the literature on the role of fundamentally different types of agents and the interaction between these types.

The use of survey data has not been uncommon in the international financial economics literature. For example, Friedman (1979, 1980), Froot (1989), and MacDonald and Macmillan (1994) have used survey data on interest rates in order to quantify term premiums and to examine whether these expectations are formed in a rational manner. They concluded that predictions were biased and respondents did not efficiently exploit the information contained in past interest movements. Similarly, Dokko and Edelstein (1989) review the usefulness of the Livingston forecasts of stock market rates of return and find evidence of adaptive behavior in the forecasts, Keane and Runkle (1990) use survey forecasts of the GNP deflator and find that expectations are rational, and MacDonald and Torrance (1988a) use survey data on expected changes in money aggregates with U.K. data and find that these survey measures of expectations are extremely useful, for, unlike statistical methods for generating estimates, they are truly exogenous. It is thus surprising that only towards the end of the 1980s the use of survey data was established in the foreign exchange literature.

On the other hand, the number of surveys on exchange rate expectations has grown considerably over the past twenty years. Most promising, these surveys 1) increasingly encompass exotic exchange rates (i.e., not only the top five most actively traded rates), 2) they have also included more cross-rates (instead of only currencies relative to the U.S. dollar), and 3) have reported expectations on a disaggregated level, instead of only reporting a consensus measure such as the arithmetic mean. It is therefore not surprising that at the end of the 1980s the literature that incorporates the forecasts from such surveys had expanded rapidly and is still growing. In this chapter, we intend to capture all of the main findings from these studies from the past twenty years.

Although this study is not the first to review this considerable, and growing, literature, it nevertheless fills some important gaps. For instance, in his review of the literature on forward market efficiency, Engel (1996) explicitly excludes the important areas of learning and peso problems, tests of rational expectations and 
time-varying risk premiums based on survey data. ${ }^{1}$ Takagi (1991), as well as Maddala (1991) and MacDonald (2000a), also summarize some of the findings in the area of survey-based exchange rate expectations, but primarily focus on the forward premium puzzle. Therefore, we focus on aspects that were not covered in-depth in the previous studies. Specifically, our studies may be seen as as a direct follow-up of MacDonald (2000a).

The outline for the remainder of this chapter is as follows. Section 2.2 will introduce the forward premium puzzle and discusses the importance of time-varying risk premiums and irrational behavior on behalf of market participants, in explaining this puzzle. Subsequently, in section 2.3 we look at various attempts to model the time-variation in these risk premiums. Section 2.4 examines the performance of market participants in forecasting exchange rates. In section 2.5 we examine the microstructure of the foreign exchange market and look at the role of heterogeneous agents. Section 2.6 will subsequently look at the role of different players in the foreign exchange market. Section 4.7 offers some concluding comments.

\subsection{The Forward Premium Puzzle}

One of the most challenging debates in the financial economics literature is the failure of the forward exchange rate as an unbiased predictor of future spot exchange rates. This failure is often referred to as the forward premium puzzle. The use of forward rates to predict future spot exchange rate is not arbitrary, because the much-debated efficient market hypothesis claims that if foreign exchange markets are efficient, then it should not be possible to generate exorbitantly high above-normal profits (where above-normal profits are defined relative to an expected equilibrium rate of return) through arbitrage in the forward market. In particular, the efficient market hypothesis encompasses the joint hypothesis that expectations are formed rationally and that market participants are risk-neutral with respect to domestic or foreign assets. This section will review some of the work on the forward premium puzzle with an emphasis on the use of survey expectations. ${ }^{2}$

A formal and simple test of the unbiasedness assumption of forward rates can be introduced by regressing the actual change in the exchange rate on the forward

\footnotetext{
${ }^{1}$ Note that the survey of Engel (1996) is limited only to those studies which have assumed rational expectations and attempted to attribute the forward rate bias primarily to a foreign exchange risk premium.

${ }^{2}$ We would like to refer to MacDonald (2000a) for an earlier and in-depth overview of this literature and focus in this section on updating his work.
} 
premium, plus a constant, or ${ }^{3}$

$$
s_{t+k}-s_{t}=\alpha_{1}+\beta_{1}\left(f_{t, t+k}-s_{t}\right)+\epsilon_{t+k},
$$

where $s_{t}$ is the natural logarithm of the current spot exchange rate and $f_{t, t+k}$ is natural logarithm of the $k$-period-ahead forward rate. The null hypothesis of forward discount unbiasedness is presented as $H_{0}: \alpha_{1}=0, \beta_{1}=1$, and $\epsilon_{t+k}$ is a mean-zero white noise process, orthogonal to the information set on which agents base their expectations. A constant should be added to account for the convexity term arising from Jensen's inequality. Under this null hypothesis, equation 2.1 in essence states that the future spot rate can be written as the weighted average of the current spot rate and the current forward rate for the delivery in period $t+k$, such that

$$
s_{t+k}=\beta_{1} f_{t, t+k}+\left(1-\beta_{1}\right) s_{t} .
$$

Finding that $\beta_{1}=1$ would thus imply that the current spot rate has no explanatory power and the future spot exchange rate is solely predicted by the respective forward rate.

The unbiasedness hypothesis has been rejected in most studies, and most seem to agree on the direction of the bias. A review of this literature is available in Hodrick (1987) and more recently in Engel (1996). In fact, it has become a well-established regularity in the international finance literature that the forward premium is a biased predictor of future changes in exchange rates. Some researchers attribute the rejection of unbiasedness to irrational behavior of exchange rate forecasters, while others, such as Fama (1984a), Hsieh (1984), and Wolff (1987a), claim that the rejection is caused by the risk preferences of market participants, that is, by the existence of a time-varying risk premium. Since true market expectations are inherently unobservable, the first line of researchers assumed investors to be risk neutral with respect to investing in domestic or foreign assets, while the second line of researchers assumed expectations to be rational. Clearly, the inherently necessary use of joint tests of rationality and for the existence of a risk premium made it impossible to truly determine what caused the existence of the forward premium.

To find explanations for the failure of the forward discount unbiasedness hypothesis we must examine the above equation in greater detail. If investors, for some reason, require a reward for the added risk of holding an open position in a foreign currency, those investors will demand a premium for this risk. When rates are quoted as units of foreign currency per unit of domestic currency, investors will require the future expected spot rate to be lower than the forward rate (a risk

\footnotetext{
${ }^{3}$ Since from most studies it appeared that both the current spot rate and the forward rate series follow a unit root process, the correct way to estimate forward rate unbiasedness is through tests in which the variables are transformed into returns, or expected returns in the case of survey-based expectations. A seminal work on unit root behavior in the empirical modeling of exchange rates is provided by Meese and Singleton (1982) and Liu and Maddala (1992a,b). Dutt and Ghosh (1997) approach the issue of unit root behavior differently by adjusting the tests for unit roots, instead of the variables. Fischer (1989) furthermore provides an excellent work on the application of cointegration tests in examining the rationality of expectations.
} 
premium is required for holding an open position in a foreign currency and domestic and foreign assets are not considered perfect substitutes anymore), in that $f_{t, t+k}=E_{t}\left[s_{t+k}\right]+\varphi_{t+k}$, or more formally in terms of returns:

$$
f_{t, t+k}-s_{t}=E_{t}\left[s_{t+k}\right]-s_{t}+\varphi_{t, t+k}
$$

and where the risk premium can be defined as

$$
\varphi_{t, t+k} \equiv f_{t, t+k}-E_{t}\left[s_{t+k}\right]
$$

Studies that use the forward rate as a proxy for the expected future spot rate will consequently not consider this risk premium. Hence, the risk premium should be isolated from the expected spot rate in unbiasedness tests, which creates a problem: the expected future spot rate, $E_{t}\left[s_{t+k}\right]$, is inherently unobservable. The rejection of forward rate unbiasedness can therefore be attributed to both biases in expectations or to the existence of a risk premium, (or both). Algebraically, this implies a decomposition of the forward discount bias in an expectational bias and a risk premium component.

Following the above decomposition, the existence of a time-varying risk premium as the principal reason for rejection of the hypothesis that forward rates are unbiased predictors of future spot rates, can be tested through a regression of the expected rate of depreciation on the forward discount. The expected future spot rate is replaced by the survey-based forecast:

$$
s_{t, t+k}^{e}-s_{t}=\alpha_{2}+\beta_{2}\left(f_{t, t+k}-s_{t}\right)+\epsilon_{t},
$$

where $s_{t, t+k}^{e}$ presents the survey-based proxy for the (unknown) market expectation $E_{t}\left[s_{t+k}\right]$. Overall, the null hypothesis of perfect substitutability (i.e., no constant, nor a time-varying risk premium) can be stated as $H_{0}: \alpha_{2}=0, \beta_{2}=1$, where $\epsilon_{t}$ is a mean zero white noise process uncorrelated with the information set on which agents base their forecasts.

Cavaglia et al. (1993a, 1994), Cavaglia and Wolff (1993), Frankel and Chinn (1993), Frankel and Froot (1987a, 1990b), Froot and Frankel (1989), Gan and Wong (1993), MacDonald and Torrance (1989, 1990), Madsen (1996), and Verschoor and Wolff $(2001 \mathrm{a}, \mathrm{b})$ find that in most instances, the hypothesis of perfect substitutability is rejected. In fact, rejection usually occurs at significant levels exceeding the 1 percent. Parameter estimates for $\beta_{2}$ are usually between zero and one.

Such a firm rejection of perfect substitutability comes as a surprise. Since the daily volume of foreign exchange that is traded worldwide is far greater than the volume that is traded in other financial markets, the foreign exchange market should be very liquid and efficient - a point made by Froot and Thaler (1990). In addition, transaction costs are comparably low and various currencies are commonly traded by the same financial institutions. For these reasons, assets denoted in the domestic or foreign currencies should be considered identical with respect to their degree of risk and it would appear that foreign currency-denoted assets are perfect substitutes to domestic-currency assets. 
The alternative explanation for the failure of the forward premium unbiasedness hypothesis is due to irrational expectations. Expectations are rational in the sense of Muth (1961, p. 316) when these "expectations, since they are informed predictions of future events, are ... the same as the predictions of the relevant economic theory." Pesaran (1987) specifies that for expectations to be rational, four conditions need to be met. First, forecasts should be unbiased, implying that the expected rate of depreciation is identical to the actual rate of depreciation, with the difference being a white noise error (distributed with a zero mean and constant variance). Second, survey-based forecast errors should be orthogonal to variables from the information set available to agents. Third, the forecast errors should be serially correlated only up to a moving average process of order $k-1$, due to the presence of overlapping observations. Finally, expectations should be efficient, where efficiency is a special case of orthogonality in that the information set now only includes past values of the variables that are expected to form the expectations. We will focus on results from the first two conditions here.

Avraham et al. (1987), Bénassy and Raymond (1994), Blake et al. (1986), Cavaglia et al. (1993b), Chinn and Frankel (1994b), Dominguez (1986), MacDonald (1992), MacDonald and Marsh (1994), Marsh (1999), Kim (1997), Sobiechowski (1996), and Verschoor and Wolff (2002), test whether survey-based expectations are biased predictors, by regressing the actual depreciation on the survey-based expected rate of depreciation. Specifically,

$$
s_{t+k}-s_{t}=\alpha_{3}+\beta_{3}\left(s_{t, t+k}^{e}-s_{t}\right)+\epsilon_{t+k},
$$

where, under the null hypothesis of unbiasedness, $\alpha_{3}=0$ and $\beta_{3}=1$, and the forecast error is a white noise process with zero mean and constant variance and is orthogonal to the information set on which individuals form their forecasts. One should usually be careful to account for moving average errors, since the overlapping nature of the expectations is such that the error terms are usually serially correlated up to an order of $k-1$.

It appears almost as an empirical regularity in the literature that the null hypothesis of survey-unbiasedness is rejected, for nearly all currencies at all horizons, in that the expected rate of depreciation does not equal the actual rate of depreciation and even misses the direction of the actual depreciation in many cases. Although for EMS cross-currencies and for rates from high inflation countries the survey-expected rate of depreciation is usually in the same direction as the actual rate of depreciation, the expectations are nevertheless significantly biased. One might even ask whether the actual rate of depreciation is not better described by a random walk forecast. Indeed, for the majority of currencies the correlation between the actual and expected rates of depreciation is close to zero, a finding that is consistent with the random walk hypothesis.

Nonetheless, it must be stressed that the presence of biases in expectations does not immediately imply that expectations are formed irrationally. Krasker (1980) shows that expectations, even when they are biased, are still formed rationally when a small probability of an event that would cause a large depreciation in an exchange rate, exists. This is the so-called 'peso problem', after the consistent discount at 
which the Mexican peso sold prior to its massive depreciation in 1976. In addition, errors in expectations may arise when the market gradually and rationally learns about the true process that generates expectations or learns about new depreciation regimes - a point made by Lewis (1989). Finally, the assumption of homogeneous expectations, as made so far, may not hold. Indeed, it will be shown later that this assumption is empirically questionable (see section 2.5). Hence, finding that the expected rate of depreciation is a biased estimate of the actual rate of depreciation is no direct evidence of the failure of the rational expectations hypothesis.

The second condition for an rational expectations to be rational is orthogonality. When agents use all available information efficiently, any variable from their information set should be orthogonal to the forecast error. Error orthogonality can be tested, for instance, by regressing the forecast error against its own lagged value:

$$
s_{t+k}-s_{t, t+k}^{e}=\alpha_{4}+\beta_{4}\left(s_{t}-s_{t-k, t}^{e}\right)+\epsilon_{t+k} .
$$

Bénassy and Raymond (1994), Dominguez (1986), Frankel and Froot (1987b), Gan and Wong (1993), MacDonald (1990, 1992), MacDonald and Torrance (1988b), Lim and McKenzie (1998), and Sobiechowski (1996) find that at shorter forecast horizons, specifically 1 week and 2 weeks ahead, rejection of such a test hardly ever occurs. At the somewhat longer 1-month horizon, rejection occurs more frequently, though the evidence is still not overwhelming. Rejection of the hypothesis of weak-form orthogonality is strongest when the forecast horizon lengthens beyond 3 months.

Since error orthogonality requires the forecast error to be orthogonal to all variables from the investor's information set, a test can be performed by analyzing the relation between the forecast error and, say, the forward premium:

$$
s_{t+k}-s_{t, t+k}^{e}=\alpha_{5}+\beta_{5}\left(f_{t, t+k}-s_{t}\right)+\epsilon_{t+k} .
$$

Cavaglia et al. (1993a,b, 1994), Cavaglia and Wolff (1993), Frankel and Froot (1990b), Froot and Frankel (1989), Gan and Wong (1993), Madsen (1996), Sobiechowski (1996), Taylor (1989), and Verschoor and Wolff (2001a) find that rejection of this version of error orthogonality becomes more likely when the forecast horizon lengthens. At the longer end of the forecast horizons (12 months), rejection becomes almost an empirical regularity. Furthermore, it is also a virtual empirical regularity that estimates for $\beta_{5}$ are negative for nearly all currencies in most studies. Such a finding would indicate that agents could have reduced their forecast errors by betting against the forward rate and focus more on the contemporaneous spot rate instead.

The rejection of error orthogonality prompts for an understanding of the behavior of the processes underlying the generation of expectations. A general framework for analyzing the formation of market expectations is by seeing these expectations as the weighted average of the contemporaneous spot rate $s_{t}$ and some other variable $x_{t}$ from the investor's information set. One common expectations formation process extrapolates the most recent trend in the spot rate into the future. That is, the 
expected future spot rate can be characterized as a weighted average of the contemporaneous spot rate and the $l$-period lagged spot rate. An empirically testable version of the above extrapolative expectations model can be presented as

$$
s_{t, t+k}^{e}-s_{t}=\alpha_{6}+\beta_{6}\left(s_{t}-s_{t-l}\right)+\epsilon_{t} .
$$

Using this test, Cavaglia et al. (1993a,b), Chinn and Frankel (1994b), Frankel and Froot (1987a, 1988, 1990b), Ito (1994), and MacDonald and Torrance (1988b) find ample evidence of a twist in expectations. In particular, at horizons of up to 1 month nearly all estimates for $\beta_{6}$ are positive, thereby indicating that short-run expectations exhibit bandwagon effects in that the most recent depreciation is extrapolated into the future. On the other hand, at horizons of 3 months or longer, nearly all estimates for $\beta_{6}$ are negative and significantly different from zero, indicating that after the 3-month horizon expectations are stabilizing in that the most recent appreciation of a currency is expected to be followed by a future depreciation.

Alternatively, the expected future spot rate can be formed adaptively, as the weighted average of the contemporaneous spot rate and the lagged expected value of the current spot rate. In a way, this model can be considered as learning process where forecasters try to learn the 'true' level of the variable, instead of its underlying process. An empirically testable version of the above adaptive expectations model can be introduced as

$$
s_{t, t+k}^{e}-s_{t}=\alpha_{7}+\beta_{7}\left(s_{t}-s_{t-k, t}^{e}\right)+\epsilon_{t} .
$$

At the short spectrum of the forecast horizon (1-week up to 1-month) expectations appear to be destabilizing in that slope estimates are positive, while at horizons exceeding the 3 months, expectations are stabilizing in that nearly all estimates are significantly negative. In contrast to the previous findings of statistically significant destabilizing bandwagon expectations at horizons of up to 1 month, empirical evidence of significant destabilizing expectations in the adaptive scheme at the same spectrum of the forecast horizon is only weak.

It is interesting to consider to what extent exchange rates are expected to appreciate or depreciate relative to their current deviation from long-run fundamentals. Dornbusch (1976) showed that the expected future spot rate can be expressed as a weighted average of the contemporaneous spot rate and a long-run equilibrium, $\bar{s}_{t}$, that is commonly based on economic fundamentals. A specification of the long-run equilibrium value is given by the purchasing power parity (PPP) assumption, where the exchange rate moves over time relative to the inflation rates of two countries. Using these tests, Frankel and Froot (1987b), Chinn and Frankel (1994b), and Gan and Wong (1993) find that expectations do regress towards their long-run equilibrium values.

When combining the empirical findings from the extrapolative, adaptive, and regressive models of expectations formation, the evidence strongly indicates that, for currencies relative to the U.S. dollar, expectations are stabilizing for forecast horizons exceeding 1 month. On the other hand, for shorter horizons, expectations appear to be destabilizing and move away from equilibrium values. 
Altogether, the consensus emanating from the literature on survey data is that the failure of the forward discount unbiasedness is attributable both to irrational expectations and to the existence of time-varying risk premiums. Furthermore, when the forecast horizon lengthens, rejection of the rational expectations hypothesis grows firmer and survey-based expectations show more evidence of stabilizing behavior in that the most recent price trend is expected to be reversed in the future.

\subsection{Modeling Risk Premiums}

When the possibility of time-varying risk premiums as an explanation of the forward premium puzzle emerged in the foreign exchange literature, academics have considered rationales for why this time-variation makes sense from an economic point of view. Ever since, there has been an ongoing debate on the source of the time-variation in the foreign exchange risk premium. Although some tentative explanations exist, such as the 'safe-haven' argument, most of the studies that looked into this issue still assume that expectations are formed in a rational way. Only a few studies have employed survey-based measures of expectations in an attempt to model this time-variation. In this section, we will examine some of the work on modeling the time-variation in risk premiums without the stringent assumption that expectations are formed in a rational manner. The discussion will focus on fundamentals-based models and time-series models.

A traditional methodology for modeling risk premiums by using macroeconomic fundamentals is through the portfolio balance model (PBM), (see e.g. Frankel, 1982). According to this approach, a portfolio of various foreign and domestic assets is composed through a mean-variance optimization process. When some assets are imperfect substitutes, an increase in the amount of a particular asset results in either an increase of the required return, or an increase of the risk of that asset. Dominguez and Frankel (1993) were the first to apply a version of the PBM to model risk premiums by using survey-based measures of expected future spot rates. Their model is stated as

$$
f_{t, t+k}-E_{t}\left[s_{t+k}\right]=\gamma_{0}+\gamma_{1} \sigma_{t}^{2}+\gamma_{2} \sigma_{t}^{2} V_{t}+\epsilon_{t},
$$

where $\sigma_{t}^{2}$ is the variance of changes in exchange rates between two consecutive dates, which is a proxy for the volatility of the spot exchange rate, and $V_{t}$ is the value of domestic assets in an investor's portfolio as a proportion of total wealth. A higher level of variability of the spot exchange rate will increase the uncertainty of the returns on assets that are denominated in the domestic currency, which on its turn will increase the risk premium. In addition, an increase in the proportion of domestic currency-denominated assets relative to assets in the foreign currency (an increase in $V_{t}$ ), will increase the risk premium.

Dominguez and Frankel (1993) implement this methodology for the risk premium of the Deutschemark versus the U.S. Dollar, using weekly 1-month-ahead and biweekly 1-month-ahead survey-based measures of the expected future spot rate for the period 1982-1988, taken from the MMS dataset. $V_{t}$ is approximated by the 
central bank intervention as a percentage of wealth, which is calculated as the total supply of U.S. and German government debt. They find that over the period 19841988 , the estimated coefficient of the variance of the spot rate, $\gamma_{1}$, is statistically significant in all regressions, usually even up to the 1 percent level. For the period 1982-1984, no such significance is found.

Giorgianni (1997) estimates equation 2.11 for the Italian Lira versus the U.S. dollar (IL/US) and Deutschemark (IL/DM) by regressing the survey-based risk premium on the expected future domestic and foreign ratios of government net borrowing to gross domestic product and finds that for the 3- and 12-month-ahead IL/US premium, the Italian (domestic) net government borrowing requirement always enters significantly and positive of sign, indicating that a higher Italian government deficit is associated with higher risk premiums on assets denominated in Italian lira. For the IL/DM premium, the results are similar, though less significant. Finally, MacDonald (2000b) uses a variation to the PBM approach by regressing the risk premium on the conditional standard deviations of the domestic stock price changes and the foreign (i.e., U.S.) stock price changes, with survey data from the 19851991, 1-month-ahead MMS dataset. He finds that the stock market volatility is statistically significantly related to the BP/US, DM/US, JY/US, and BP/DM risk premiums.

An alternative methodology that also relies on fundamentals for modeling risk premiums is the general equilibrium asset-pricing (GEAP) model, due to Lucas (1982), that relates the risk premium to several macroeconomic variables. A closed form, empirically testable specification of this model can be expressed as

$$
f_{t, t+k}-E_{t}\left[s_{t+k}\right]=\gamma_{0}+\gamma_{1} E_{t}\left[X_{t+k}\right]+\gamma_{2} \sigma^{2}\left[X_{t+k}\right]+\epsilon_{t}
$$

where $X_{t}$ is a vector of fiscal and monetary variables and $\sigma^{2}\left[X_{t}\right]$ proxies the volatility of these variables through their variance and covariance terms.

Giorgianni (1997) implements a testable version of the GEAP model by regressing the survey-based risk premium on the variance and covariance terms of the domestic and foreign government expenditures, for the IL/US and IL/DM rates. Interestingly, all regressors are significantly different from zero and with the correct sign: a higher (lower) volatility of the future Italian (U.S.) fiscal policy is associated with higher risk premiums on assets denominated in Italian lira. This makes sense, for a fiscal expansion in a country may increase the risk of assets that are denominated in that country's currency, thereby depreciating the domestic currency. However, the model has little explanatory power overall. For the models that focus on the IL/DM rate, the evidence is even less convincing. The introduction of monetary variables to the model - the covariance of the foreign and domestic money growth with the government expenditures - does not substantially alter the earlier findings for neither currency.

MacDonald (2000b) proxies the GEAP model by regressing the risk premium on the conditional standard deviation of $\mathrm{ARCH}$ - and $\mathrm{GARCH}$-based forecast errors and finds that for the JY/US, BP/DM, and BP/US rates there is evidence that the conditional standard deviation calculated through both models for the error process 
is important in determining the risk premium. For the DM/US market, no such evidence is present.

A second strand of the literature tries to model the risk premiums using timeseries models. Cavaglia et al. (1994) use survey-based measures of the risk premium for some eighteen EMS and non-EMS exchange rates relative to the U.S. dollar and Deutsche mark from the 1986-1990 Business International Corporation (BIC) survey and try to model the risk premium using different time-series models of the ARMA class. They find that the AR(1) model appears to be the best model for nearly all currency-horizon combinations. Apparently, low-order time-series models (especially when measuring the risk premium through survey datasets) appear to be capable of capturing the variability in the risk premium. Indeed, Peel and Pope (1989) find that for five out of nine currencies relative to the U.S. dollar, using data from a monthly survey conducted by Euromoney over the period 1984-1988, the 3-month-ahead survey-based estimates of the risk premium are white noise, while the other premiums follow an MA(2) process. Also Giorgianni (1997) tries to model the risk premium for the IL/US and IL/DM rates using low-order variations of the ARMA family, with or without a time trend. He finds that the 3 - and 12-monthahead IL/US risk premiums are best described by an $\mathrm{AR}(1)$ model without a time trend. For the 3-month IL/DM risk premium the mere sample mean gives the best fit and for the 12-month premium a MA(1) model with a constant seems to offer the best fit. Yet, the explanatory power of these two models for the IL/DM rate is very low. A possible reason for this poor fit is the presence of many institutional arrangements in the EMS in an attempt to reduce volatility of EMS-currencies. As a result, a time-series model for the IL/DM risk premium will likely not be a time-invariant model and stochastic properties are hence not guaranteed.

A third strand of the literature attempts to explain the time-variation through direct application of ARCH or GARCH type of models - initiated for the foreign exchange market by Domowitz and Hakkio (1985). Nieuwland et al. (1998, 2000) and Verschoor (1993) specify an ARCH-in-mean model (or ARCH-M), due to Engle et al. (1987), that extends the original ARCH model to allow the conditional variance to affect the conditional mean directly, by

$$
s_{t, t+k}^{e}-s_{t}=\gamma_{0}+\gamma_{1}\left(f_{t, t+k}-s_{t}\right)+\gamma_{2} \sigma_{t}^{2}+\epsilon_{t} .
$$

When assuming that the error term conditional on the information set at time $t$ is normally distributed, the ARCH effect can be introduced as

$$
\sigma_{t}^{2}=\delta_{0}+\delta_{1} \sum_{i=1}^{p} \omega_{i} \epsilon_{t-i}^{2}
$$

where $p$ equals the number of lagged squared disturbances and $\omega_{i}$ the weight attached to each of them. Following Baillie and Bollerslev (1990), the above ARCH effect can be generalized as a GARCH effect by including one or several $(q)$ lags of the conditional variance.

Nieuwland et al. $(1998,2000)$ and Verschoor (1993) show that over the period 1986-1991 using 3-, 6-, and 12-month-ahead estimates for the BF/DM, DG/DM, 
$\mathrm{FF} / \mathrm{DM}$, IL/DM, and SP/DM rates from the BIC dataset, these models - and in particular the GARCH model - appear to be reasonably successful in modeling the risk premium in about half of the currency-horizon combinations. Berk and Knot (2001) use the same dataset, as well as the Consensus dataset, and find largely significant ARCH-M terms ( $\gamma_{2}$ significantly different from zero) for the four most actively traded rates plus the FF/US rate at the 3 - and 12-month horizons. Taylor (1989), however, using monthly 12-month-ahead survey-expected measures of the risk premium for the $\mathrm{BP} / \mathrm{US}$ rate from a survey conducted by Godwins, a firm of British management consultants, finds that over the period 1981 to 1985 his specification of an $\mathrm{ARCH}$ model fails to explain variation in the risk premium. Hence, the evidence of successfully modeling the risk premium through specifications of $\mathrm{ARCH}$ or GARCH models is mixed.

Overall, it can be stated that the literature on modeling the risk premium using survey-based measures of expected future spot rates produces somewhat mixed results. Although most models based on fundamentals have difficulties in finding the right variables to analyze, simple time-series models have been quite successful in modeling the risk premiums for most currencies. One of the future challenging avenues in this area is to use the information that is available from individual market participants, instead of assuming a representative agent.

Chionis and MacDonald (2002) question whether aggregate survey-based measures of expectations are of any use at all to derive a model of the risk premium. When comparing aggregate (mean), individual, and sector-average measures of the risk premium for the BP/US, DM/US, and JY/US rates from the 1989-1995 Consensus dataset, using an ARCH-in-mean strategy, they find that the disaggregate survey-based risk premium for each individual is more volatile than the survey consensus measure. This finding would imply that aggregate measures of the risk premium "average out much of the heterogeneity and richness of the individual survey expectations" (Chionis and MacDonald, 2002, p. 67). An interesting finding is that these findings are irrespective of whether the aggregate measures come from survey data or from realized spot rate data.

\subsection{Foreign Exchange Forecasting Performance}

There has been an ongoing debate in the literature about whether foreign exchange rates can be forecasted. The general consensus thus far is that forecasting exchange rates in a consistent way is cumbersome. Meese (1990), Meese and Rogoff (1983), Wolff (1987b, 2000) show that most methods of exchange rate determination cannot outperform a simple random walk characterization. A natural extension to this debate is the question whether market participants themselves can better forecast future exchange rates, or perform worse.

There exists a spectrum of competing approaches for calculating the accuracy of (individual) forecasts, among which those in the statistical angle (of which the root mean squared error (RMSE) methodology is most notable). MacDonald and Marsh $(1994,1996)$ determine the RMSEs for some 30 individual forecasters, the 
country averages, and the total cross-sectional mean, as well as the RMSE for the forward rate and random walk-based forecasts for 3-month-ahead BP/US, DM/US, and JY/US rates for the period of 1989-1991, yet only find two individual forecasters that succeed in outperforming a random walk (in terms of lower RMSE values). Using a larger set of individual forecasters for the same three rates, Marsh (1999) still finds only one individual forecaster for both the BP/US and DM/US rates whose RMSE was less than that of a random walk over the same period. Elliott and Ito (1999) corroborate these findings for a disaggregate set of 1-, 3-, and 6month-ahead estimates of the future JY/US rate from the 1985-1996 Japan Center for International Finance (JCIF) survey (nearly all of the individual forecasts have larger standard errors of the deviation of the forecast from the ex post spot rate than the benchmark of a random walk forecast). Altogether, one may justly argue than the Meese and Rogoff (1983) claim remains upheld in that the vast majority of disaggregate survey-based expectations appears to be statistically worse estimators of future spot rates than a simple random walk estimate.

At the same time, Elliott and Ito (1999) claim that finding such a forecasting performance that is below the benchmark does not immediately imply that disaggregate survey data are of poor quality. In fact, survey-based forecasts may be more valuable in terms of generating profits as compared to a random walk forecast. Therefore, Elliott and Ito (1999) define a simple profit statement in which an agent takes a long (short) fixed position forward in the foreign currency if she believes that the forward rate undervalues (overvalues) the value of the domestic currency. With log profits for each individual agent given by $\pi_{i, t+k}=\left(2 I\left[s_{i, t, t+k}^{e}>f_{t, t+k}\right]-1\right)\left(s_{t+k}-f_{t, t+k}\right){ }^{4}$ it appears that profits stemming from a random walk strategy (where $s_{i, t, t+k}^{e}=s_{t}$ ) only outperform survey-based forecasts for 2 out of 42 individual forecasts in terms of profitability at the 1- and 3-month horizon, and for none individual forecast at the 6-month horizon.

One notable shortcoming of these simple profit-based trading rules is that no explicit measure of risk is incorporated in the transactions. Moreover, the inherently assumed fixed positions in size, as well as the fact that each single agent's forecasts of individual currencies are analyzed one at a time, regardless of the probable dependence between forecasts for different currencies, make such methods rather unpractical. In an attempt to address these shortcomings, Marsh and Power (1996) propose to construct portfolios of positions on the BP/US, DM/US, and JY/US rates based on estimates from each of 22 individual forecasters from the 1989-1992 Consensus survey. In particular, one portfolio minimizes the risk of this portfolio subject to a predefined minimum level of profit constraint, whereas a second portfolio uses a more orthodox approach in which a utility function of expected profits and risk is maximized. In contrast to the findings of Elliott and Ito, it appears that only one forecaster manages to generate returns in excess of those stemming from a simple random walk benchmark (and only in the first portfolio specification); thereby, again, questioning the ability of individual forecasters to forecast exchange rates.

\footnotetext{
${ }^{4}$ Here, $I[$.$] is an indicator function yielding 1$ if the statement between the brackets is true and 0 otherwise.
} 
Combining these findings, one may safely claim that the random walk model remains pre-eminent. Survey-based forecasts do not appear to produce statistically significantly smaller forecast errors than a random walk forecast. For the rare instance in which an individual forecaster does generate statistically more accurate forecasts, the information therein cannot be exploited to generate more accurate forecasts in the future.

\subsection{Market Microstructure and Heterogeneity}

In their survey on nominal exchange rates, Frankel and Rose (1995) note that there is little evidence that macroeconomic variables have a strong and consistent relationship with floating exchange rates. In particular, the fluctuation in exchange rates is usually much larger than the fluctuation in the underlying fundamental exchange rate. Instead, attention has been directed towards a microstructure approach that analyzes the interaction between information flows, price volatility, trading volume, and the heterogeneity of agents' expectations, and investigates the effect hereof on the movement of exchange rates. The investigation of various aspects of microeconomic theory, particularly the heterogeneity in agents' expectations, appears useful in explaining some of the anomalies in the foreign exchange literature.

Yet, little is known about the microstructure of the foreign exchange market. This is surprising, since the daily amount of foreign exchange that is traded worldwide is vastly in excess of the amount that is required for trade in goods and services. Most studies assume a single representative agent, and thereby assume that market participants are homogeneous in their beliefs about the future avenue of the exchange rates. However, if all market participants have homogeneous beliefs and act according to these, the large excess volume of trade in the foreign exchange market cannot be explained. In this section we review some of the work on heterogeneous beliefs in the foreign exchange market.

Heterogeneity is a concept that is used in a variety of ways in the foreign exchange literature. There are two commonly used explanations for the existence of heterogeneity of beliefs in financial markets. One strand of the literature argues that dispersion of beliefs arises because of the asymmetry in information. Different market participants are assumed to hold different sets of information, whereby part of the information is common for all participants and part is private. The asymmetry in information may be caused by the rigidity in the transmission of public information, so that the heterogeneity in agents' beliefs is caused by an artificial informational assumption (Kurz and Motolese, 2001).

Another strand of the literature assumes that all market participants hold different beliefs about economic variables even when there is no difference in the information that is available to them. The difference in beliefs arises because agents disagree about the interpretation of this information. To argue why the difference in interpretation occurs, we can follow the rational beliefs theory due to Kurz (1994) that assumes that heterogeneity of beliefs is caused by the fact that economic agents do not know the structural relations of the economy. Agents only have 'information' 
or 'empirical knowledge', which is readily observable from the economy, usually in the form of a large amount of data about the past performance of an asset or economy in general. Agents form their opinions about the future by using the empirical distribution that is derived from the occurrence of events in the past.

The number of methods to measure or quantify heterogeneity in expectations is small because of the relatively scarcity of data on individual (survey) expectations. Ito (1990) develops a simple and robust test for detecting any differences in opinion among agents when forming expectations; that is, whether expectations are heterogeneous. Suppose that an individual forecast $i$ made at time $t$ (where $i \in n$ total cross-section individual forecasts) consists of a collectively held function of all publicly available information, $f\left(\Omega_{t}\right)$, and an individual effect, $g_{i}$, that may be based on private information. The expected future spot rate for this individual forecast can then be described algebraically as

$$
s_{i, t, t+k}^{e}=f\left(\Omega_{t}\right)+g_{i}+\epsilon_{i, t},
$$

where $\epsilon_{i, t}$ is an individual white noise disturbance term that may arise due to measurement errors. It should be noted that we make the explicit assumption that all individual forecasters attach the same weight to a particular variable from the common information set $\Omega_{t}$ : there are no idiosyncratic effects with respect to the publicly available information. The cross-sectional average of the individual forecasts, at time $t$, can be portrayed in a similar fashion as

$$
\bar{s}_{t, t+k}^{e}=f\left(\Omega_{t}\right)+\bar{g}+\bar{\epsilon}_{t} .
$$

When $\bar{g}$ can be normalized to be zero, equation 2.16 can be subtracted from equation 2.15 , yielding

$$
s_{i, t, t+k}^{e}-\bar{s}_{t, t+k}^{e}=g_{i}+\epsilon_{i, t}-\bar{\epsilon}_{t} .
$$

Now, the individual effects can be determined by solving the above equation for $g_{i}$. This can be done by means of a least squares regression of the difference in expectation of an individual agent from the cross-sectional average on a constant, and adjusting for any patterns in the error terms (for instance, due to overlapping data) by means of the inclusion of MA terms. Clearly, no knowledge whatsoever regarding the underlying information set is hence required when investigating heterogeneous behavior.

In the above specification, the assumption of the identical use of the publicly available information set can be relaxed when allowing for idiosyncratic effects, that is, beside individual biases (which occurs when $g_{i} \neq 0$ ) each agent attaches a different weight to various elements from the publicly available information set. Suppose that on one variable in this information set, $x_{t}$, agents indeed attach different weights. One can then test for both individual biases and idiosyncratic effects $\left(\beta_{i}-\bar{\beta} \neq 0\right)$ by estimating, using least squares regression for all $i$, the following equation:

$$
s_{i, t, t+k}^{e}-\bar{s}_{t, t+k}^{e}=\left(g_{i}-\bar{g}\right)+\left(\beta_{i}-\bar{\beta}\right) x_{t}+\epsilon_{i, t}-\bar{\epsilon}_{t} .
$$

Ito (1990) estimates regressions of both the type in equation 2.17 and in equation 2.18 for a set of disaggregate expectations for the 1-, 3-, and 6-month-ahead 
JY/US rate from the JCIF survey over the period 1985-1987 and finds that for some 44 companies industry effects enter significantly, with an appreciation bias for the export industry (estimates for $g_{i}$ are significantly positive), and with a depreciation bias for trading companies. When allowing for idiosyncratic group coefficients, and setting the variable $x_{t}$ equal to the two most recent lags in depreciation, none of the results change considerably. Hence, it appears that heterogeneous behavior of the various trading groups arises because of different individual effects, not because of idiosyncratic coefficients of the variables in the publicly available information set. The finding of such systematic heterogeneity in expectations remains upheld for an updated JCIF dataset in Elliott and Ito (1999).

MacDonald and Marsh (1996) mimic the above tests for 3- and 12-month-ahead estimates of the BP/US, DM/US, and JY/US rates from the 1989-1992 Consensus dataset and find significant evidence of heterogeneous expectations in that significant individual effects exist, regardless of whether the overall average or country average is used as benchmark. This latter finding is of particular interest, for it would indicate that asymmetries in information between various countries are marginal. Furthermore, in contrast to the results of Elliott and Ito, there is significant evidence of idiosyncratic coefficients when using either the forward discount or the most recent lag in depreciation as explanatory variables in equation 2.18. Interestingly, the number of individuals for which we cannot reject the joint null hypothesis of no individual and no idiosyncratic effects, seems to decrease as the forecast horizon lengthens. This would indicate that on the longer run agents vary more in the way they use information from the common information set, or attach less weight at all to the common information set and instead focus more on their own, private information $g_{i}$. Extending the Consensus dataset to 1995, Chionis and MacDonald (1997) find that still around 40 percent of the forecasters, regardless of the forecast horizon or currency employed, display significant individual effects.

Having confirmed heterogeneous behavior in expectations, Chionis and MacDonald (2002) question whether aggregate survey-based measures of expectations are of any use at all in tests of unbiasedness, error orthogonality, or perfect substitutability. When comparing aggregate (mean), individual, and sector-average measures of the risk premium for the BP/US, DM/US, and JY/US rates from the 1989-1995 Consensus dataset, they find that the disaggregate survey-based risk premium for each individual is more volatile than the survey consensus measure. This finding would imply that aggregate measures of the risk premium "average out much of the heterogeneity and richness of the individual survey expectations" (Chionis and MacDonald, 2002, p. 67)).

With the availability of disaggregate measures of expectations, and realizing that expectations are heterogeneous, one can also directly test the market microstructure hypothesis that trading volume is related to dispersion in expectations by employing Granger causality tests. Frankel and Froot (1990b) use bivariate Granger causality tests to examine the relationship between volume, heterogeneity and the volatility in the market. Volume was measured as the weekly number of futures contracts traded on the Chicago Mercantile Exchange (CME), exchange rate volatility as the average weekly squared percentage change in the exchange rate every 15 minutes, and 
dispersion as the standard deviation of individual forecaster's 1-week and 1-monthahead expectations from the 1984-1988 Money Market Survey (MMS) survey for the individual BP/US, DM/US, JY/US, and SF/US rates. It appears that dispersion Granger-causes both volume (at the 10 percent significance level, for all except the $\mathrm{SF} / \mathrm{US}$ rate at both the 1-week and 1-month horizon) and volatility (for all of the 4 currencies at the 1-week horizon and for all except the JY/US rate at the 1month horizon). Furthermore, there is some evidence that volatility Granger-causes dispersion at both the 1-week and 1-month horizon.

Chionis and MacDonald (1997) mimic these bivariate tests for 3- and 12-monthahead forecasts of the BP/US, DM/US, and JY/US rates from the 1989-1995 Consensus dataset, where measures of dispersion are calculated either as the standard deviation of the difference between the largest and smallest expectation of a particular currency or the difference between an individual expectation and the crosssectional mean. Both measures of dispersion appear to Granger-cause volatility at the 5 percent level (except for the 12-month-ahead DM/US rate), as well as Grangercause volume at the 5 percent level-thereby corroborating the results of Frankel and Froot. In addition, there is lucid evidence of reverse Granger-causality from volatility to dispersion.

Using the same survey dataset, MacDonald and Marsh (1996) investigate the relationship between trading volume and heterogeneity in expectations through a mean-variance model of trading volume, by regressing turnover (defined as the daily average dollar value of trade on the CME) on the standard deviation of the actual and expected future spot rate, the latter of which is a measure of dispersion. For the DM/US and JY/US rates from the 1989-1992 Consensus dataset, the dispersion of expectations enters positively and significantly. For the BP/US rate, no such evidence exists. Finally, Beine et al. (2007) investigate whether central bank intervention has an impact on the dispersion of beliefs in exchange rate forecasts. They show that forecast heterogeneity increases as a result of interventions, regardless of whether these interventions are expected or unexpected. This finding is interesting, for it stresses the role of rumors in foreign exchange markets.

A final question that naturally arises is whether one market participant's action or beliefs influences the others' in subsequent periods. If this would be the case, then deviations of the exchange rate from their long-run fundamental value could be explained by herding behavior of market participants. Beine et al. (2003) assess the extent of herding behavior in foreign exchange markets by using individual survey expectations for two currencies versus the dollar. By using Granger-causality tests they find that although forecasters are connected to each other through leader and imitation patterns, there is no evidence of sequential herding. Interestingly, leaders do not appear to be selected based on their past forecast performance.

Altogether, the albeit limited microstructure literature of the foreign exchange market and the associated heterogeneity of beliefs on behalf of market participants presents a challenging opportunity for future research in explaining some of the anomalies in this market. The debate thus far shows that expectations are heterogeneous to such an extent that we cannot simply consider models anymore based on one representative agent. This would imply in practice that aggregate expectations, 
for instance from a survey panel, average out much of the heterogeneity of individual expectations and therefore tests that use these aggregate measures may not be capable of explaining the anomalies in the foreign exchange market.

\subsection{Noise Trading, Chartism, and the Role of Fun- damentals}

An alternative explanation for why market participants hold different beliefs about the future may be related to the existence of fundamentally different types of market participants. In the financial economics literature there have been several attempts to present models with different types of investors who in essence all have the same information. For instance, De Long et al. (1990) present a model where noise traders, with no access to inside information, act irrationally on noise as if it were information that would give them an advantage over rational arbitrageurs. These noise traders can earn higher expected returns, due to their own destabilizing influence and not because they bear more of the fundamental risk.

The establishment of heterogeneous beliefs among currency forecasters may furthermore alleviate some of the debate regarding the formation of expectations. Specifically, such heterogeneous behavior can contribute to the explanation of the before-mentioned twist in expectations at approximately the 1- to 3-month horizon, as well as shed new light on how agents form their expectations. To this end, Frankel and Froot $(1986,1988)$ establish a model that assumes the foreign exchange market to consists of three different players, i.e., fundamentalists, chartists, and portfolio managers; all of which have their own, heterogeneous, beliefs towards the future value of an exchange rate and behave rationally in that each uses all information available.

The expectations of portfolio managers (i.e., $m$, those who actually participate in market transactions) is defined as the weighted average of the expectations of fundamentalists $(f)$, who base expectations on some structural model of exchange rate determination, and chartists $(c)$, who use non-fundamentals-based based techniques like autoregressive models, or:

$$
s_{m, t, t+k}^{e}-s_{t}=\omega_{t}\left(s_{f, t, t+k}^{e}-s_{t}\right)+(1-\omega)\left(s_{c, t, t+k}^{e}-s_{t}\right) .
$$

If, for the moment, one assumes that the chartists-expected rate of depreciation is zero $\left(s_{c, t, t+k}^{e}-s_{t}=0\right),{ }^{5}$ we can analyze the weight attached to the fundamentalists' expectations, $\omega$, at time $t$ as

$$
\left.\left(s_{m, t, t+k}^{e}-s_{t}\right)=\omega_{t}\left(s_{f, t, t+k}^{e}-s_{t}\right) \Leftrightarrow \omega_{t}=\Delta s_{m, t, t+k}^{e} / \Delta s_{f, t, t+k}^{e}\right),
$$

\footnotetext{
${ }^{5} \mathrm{Liu}$ (1996) uses a somewhat different approach by considering the weight $\omega_{t}$ to be fixed over the sample period and assuming that fundamentalists adopt a random walk model (of no change) for the depreciation of the BP/US, DM/US, JY/US, and SF/US exchange rates, and shows that the percentage weight assigned to fundamentalists' views over the period from 1984 to 1989 never exceeds 40 percent.
} 
where the expected rate of depreciation of fundamentalists is approximated by the survey-based expectations and the expected depreciation of portfolio managers by the forward discount. Using pooled survey-based expectations for the four most actively traded rates from the AMEX and Economist surveys, Frankel and Froot $(1986,1988)$ find that the weight $\omega_{t}$ has been decreasing since the early 1980sa phenomenon indicating that gradually less weight is attached to fundamentalist forecasting techniques. Instead, chartists' methods of forming expectations have become the primary tools for generating forecasts in the above four markets.

In a companion paper, Frankel and Froot (1990a) analyze a 1978-1985 Euromoney survey that investigates the extent to which a selection of forecasting companies use various specifications of chartist or fundamentalists forecasting techniques, and conclude that the number of companies using the latter techniques as the primary tools for estimating future spot rates has declined over the years, at the benefit of technical, or chartist, analysis. In two auxiliary studies, Allen and Taylor (1990) and Taylor and Allen (1992) attempt to ascertain the influence of chartist methods used in the London foreign exchange market and uncover that at the short run spectrum of the forecast horizon up to 90 percent of all survey respondents use some chartist input when forming expectations regarding future exchange rates. When the forecast horizon lengthens (3 months up to 12 months), weight given to fundamental variables increases.

These findings also have the potential of explaining some of the above-mentioned anomalies in the foreign exchange market. Most important is that the earlier discovered shift in expectations can now be attributed to an alteration in the use of forecasting methodologies, shifting towards chartist techniques as the forecast horizon shortens. In the same line, a somewhat different and carefully advocated alternative explanation, provided by Frankel and Froot (1986), states that chartists are simply people who think only in terms of the short run horizon, whereas fundamentalists think long term. Thus, both groups (which inherently hold heterogeneous beliefs regarding the future value of a spot rate) are taking direct positions in the market. This latter view is challenging and provides a ground for future research.

Second, the model of chartists and fundamentalists has the potential of explaining the microstructure anomaly of excessive trading volume. When considering the finding that currency forecasters have increasingly relied on chartist methods of forecasting, and when maintaining that noise traders encompass those traders who employ such chartist analysis, the noise trader model of De Long et al. (1990) then explains that an increase in the number of trades based on noise (which inherently rely on diverse, and often conflicting, sources of information) will make the foreign exchange rate more volatile. In addition, a shift towards more noise trading will imply an increase in the number of trades based on heterogeneous information, which on its turn may Granger-cause an increase in trading volume (although this reasoning has so far not been verified empirically). 


\subsection{Conclusions}

This study has attempted to shed new light on some of the anomalies in the foreign exchange market by analyzing over twenty years of empirical work that employs survey-based measures of expected future spot rates. Five topics that gained considerable attention in the past years, or that will play a more important role in future research, are covered. First, we have attempted to determine the relative importance of both irrationality in the behavior of market participants and the existence of time-varying risk premiums in explaining the forward premium puzzle, and see how market participants form their expectations about future spot exchange rates. Second, we analyzed the rationales behind the existence of time-varying term premiums and how these premiums can be modeled best. Third, we looked at the relative performance of market participants in forecasting future spot exchange rates, relative to a simple random walk forecast, using a range of performance criteria. Fourth, we touched upon a relatively new topic in the foreign exchange literature: market microstructure and the role of heterogeneity in beliefs, and examine how microstructure theory is capable of explaining some of the anomalies in the foreign exchange market. Finally, we looked at the relative role of different players in the foreign exchange market.

Survey-based measures of expectations have allowed a direct measure of biases in expectations and risk premiums, and consequently allow a decomposition of the forward premium into a part that is attributable to irrationality on behalf of market participants and a part that is attributable to the existence of time-varying risk premiums. The consensus emanating from the literature is that the failure of the forward premium unbiasedness is attributable both to irrational expectations and to the existence of time-varying risk premiums.

In particular, the survey-based expected future spot rates are biased estimates of the true level of the future spot rate and that expectations are irrational in that agents do not use all available information efficiently. The survey-based forecast error is not orthogonal to the most important elements from agents' information sets, at least at forecast horizons exceeding 1 month. Agents could have reduced their forecast errors by betting against the various elements from the information set and instead should have focused more on the contemporaneous spot rate. When analyzing the process of expectations formation in greater depth, it appears that at horizons up to approximately one month, agents extrapolate the most recent trend in the behavior of exchange rates and do not sufficiently adapt to the most recent survey-based forecast error. Also, expectations appear to diverge from their hypothesized long-run equilibrium values. At horizons exceeding one month, expectations appear to stabilize, in that expectations regress towards their equilibrium values.

The existence of time-varying risk premiums at horizons larger than 1 month has led to several attempts to model these premiums. There is some support for the claim that survey-based risk premiums can be modeled by simple, low-order time series models (in particular of the ARMA class), and that exchange rate risk premiums are not constant over time, in that they systematically vary with agents' perception of the underlying uncertainty in the exchange rate itself. Models using a combina- 
tion of macroeconomic or fiscal variables occasionally contain significant explanatory variables, although most fundamentals-based models have little explanatory power overall.

Yet, most of the earlier studies are hampered by the fact that they use aggregate measures of expectations when modeling the risk premiums. Since risk premiums are associated with the attitude towards risk and uncertainty of market participants, using aggregate measures of risk premiums averages out much of the heterogeneity and richness of the individual survey expectations. Indeed, risk premiums based on disaggregated market expectations have shown to be more volatile than the survey consensus measure. One of the challenges in modeling risk premiums is to use the information that is available from individual market participants, instead of relying on a single representative-agent model.

The debate about whether market participants can forecast exchange rates in a consistent way has also led to several interesting findings. The earlier literature has shown that macroeconomic or time-series models cannot outperform a simple random walk forecast. Evidence from survey data now shows that actual market participants (irrespective of which techniques they use), do not seem to outperform a simple random walk forecast either, at least when measured in terms of lower forecast errors. Although studies that use a profit-based criterion to assess the forecast performance of individual market participants show that most forecasters are successful in forecasting the directional change, these simple profit-based rules often have the shortcoming that no explicit measures of risk is incorporated in the transactions. The random walk model therefore remains pre-eminent.

This does not mean that the study on the behavior of individual market participants is futile. There is relatively little known about the microstructure of the foreign exchange market. This is surprising, since the daily volume of foreign exchange that is traded worldwide is far in excess of the amount that is required for trade in goods and services. The examination of disaggregate measures of expectations has shed new light on the efficiency of the foreign exchange market and on the preceding tests of rational expectations and perfect substitutability. Not only has the presence of heterogeneous expectations been revealed; aggregate measures of various variables have furthermore been shown to average out much of the heterogeneity and richness of the individual survey expectations. The analysis of individual market expectations has also provided new insights on some of the anomalies in this market, for instance, that the volume of foreign exchange traded weekly is related to the dispersion in beliefs and uncertainty in the foreign exchange market.

Finally, the claim that the foreign exchange market consists of players that hold essentially different views about the behavior of the exchange rate is shown to have considerable empirical ground. Categorizing market participants as either pursuing a chartist forecast strategy or a fundamentalist strategy has revealed new insights into how market participants form their forecasts. It seems that over the years the role of macroeconomic fundamentals in forecasting has declined, and are only used for longer-term forecasts, while the use of chartist techniques has increased. Still, most market participants use a combination of these two techniques. The increased use of chartist techniques and the presence of noise traders in the foreign exchange 
market can, at least to some extent, explain the large trading volume in the foreign exchange market.

These findings have significant implications for future research on several topics in international finance. First, one can conclude that investors' exchange rate expectations do not conform to the rational expectations hypothesis. Although the rational expectations hypothesis has considerable appeal as a theoretical model, it does not appear to provide an adequate explanation of exchange rate expectation in most survey-based studies. It is therefore important to consider alternative models of expectations formation. Clearly, there is considerable scope for further research in this area. The finding of systematic exchange rate forecast errors can plausibly stern from a variety of sources, including - but certainly not limited to - investors' irrationality.

Furthermore, the possibility of influential, yet uncommon events should be considered. Most notably, peso problems may lead to repetitive exchange rate forecast errors in small samples and consequently invalidate standard statistical inference. While this argument applies equally to all empirical analyses, it may be that the type of government policies and other exogenous processes that determine exchange rates make this problem a particularly strikingly one in most studies. Such a possibility probably deserves more study than it has received so far. Especially within the European Monetary System, where such peso problems may result from expectations of periodic realignments of central parities, further research hereof will be desirable.

As a second alternative explanation to the failure of the rational expectations hypothesis, one might investigate whether investors learn as they go. Explicit examples of the failure of the rational expectations assumption because of learning gradually emerges in the literature. If investors are in the process of learning about floating exchange rates or other regime changes, then exchange rate changes will be affected by such learning.

In future work, considerable attention should also be paid to the heterogeneity in exchange rate expectations among investors. Although homogeneity has been assumed by a great many investigators of foreign exchange market efficiency (heterogeneity amongst market participants was aggregated out), the diverse patchwork on heterogeneous behavior suggests conclusively that homogeneity is not a reasonable assumption. It may well be that many studies that employed some form of aggregate expectations found degrees of time-varying risk premiums and biases in expectations that were understated. Heterogeneous expectations and their role in determining foreign exchange market dynamics may hence be important areas for future research.

Finally, the role of survey-based measures of expected future spot rates in the process of modeling risk premiums is only at its preliminary phase. The 'true' observation of risk premiums only now allows a 'true' modeling hereof. Beyond doubt, the future course of empirical studies on the modeling of risk premiums employing some form of survey-based expectations of future spot rates is likely to produce interesting and successful methodologies, which might be capable of withstanding the ultimate test of consistently outperforming a simple random walk forecast. 


\section{Chapter 3}

\section{On the Rationality of Interest Rate Expectations*}

\subsection{Introduction}

The debate regarding the rationality of agents' expectations and the informational efficiency of financial markets continues to be an issue of central concern in the financial economics literature - see Hodrick (1987) and Engel (1996), for instance. These propositions have been tested in the foreign exchange literature by analyzing survey data for some of the major currencies - see Dominguez (1986), Cavaglia et al. (1993a,b, 1994), Frankel and Froot (1987a,b), Froot and Frankel (1989), Taylor (1989), and Verschoor and Wolff (2001a,b). Broadly speaking, the results of these studies suggest significant failures of the rationality assumption in exchange rate expectations, for many different currencies and different sample periods.

The use of survey-based measures of interest rate expectations has shed new light on this debate. The principal benefit of using survey data is that one obtains a direct measure of agents' beliefs, thus allowing for separate testing of an underlying model of exchange rate determination and testing a hypothesis about the way expectations are formed. On the other hand, critics of survey data often question the extent to which such data is representative of 'the market's' expectation or whether the data truly reflects the individual survey respondents' beliefs. Furthermore, the rather narrow survey data sets that are collected often limit the scope of investigative analysis.

In the 1970s macroeconomics literature, Lucas (1972, 1976), Sargent and Wallace (1975), and Barro (1976) demonstrate that the assumption of rationality of agents' expectations in the Muth (1961) sense has strong implications for economic behavior and policy. However, despite the central role of expectations in the asset market theory in general and the interest rate literature in particular, the use of survey

* Part of this chapter is forthcoming in the Journal of International Financial Markets, Institutions, and Money as joint work with Willem F.C. Verschoor. 
data to proxy interest rate expectations has largely been avoided. The reason for this was the absence of independent information about market participants' expectations. The majority of studies on interest rate expectations have used the theory of the term structure of interest rates, due to Hicks (1939) and Lutz (1940), to infer expectations by comparing the yields on two or more assets, in conjunction with a theory of the determination of relative yields (i.e., relative asset prices). The validity of the inference about interest rate expectations is, of course, conditional on the underlying asset pricing hypothesis.

As such, little effort has been made in the literature to exploit the survey-based approach in verifying the properties that are directly implied by rationality. In light of the absence of survey-based on interest expectations, convincing empirical evidence on whether interest rate expectations are indeed rational is understandably scarce. To the best of our knowledge, Friedman (1980), Froot (1989) and MacDonald and Macmillan (1994) are the only survey-based studies that have investigated the hypothesis of whether interest rate expectations are rational and whether agents use all available information efficiently. ${ }^{1}$

In this chapter we extend the limited work on interest rate expectations to a broad set of foreign interest rates over the period of January 1995 until December 2004. We employ survey data for these interest rates in order to examine the validity of properties directly implied by rationality. We use a data set that allows us to focus on differences between EMS and non-EMS interest rate expectations.

Furthermore, earlier research has focused exclusively on U.S. and U.K. interest rates in the 1970's through the very early 1990's - the different sample period and different overall pattern of interest rate movements thus permit an additional test of the robustness of previously reported results and allows us to compare the behavior of interest series from different countries. In addition to exploring differences between EMS and non-EMS interest rates, we address three questions that were considered earlier in studies on exchange expectations by Cavaglia et al. (1993a,b) and Frankel and Froot (1987b): 1) whether economic agents' interest rate forecasts are unbiased, 2) whether economic agents use all available information efficiently, and 3) which time series process best characterizes the investors' expectations formation process.

Our results are easily summarized. We find that interest rate expectations are not rational and that agents do not use all available information in an efficient manner. Although forecast errors of EMS interest rates are smaller and less volatile than errors of non-EMS rates, expectations of future EMS rates are still biased. Extrapolative and adaptive expectations formation mechanisms describe interest rate expectations to a certain extent, although a combination of these two is usually preferred. Our evidence indicates that long-term expected interest rates tend to underreact to current (unanticipated) changes in the interest rate, as implied by stabilizing expectations models. Finally, we find that learning about past forecast mistakes has a greater influence on the formation of expectations than the past performance of the interest rate itself.

\footnotetext{
${ }^{1}$ Hafer et al. (1992) also employ survey data on interest rate expectations, yet their emphasis is on the out-of-sample performance of survey-based forecasts in relation to other forecasting techniques, and not on the rationality of expectations.
} 
The chapter is presented in four sections. In section 3.2, the construction of the interest rate survey is outlined and summary statistics describing the data are provided. In section 3.3, we examine whether expectations are formed in a rational manner. In particular, we examine the unbiasedness of expectations as well as the efficiency with which economic agents use publicly available information. Models characterizing the formation of interest rate expectations are considered in section 3.4. Finally, in section 3.5 the results of this investigation are summarized and discussed.

\subsection{Survey Data and Standard Propositions Re- garding Expectations}

Every second Monday of each calendar month Consensus Economics of London publishes results from a survey that was conducted among up to 150 professional market participants and forecasting agencies (per rate) worldwide for their 3 - and 12-months-ahead forecasts for a large number of international interest rates. The expectations are all for interest rate contracts that have a maturity of 3 months. ${ }^{2}$ To keep the analysis tractable and to delete various forecast biases we take the crosssectional arithmetic average of the individual market participants and use this in the analyses. Furthermore, consensus measures of expectations are likely to perform better than the individual expectations that together make the consensus. Although some individuals' forecast performance may be better than others' in terms of criteria like root mean squared errors, it is difficult to identify a priori who these individuals are, in particular since forecast performance is not constant.

Replications of the analyses using other aggregate measures of expectations, like the median, did not alter the general message from the results that will presented below. From a subset of individual interest rate expectations we learned that the distribution of their forecasts at each point in time is not skewed, and therefore the mean is very close to other consensus measures of expectations.

For our sample, we obtain the expectations on 20 interest rate series from developed economies for the period of January 1995 through December 2004 (see table 3.1 for an inventory). The panel is unbalanced since for some series the expectations were discontinued in January 1999, while for others the first expectations were published somewhere along the above sample period (also see table 3.1 for details). The sample is chosen in such a way that about half consists of expectations on EMS rates and the other half of expectations on non-EMS rates.

Although survey participants have a few days time to return their expectations, we learned that the vast majority send their responses by e-mail on the Friday before the publication day (second Monday of the month). We consider this Friday as the day on which the expectations are formed. On this Friday, we obtain spot interest rate series with different maturities to match with the survey data. All spot

\footnotetext{
${ }^{2}$ Thus, the participants are asked to forecast the 3-month interest rate 3 -months ahead and the 3 -month interest rate 12 -months ahead.
} 
rate series are obtained through Datastream. To verify that the information sets of market participants are not too diverse, all of the analyses throughout this study were re-estimated by using spot data from various days surrounding this Friday, yet the overall results remained unchanged.

For the remainder of the chapter, we define

$$
r_{t}^{(n)}=-\frac{1}{n} \ln \left[P_{t}^{(n)}\right]
$$

as the continuously compounded yield to maturity at time $t$ on an $n$-period zero coupon (or discount) bond with a normalized face value of 1 currency unit and a market price of $P_{t}^{(n)}$. Thus, the bond is purchased at time $t$ and matures at time $t+n$. We define $E_{t}\left[r_{t+k}\right]$ as the expected $(n-k)$-month interest rate at time $t+k$ formed at $t$ and maturing at time $t+n$, where in our sample $k$ equals 3 or 12 and $n-k$ is generally 3 months. We furthermore derive the forward rate that is implicit in the term structure, for period $t+k$ through $t+n$, and denote it as $f_{t, t+k}^{(n, k)}{ }^{3}$. Since for the 12 -month ahead forward rate we require zero-coupon rate deposits with a maturity of 12- and 15-months, and the latter are not commonly available, we estimate this forward rate from zero curve yields obtained from Datastream.

The survey-based forecasts are all for interest rate series that have a maturity of 3 months. Therefore, the interest rate series that match these survey rates also have a maturity of only 3 months. We can therefore simplify the notation where we leave the superscript $n$ out of $r_{t}^{(n)}$ and use $r_{t}$ in the remainder of this chapter to denote the 3 month spot rate and $f_{t, t+k}$ as the $k$-period ahead 3 month forward rate (since then $n-k$ equals 3 months). With these definitions, we define the survey-based forecast error at horizon $k$ as

$$
\xi_{t+k} \equiv r_{t+k}-r_{t, t+k}^{e}
$$

Table 3.1 provides summary statistics for the survey-based forecast error for all interest rate series across the two forecast horizons. ${ }^{4}$

For the period analyzed, both the absolute values and the standard deviations of the mean forecast error rise considerably as the length of the forecast horizon goes from three months to twelve months. This empirical finding is similar to the results of Dominguez (1986), who found that the variance of one-week- and two-week-ahead exchange rate forecast errors were smaller than the variance of one-month- and threemonths-ahead forecast errors. Furthermore, for the 12-month forecast horizon all mean forecast errors are negative, which indicates that market participants always overestimated the true level of future interest rates. These results provide a preliminary indication that biases in expectations are likely to be of bigger concern when the forecast horizon lengthens. It must be mentioned that the consistent overestimation of interest rates can also be a manifestation of a peso problem: if a small

\footnotetext{
${ }^{3}$ For a particular interest rate series, we follow the commonly used convention to determine the implicit forward such that $f_{t, t+k}^{(n, k)}=\frac{1}{n-k}\left(\ln \left[P_{t}^{(n)}\right]-\ln \left[P_{t}^{(k)}\right]\right)=\frac{n}{n-k} r_{t}^{(n)}-\frac{k}{n-k} r_{t}^{(k)}$, where $P_{t}^{(n)}$ equals the market price of an $n$-period zero coupon (or discount) bond with a normalized face value of 1 currency unit.

${ }^{4}$ All rates are annualized on a 360-day basis.
} 


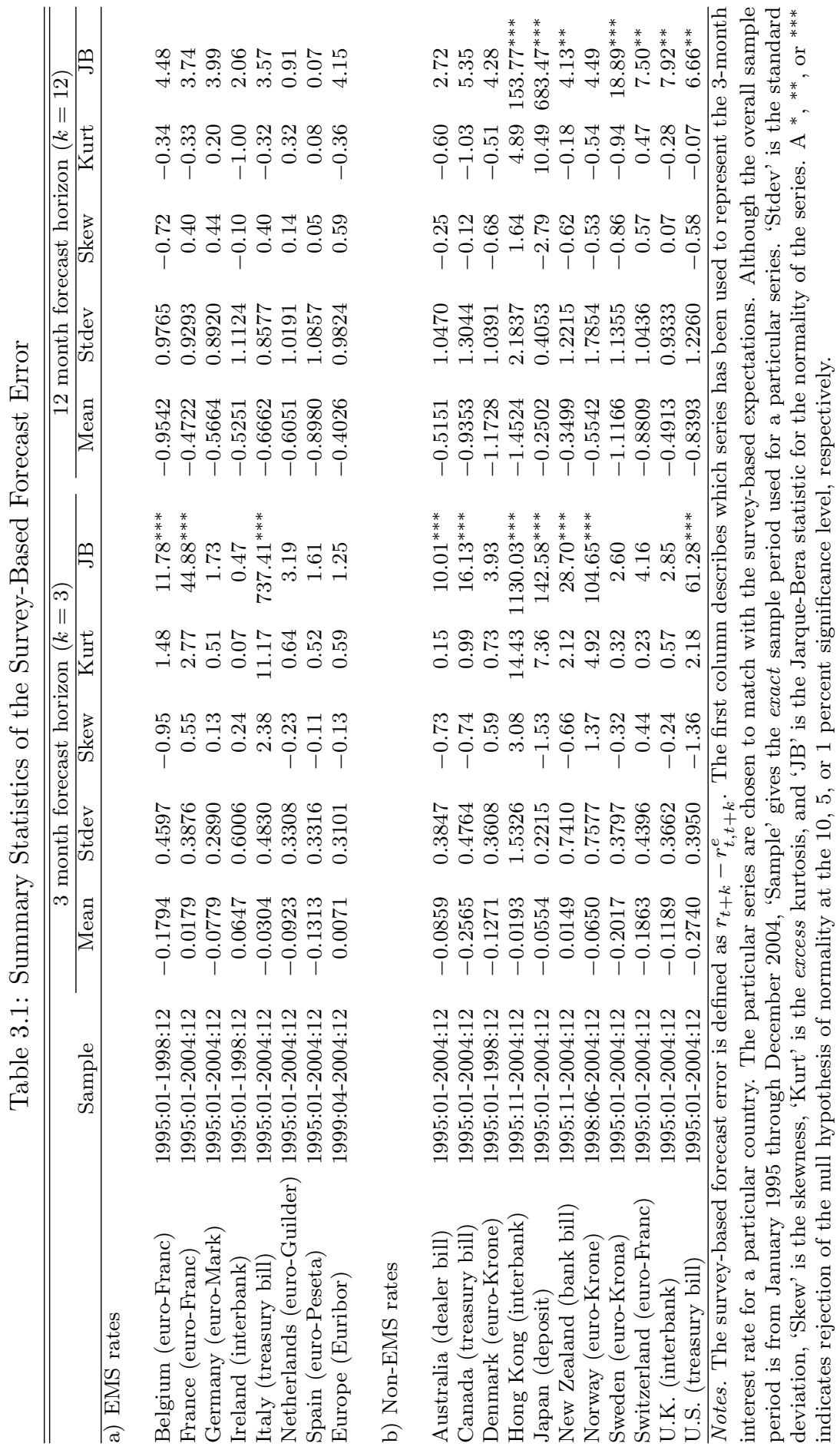


probability of a significant increase in the general level of interest rates is expected, but this increase did not materialize in-sample, then expectations overestimate the true level of future interest rates.

While the distribution of the forecast errors is not consistently skewed in one direction, it is interesting to note that forecast errors are predominantly platykurtic at the shorter forecast horizon, while leptokurtic at the longer horizon. The latter could be an indication of fat tail behavior in the long-run expectations, although we must be cautious here, since kurtosis is not a measure of tail behavior.

Furthermore, we document significant differences in the distribution of forecast errors for EMS versus non-EMS interest rates. The normality test due to Bera and Jarque (1982) is rarely rejected for the EMS interest rates (long-run errors even appear to be all distributed normally), while it is usually rejected for the non-EMS rates. It is also interesting to note that for the 12-month horizon the standard deviation of the mean forecast errors is smaller for EMS currency deposits than for non-EMS deposits (except for the Japanese and U.K. interest rates). All this corroborates the findings of, for instance, Cavaglia et al. (1993a) and Nieuwland et al. (2000) that, since the structure of the EMS is such that it should promote stability, it exerts a stabilizing role on interest rate expectations. As will be shown in the next section, this need not imply that interest rate forecasts are unbiased estimates of future interest rates.

\subsection{The Rationality of Interest Rate Expectations}

The expectations hypothesis of the term structure of interest rates asserts that forward rates should be equal to the expectation of the corresponding future realized interest rates, and hence forward rates can be used to forecast future rates. Since expected rates are inherently unobservable, one generally assumes that expectations are formed in a rational way and expected rates are therefore assumed to be equal to realized ex post future rates. The empirical literature on the expectations hypothesis of the term structure of interest rates suggests that there is overwhelming evidence in favor of the view that the forward rates implied by the term structure are biased predictors of future spot interest rates. The general procedure on how this is tested is by means of a test of the following specification: ${ }^{5}$

$$
r_{t+k}-r_{t}=\alpha_{1}+\beta_{1}\left(f_{t, t+k}-r_{t}\right)+\epsilon_{t+k} .
$$

\footnotetext{
${ }^{5}$ We tested for the existence of a unit root in the levels of the interest rate series, the expectations series, and the implicit forward rates. To deal with the critique that standard unit root tests cannot distinguish between a unit root and a near-unit root process, we employ the test due to Kwiatkowski et al. (1992) (KPSS) where the null hypothesis is that of stationarity against the alternative of a unit root. Both in the case where the lag structure needed for the KPSS test was set to depend on the number of observations as suggested by Newey and West (1994), as well as in the case where we set the lag length ourselves based on prior information (see further on for more information), we could reject the null hypothesis of stationarity. For the difference series, among which $r_{t+k}-r_{t}$ and $f_{t, t+k}-r_{t}$, we cannot reject the null of stationarity. We therefore choose to perform all tests using return, instead of level, series.
} 
Table 3.2: Pooled Test of Forward Rate Unbiasedness

\begin{tabular}{|c|c|c|c|c|c|c|}
\hline & \multicolumn{3}{|c|}{3 month forecast horizon $(k=3)$} & \multicolumn{3}{|c|}{12 month forecast horizon $(k=12)$} \\
\hline & $\alpha_{1}$ & $\beta_{1}$ & \# obs & $\alpha_{1}$ & $\beta_{1}$ & \# obs \\
\hline \multicolumn{7}{|c|}{ a) Regression estimates } \\
\hline Full sample & $\begin{array}{c}-0.1307 \\
(0.0138)\end{array}$ & $\begin{array}{c}0.7141 \\
(0.0295)\end{array}$ & 1989 & $\begin{array}{c}-0.5245 \\
(0.0318)\end{array}$ & $\begin{array}{c}0.5950 \\
(0.0406)\end{array}$ & 1156 \\
\hline EMS rates & $\begin{array}{c}-0.1457 \\
(0.0251)\end{array}$ & $\begin{array}{c}0.7892 \\
(0.0757)\end{array}$ & 813 & $\begin{array}{c}-0.6941 \\
(0.0920)\end{array}$ & $\begin{array}{c}0.9165 \\
(0.0660)\end{array}$ & 510 \\
\hline Non-EMS rates & $\begin{array}{c}-0.1120 \\
(0.0210)\end{array}$ & $\begin{array}{c}0.6768 \\
(0.0400)\end{array}$ & 1176 & $\begin{array}{c}-0.4649 \\
(0.0484)\end{array}$ & $\begin{array}{c}0.4548 \\
(0.0586)\end{array}$ & 646 \\
\hline & $T(\alpha=0)$ & $T(\beta=1)$ & $\begin{array}{c}\chi^{2}(\alpha=0, \\
\beta=1)\end{array}$ & $T(\alpha=0)$ & $T(\beta=1)$ & $\begin{array}{c}\chi^{2}(\alpha=0, \\
\beta=1)\end{array}$ \\
\hline \multicolumn{7}{|c|}{ b) Wald coefficient tests } \\
\hline Full sample & $88.70^{* * *}$ & $93.27^{* * *}$ & $238.40^{* * *}$ & $271.44^{* * *}$ & $99.01^{* * *}$ & $927.72^{* * *}$ \\
\hline EMS rates & $33.69^{* * *}$ & $7.83^{* * *}$ & $42.83^{* * *}$ & $56.84^{* * *}$ & 1.59 & $56.90^{* * *}$ \\
\hline Non-EMS rates & $28.36^{* * *}$ & $65.03^{* * *}$ & $105.77^{* * *}$ & $92.18^{* * *}$ & $86.25^{* * *}$ & $457.31^{* * *}$ \\
\hline
\end{tabular}

Notes. The regression results are for the pooled test $r_{t+k}-r_{t}=\alpha_{1}+\beta_{1}\left(f_{t, t+k}-r_{t}\right)+\epsilon_{t+k}$. The sample period is from January 1995 until December 2004. The standard errors are give in parentheses. $\mathrm{A}^{*},{ }^{* *}$, or ${ }^{* * *}$ indicates rejection at the 10,5 , or 1 percent significance level, respectively. '\# obs' gives the total number of observations that is used for the pooled regression test.

The null hypothesis that forward rates are unbiased estimates of future interest rates implies that $\alpha_{1}=0$ and $\beta_{1}=1$, and $\epsilon_{t+k}$ has mean zero and is uncorrelated with $f_{t}-r_{t}$. In fact, this is the strong version of the expectations hypothesis, where no constant liquidity premium is allowed. A weaker version can be presented by $\beta_{1}=1$, while $\alpha_{1}$ is a nonzero, though constant liquidity premium.

Hansen (1982) and Hansen and Hodrick (1980) demonstrate that, when the forecast horizon is longer than the observational frequency, the forward rate forecast error $\epsilon_{t+k}$ will be serially correlated up to a moving average process of order $k-1$. While least squares point estimates of $\alpha_{1}$ and $\beta_{1}$ remain consistent in spite of the serially correlated residuals, the least squares standard errors for the regression coefficients are biased. Therefore, we choose estimating equation 3.3 using generalized method of moments (GMM) and adjust the standard errors nonparametrically using the procedure of Newey and West (1987, 1994), employing the Bartlett kernel and assuming a moving average process of order $k$, instead of $k-1 .^{6} 7$

We commence the analysis by replicating tests of the type in equation 3.3 for blocks of countries and for each forecast horizon. We split the sample up in EMS and non-EMS deposits. Table 3.2 summarizes the results. Given are the parameter

\footnotetext{
${ }^{6}$ The survey forecasts are for 'approximately 3 and 12 months ahead' projections. Since panelists are known to often make their projections towards the end of a calendar month, we expect that the $k$-month-ahead forecast is in fact a $k$-month-plus-a-few-days-ahead forecast. We have replicated all results assuming a moving average process of order $k-1$, yet these results differ only marginally from the ones reported and do not alter any of our conclusions.

${ }^{7}$ Since we have prior information about the lag structure, we do not employ any automatic lag selection mechanism, as in Newey and West (1994), in determining the appropriate lag length of the moving average process.
} 
estimates and their (corrected) standard errors, as well as results of $T$ and $\chi^{2}$ tests for the significance of the individual parameters, or combinations thereof. Overall, the evidence presented suggests a fairly consistent rejection of the null hypothesis that implied forward interest rates are unbiased predictors of future changes in interest rates. In particular, both the weak $\left(\beta_{1}=1\right)$ and strong versions $\left(\alpha_{1}=0\right.$ and $\left.\beta_{1}=1\right)$ of the expectations hypothesis are firmly rejected. Only for the long-run EMS rates can the weak version of the expectations hypothesis not be rejected.

While the null hypothesis of forward rate unbiasedness is strongly rejected for all blocks, the rejection is strongest for non-EMS interest rates. Since the structure of the EMS is such that it should enhance stability, at least on the longer run, and since EMS countries try to align the level of (future) inflation of its member states by adjusting the general level of interest rates, the direction of future interest rate actions may, to some extent, be anticipated. This may explain why for EMS countries the rejection is not strong.

Most of the literature on the expectations hypothesis has focused either on only the major international rates, or on pooled tests for blocks of countries. A simultaneous analysis of a broad set of individual deposits is still lacking. To get a better overview of the failure of the expectations hypothesis for the individual countries, table 3.3 reports least squares parameter estimates for the individual rates. The null hypothesis of unbiasedness in this traditional test (the strong version of the expectations hypothesis) is rejected for the vast majority of the individual interest rates. Furthermore, the slope estimate for $\beta_{1}$ is less than unity for the majority of the cases. Although only significant in a few number of instances due to relatively large standard errors, this latter finding corroborates the findings of, for instance, Froot (1989) and MacDonald and Macmillan (1994). In addition, the constant forward rate error term, $\alpha_{1}$, is almost always negative, suggesting that the implicit forward rate, and hence the term structure of interest rates, overestimates the true level of future interest rates.

Rejection of the expectations hypothesis may be attributable to the irrationality of market participants, as suggested by Friedman (1980) and MacDonald and Macmillan (1994), to the existence of a time-varying term premium, as suggested by Friedman (1979), Froot (1989), and Modigliani and Shiller (1973), to some combination of both of these phenomena, to the existence of peso problems (Lewis, 1989; Bekaert et al., 2001), learning behavior, or other statistical arguments. The availability of survey data enables us to identify the relative importance of the explanations. In this chapter we focus our attention on the rationality issue and in the next chapter we examine the economic importance of the time-varying term premium explanation.

We follow the definition of a rational expectation by Pesaran (1987). First, forecasts should be unbiased, implying that the expected rate of change is identical to the actual change. Second, forecast errors should be orthogonal to variables from the information set available to agents, in other words, economic agents use information that is available to them in an efficient way to forecast future rates. Third, the forecast errors should be serially correlated only up to a moving average process of order $k-1$, due to the presence of overlapping observations. Fourth, 
Table 3.3: Individual Test of Forward Rate Unbiasedness

\begin{tabular}{|c|c|c|c|c|c|c|c|c|}
\hline & \multicolumn{4}{|c|}{3 month forecast horizon $(k=3)$} & \multicolumn{4}{|c|}{12 month forecast horizon $(k=12)$} \\
\hline & $\alpha_{1}$ & $\beta_{1}$ & $\chi^{2}$ & $R_{a}^{2}$ & $\alpha_{1}$ & $\beta_{1}$ & $\chi^{2}$ & $R_{a}^{2}$ \\
\hline \multicolumn{9}{|l|}{ a) EMS rates } \\
\hline Austria & -0.1110 & $-0.0811^{* * *}$ & $37.05^{* * *}$ & 0.00 & NA & NA & NA & NA \\
\hline & $(0.0908)$ & $(0.4161)$ & & & NA & NA & & \\
\hline Belgium & $\begin{array}{r}-0.1794 \\
(0.1105)\end{array}$ & $\begin{array}{c}-0.0154^{* * *} \\
(0.2925)\end{array}$ & $47.77^{* * *}$ & 0.00 & $\begin{array}{c}0.6170 \\
(0.5209)\end{array}$ & $\begin{array}{c}-0.8708^{* * *} \\
(0.2961)\end{array}$ & $1121.80^{* * *}$ & 0.27 \\
\hline France & $\begin{array}{c}-0.1374^{* * *} \\
(0.0450)\end{array}$ & $\begin{array}{c}1.2009^{*} \\
(0.1209)\end{array}$ & $11.26^{* * *}$ & 0.55 & $\begin{array}{c}-0.5494^{* * *} \\
(0.1360)\end{array}$ & $\begin{array}{c}1.1053 \\
(0.3340)\end{array}$ & $16.95^{* * *}$ & 0.28 \\
\hline Germany & $\begin{array}{c}-0.1129^{* * *} \\
(0.0324)\end{array}$ & $\begin{array}{c}0.9362 \\
(0.1895)\end{array}$ & $12.14^{* * *}$ & 0.36 & $\begin{array}{c}-0.5265^{* * *} \\
(0.1460)\end{array}$ & $\begin{array}{c}1.0374 \\
(0.3309)\end{array}$ & $14.55^{* * *}$ & 0.25 \\
\hline Ireland & $\begin{array}{c}-0.0959 \\
(0.1110)\end{array}$ & $\begin{array}{c}0.6337 \\
(0.3529)\end{array}$ & 1.96 & 0.28 & $\begin{array}{l}\text { NA } \\
\text { NA }\end{array}$ & $\begin{array}{l}\text { NA } \\
\text { NA }\end{array}$ & NA & NA \\
\hline Italy & $\begin{array}{c}-0.1605^{* * *} \\
(0.0531)\end{array}$ & $\begin{array}{l}0.6987^{* *} \\
(0.1338)\end{array}$ & $12.81^{* * *}$ & 0.35 & $\begin{array}{c}-0.6816^{* * *} \\
(0.1308)\end{array}$ & $\begin{array}{c}1.1514 \\
(0.1545)\end{array}$ & $46.16^{* * *}$ & 0.66 \\
\hline Netherlands & $\begin{array}{c}-0.1421^{* * *} \\
(0.0375)\end{array}$ & $\begin{array}{c}0.8491 \\
(0.2176)\end{array}$ & $14.61^{* * *}$ & 0.26 & $\begin{array}{c}-0.5651^{* * *} \\
(0.1502)\end{array}$ & $\begin{array}{c}1.0110 \\
(0.3330)\end{array}$ & $16.99^{* * *}$ & 0.24 \\
\hline Spain & $\begin{array}{c}-0.1456 \\
(0.0403)\end{array}$ & $\begin{array}{c}0.9666 \\
(0.1742)\end{array}$ & $13.60^{* * *}$ & 0.48 & $\begin{array}{c}-0.6305^{* * *} \\
(0.1411)\end{array}$ & $\begin{array}{c}1.2591 \\
(0.3207)\end{array}$ & 0.65 & 0.39 \\
\hline Europe & $\begin{array}{r}-0.0725^{*} \\
(0.0398)\end{array}$ & $\begin{array}{c}1.1612 \\
(0.1678)\end{array}$ & 3.78 & 0.59 & $\begin{array}{c}-0.7329^{* * *} \\
(0.1237)\end{array}$ & $\begin{array}{c}0.7015 \\
(0.2885)\end{array}$ & $41.68^{* * *}$ & 0.26 \\
\hline
\end{tabular}

b) Non-EMS rates

\begin{tabular}{|c|c|c|c|c|c|c|c|c|}
\hline Australia & $\begin{array}{c}-0.0421 \\
(0.0499)\end{array}$ & $\begin{array}{c}0.7760 \\
(0.1833)\end{array}$ & 2.86 & 0.19 & $\begin{array}{c}-0.0517 \\
(0.2111)\end{array}$ & $\begin{array}{c}0.8379 \\
(0.4203)\end{array}$ & 0.51 & 0.19 \\
\hline Canada & $\begin{array}{c}-0.3860^{* * *} \\
(0.0769)\end{array}$ & $\begin{array}{c}0.9392 \\
(0.1572)\end{array}$ & $34.59^{* * *}$ & 0.29 & $\begin{array}{c}-1.6873^{* * *} \\
(0.3571)\end{array}$ & $\begin{array}{c}1.6113^{*} \\
(0.3290)\end{array}$ & $58.71^{* * *}$ & 0.58 \\
\hline Denmark & $\begin{array}{c}-0.2827^{* * *} \\
(0.1038)\end{array}$ & $\begin{array}{c}1.1771 \\
(0.2458)\end{array}$ & $9.34^{* * *}$ & 0.30 & $\begin{array}{c}-0.9662^{* * *} \\
(0.1820)\end{array}$ & $\begin{array}{c}0.5796 \\
(0.2833)\end{array}$ & $63.43^{* * *}$ & 0.21 \\
\hline Hong Kong & $\begin{array}{c}-0.3590 \\
(0.2976)\end{array}$ & $\begin{array}{c}0.6402 \\
(0.4513)\end{array}$ & $6.14^{* *}$ & 0.03 & $\begin{array}{l}\text { NA } \\
\text { NA }\end{array}$ & $\begin{array}{l}\text { NA } \\
\text { NA }\end{array}$ & NA & NA \\
\hline Japan & $\begin{array}{c}-0.0472 \\
(0.0323)\end{array}$ & $\begin{array}{l}0.4877^{* * *} \\
(0.1578)\end{array}$ & $11.46^{* * *}$ & 0.09 & $\begin{array}{c}-0.1014^{* *} \\
(0.0493)\end{array}$ & $\begin{array}{l}0.0184^{* * *} \\
(0.0127)\end{array}$ & $8494.76^{* * *}$ & 0.00 \\
\hline New Zealand & $\begin{array}{c}-0.0477 \\
(0.1214)\end{array}$ & $\begin{array}{c}0.7807 \\
(0.2516)\end{array}$ & 1.54 & 0.13 & $\begin{array}{l}\text { NA } \\
\text { NA }\end{array}$ & $\begin{array}{l}\text { NA } \\
\text { NA }\end{array}$ & NA & NA \\
\hline Norway & $\begin{array}{c}0.0874 \\
(0.1205)\end{array}$ & $\begin{array}{c}0.9938 \\
(0.2323)\end{array}$ & 0.64 & 0.26 & $\begin{array}{c}-0.6011^{*} \\
(0.3172)\end{array}$ & $\begin{array}{c}0.7397 \\
(0.2372)\end{array}$ & $5.42^{*}$ & 0.15 \\
\hline Sweden & $\begin{array}{c}-0.2322^{* * *} \\
(0.0660)\end{array}$ & $\begin{array}{c}1.1322 \\
(0.2819)\end{array}$ & $20.00^{* * *}$ & 0.32 & $\begin{array}{c}-0.8942^{* * *} \\
(0.2230)\end{array}$ & $\begin{array}{c}0.7630 \\
(0.1662)\end{array}$ & $86.56^{* * *}$ & 0.27 \\
\hline Switzerland & $\begin{array}{c}-0.2194^{* * *} \\
(0.0578)\end{array}$ & $\begin{array}{c}0.8822 \\
(0.1911)\end{array}$ & $20.38^{* * *}$ & 0.19 & $\begin{array}{c}-0.5999 \\
(0.6110)\end{array}$ & $\begin{array}{c}0.5579 \\
(0.6758)\end{array}$ & $15.96^{* * *}$ & 0.35 \\
\hline U.K. & $\begin{array}{r}-0.0911^{*} \\
(0.0548)\end{array}$ & $\begin{array}{c}0.7807 \\
(0.2095)\end{array}$ & $7.35^{* *}$ & 0.27 & $\begin{array}{c}-0.4605^{*} \\
(0.2631)\end{array}$ & $\begin{array}{c}0.8988 \\
(0.3872)\end{array}$ & 4.31 & 0.29 \\
\hline U.S. & $\begin{array}{c}-0.2062^{* * *} \\
(0.0641)\end{array}$ & $\begin{array}{c}1.1173 \\
(0.2693)\end{array}$ & $19.32^{* * *}$ & 0.38 & $\begin{array}{c}-0.7566 \\
(0.5933)\end{array}$ & $\begin{array}{c}0.8425 \\
(0.7290)\end{array}$ & $7.14^{* *}$ & 0.18 \\
\hline
\end{tabular}

Notes. The parameter estimates are for the test $r_{t+k}-r_{t}=\alpha_{1}+\beta_{1}\left(f_{t, t+k}-r_{t}\right)+\epsilon_{t+k}$. The sample period is January 1995 through December 2004. The standard errors of the coefficients are given in parenthesis. $\mathrm{A}^{*},{ }^{* *}$, or ${ }^{* * *}$ denotes rejection at the 10,5 , or 1 percent significant level, respectively, of the hypothesis that $\alpha_{1}=0$ or that $\beta_{1}=1$. The $\chi^{2}$ statistic pertains to the joint hypotheses that $\alpha_{1}=0$ and $\beta_{1}=1$. ' $\mathrm{NA}$ ' indicates the non-availability of a statistic due to data non-avaliability. $R_{a}^{2}$ is the adjusted $R^{2}$ measure. 
expectations should be efficient, where efficiency is a special case of orthogonality in that the information set now only includes past values of the variables that are expected to form the expectations.

The null hypothesis of unbiased expectations implies that $\alpha_{2}=0$ and $\beta_{2}=1$ in a regression of the following form:

$$
r_{t+k}-r_{t}=\alpha_{2}+\beta_{2}\left(r_{t, t+k}^{e}-r_{t}\right)+\epsilon_{t+k},
$$

where $\epsilon_{t+k}$ again is a random forecast error term.

Table 3.4 reports estimates for the parameters in equation 3.4. Although for the 3-month horizon the evidence is mixed, we find that for the longer horizon the evidence presented suggest a fairly consistent rejection of the null hypothesis that the expected interest rate is an unbiased predictor of the realized interest rate. In most cases, rejection of the null is attributable to the combined finding that estimates for $\alpha_{2}$ are significantly different from zero and estimates for $\beta_{2}$ are significantly different from one. In addition, we find that, especially for the short-run forecast horizon, market participants predicted the correct direction of the interest rate movement, given significantly positive parameter estimates of $\beta_{2}$ for most of the interest rates. It is also interesting to note that the significance of the (absolute) level bias in our tests, which can be verified via a standard $T$-test on the estimated $\alpha_{2}$-coefficient, increases as the length of the forecast horizon increases, and is commonly negative, thus corroborating the earlier findings that market participants generally overestimate the true level of future interest rates.

Finally, we note that for the long-run horizon the null of unbiasedness is rejected for all but one EMS currency deposit. This is a surprising result, for one would expect that the stabilizing role of the EMS would enhance the forecast ability of future EMS interest rates, and lead to a less frequent rejection of the unbiasedness hypothesis for EMS currency deposits than for non-EMS deposits.

These results should be interpreted with some caution. If conditional forecasts are formed rationally, allowing for a small probability of a large interest rate movement, then forecasts will appear biased when judged from ex-post forecast errorsthis is the familiar 'peso problem' (see Krasker, 1980). However, it is unlikely that this was the case in our sample period, nor that it would affect all interest rate deposits. An alternative explanation would be that the time series process, which describes the expected interest rate movement, is not ergodic as is implied in the application of the GMM procedure.

The second type of test of the rational expectations hypothesis is concerned with the efficient use of information available at the time expectations are formed. If economic agents use all available information efficiently, then the expectational errors must be orthogonal to any variable in the information set known to agents at the time they form their expectations. The null hypothesis of rational expectations (orthogonality) implies that the vector $\beta=0$ in regressions of the following form:

$$
\xi_{t+k}=\beta X_{t}+\epsilon_{t+k},
$$

where the left hand side variable is the survey forecast error, $X_{t}$ is a vector of elements from the information known at time $t$, and $\epsilon_{t+k}$ is a random error term. 
Table 3.4: Unbiasedness Test of Survey-Based Expectations

\begin{tabular}{|c|c|c|c|c|c|c|c|c|}
\hline & \multicolumn{4}{|c|}{3 month forecast horizon $(k=3)$} & \multicolumn{4}{|c|}{12 month forecast horizon $(k=12)$} \\
\hline & $\alpha_{2}$ & $\beta_{2}$ & $\chi^{2}$ & $R_{a}^{2}$ & $\alpha_{2}$ & $\beta_{2}$ & $\chi^{2}$ & $R_{a}^{2}$ \\
\hline \multicolumn{9}{|l|}{ a) EMS rates } \\
\hline Austria & $\begin{array}{c}-0.1031^{*} \\
(0.0587)\end{array}$ & $\begin{array}{c}0.2133^{* *} \\
(0.3556)\end{array}$ & $6.59^{* *}$ & 0.01 & $\begin{array}{c}0.1671 \\
(0.2303)\end{array}$ & $\begin{array}{c}-1.4372 \\
(0.2923)\end{array}$ & $123.95^{* * *}$ & 0.44 \\
\hline Belgium & $\begin{array}{r}-0.1805^{*} \\
(0.0962)\end{array}$ & $\begin{array}{c}0.2916^{* *} \\
(0.3164)\end{array}$ & $11.30^{* * *}$ & 0.01 & $\begin{array}{c}-0.2919 \\
(0.3399)\end{array}$ & $\begin{array}{c}-0.4497 \\
(0.2737)\end{array}$ & $38.84^{* * *}$ & 0.02 \\
\hline France & $\begin{array}{c}0.0361 \\
(0.0518)\end{array}$ & $\begin{array}{c}1.1298 \\
(0.1681)\end{array}$ & 0.86 & 0.45 & $\begin{array}{c}-0.4801^{* *} \\
(0.2219)\end{array}$ & $\begin{array}{c}1.5940^{*} \\
(0.3351)\end{array}$ & $13.85^{* * *}$ & 0.43 \\
\hline Germany & $\begin{array}{c}-0.0792^{*} \\
(0.0427)\end{array}$ & $\begin{array}{c}1.2151 \\
(0.3359)\end{array}$ & 0.41 & 0.23 & $\begin{array}{c}-0.3281 \\
(0.3262)\end{array}$ & $\begin{array}{c}0.2725 \\
(0.7863)\end{array}$ & $6.36^{* *}$ & 0.00 \\
\hline Ireland & $\begin{array}{c}-0.0440 \\
(0.1105)\end{array}$ & $\begin{array}{c}0.6100 \\
(0.3230)\end{array}$ & 1.50 & 0.25 & $\begin{array}{c}-0.5686 \\
(0.3617)\end{array}$ & $\begin{array}{c}0.8629 \\
(0.2930)\end{array}$ & 2.47 & 0.43 \\
\hline Italy & $\begin{array}{c}-0.0526 \\
(0.0522)\end{array}$ & $\begin{array}{c}0.8698 \\
(0.0991)\end{array}$ & 2.54 & 0.42 & $\begin{array}{c}-0.6027^{* *} \\
(0.2338)\end{array}$ & $\begin{array}{c}1.2536 \\
(0.2445)\end{array}$ & $19.55^{* * *}$ & 0.62 \\
\hline Netherlands & $\begin{array}{c}-0.0881^{*} \\
(0.0488)\end{array}$ & $\begin{array}{c}0.7313 \\
(0.3455)\end{array}$ & 3.46 & 0.09 & $\begin{array}{c}-0.1018 \\
(0.3769)\end{array}$ & $\begin{array}{c}-0.3519^{* *} \\
(0.6594)\end{array}$ & $12.73^{* *}$ & 0.01 \\
\hline Spain & $\begin{array}{c}-0.1245^{* *} \\
(0.0515)\end{array}$ & $\begin{array}{c}1.1483 \\
(0.2003)\end{array}$ & $7.40^{* *}$ & 0.35 & $\begin{array}{c}-0.8810^{* * *} \\
(0.2589)\end{array}$ & $\begin{array}{c}0.8855 \\
(0.5398)\end{array}$ & $13.78^{* * *}$ & 0.11 \\
\hline Europe & $\begin{array}{c}0.0179 \\
(0.0642)\end{array}$ & $\begin{array}{c}1.3667 \\
(0.4444)\end{array}$ & 0.68 & 0.30 & $\begin{array}{c}-0.4473 \\
(0.2990)\end{array}$ & $\begin{array}{c}1.1880 \\
(1.2753)\end{array}$ & 2.46 & 0.07 \\
\hline \multicolumn{9}{|c|}{ b) Non-EMS rates } \\
\hline Australia & $\begin{array}{c}-0.0671 \\
(0.0611)\end{array}$ & $\begin{array}{c}0.5063 \\
(0.2807)\end{array}$ & $5.36^{*}$ & 0.03 & $\begin{array}{c}-0.1262 \\
(0.4038)\end{array}$ & $\begin{array}{c}-0.2447 \\
(0.8192)\end{array}$ & $7.17^{* *}$ & 0.00 \\
\hline Canada & $\begin{array}{c}-0.3182^{* * *} \\
(0.0778)\end{array}$ & $\begin{array}{c}1.4768 \\
(0.2874)\end{array}$ & $2.75^{*}$ & 0.31 & $\begin{array}{c}-0.9909^{*} \\
(0.5328)\end{array}$ & $\begin{array}{c}1.1159 \\
(0.5476)\end{array}$ & $8.02^{* *}$ & 0.15 \\
\hline Denmark & $\begin{array}{c}-0.1221^{*} \\
(0.0714)\end{array}$ & $\begin{array}{c}1.2339 \\
(0.1736)\end{array}$ & 3.95 & 0.51 & $\begin{array}{c}-0.9763^{* * *} \\
(0.3368)\end{array}$ & $\begin{array}{c}0.5945 \\
(0.3521)\end{array}$ & $8.78^{* *}$ & 0.06 \\
\hline Hong Kong & $\begin{array}{c}-0.0060 \\
(0.2035)\end{array}$ & $\begin{array}{c}1.1339 \\
(0.1967)\end{array}$ & 0.54 & 0.30 & $\begin{array}{c}-0.4575 \\
(0.5724)\end{array}$ & $\begin{array}{c}1.1378 \\
(0.1314)\end{array}$ & 4.45 & 0.31 \\
\hline Japan & $\begin{array}{r}-0.0553^{*} \\
(0.0326)\end{array}$ & $\begin{array}{c}0.7367 \\
(0.1715)\end{array}$ & $7.92^{* *}$ & 0.08 & $\begin{array}{r}-0.1298^{*} \\
(0.0707)\end{array}$ & $\begin{array}{l}0.0804^{* *} \\
(0.4081)\end{array}$ & $14.30^{* * *}$ & 0.00 \\
\hline New Zealand & $\begin{array}{c}0.0107 \\
(0.1110)\end{array}$ & $\begin{array}{c}0.9110 \\
(0.3966)\end{array}$ & 0.05 & 0.13 & $\begin{array}{c}-0.4116 \\
(0.2688)\end{array}$ & $\begin{array}{l}1.7399^{* * *} \\
(0.2281)\end{array}$ & $10.56^{* * *}$ & 0.62 \\
\hline Norway & $\begin{array}{c}-0.0846 \\
(0.1297)\end{array}$ & $\begin{array}{c}0.6719^{*} \\
(0.1808)\end{array}$ & 3.31 & 0.07 & $\begin{array}{c}-0.7325 \\
(0.5544)\end{array}$ & $\begin{array}{l}0.1723^{* * *} \\
(0.2176)\end{array}$ & $14.46^{* * *}$ & 0.00 \\
\hline Sweden & $\begin{array}{c}-0.2141^{* * *} \\
(0.0578)\end{array}$ & $\begin{array}{c}1.2305 \\
(0.2086)\end{array}$ & $14.69^{* * *}$ & 0.43 & $\begin{array}{c}-1.2473^{* * *} \\
(0.4460)\end{array}$ & $\begin{array}{l}1.3100 \\
(0.5004)\end{array}$ & $16.69^{* * *}$ & 0.21 \\
\hline Switzerland & $\begin{array}{c}-0.1482^{* *} \\
(0.0716)\end{array}$ & $\begin{array}{c}0.6322^{*} \\
(0.2197)\end{array}$ & 14.69 & 0.07 & $\begin{array}{c}-0.5999 \\
(0.6110)\end{array}$ & $\begin{array}{c}0.5578 \\
(0.6758)\end{array}$ & $15.96^{* * *}$ & 0.03 \\
\hline U.K. & $\begin{array}{c}-0.1107 \\
(0.0695)\end{array}$ & $\begin{array}{c}0.8925 \\
(0.3273)\end{array}$ & $5.63^{*}$ & 0.16 & $\begin{array}{r}-0.4605^{*} \\
(0.2631)\end{array}$ & $\begin{array}{c}0.8988 \\
(0.3872)\end{array}$ & 4.31 & 0.20 \\
\hline U.S. & $\begin{array}{c}-0.2995^{* * *} \\
(0.1003)\end{array}$ & $\begin{array}{c}1.1322 \\
(0.2990)\end{array}$ & 0.19 & 0.20 & $\begin{array}{c}-0.7566 \\
(0.5933) \\
\end{array}$ & $\begin{array}{c}0.8425 \\
(0.7260) \\
\end{array}$ & $7.41^{* *}$ & 0.08 \\
\hline
\end{tabular}

Notes. The parameter estimates are for the test $r_{t+k}-r_{t}=\alpha_{2}+\beta_{2}\left(f_{t, t+k}-r_{t}\right)+\epsilon_{t+k}$. The sample period is January 1995 through December 2004. The standard errors of the coefficients are given in parenthesis. $\mathrm{A}^{*},{ }^{* *}$, or ${ }^{* * *}$ denotes rejection at the 10,5 , or 1 percent significant level, respectively, of the hypothesis that $\alpha_{2}=0$ or $\beta_{2}=1$. The $\chi^{2}$ statistic pertains to the joint hypotheses that $\alpha_{2}=0$ and $\beta_{2}=1 . R_{a}^{2}$ is the adjusted $R^{2}$ measure. 
Although the elements that can be included is virtually endless, ${ }^{8}$ we assume that investors' forecasts are primarily driven by past information on the interest rates and their own forecast performance (chartist behavior) and by basic fundamentals describing interest rates (fundamentalist behavior). As for elements from the investor's information set we choose the most recent forecast error, $\xi_{t},{ }^{9}$ the most recent change in the spot interest rate, $r_{t}-r_{t-1}$, the $k$-period implicit forward premium, $f_{t, t+k}-r_{t}$, and the yield spread, $r_{t}^{(L)}-r_{t} \cdot{ }^{10}$ These variables are all known to the investor at the time expectations are formed. In order to test whether economic agents use all available information efficiently, equation 3.5 was fitted for each interest rate on both forecast horizons.

Tables 3.5 and 3.6 report estimates of the orthogonality tests using the information from the above variables. From the $\chi^{2}$ statistics we learn that for nearly all deposits the null hypothesis that all of the variables are orthogonal to the forecast error, is strongly rejected. In fact, the variables included can explain over 20 percent of the variation in the forecast errors in terms of adjusted $R^{2}$ statistics for several deposits. Although it is not always clear which variable is most informative, the most recent change in the level of the interest rates seems to be positively related to the forecast error, and significant in a considerable number of cases.

The inclusion of the forward premium $f_{t, t+k}-r_{t}$ in the orthogonality test has an other important feature. Observe that the probability limit of $\beta_{1}$ in the classical expectations hypothesis test in equation 3.3 reduces to

$$
\operatorname{plim} \beta_{1}=1-\frac{\operatorname{cov}\left(f_{t, t+k}-r_{t+k}, f_{t, t+k}-r_{t}\right)}{\operatorname{var}\left(f_{t, t+k}-r_{t}\right)} .
$$

This probability limit can be decomposed into an expectational error and timevarying term premium component as $\beta_{1}=\beta_{3}+\beta_{4}$, where

$$
\beta_{3} \equiv \frac{\operatorname{cov}\left(f_{t, t+k}-r_{t, t+k}, f_{t, t+k}-r_{t}\right)}{\left.\operatorname{var} f_{t, t+k}-r_{t}\right)}
$$

and

$$
\beta_{4} \equiv 1-\frac{\operatorname{cov}\left(f_{t, t+k}-r_{t, t+k}^{e}, f_{t, t+k}-r_{t}\right)}{\operatorname{var}\left(f_{t, t+k}-r_{t}\right)} .
$$

If the forward discount is included as the sole regressor in equation 3.5, then the $\beta_{3}$ coefficient in the resulting orthogonality test:

$$
\xi_{t+k}=\alpha_{3}+\beta_{3}\left(f_{t, t+k}-r_{t}\right)+\epsilon_{t+k}
$$

\footnotetext{
${ }^{8}$ Provided that the elements are known to the investor at the time she forms her forecast.

${ }^{9}$ The analysis can be extended easily to include multiple (preferably non-overlapping) lags of the forecast error. However, we chose to restrict the analysis to one lag to economize on degrees of freedom.

${ }^{10}$ We define $r_{t}^{(L)}-r_{t}$ as the yield on a long-term contract. We choose the 10-year benchmark bond yield for most deposits, since this is available for nearly all deposits and has a sufficiently long history. If not available, we use the 10-year government bond yield. All yields are obtained from Datastream. The short-term rate is simply the yield on the 3-month contract used earlier.
} 
Table 3.5: Multivariate Orthogonality Test (3-month forecast horizon)

\begin{tabular}{|c|c|c|c|c|c|c|}
\hline & $\begin{array}{l}\text { Forward } \\
\text { discount }\end{array}$ & $\begin{array}{l}\text { Recent } \\
\text { error }\end{array}$ & $\begin{array}{l}\text { Recent } \\
\text { change }\end{array}$ & $\begin{array}{c}\text { Yield } \\
\text { spread }\end{array}$ & $\chi^{2}$ & $R_{a}^{2}$ \\
\hline \multicolumn{7}{|l|}{ a) EMS rates } \\
\hline Austria & $\begin{array}{c}-0.2336 \\
(0.4261)\end{array}$ & $\begin{array}{c}0.1231 \\
(0.2062)\end{array}$ & $\begin{array}{c}0.0715 \\
(0.4124)\end{array}$ & $\begin{array}{l}0.1210^{* * *} \\
(0.0430)\end{array}$ & $17.22^{* * *}$ & 0.03 \\
\hline Belgium & $\begin{array}{r}-0.9348^{*} \\
(0.4953)\end{array}$ & $\begin{array}{l}0.2882^{* * *} \\
(0.1050)\end{array}$ & $\begin{array}{c}0.4804^{* *} \\
(0.2267)\end{array}$ & $\begin{array}{l}0.0909^{* *} \\
(0.0407)\end{array}$ & $76.76^{* * *}$ & 0.40 \\
\hline France & $\begin{array}{l}0.3955^{* * *} \\
(0.1441)\end{array}$ & $\begin{array}{c}0.0840 \\
(0.1084)\end{array}$ & $\begin{array}{c}-0.0241 \\
(0.1818)\end{array}$ & $\begin{array}{c}0.1082^{* *} \\
(0.0495)\end{array}$ & $17.43^{* * *}$ & 0.20 \\
\hline Germany & $\begin{array}{c}0.5894^{* * *} \\
(0.1825)\end{array}$ & $\begin{array}{c}-0.1274 \\
(0.1673)\end{array}$ & $\begin{array}{c}0.3826^{* *} \\
(0.1649)\end{array}$ & $\begin{array}{c}0.0485 \\
(0.0327)\end{array}$ & $22.59^{* * *}$ & 0.25 \\
\hline Ireland & $\begin{array}{c}-0.0908 \\
(0.5654)\end{array}$ & $\begin{array}{c}0.0009 \\
(0.1826)\end{array}$ & $\begin{array}{l}0.8371^{* * *} \\
(0.3027)\end{array}$ & $\begin{array}{c}-0.0602 \\
(0.1859)\end{array}$ & $15.07^{* * *}$ & 0.09 \\
\hline Italy & $\begin{array}{c}-0.0544 \\
(0.0689)\end{array}$ & $\begin{array}{c}-0.0113 \\
(0.0685)\end{array}$ & $\begin{array}{c}-0.0545 \\
(0.0712)\end{array}$ & $\begin{array}{c}-0.0457 \\
(0.0451)\end{array}$ & 3.53 & 0.00 \\
\hline Netherlands & $\begin{array}{c}0.3691 \\
(0.2359)\end{array}$ & $\begin{array}{c}0.0974 \\
(0.1415)\end{array}$ & $\begin{array}{c}0.3478^{* *} \\
(0.1721)\end{array}$ & $\begin{array}{c}0.0419 \\
(0.0391)\end{array}$ & $19.05^{* * *}$ & 0.18 \\
\hline Spain & $\begin{array}{c}0.2693 \\
(0.2281)\end{array}$ & $\begin{array}{c}0.0161 \\
(0.1555)\end{array}$ & $\begin{array}{l}0.3355^{* *} \\
(0.1668)\end{array}$ & $\begin{array}{c}0.1201^{*} \\
(0.0626)\end{array}$ & $22.26^{* * *}$ & 0.21 \\
\hline Europe & $\begin{array}{l}0.7767^{* * *} \\
(0.2029)\end{array}$ & $\begin{array}{c}-0.2702 \\
(0.2199)\end{array}$ & $\begin{array}{c}0.2752 \\
(0.1875)\end{array}$ & $\begin{array}{c}0.0367 \\
(0.0516)\end{array}$ & $21.64^{* * *}$ & 0.30 \\
\hline \multicolumn{7}{|c|}{ b) Non-EMS rates } \\
\hline Australia & $\begin{array}{c}0.2838 \\
(0.3854)\end{array}$ & $\begin{array}{c}-0.0522 \\
(0.1943)\end{array}$ & $\begin{array}{c}0.2552 \\
(0.2782)\end{array}$ & $\begin{array}{c}0.0417 \\
(0.1312)\end{array}$ & 4.61 & 0.02 \\
\hline Canada & $\begin{array}{c}0.2890 \\
(0.2242)\end{array}$ & $\begin{array}{c}-0.0619 \\
(0.1650)\end{array}$ & $\begin{array}{c}0.4990^{*} \\
(0.2551)\end{array}$ & $\begin{array}{c}-0.0133 \\
(0.0648)\end{array}$ & $14.97^{* * *}$ & 0.08 \\
\hline Denmark & $\begin{array}{c}0.2511 \\
(0.2473)\end{array}$ & $\begin{array}{c}0.0719 \\
(0.2452)\end{array}$ & $\begin{array}{c}0.1129 \\
(0.1899)\end{array}$ & $\begin{array}{c}0.0176 \\
(0.0813)\end{array}$ & 2.94 & 0.00 \\
\hline Hong Kong & $\begin{array}{c}0.3376 \\
(0.5865)\end{array}$ & $\begin{array}{c}-0.4240^{* *} \\
(0.2032)\end{array}$ & $\begin{array}{c}0.3143 \\
(0.2756)\end{array}$ & $\begin{array}{c}-0.2033 \\
(0.1999)\end{array}$ & 5.61 & 0.05 \\
\hline Japan & $\begin{array}{c}0.3396^{* *} \\
(0.1587)\end{array}$ & $\begin{array}{c}0.1273 \\
(0.1480)\end{array}$ & $\begin{array}{l}0.5731^{* * *} \\
(0.2020)\end{array}$ & $\begin{array}{c}-0.0918^{* *} \\
(0.0430)\end{array}$ & $35.85^{* * *}$ & 0.29 \\
\hline New Zealand & $\begin{array}{c}-0.2823 \\
(0.3132)\end{array}$ & $\begin{array}{c}0.2432^{* *} \\
(0.1177)\end{array}$ & $\begin{array}{c}0.4980 \\
(0.3050)\end{array}$ & $\begin{array}{c}0.2517^{*} \\
(0.1510)\end{array}$ & $18.58^{* * *}$ & 0.21 \\
\hline Norway & $\begin{array}{c}0.2501 \\
(0.2089)\end{array}$ & $\begin{array}{c}0.3212^{* *} \\
(0.1481)\end{array}$ & $\begin{array}{r}-0.0958 \\
(0.1616)\end{array}$ & $\begin{array}{c}-0.0300 \\
(0.0551)\end{array}$ & $17.21^{* * *}$ & 0.18 \\
\hline Sweden & $\begin{array}{c}0.2334 \\
(0.2373)\end{array}$ & $\begin{array}{c}-0.0103 \\
(0.1194)\end{array}$ & $\begin{array}{c}0.2467 \\
(0.1831)\end{array}$ & $\begin{array}{c}0.1369^{* *} \\
(0.0673)\end{array}$ & $10.06^{* *}$ & 0.13 \\
\hline Switzerland & $\begin{array}{l}0.5791^{* * *} \\
(0.2187)\end{array}$ & $\begin{array}{c}0.0321 \\
(0.1791)\end{array}$ & $\begin{array}{l}0.3481^{* *} \\
(0.1701)\end{array}$ & $\begin{array}{c}0.0425 \\
(0.0754)\end{array}$ & $19.77^{* * *}$ & 0.13 \\
\hline U.K. & $\begin{array}{c}0.0584 \\
(0.1609)\end{array}$ & $\begin{array}{c}0.1451 \\
(0.1353)\end{array}$ & $\begin{array}{c}0.3390 \\
(0.2123)\end{array}$ & $\begin{array}{c}0.0836^{*} \\
(0.0433)\end{array}$ & $15.11^{* * *}$ & 0.15 \\
\hline U.S. & $\begin{array}{c}0.7421^{* *} \\
(0.3034)\end{array}$ & $\begin{array}{c}-0.0531 \\
(0.1164) \\
\end{array}$ & $\begin{array}{l}0.4227^{* * *} \\
(0.1282)\end{array}$ & $\begin{array}{c}0.0102 \\
(0.0420)\end{array}$ & $22.00^{* * *}$ & 0.26 \\
\hline
\end{tabular}

Notes. This table shows the results from multivariate regressions of the forecast error on four variables from the investor's information set related to past performance and fundamentals describing interest rates, namely the contemporaneous forward discount, $f_{t}-r_{t}$, the most recent realized forecast error, $\xi_{t}$, the most recent change in the spot rate, $r_{t}-r_{t-1}$, and the yield spread $r_{t}^{(L)}-r_{t}$. The standard errors of the coefficients are given in parenthesis. 
Table 3.6: Multivariate Orthogonality Test (12-month forecast horizon)

\begin{tabular}{|c|c|c|c|c|c|c|}
\hline & $\begin{array}{l}\text { Forward } \\
\text { discount }\end{array}$ & $\begin{array}{l}\text { Recent } \\
\text { error }\end{array}$ & $\begin{array}{l}\text { Recent } \\
\text { change }\end{array}$ & $\begin{array}{c}\text { Yield } \\
\text { spread }\end{array}$ & $\chi^{2}$ & $R_{a}^{2}$ \\
\hline \multicolumn{7}{|l|}{ a) EMS rates } \\
\hline \multirow[t]{2}{*}{ Austria } & NA & NA & NA & NA & \multirow[t]{2}{*}{ NA } & \multirow[t]{2}{*}{ NA } \\
\hline & NA & NA & NA & NA & & \\
\hline Belgium & $\begin{array}{c}-1.8215^{* * *} \\
(0.4909)\end{array}$ & $\begin{array}{c}-0.0510 \\
(0.1389)\end{array}$ & $\begin{array}{c}0.5920 \\
(0.4797)\end{array}$ & $\begin{array}{c}0.0631 \\
(0.2903)\end{array}$ & $15.43^{* * *}$ & 0.46 \\
\hline France & $\begin{array}{c}0.2008 \\
(0.6366)\end{array}$ & $\begin{array}{c}-0.1935 \\
(0.2341)\end{array}$ & $\begin{array}{c}0.6538^{* *} \\
(0.3024)\end{array}$ & $\begin{array}{c}0.4117 \\
(0.4009)\end{array}$ & $21.92^{* * *}$ & 0.19 \\
\hline Germany & $\begin{array}{c}0.3644 \\
(0.5920)\end{array}$ & $\begin{array}{c}-0.1695 \\
(0.2173)\end{array}$ & $\begin{array}{c}0.6414 \\
(0.4903)\end{array}$ & $\begin{array}{c}0.1996 \\
(0.2947)\end{array}$ & $16.11^{* * *}$ & 0.13 \\
\hline Ireland & $\begin{array}{l}\text { NA } \\
\text { NA }\end{array}$ & $\begin{array}{l}\text { NA } \\
\text { NA }\end{array}$ & $\begin{array}{l}\text { NA } \\
\text { NA }\end{array}$ & $\begin{array}{l}\text { NA } \\
\text { NA }\end{array}$ & NA & NA \\
\hline Italy & $\begin{array}{c}0.1256 \\
(0.4423)\end{array}$ & $\begin{array}{c}-0.2503 \\
(0.1714)\end{array}$ & $\begin{array}{c}0.0406 \\
(0.1796)\end{array}$ & $\begin{array}{c}0.1343 \\
(0.3529)\end{array}$ & $11.27^{* *}$ & 0.16 \\
\hline Netherlands & $\begin{array}{c}0.2458 \\
(0.5444)\end{array}$ & $\begin{array}{c}-0.1987 \\
(0.2122)\end{array}$ & $\begin{array}{c}0.9084^{* *} \\
(0.4440)\end{array}$ & $\begin{array}{c}0.2776 \\
(0.3069)\end{array}$ & $15.67^{* * *}$ & 0.14 \\
\hline Spain & $\begin{array}{c}0.6802 \\
(0.5990)\end{array}$ & $\begin{array}{c}-0.2746 \\
(0.1957)\end{array}$ & $\begin{array}{c}0.6838 \\
(0.4867)\end{array}$ & $\begin{array}{c}-0.0278 \\
(0.4047)\end{array}$ & $8.28^{*}$ & 0.26 \\
\hline Europe & $\begin{array}{c}-0.2760 \\
(0.4920)\end{array}$ & $\begin{array}{c}0.1001 \\
(0.1598)\end{array}$ & $\begin{array}{c}0.3007 \\
(0.6465)\end{array}$ & $\begin{array}{c}0.5401 \\
(0.2668)\end{array}$ & $21.92^{* * *}$ & 0.14 \\
\hline \multicolumn{7}{|c|}{ b) Non-EMS rates } \\
\hline Australia & $\begin{array}{c}0.9697 \\
(0.7467)\end{array}$ & $\begin{array}{c}-0.2299 \\
(0.2012)\end{array}$ & $\begin{array}{c}0.6197 \\
(0.5783)\end{array}$ & $\begin{array}{c}-0.5616 \\
(0.4991)\end{array}$ & 5.47 & 0.03 \\
\hline Canada & $\begin{array}{l}1.1072^{* * *} \\
(0.4202)\end{array}$ & $\begin{array}{c}0.0480 \\
(0.2594)\end{array}$ & $\begin{array}{c}0.1747 \\
(0.5308)\end{array}$ & $\begin{array}{c}0.0434 \\
(0.3455)\end{array}$ & $12.44^{* *}$ & 0.24 \\
\hline Denmark & $\begin{array}{c}-1.2073^{* * *} \\
(0.3205)\end{array}$ & $\begin{array}{l}0.4682^{* * *} \\
(0.0870)\end{array}$ & $\begin{array}{r}-0.3898^{*} \\
(0.1982)\end{array}$ & $\begin{array}{c}0.4514^{*} \\
(0.2321)\end{array}$ & $45.46^{* * *}$ & 0.47 \\
\hline Hong Kong & $\begin{array}{l}\text { NA } \\
\text { NA }\end{array}$ & $\begin{array}{l}\text { NA } \\
\text { NA }\end{array}$ & $\begin{array}{l}\text { NA } \\
\text { NA }\end{array}$ & $\begin{array}{l}\mathrm{NA} \\
\mathrm{NA}\end{array}$ & NA & NA \\
\hline Japan & $\begin{array}{r}0.0178^{*} \\
(0.0104)\end{array}$ & $\begin{array}{c}-0.0521 \\
(0.0974)\end{array}$ & $\begin{array}{c}0.2393 \\
(0.3164)\end{array}$ & $\begin{array}{c}-0.0607 \\
(0.0922)\end{array}$ & 5.76 & 0.08 \\
\hline New Zealand & $\begin{array}{l}\text { NA } \\
\text { NA }\end{array}$ & $\begin{array}{l}\text { NA } \\
\text { NA }\end{array}$ & $\begin{array}{l}\text { NA } \\
\text { NA }\end{array}$ & $\begin{array}{l}\text { NA } \\
\text { NA }\end{array}$ & NA & NA \\
\hline Norway & $\begin{array}{c}0.8346 \\
(1.0384)\end{array}$ & $\begin{array}{c}0.8063^{* *} \\
(0.3207)\end{array}$ & $\begin{array}{c}-0.9059 \\
(1.1655)\end{array}$ & $\begin{array}{c}0.5063 \\
(0.6835)\end{array}$ & $23.19^{* * *}$ & 0.21 \\
\hline Sweden & $\begin{array}{c}-0.0860 \\
(0.3980)\end{array}$ & $\begin{array}{c}-0.2190 \\
(0.1937)\end{array}$ & $\begin{array}{c}0.6101 \\
(0.5591)\end{array}$ & $\begin{array}{c}0.2609 \\
(0.3507)\end{array}$ & 6.19 & 0.10 \\
\hline Switzerland & $\begin{array}{c}0.9831 \\
(0.8235)\end{array}$ & $\begin{array}{c}0.0877 \\
(0.2002)\end{array}$ & $\begin{array}{c}0.5645^{* *} \\
(0.2656)\end{array}$ & $\begin{array}{c}0.0908 \\
(0.4323)\end{array}$ & $25.07^{* * *}$ & 0.18 \\
\hline U.K. & $\begin{array}{c}-0.3179 \\
(0.3672)\end{array}$ & $\begin{array}{c}-0.1276 \\
(0.2046)\end{array}$ & $\begin{array}{c}0.4283 \\
(0.6176)\end{array}$ & $\begin{array}{c}0.3524 \\
(0.2960)\end{array}$ & 6.65 & 0.14 \\
\hline U.S. & $\begin{array}{c}0.2005 \\
(0.5648)\end{array}$ & $\begin{array}{c}0.1187 \\
(0.2099)\end{array}$ & $\begin{array}{c}0.9105 \\
(0.5788)\end{array}$ & $\begin{array}{c}0.2565 \\
(0.2675)\end{array}$ & 7.68 & 0.11 \\
\hline
\end{tabular}

Notes. See table 3.5 for details.

is precisely equal to $\beta_{3}$ in equation 3.7. The decomposition in equation 3.7 then examines how much of the failure on the expectations hypothesis is attributed to the existence of irrational behavior of market participants, as in equation 3.9, while 
the decomposed component in equation 3.8 solely looks at the existence of timevariation in the term premia. The null hypothesis of orthogonality is presented by $\alpha_{3}=0$ and $\beta_{3}=0$.

Table 3.7 reports parameter estimates of the univariate orthogonality regression of the survey-based forecast error on the contemporaneous forward discount. The null hypothesis of error orthogonality is rejected for half of the rates on the short-term horizon, and rejection becomes more apparent when the forecast horizon lengthens to 12 months. The rejection is particularly strong for long-run EMS forecasts. It is interesting to note that the rejection can often be attributed solely to the finding that $\beta_{3}$ is sufficiently remote from unity. These findings indicate that failure of the expectations hypothesis can at least be partly attributed to the failure of the rational expectations hypothesis.

Taken together, the results of both the unbiasedness test and the orthogonality tests provide a fairly sound rejection of the rational expectations hypothesis for many international interest rate series. This is not an isolated finding, but is in line with the general conclusion that so far has emerged from the analysis of survey results on exchange rate expectations for some of the major currencies relative to the U.S. dollar - see, for instance, Cavaglia et al. (1993a,b, 1994), Verschoor and Wolff $(2001 \mathrm{a}, \mathrm{b})$, and Frankel and Froot $(1987 \mathrm{a}, \mathrm{b})$. Thus, although the rational expectations hypothesis has considerable appeal as a theoretical model, it does not always appear to provide an adequate explanation of many interest rate expectations in the sampled period. It is therefore important to consider other models of expectations formation. In the next section we examine two alternative models: extrapolative and adaptive expectations.

\subsection{Models of Expectations Formation}

Empirical evidence suggests that interest rates are highly persistent, yet difficult to predict (see, for instance, Thornton, 2005). This would suggest that the random walk may also be a proper characterization of investor's expectations formation, namely that $E_{t}\left[r_{t+k}\right]-r_{t}=0$. The availability of survey data permits us to test directly how economic agents form their expectations of future interest rate movements, and whether the random walk hypothesis holds for expected interest rates. The finding in the previous section that agents may not use all information that is available to them in an optimal way to improve their forecasts suggests that the rational expectations model may not be valid. In this section, two commonly used alternative models of expectations formation are considered, i.e. the extrapolative and adaptive model. In an extrapolative expectations framework, agents extrapolate the most recent trend into the future. The expected interest rate is formed as a weighted average of the contemporaneous and the lagged interest rate, so that the test describes a form of a distributed lag expectation:

$$
E_{t}\left[r_{t+k}\right]=(1-\omega) r_{t}+\omega r_{t-1}
$$

The number of lags of the interest rate is not per se restricted to one, yet we 
Table 3.7: Test of Error Orthogonality to Forward Premiums

\begin{tabular}{|c|c|c|c|c|c|c|c|c|}
\hline & \multicolumn{4}{|c|}{3 month forecast horizon $(k=3)$} & \multicolumn{4}{|c|}{12 month forecast horizon $(k=12)$} \\
\hline & $\alpha_{3}$ & $\beta_{3}$ & $\chi^{2}$ & $R_{a}^{2}$ & $\alpha_{3}$ & $\beta_{3}$ & $\chi^{2}$ & $R_{a}^{2}$ \\
\hline \multicolumn{9}{|l|}{ a) EMS rates } \\
\hline Austria & 0.0518 & $-0.8051^{*}$ & 4.37 & 0.13 & NA & NA & NA & NA \\
\hline & $(0.0798)$ & $(0.4284)$ & & & NA & NA & & \\
\hline Belgium & $\begin{array}{r}-0.1138 \\
(0.1115)\end{array}$ & $\begin{array}{r}-0.6548^{*} \\
(0.3367)\end{array}$ & $7.44^{* *}$ & 0.05 & $\begin{array}{c}1.5305 \\
(0.8635)\end{array}$ & $\begin{array}{c}-1.7628^{* * *} \\
(0.4929)\end{array}$ & $327.79^{* * *}$ & 0.43 \\
\hline France & $\begin{array}{c}0.0121 \\
(0.0487)\end{array}$ & $\begin{array}{l}0.4501^{* *} \\
(0.2143)\end{array}$ & $5.35^{*}$ & 0.14 & $\begin{array}{c}-0.5688^{* * *} \\
(0.1482)\end{array}$ & $\begin{array}{c}0.6971^{* *} \\
(0.3496)\end{array}$ & $16.04^{* * *}$ & 0.11 \\
\hline Germany & $\begin{array}{c}-0.1012^{* * *} \\
(0.0352)\end{array}$ & $\begin{array}{l}0.5315^{* * *} \\
(0.1942)\end{array}$ & $17.23^{*}$ & 0.15 & $\begin{array}{c}-0.6915^{* * *} \\
(0.1556)\end{array}$ & $\begin{array}{c}0.6855^{*} \\
(0.3538)\end{array}$ & $19.98^{* * *}$ & 0.11 \\
\hline Ireland & $\begin{array}{c}0.0525 \\
(0.1248)\end{array}$ & $\begin{array}{c}-0.0654 \\
(0.3693)\end{array}$ & 0.21 & 0.00 & $\begin{array}{l}\text { NA } \\
\text { NA }\end{array}$ & $\begin{array}{l}\text { NA } \\
\text { NA }\end{array}$ & NA & NA \\
\hline Italy & $\begin{array}{c}-0.0299 \\
(0.0567)\end{array}$ & $\begin{array}{c}0.0075 \\
(0.1119)\end{array}$ & 0.33 & 0.00 & $\begin{array}{c}-0.5847^{* * *} \\
(0.1510)\end{array}$ & $\begin{array}{c}0.2809 \\
(0.1779)\end{array}$ & $24.52^{* * *}$ & 0.08 \\
\hline Netherlands & $\begin{array}{c}-0.1255^{* * *} \\
(0.0417)\end{array}$ & $\begin{array}{c}0.4291^{*} \\
(0.2440)\end{array}$ & $12.71^{* * *}$ & 0.07 & $\begin{array}{c}-0.0678^{* * *} \\
(0.1638)\end{array}$ & $\begin{array}{c}0.6539^{*} \\
(0.3593)\end{array}$ & $17.22^{* *}$ & 0.09 \\
\hline Spain & $\begin{array}{c}-0.1168^{* *} \\
(0.0466)\end{array}$ & $\begin{array}{c}0.4462 \\
(0.1758)\end{array}$ & 18.78 & 0.15 & $\begin{array}{c}-0.7243^{* * *} \\
(0.1450)\end{array}$ & $\begin{array}{l}0.7637^{* *} \\
(0.3259)\end{array}$ & $32.16^{* * *}$ & 0.18 \\
\hline Europe & $\begin{array}{c}-0.0232 \\
(0.0478)\end{array}$ & $\begin{array}{l}0.7027^{* * *} \\
(0.1819)\end{array}$ & $14.95^{* * *}$ & 0.30 & $\begin{array}{c}-0.8474^{* * *} \\
(0.1295)\end{array}$ & $\begin{array}{c}0.3460 \\
(0.3272)\end{array}$ & $42.81^{* * *}$ & 0.06 \\
\hline
\end{tabular}

b) Non-EMS rates

\begin{tabular}{|c|c|c|c|c|c|c|c|c|}
\hline Australia & $\begin{array}{c}-0.0831 \\
(0.0568)\end{array}$ & $\begin{array}{c}0.3673^{*} \\
(0.2077)\end{array}$ & $4.81^{*}$ & 0.04 & $\begin{array}{c}-0.2731 \\
(0.1930)\end{array}$ & $\begin{array}{c}0.4348 \\
(0.4140)\end{array}$ & 2.29 & 0.06 \\
\hline Canada & $\begin{array}{c}-0.3904^{* * *} \\
(0.0757)\end{array}$ & $\begin{array}{l}0.4859^{\text {*** }} \\
(0.1557)\end{array}$ & $26.97^{* * *}$ & 0.11 & $\begin{array}{c}-1.9360^{* * *} \\
(0.3192)\end{array}$ & $\begin{array}{l}1.1558^{* * *} \\
(0.3393)\end{array}$ & $45.88^{* * *}$ & 0.38 \\
\hline Denmark & $\begin{array}{r}-0.1552^{*} \\
(0.0864)\end{array}$ & $\begin{array}{c}0.2463 \\
(0.2478)\end{array}$ & 3.22 & 0.02 & $\begin{array}{c}-0.8228^{* * *} \\
(0.1526)\end{array}$ & $\begin{array}{c}-0.7063^{* *} \\
(0.2760)\end{array}$ & $65.17^{* * *}$ & 0.38 \\
\hline Hong Kong & $\begin{array}{c}-0.0463 \\
(0.2813)\end{array}$ & $\begin{array}{c}0.0719 \\
(0.4485)\end{array}$ & 0.03 & 0.00 & $\begin{array}{l}\text { NA } \\
\text { NA }\end{array}$ & $\begin{array}{l}\text { NA } \\
\text { NA }\end{array}$ & NA & NA \\
\hline Japan & $\begin{array}{r}-0.0552^{*} \\
(0.0329)\end{array}$ & $\begin{array}{c}0.0142 \\
(0.1839)\end{array}$ & 2.81 & 0.00 & $\begin{array}{c}-0.1341^{* * *} \\
(0.0467)\end{array}$ & $\begin{array}{c}0.0139^{*} \\
(0.0076)\end{array}$ & $8.44^{* * *}$ & 0.00 \\
\hline New Zealand & $\begin{array}{c}0.0127 \\
(0.1238)\end{array}$ & $\begin{array}{c}0.1110 \\
(0.2687)\end{array}$ & 0.28 & 0.00 & $\begin{array}{l}\text { NA } \\
\text { NA }\end{array}$ & $\begin{array}{l}\text { NA } \\
\text { NA }\end{array}$ & NA & NA \\
\hline Norway & $\begin{array}{c}0.0102 \\
(0.1297)\end{array}$ & $\begin{array}{c}0.3522 \\
(0.1808)\end{array}$ & 1.71 & 0.03 & $\begin{array}{c}-0.5909 \\
(0.5544)\end{array}$ & $\begin{array}{r}-0.1610 \\
(0.2176)\end{array}$ & 3.09 & 0.00 \\
\hline Sweden & $\begin{array}{c}-0.2325^{* * *} \\
(0.0576)\end{array}$ & $\begin{array}{c}0.4624 \\
(0.2406)\end{array}$ & 0.1647 & 0.09 & $\begin{array}{c}-0.9549^{* * *} \\
(0.2803)\end{array}$ & $\begin{array}{c}0.1800 \\
(0.2455)\end{array}$ & 28.23 & 0.01 \\
\hline Switzerland & $\begin{array}{c}-0.2731^{* * *} \\
(0.0634)\end{array}$ & $\begin{array}{c}0.5604^{*} \\
(0.2243)\end{array}$ & $19.46^{* * *}$ & 0.08 & $\begin{array}{l}1.4672^{* *} \\
(0.2273)\end{array}$ & $\begin{array}{l}1.0737^{* *} \\
(0.4574)\end{array}$ & $67.98^{* * *}$ & 0.18 \\
\hline U.K. & $\begin{array}{c}-0.1354^{* *} \\
(0.0565)\end{array}$ & $\begin{array}{c}0.2691 \\
(0.2056)\end{array}$ & $6.22^{* *}$ & 0.03 & $\begin{array}{c}-0.5479^{* * *} \\
(0.1955)\end{array}$ & $\begin{array}{c}0.1911 \\
(0.2731)\end{array}$ & $7.87^{* *}$ & 0.01 \\
\hline U.S. & $\begin{array}{c}-0.3484^{* * *} \\
(0.0677)\end{array}$ & $\begin{array}{c}0.6643^{* *} \\
(0.2689)\end{array}$ & $29.88^{* * *}$ & 0.16 & $\begin{array}{c}-1.5748^{* *} \\
(0.6886)\end{array}$ & $\begin{array}{c}0.5731 \\
(0.5417)\end{array}$ & $12.61^{* * *}$ & 0.05 \\
\hline
\end{tabular}

Notes. The parameter estimates are for the test $\xi_{t+k}=\alpha_{3}+\beta_{3}\left(f_{t, t+k}-r_{t}\right)+\epsilon_{t+k}$. The sample period is January 1995 through December 2004. The standard errors of the coefficients are given in parenthesis. $\mathrm{A}^{*},{ }^{* *}$, or ${ }^{* * *}$ denotes rejection at the 10,5 , or 1 percent significant level, respectively, of the hypothesis that $\alpha_{3}=0$ or $\beta_{3}=0$. The $\chi^{2}$ statistic pertains to the joint hypotheses that $\alpha_{3}=0$ and $\beta_{3}=0$. NA indicates the non-availability of a statistic due to data non-avaliability. 
choose to include only the most recent lag to preserve model parsimony. We experimented with multiple lags, but none of the alternatives could improve a single-lag model in terms of model selection criteria. An empirically testable version of this model is presented as

$$
r_{t, t+k}^{e}-r_{t}=\gamma_{0}+\gamma_{1}\left(r_{t}-r_{t-1}\right)+\epsilon_{t},
$$

where $\gamma_{0}=0$ and $\gamma_{1}=-\omega$ and the expected future interest rate $E_{t}\left[r_{t+k}\right]$ is replaced by its survey-based forecast $r_{t, t+k}^{e}{ }^{11}$ If estimates for $\gamma_{1}$ are greater than zero, then interest rate expectations are said to exhibit 'bandwagon' effects: past changes in the interest rates are expected to be reversed in the future. If estimates for $\gamma_{1}$ are equal to zero, then expectations are said to be static in that the best predictor of the future level of the interest rate is today's spot rate. Hence, if we define 'speculation' as buying and selling foreign currency rates in response to non-zero expected interest rate changes, one can interpret a finding of $\gamma_{1}>0$ ('bandwagon' expectations) as implying that speculation is destabilizing in that the speculation does not lead to mean-reverting behavior and a finding of $\gamma_{1}<0$ (distributed lag expectations) as implying that speculation is stabilizing. Least squares estimates of the parameters in equation 3.11 are reported in table 3.8 .

We find that the null hypothesis of static expectations is strongly rejected across both horizons (although it must be noted that for EMS deposits rejection is primarily attributable to rejection of the joint hypothesis that $\gamma_{0}=0$ and $\gamma_{1}=0$ ). Interestingly, we find that the sign of the $\gamma_{1}$-coefficients that are statistically significant, are negative in the majority of cases - an indication that the expectations on interest rates are mean-reverting. Thus, past interest rate movements are expected to be reversed in the future.

Interpreting the regression coefficient for the 3-month Hong Kong interbank rate at the 3 -month forecast horizon, a current interest rate change of 10 percent is expected to be reversed over the next 3 months by about 4.6 percent. Acting on the basis of such expectations, investors are more likely to buy (sell) when the price of foreign currency deposits is already low (high), thereby dampening the original interest rate movement.

Furthermore, from the information on the adjusted $R^{2}$ statistic it appears that the extrapolative model can only account for a small fraction of the variation in the expected interest rate change, in particular for EMS deposits, and that the extrapolative model does not improve to capture the dynamics when the forecast horizon lengthens.

Adaptive expectations models were subsequently considered; namely, the expected future interest rate is formed as a weighted average of the current spot interest rate and the lagged expected rate, maturing at time $t$, or

$$
E_{t}\left[r_{t+k}\right]=(1-\omega) r_{t}+\omega E_{t-k}\left[r_{t}\right]
$$

\footnotetext{
${ }^{11}$ In this section, where the expected depreciation is on the left-hand side of the regressions, forecast horizons longer than the observational frequency do not themselves imply that the error term is serially correlated, since expectations are formed using only contemporaneous and past information. Therefore, equations 3.11 and 3.13 are estimated using the standard least squares procedure.
} 
Table 3.8: Extrapolative Expectations Model

\begin{tabular}{|c|c|c|c|c|c|c|c|c|}
\hline & \multicolumn{4}{|c|}{3 month forecast horizon $(k=3)$} & \multicolumn{4}{|c|}{12 month forecast horizon $(k=12)$} \\
\hline & $\gamma_{0}$ & $\gamma_{1}$ & $\chi^{2}$ & $R_{a}^{2}$ & $\gamma_{0}$ & $\gamma_{1}$ & $\chi^{2}$ & $R_{a}^{2}$ \\
\hline a) EMS rates & & & & & & & & \\
\hline Austria & $\begin{array}{c}-0.0855^{* * *} \\
(0.0269)\end{array}$ & $\begin{array}{c}-0.0406 \\
(0.1892)\end{array}$ & $10.48^{* * *}$ & 0.00 & $\begin{array}{l}0.3945^{* * *} \\
(0.0456)\end{array}$ & $\begin{array}{r}-0.1744 \\
(0.3205)\end{array}$ & $83.16^{* * *}$ & 0.00 \\
\hline Belgium & $\begin{array}{c}-0.0293 \\
(0.0246)\end{array}$ & $\begin{array}{c}-0.4940^{* * *} \\
(0.0633)\end{array}$ & $60.91^{* * *}$ & 0.57 & $\begin{array}{l}0.4249^{* * *} \\
(0.0349)\end{array}$ & $\begin{array}{c}-0.4669^{* * *} \\
(0.0899)\end{array}$ & $190.21^{* * *}$ & 0.37 \\
\hline France & $\begin{array}{c}-0.1486^{* * *} \\
(0.0269)\end{array}$ & $\begin{array}{c}-0.2758^{* * *} \\
(0.0681)\end{array}$ & $43.39^{* * *}$ & 0.12 & $\begin{array}{c}0.0161 \\
(0.0432)\end{array}$ & $\begin{array}{c}-0.2730^{* *} \\
(0.1092)\end{array}$ & $6.57^{* *}$ & 0.05 \\
\hline Germany & $\begin{array}{c}0.0068 \\
(0.0122)\end{array}$ & $\begin{array}{c}0.0413 \\
(0.0767)\end{array}$ & $0.51^{*}$ & 0.00 & $\begin{array}{l}0.3317^{* * *} \\
(0.0210)\end{array}$ & $\begin{array}{c}0.0802 \\
(0.1316)\end{array}$ & $250.59^{* * *}$ & 0.00 \\
\hline Ireland & $\begin{array}{c}-0.2893 \\
(0.0816)\end{array}$ & $\begin{array}{c}-0.0431 \\
(0.2358)\end{array}$ & $15.99^{* * *}$ & 0.00 & $\begin{array}{c}-0.3421^{* *} \\
(0.1673)\end{array}$ & $\begin{array}{c}-0.0887 \\
(0.4830)\end{array}$ & 4.21 & 0.00 \\
\hline Italy & $\begin{array}{r}-0.1649 \\
(0.0443)\end{array}$ & $\begin{array}{c}0.0993 \\
(0.1191)\end{array}$ & $15.99^{* * *}$ & 0.00 & $\begin{array}{c}-0.2060^{* *} \\
(0.0803)\end{array}$ & $\begin{array}{c}0.2574 \\
(0.2159)\end{array}$ & $9.25^{* * *}$ & 0.01 \\
\hline Netherlands & $\begin{array}{c}0.0118 \\
(0.0132)\end{array}$ & $\begin{array}{c}-0.0910 \\
(0.0766)\end{array}$ & 2.57 & 0.01 & $\begin{array}{l}0.3657^{* * *} \\
(0.0300)\end{array}$ & $\begin{array}{c}-0.2350 \\
(0.1729)\end{array}$ & $158.63^{* * *}$ & 0.01 \\
\hline Spain & $\begin{array}{c}-0.0462^{* *} \\
(0.0202)\end{array}$ & $\begin{array}{c}-0.0089 \\
(0.0828)\end{array}$ & $5.44^{*}$ & 0.00 & $\begin{array}{l}0.1812^{\text {*** }} \\
(0.0422)\end{array}$ & $\begin{array}{l}0.3405^{* *} \\
(0.1732)\end{array}$ & $19.27^{* * *}$ & 0.03 \\
\hline Europe & $\begin{array}{c}-0.0267 \\
(0.0173)\end{array}$ & $\begin{array}{c}0.2076^{* *} \\
(0.0994)\end{array}$ & $7.30^{* *}$ & 0.06 & $\begin{array}{l}0.2534^{* * *} \\
(0.0283)\end{array}$ & $\begin{array}{c}0.2442 \\
(0.1632)\end{array}$ & $80.28^{* * *}$ & 0.03 \\
\hline
\end{tabular}

b) Non-EMS rates

\begin{tabular}{|c|c|c|c|c|c|c|c|c|}
\hline Australia & $\begin{array}{l}0.0427^{* * *} \\
(0.0139)\end{array}$ & $\begin{array}{l}0.2498^{* * *} \\
(0.0799)\end{array}$ & $17.32^{* * *}$ & 0.08 & $\begin{array}{l}0.3083^{* * *} \\
(0.0295)\end{array}$ & $\begin{array}{c}-0.0321 \\
(0.1698)\end{array}$ & $110.63^{* * *}$ & 0.00 \\
\hline Canada & $\begin{array}{l}0.1292^{* * *} \\
(0.0185)\end{array}$ & $\begin{array}{l}0.1590^{* *} \\
(0.0674)\end{array}$ & $50.92^{* * *}$ & 0.04 & $\begin{array}{l}0.4971^{* * *} \\
(0.0471)\end{array}$ & $\begin{array}{c}0.0318 \\
(0.1718)\end{array}$ & $112.30^{* * *}$ & 0.00 \\
\hline Denmark & $\begin{array}{c}-0.0307 \\
(0.0437)\end{array}$ & $\begin{array}{c}-0.0565 \\
(0.1402)\end{array}$ & 0.59 & 0.00 & $\begin{array}{l}0.4579^{* * *} \\
(0.0673)\end{array}$ & $\begin{array}{c}-0.2236 \\
(0.2157)\end{array}$ & $50.15^{* * *}$ & 0.02 \\
\hline Hong Kong & $\begin{array}{c}-0.1227^{*} \\
(0.0624)\end{array}$ & $\begin{array}{c}-0.4611^{* * *} \\
(0.0476)\end{array}$ & $96.32^{* * *}$ & 0.46 & $\begin{array}{c}0.0776 \\
(0.1098)\end{array}$ & $\begin{array}{c}-0.4914^{* * *} \\
(0.0838)\end{array}$ & $35.24^{* * *}$ & 0.24 \\
\hline Japan & $\begin{array}{c}-0.0039 \\
(0.0083)\end{array}$ & $\begin{array}{c}-0.2121 \\
(0.0783)\end{array}$ & 7.32 & 0.05 & $\begin{array}{l}0.1197^{* * *} \\
(0.0172)\end{array}$ & $\begin{array}{c}-0.3324^{* *} \\
(0.1619)\end{array}$ & $59.20^{* * *}$ & 0.03 \\
\hline New Zealand & $\begin{array}{c}-0.0501 \\
(0.0305)\end{array}$ & $\begin{array}{r}-0.1350^{*} \\
(0.0783)\end{array}$ & $5.36^{*}$ & 0.02 & $\begin{array}{c}0.0621 \\
(0.0751)\end{array}$ & $\begin{array}{c}-0.1553 \\
(0.1926)\end{array}$ & 1.41 & 0.00 \\
\hline Norway & $\begin{array}{c}-0.0599 \\
(0.0367)\end{array}$ & $\begin{array}{c}-0.0024 \\
(0.0920)\end{array}$ & 2.66 & 0.00 & $\begin{array}{c}-0.1611 \\
(0.1045)\end{array}$ & $\begin{array}{c}-0.2458 \\
(0.2615)\end{array}$ & 3.07 & 0.01 \\
\hline Sweden & $\begin{array}{c}0.0486^{* *} \\
(0.0243)\end{array}$ & $\begin{array}{l}0.2370^{* *} \\
(0.0952)\end{array}$ & $8.59^{* *}$ & 0.05 & $\begin{array}{l}0.4549^{* * *} \\
(0.0414)\end{array}$ & $\begin{array}{l}0.5394^{* * *} \\
(0.1620)\end{array}$ & $121.97^{* *}$ & 0.08 \\
\hline Switzerland & $\begin{array}{l}0.0933^{* * *} \\
(0.0155)\end{array}$ & $\begin{array}{c}-0.3732^{* * *} \\
(0.0606)\end{array}$ & $83.72^{* * *}$ & 0.24 & $\begin{array}{l}0.6295^{* *} \\
(0.0306)\end{array}$ & $\begin{array}{c}-0.4281^{* * *} \\
(0.1200)\end{array}$ & $455.99^{* * *}$ & 0.09 \\
\hline U.K. & $\begin{array}{l}0.0767^{* * *} \\
(0.0164)\end{array}$ & $\begin{array}{l}0.2464^{* * *} \\
(0.0893)\end{array}$ & $27.51^{* * *}$ & 0.06 & $\begin{array}{l}0.3053^{* * *} \\
(0.0466)\end{array}$ & $\begin{array}{l}0.7125^{* * *} \\
(0.2533)\end{array}$ & $48.08^{* * *}$ & 0.06 \\
\hline U.S. & $\begin{array}{l}0.1881^{* * *} \\
(0.0160)\end{array}$ & $\begin{array}{c}-0.0843 \\
(0.0708)\end{array}$ & $144.77^{* * *}$ & 0.01 & $\begin{array}{l}0.5526^{* * *} \\
(0.0430)\end{array}$ & $\begin{array}{c}0.0503 \\
(0.1899)\end{array}$ & $166.60^{* * *}$ & 0.00 \\
\hline
\end{tabular}

Notes. The parameter estimates are for the test $r_{t, t+k}^{e}-r_{t}=\gamma_{0}+\gamma_{1}\left(r_{t}-r_{t-1}\right)+\epsilon_{t}$. The sample period is January 1995 through December 2004. The standard errors of the coefficients are given in parenthesis. A ${ }^{*},{ }^{* *}$, or ${ }^{* * *}$ denotes rejection at the 10,5 , or 1 percent significant level, respectively, of the hypothesis that $\gamma_{0}=0$ or $\gamma_{1}=0$. The $\chi^{2}$ statistic pertains to the joint hypotheses that $\gamma_{0}=0$ and $\gamma_{1}=0 . R_{a}^{2}$ is the adjusted $R^{2}$ measure. 
Alternatively, one can view the expected interest rate movement as a function of past forecast errors, and then the following equation may be fitted:

$$
r_{t, t+k}^{e}-r_{t}=\delta_{0}+\delta_{1}\left(r_{t}-r_{t-k, t}^{e}\right)+\epsilon_{t} .
$$

Equation 3.13 corresponds to equation 3.12 if we set $\delta_{0}=0$ and $\delta_{1}=-\omega$ and when the expected future interest rate $E_{t}\left[r_{t+k}\right]$ is replaced by its survey-based forecast $r_{t, t+k}^{e}$. In essence, this is a version of the class of learning models, where markets participants learn from their past behavior and mistakes. Parameter estimates for this test are reported in table 3.9.

The results on the model of adaptive expectations corroborate our earlier finding in that the null hypothesis of static expectations is strongly rejected. For the majority of the interest rates at the 3 -month horizon the estimates for $\delta_{1}$ are significantly negative, indicating that expectations again appear to be mean-reverting. Interpreting the regression coefficient for the 3-month Hong Kong interbank rate at the 12-month horizon, an unexpected interest rate change of 10 percent implies an expected future change in the interest rate over the next 12 months of about -4.7 percent. From tables 3.8 and 3.9, it is clear that interest rate expectations display a considerable positive weight on the lagged spot interest rate or on the lagged expected spot rate, rather than placing all the weight on the contemporaneous spot rate, and in this sense are stabilizing.

In terms of explanatory power, the adaptive model can better explain the variability in the expected interest rate changes than the extrapolative model: adjusted $R^{2}$ are in general higher for the adaptive model, and for a number of deposits the increase in model fit is considerable. ${ }^{12}$ The latter finding is interesting, for though both models indicate that expectations are mean-reverting (in particular when the forecast horizon lengthens) expectations are more influenced by the most recent behavior of the market participants than they are by the past behavior of the market itself. This would indicate that expectations evolve from learning more than they do by way of adapting to the past market status.

In can be questioned whether the underlying processes that generate expectations can better be described by using a more dynamic model than either the extrapolative or adaptive framework. We therefore present in tables 3.10 and 3.11 results from a multivariate regression of the expected changes on both the most recent change in the level of the interest rates and the most recent forecast error. In terms of adjusted $R^{2}$ statistics the mixed model explains the variation in the expected interest rate change better, or at minimum no worse, than either the adaptive or extrapolative model. The parameters of the original adaptive model retain their sign, while the parameters of the original extrapolative model change sign frequently.

We continue by examining formally whether an adaptive, an extrapolative, or a 'mixed' model can best describe the expectations formation process, by using the Schwarz-Bayesian information criterion ${ }^{13}$ and find that either the mixed model or the

\footnotetext{
${ }^{12}$ Only for the United Kingdom and Belgium does the extrapolative model have more explanatory power, albeit marginally.

${ }^{13}$ We do not provide statistics here, but rather choose to describe the findings. All results on the selection criteria test are available upon request.
} 
Table 3.9: Adaptive Expectations Model

\begin{tabular}{|c|c|c|c|c|c|c|c|c|}
\hline & \multicolumn{4}{|c|}{3 month forecast horizon $(k=3)$} & \multicolumn{4}{|c|}{12 month forecast horizon $(k=12)$} \\
\hline & $\delta_{0}$ & $\delta_{1}$ & $\chi^{2}$ & $R_{a}^{2}$ & $\delta_{0}$ & $\delta_{1}$ & $\chi^{2}$ & $R_{a}^{2}$ \\
\hline \multicolumn{9}{|l|}{ a) EMS rates } \\
\hline Austria & $\begin{array}{c}-0.0994^{* * *} \\
(0.0250)\end{array}$ & $\begin{array}{c}-0.0279 \\
(0.0810)\end{array}$ & $15.74^{* * *}$ & 0.00 & $\begin{array}{l}0.3717^{* * *} \\
(0.0476)\end{array}$ & $\begin{array}{c}0.0841^{* *} \\
(0.0403)\end{array}$ & $74.77^{* * *}$ & 0.11 \\
\hline Belgium & $\begin{array}{c}-0.0255 \\
(0.0360)\end{array}$ & $\begin{array}{c}-0.1676^{* *} \\
(0.0720)\end{array}$ & $5.42^{*}$ & 0.11 & $\begin{array}{l}0.4146^{* * *} \\
(0.0542)\end{array}$ & $\begin{array}{c}0.0169 \\
(0.0386)\end{array}$ & $94.23^{* * *}$ & 0.00 \\
\hline France & $\begin{array}{c}-0.1208^{* * *} \\
(0.0223)\end{array}$ & $\begin{array}{c}-0.1773^{* * *} \\
(0.0530)\end{array}$ & $42.86^{* * *}$ & 0.08 & $\begin{array}{l}0.1670^{\text {*** }} \\
(0.0270)\end{array}$ & $\begin{array}{l}0.0676^{* * *} \\
(0.0251)\end{array}$ & $38.20^{* * *}$ & 0.06 \\
\hline Germany & $\begin{array}{c}0.0134 \\
(0.0123)\end{array}$ & $\begin{array}{l}0.1154^{* * *} \\
(0.0403)\end{array}$ & $8.31^{* *}$ & 0.06 & $\begin{array}{l}0.3075^{* * *} \\
(0.0255)\end{array}$ & $\begin{array}{c}-0.0176 \\
(0.0234)\end{array}$ & $218.29^{* * *}$ & 0.00 \\
\hline Ireland & $\begin{array}{c}-0.2577^{* * *} \\
(0.0737)\end{array}$ & $\begin{array}{c}-0.4359^{* * *} \\
(0.1246)\end{array}$ & $28.85^{* * *}$ & 0.22 & $\begin{array}{c}-0.8021^{* * *} \\
(0.1698)\end{array}$ & $\begin{array}{c}-0.4052^{* * *} \\
(0.1412)\end{array}$ & $24.74^{* * *}$ & 0.19 \\
\hline Italy & $\begin{array}{c}-0.1804^{* * *} \\
(0.0413)\end{array}$ & $\begin{array}{c}-0.3422^{* * *} \\
(0.0852)\end{array}$ & $34.29^{* * *}$ & 0.12 & $\begin{array}{c}-0.1143 \\
(0.1037)\end{array}$ & $\begin{array}{c}0.0673 \\
(0.0929)\end{array}$ & 4.15 & 0.00 \\
\hline Netherlands & $\begin{array}{c}0.0165 \\
(0.0134)\end{array}$ & $\begin{array}{c}0.0673^{*} \\
(0.0386)\end{array}$ & 3.66 & 0.02 & $\begin{array}{l}0.2911^{* * *} \\
(0.0326)\end{array}$ & $\begin{array}{r}-0.0465^{*} \\
(0.0266)\end{array}$ & $134.69^{* * *}$ & 0.02 \\
\hline Spain & $\begin{array}{c}-0.0306 \\
(0.0196)\end{array}$ & $\begin{array}{l}0.1575^{* * *} \\
(0.0539)\end{array}$ & $16.49^{*}$ & 0.06 & $\begin{array}{l}0.2572^{\text {*** }} \\
(0.0447)\end{array}$ & $\begin{array}{l}0.1592^{* * *} \\
(0.0308)\end{array}$ & $36.64^{* * *}$ & 0.20 \\
\hline Europe & $\begin{array}{c}-0.0344^{* *} \\
(0.0164)\end{array}$ & $\begin{array}{l}0.2185^{* * *} \\
(0.0520)\end{array}$ & $21.29^{* * *}$ & 0.21 & $\begin{array}{l}0.2227^{* * *} \\
(0.0354)\end{array}$ & $\begin{array}{c}-0.0147 \\
(0.0317)\end{array}$ & $48.63^{* * *}$ & 0.00 \\
\hline
\end{tabular}

b) Non-EMS rates

\begin{tabular}{|c|c|c|c|c|c|c|c|c|}
\hline Australia & $\begin{array}{l}0.0527^{* * *} \\
(0.0140)\end{array}$ & $\begin{array}{l}0.1521^{* * *} \\
(0.0356)\end{array}$ & $26.24^{* * *}$ & 0.14 & $\begin{array}{l}0.2141^{* * *} \\
(0.0328)\end{array}$ & $\begin{array}{c}-0.1221^{* * *} \\
(0.0271)\end{array}$ & $116.20^{* * *}$ & 0.17 \\
\hline Canada & $\begin{array}{l}0.1541^{* * *} \\
(0.0207)\end{array}$ & $\begin{array}{l}0.1050^{* * *} \\
(0.0387)\end{array}$ & $55.78^{* * *}$ & 0.06 & $\begin{array}{l}0.4019^{* * *} \\
(0.0541)\end{array}$ & $\begin{array}{c}-0.1499^{* * *} \\
(0.0327)\end{array}$ & $117.31^{* * *}$ & 0.16 \\
\hline Denmark & $\begin{array}{r}-0.0719^{*} \\
(0.0380)\end{array}$ & $\begin{array}{c}-0.0696 \\
(0.0996)\end{array}$ & 3.61 & 0.01 & $\begin{array}{l}0.3001^{* * *} \\
(0.0977)\end{array}$ & $\begin{array}{r}-0.1128^{*} \\
(0.0573)\end{array}$ & $46.78^{* * *}$ & 0.10 \\
\hline Hong Kong & $\begin{array}{c}-0.1078^{* *} \\
(0.0452)\end{array}$ & $\begin{array}{c}-0.5078^{* * *} \\
(0.0298)\end{array}$ & $293.26^{* * *}$ & 0.73 & $\begin{array}{r}-0.1643^{*} \\
(0.0917)\end{array}$ & $\begin{array}{c}-0.4866^{* * *} \\
(0.0403)\end{array}$ & $146.93^{* * *}$ & 0.60 \\
\hline Japan & $\begin{array}{c}-0.0091 \\
(0.0079)\end{array}$ & $\begin{array}{c}-0.1779^{* * *} \\
(0.0344)\end{array}$ & $26.70^{* * *}$ & 0.18 & $\begin{array}{l}0.0604^{* * *} \\
(0.0197)\end{array}$ & $\begin{array}{c}-0.1954^{* * *} \\
(0.0400)\end{array}$ & $70.60^{* * *}$ & 0.18 \\
\hline New Zealand & $\begin{array}{c}-0.0355 \\
(0.0292)\end{array}$ & $\begin{array}{c}-0.1375^{* * *} \\
(0.0379)\end{array}$ & $14.62^{* * *}$ & 0.11 & $\begin{array}{c}0.0600 \\
(0.0663)\end{array}$ & $\begin{array}{c}-0.2946^{* * *} \\
(0.0516)\end{array}$ & $42.89^{* * *}$ & 0.25 \\
\hline Norway & $\begin{array}{c}-0.0699^{*} \\
(0.0363)\end{array}$ & $\begin{array}{c}-0.1260^{* * *} \\
(0.0455)\end{array}$ & $10.63^{* * *}$ & 0.09 & $\begin{array}{c}-0.0099 \\
(0.0634)\end{array}$ & $\begin{array}{c}-0.1998^{* * *} \\
(0.0325)\end{array}$ & $40.08^{* * *}$ & 0.36 \\
\hline Sweden & $\begin{array}{c}0.0676^{* *} \\
(0.0268)\end{array}$ & $\begin{array}{l}0.1654^{* * *} \\
(0.0620)\end{array}$ & $9.28^{* * *}$ & 0.05 & $\begin{array}{l}0.5208^{* * *} \\
(0.0573)\end{array}$ & $\begin{array}{l}0.0763^{* *} \\
(0.0354)\end{array}$ & $114.04^{* * *}$ & 0.04 \\
\hline Switzerland & $\begin{array}{l}0.0680^{* * *} \\
(0.0173)\end{array}$ & $\begin{array}{c}-0.1792^{* * *} \\
(0.0356)\end{array}$ & $64.14^{* * *}$ & 0.18 & $\begin{array}{l}0.4961^{* * *} \\
(0.0386)\end{array}$ & $\begin{array}{c}-0.1222^{* * *} \\
(0.0274)\end{array}$ & $443.39^{* * *}$ & 0.15 \\
\hline U.K. & $\begin{array}{l}0.0821^{* * *} \\
(0.0171)\end{array}$ & $\begin{array}{l}0.1193^{* * *} \\
(0.0447)\end{array}$ & $24.43^{* * *}$ & 0.05 & $\begin{array}{l}0.2119^{* * *} \\
(0.0564)\end{array}$ & $\begin{array}{c}-0.1132^{* *} \\
(0.0517)\end{array}$ & $34.62^{* * *}$ & 0.04 \\
\hline U.S. & $\begin{array}{l}0.2002^{* * *} \\
(0.0193)\end{array}$ & $\begin{array}{c}0.0525 \\
(0.0395)\end{array}$ & $141.01^{* * *}$ & 0.01 & $\begin{array}{l}0.4600^{* * *} \\
(0.0543)\end{array}$ & $\begin{array}{c}-0.1236^{* * *} \\
(0.0354)\end{array}$ & $190.24^{* *}$ & 0.10 \\
\hline
\end{tabular}

Notes. The parameter estimates are for the test $r_{t, t+k}^{e}-r_{t}=\delta_{0}+\delta_{1}\left(r_{t}-r_{t-k, t}^{e}\right)+\epsilon_{t}$. The sample period is January 1995 through December 2004. The standard errors of the coefficients are given in parenthesis. A ${ }^{*},{ }^{* *}$, or ${ }^{* * *}$ denotes rejection at the 10,5 , or 1 percent significant level, respectively, of the hypothesis that $\delta_{0}=0$ or $\delta_{1}=0$. The $\chi^{2}$ statistic pertains to the joint hypotheses that $\delta_{0}=0$ and $\delta_{1}=0 . R_{a}^{2}$ is the adjusted $R^{2}$ measure. 
Table 3.10: Mixed Expectations Model (3-month forecast horizon)

\begin{tabular}{|c|c|c|c|c|}
\hline & Recent change & Recent error & $R_{\mathrm{a}}^{2}$ & Model \\
\hline \multicolumn{5}{|l|}{ a) EMS rates } \\
\hline Austria & $\begin{array}{c}0.0675 \\
(0.2110)\end{array}$ & $\begin{array}{c}-0.0430 \\
(0.0946)\end{array}$ & 0.00 & adaptive \\
\hline Belgium & $\begin{array}{c}-0.5257^{* * *} \\
(0.0874)\end{array}$ & $\begin{array}{c}-0.0176 \\
(0.0589)\end{array}$ & 0.50 & extrapolative \\
\hline France & $\begin{array}{l}0.2683^{* * *} \\
(0.0836)\end{array}$ & $\begin{array}{c}-0.2279^{* * *} \\
(0.0534)\end{array}$ & 0.14 & mixed \\
\hline Germany & $\begin{array}{r}-0.1655^{*} \\
(0.0974)\end{array}$ & $\begin{array}{l}0.1736^{* *} \\
(0.0527)\end{array}$ & 0.07 & adaptive \\
\hline Ireland & $\begin{array}{c}0.3596 \\
(0.2675)\end{array}$ & $\begin{array}{c}-0.4948^{* * *} \\
(0.1310)\end{array}$ & 0.21 & adaptive \\
\hline Italy & $\begin{array}{l}0.3395^{* * *} \\
(0.1218)\end{array}$ & $\begin{array}{c}-0.4543^{* * *} \\
(0.0921)\end{array}$ & 0.16 & mixed \\
\hline Netherlands & $\begin{array}{c}-0.2542^{* * *} \\
(0.0901)\end{array}$ & $\begin{array}{l}0.1445^{* * *} \\
(0.0464)\end{array}$ & 0.07 & mixed \\
\hline Spain & $\begin{array}{c}-0.1288 \\
(0.1157)\end{array}$ & $\begin{array}{l}0.2035^{* * *} \\
(0.0679)\end{array}$ & 0.06 & adaptive \\
\hline Europe & $\begin{array}{c}-0.0639 \\
(0.1348)\end{array}$ & $\begin{array}{l}0.2420^{* * *} \\
(0.0720)\end{array}$ & 0.19 & adaptive \\
\hline \multicolumn{5}{|c|}{ b) Non-EMS rates } \\
\hline Australia & $\begin{array}{c}0.0277 \\
(0.1112)\end{array}$ & $\begin{array}{l}0.1431^{* * *} \\
(0.0509)\end{array}$ & 0.13 & adaptive \\
\hline Canada & $\begin{array}{c}0.2079^{* *} \\
(0.1021)\end{array}$ & $\begin{array}{c}0.0306 \\
(0.0529)\end{array}$ & 0.07 & mixed \\
\hline Denmark & $\begin{array}{c}-0.0055 \\
(0.1517)\end{array}$ & $\begin{array}{c}-0.0666 \\
(0.1299)\end{array}$ & 0.00 & adaptive \\
\hline Hong Kong & $\begin{array}{c}-0.1875^{* * *} \\
(0.0378)\end{array}$ & $\begin{array}{c}-0.4119^{* * *} \\
(0.0332)\end{array}$ & 0.78 & mixed \\
\hline Japan & $\begin{array}{c}0.0503 \\
(0.0971)\end{array}$ & $\begin{array}{c}-0.1934^{* * *} \\
(0.0457)\end{array}$ & 0.18 & adaptive \\
\hline New Zealand & $\begin{array}{c}0.0565 \\
(0.0987)\end{array}$ & $\begin{array}{c}-0.1557^{* * *} \\
(0.0495)\end{array}$ & 0.10 & adaptive \\
\hline Norway & $\begin{array}{l}0.2710^{* *} \\
(0.1178)\end{array}$ & $\begin{array}{c}-0.2135^{* * *} \\
(0.0584)\end{array}$ & 0.13 & mixed \\
\hline Sweden & $\begin{array}{c}0.1079 \\
(0.1350)\end{array}$ & $\begin{array}{c}0.1205 \\
(0.0837)\end{array}$ & 0.05 & adaptive \\
\hline Switzerland & $\begin{array}{c}-0.2724^{* * *} \\
(0.0719)\end{array}$ & $\begin{array}{c}-0.0950^{* *} \\
(0.0404)\end{array}$ & 0.26 & mixed \\
\hline U.K. & $\begin{array}{c}0.1389 \\
(0.1192)\end{array}$ & $\begin{array}{c}0.0719 \\
(0.0604)\end{array}$ & 0.05 & adaptive \\
\hline U.S. & $\begin{array}{c}-0.2553^{* * *} \\
(0.0880)\end{array}$ & $\begin{array}{l}0.1469^{* * *} \\
(0.0502)\end{array}$ & 0.07 & mixed \\
\hline
\end{tabular}

Notes. This table shows the results from multivariate regressions of the expected change in the interest rate on the most recent realized change, $r_{t}-r_{t-1}$, and the most recent forecast error, $r_{t}-r_{t-k, t}^{e}$. The standard errors of the coefficients are given in parentheses. A ${ }^{*},{ }^{* *}$, or ${ }^{* * *}$ denotes significance at the 10,5 , or 1 percent significant level, respectively. $R_{a}^{2}$ is the adjusted $R^{2}$ measure. 'Model' gives the model that best describes the expectations formation process, in terms of the Schwartz-Bayesian information criterion. 
Table 3.11: Mixed Expectations Model (12-month forecast horizon)

\begin{tabular}{|c|c|c|c|c|}
\hline & Recent change & Recent error & $R_{\mathrm{a}}^{2}$ & Model \\
\hline \multicolumn{5}{|l|}{ a) EMS rates } \\
\hline Austria & $\begin{array}{c}-0.1949 \\
(0.2955)\end{array}$ & $\begin{array}{c}0.0940^{* *} \\
(0.0433)\end{array}$ & 0.07 & adaptive \\
\hline Belgium & $\begin{array}{c}-0.6170^{* *} \\
(0.2539)\end{array}$ & $\begin{array}{c}0.0448 \\
(0.0379)\end{array}$ & 0.10 & extrapolative \\
\hline France & $\begin{array}{c}-0.0021 \\
(0.1321)\end{array}$ & $\begin{array}{c}0.0678^{* *} \\
(0.0275)\end{array}$ & 0.05 & adaptive \\
\hline Germany & $\begin{array}{c}0.2304 \\
(0.1454)\end{array}$ & $\begin{array}{c}-0.0339 \\
(0.0254)\end{array}$ & 0.01 & adaptive \\
\hline Ireland & $\begin{array}{c}0.0815 \\
(0.5717)\end{array}$ & $\begin{array}{c}-0.4042^{* * *} \\
(0.1434)\end{array}$ & 0.14 & adaptive \\
\hline Italy & $\begin{array}{l}0.5862^{* *} \\
(0.2850)\end{array}$ & $\begin{array}{c}0.0017 \\
(0.0969)\end{array}$ & 0.03 & extrapolative \\
\hline Netherlands & $\begin{array}{c}0.0813 \\
(0.1753)\end{array}$ & $\begin{array}{r}-0.0517^{*} \\
(0.0289)\end{array}$ & 0.01 & adaptive \\
\hline Spain & $\begin{array}{c}0.2677 \\
(0.2016)\end{array}$ & $\begin{array}{l}0.1372^{* * *} \\
(0.0349)\end{array}$ & 0.20 & adaptive \\
\hline Europe & $\begin{array}{c}0.4824^{* *} \\
(0.2321)\end{array}$ & $\begin{array}{c}-0.0465 \\
(0.0344)\end{array}$ & 0.04 & extrapolative \\
\hline \multicolumn{5}{|c|}{ b) Non-EMS rates } \\
\hline Australia & $\begin{array}{c}0.4080^{* *} \\
(0.1858)\end{array}$ & $\begin{array}{c}-0.1497^{* * *} \\
(0.0294)\end{array}$ & 0.19 & mixed \\
\hline Canada & $\begin{array}{l}0.7006^{* * *} \\
(0.1943)\end{array}$ & $\begin{array}{c}-0.2014^{* * *} \\
(0.0341)\end{array}$ & 0.24 & mixed \\
\hline Denmark & $\begin{array}{c}-0.1904 \\
(0.2617)\end{array}$ & $\begin{array}{c}-0.0970 \\
(0.0616)\end{array}$ & 0.06 & adaptive \\
\hline Hong Kong & $\begin{array}{c}-0.2477^{* * *} \\
(0.0642)\end{array}$ & $\begin{array}{c}-0.4307^{* * *} \\
(0.0404)\end{array}$ & 0.64 & mixed \\
\hline Japan & $\begin{array}{c}-0.1883 \\
(0.1957)\end{array}$ & $\begin{array}{c}-0.1923^{* * *} \\
(0.0401)\end{array}$ & 0.18 & adaptive \\
\hline New Zealand & $\begin{array}{c}0.2134 \\
(0.1626)\end{array}$ & $\begin{array}{c}-0.3134^{* * *} \\
(0.0534)\end{array}$ & 0.25 & adaptive \\
\hline Norway & $\begin{array}{l}0.8922^{* * *} \\
(0.2438)\end{array}$ & $\begin{array}{c}-0.2507^{* * *} \\
(0.0329)\end{array}$ & 0.46 & mixed \\
\hline Sweden & $\begin{array}{c}0.4609^{* *} \\
(0.1829)\end{array}$ & $\begin{array}{c}0.0353 \\
(0.0382)\end{array}$ & 0.08 & mixed \\
\hline Switzerland & $\begin{array}{r}-0.2338^{*} \\
(0.1201)\end{array}$ & $\begin{array}{c}-0.1061^{* * *} \\
(0.0283)\end{array}$ & 0.17 & adaptive \\
\hline U.K. & $\begin{array}{l}1.0845^{* * *} \\
(0.2717)\end{array}$ & $\begin{array}{c}-0.1895^{* * *} \\
(0.0520)\end{array}$ & 0.15 & mixed \\
\hline U.S. & $\begin{array}{c}0.3749^{*} \\
(0.1993)\end{array}$ & $\begin{array}{c}-0.1531^{* * *} \\
(0.0383)\end{array}$ & 0.12 & adaptive \\
\hline
\end{tabular}

Notes. See table 3.10 .

adaptive expectations model is preferred over the extrapolative expectations model. Only for Belgium does an extrapolative model have more explanatory power.

We conclude from the above that expected changes in interest rates display meanreversion, that learning about past mistakes has a greater influence on the forma- 
tion of expectations than the past performance of the interest rate series, and that non-rational models have appeal as alternatives to the rational expectations model. Finally, it must be stressed that the expectations formation process is very complex, in that no single model can capture all of the dynamics in the formation process. The models described above could only capture part of these dynamics. It is also reasonable to assume that the way market participants form their expectations is influenced differently over different time periods, by the country at question, and by the specific setting of the asset. For instance, the adaptive and mixed model capture more of the dynamics of the expected interest rate changes when interest rate volatility is high or when there is an apparent trend in the series, like with the Hong Kong interbank rate, that experienced an almost 15 percent decrease since 1997. Altogether, this discussion has been an initial step to get more insight in how expectations of future interest rates are formed.

\subsection{Conclusions}

In this chapter we examined whether expectations of future EMS and non-EMS interest rates are formed rationally during the period of January 1995 through December 2004. While short-term interest rates sometimes appear to be rational, we corroborate the earlier finding in the literature that (longer-term) interest rate forecasts are not rational and that agents do not use all available information in an efficient manner; this finding applies to the post-1990 period, thus questioning the assertion of Frankel and Froot (1987a, p.151) that "the nature of the rejection of rational expectations strongly depends on the sample period."

As to the expectations formation mechanism, market participants tend to underreact to current (unanticipated) changes in the interest rate at the 3 - and 12-month horizons, as implied by stabilizing expectations models. Our results demonstrate that the pattern across long-term forecast horizons for foreign currency deposits corroborates the long-held view that speculation based on long-term expectations may be stabilizing. This is in line with the general conclusion that so far has emerged from survey data on exchange rate expectations. For instance, Cavaglia et al. (1993a,b) and Frankel and Froot (1987a,b, 1990b) obtained parameter estimates suggesting stabilizing expectation models for long-term horizons. At shorter horizons of one week to one month, however, investors tended to extrapolate recent trends. This lack of unity across different forecast horizons raises the possibility that different types of market participants form their expectations in different ways, with speculators more heavily represented at the short horizon and investors at the long horizons.

In the current chapter, we have focused our attention on characterizing the formation of expectations at various forecast horizons for a set of interest rates. Our analysis is extended in the next chapter, which examines the expectations hypothesis of the term structure of interest rates. We will use the implicit forward rates to impute interest rate term premia to assess whether the rejection of the forward rate as an unbiased predictor of the spot rate is predominantly attributable to irrationality (as discussed in this chapter) or significant variation in term premia. 



\section{Chapter 4}

\section{Time-Variation in Term Premia*}

\subsection{Introduction}

The term structure of interest rates describes the relationship between short- and long-term interest rates, and has become an important concept both for academics and policy makers. One of the theories explaining the shape of the term structure is the expectations hypothesis, which states that the entire term structure at a given point in time reflects the market's expectations of future rates. In one version of the expectations hypothesis (see, for instance, the seminal paper by Fama, 1984b) the forward rate that is implied by the term structure is an unbiased predictor of the future realized spot interest rate, up to a constant liquidity premium. In other versions the expected holding return is equal for all bond maturities except for a maturity-specific constant term premium, or long-term interest rates are equal to the (weighted) average of expected future short rates, up to a constant difference.

Shiller (1990) and Campbell (1995) review some of the literature on term structure studies and find that the expectations hypothesis for the U.S. term structure is rejected. The general result is that although the forward rate contains some information about future spot rates, it is by no means an unbiased predictor. In fact, it has become a well-established empirical regularity in the financial economics literature that the implicit forward rate is a biased predictor of the future spot interest rate. It must be stressed that results are sample-dependent. Christiansen (2003) finds that, when investigating two sample periods, the expectations hypothesis is rejected in one, though not in the other. Rejection of the expectations hypothesis has traditionally been attributed to the existence of a time-varying term premia, as manifested by Fama (1984b) or more recently by Harris (2001) and Dai and Singleton (2002), the existence of irrational behavior on the part of market participants,

${ }^{*}$ Part of this chapter is from a working paper with Willem F.C. Verschoor and Christian C.P. Wolff. 
or some combination thereof.

However, international evidence in favor of the expectations hypothesis is by far not as strong as for the U.S. Dahlquist and Jonsson (1995), Gerlach and Smets (1997), Jondeau and Ricart (1999), and Domínguez and Novales (2000) find that while for the U.S. the expectations hypothesis is firmly rejected, this is by no means the case in a broader international, non-U.S. context. Their results are irrespective of the various forms in which the expectations hypothesis has been presented in the literature and are focused both on forward rate unbiasedness regressions or cointegration techniques, and on spread regressions. In the current chapter we address this issue by relying on a large international dataset that includes simultaneous American, European, and Asian interest rate deposits, thus allowing an interesting comparison of the strength of the expectations hypothesis in a broader setting.

Moreover, even when the expectations hypothesis cannot be rejected in a wider international context, it may still be the case that time-varying term premia exist in the term structure. Dahlquist and Jonsson (1995) show that while the expectations hypothesis cannot be rejected for the Swedish term structure over the sample under investigation - in that forward rates are not biased estimates of future spot rates the parameter estimates are nevertheless unstable over time and this instability is getting larger with the forecast horizon. The instability in turn may then well be the result of time-variation in the term premia. So even though the expectations hypothesis may not be rejected for the usual data sources, time-variation in term premia may still exist.

However, the inherently unobserved nature of the term premium never allows a clear assessment of how the results from previous expectations hypothesis studies are biased by the assumption of rational expectations and whether rejection of the expectations hypothesis is in fact attributed to the existence of a time-varying term premium. In the current chapter we try to address this issue by relying on survey measures of interest rate expectations. Using survey measures of expectations allows us to verify whether commonly-used assumptions about the underlying process that characterizes the expectations hypothesis are correct. Not only does the use of survey measures of expectations allow us to assess whether time-varying term premia exist in the term structure of interest rates, it also allows to model the term premia, in terms of time series models or economic fundamentals.

The use of survey data is not uncommon in the literature. Frankel and Froot (1987b) and Cavaglia et al. (1993b, 1994) use survey data on foreign exchange to examine whether exchange rate expectations are formed rationally. Dokko and Edelstein (1989) review the usefulness of the Livingston forecasts of stock market rates of returns and Branch (2004) re-examines rational inflation expectations. Although Friedman (1979) and Froot (1989) briefly examine the expectations hypothesis of the U.S. term structure using survey data, these studies are hampered by small sample problems and do not allow an assessment of the expectations hypothesis in a wider international context.

While the failure of the expectations hypothesis of the term structure of interest rates in the U.S. is often attributed to the existence of a time-varying term premium, it remains ambiguous as to what the sources of this time-variability are. Most of the 
recent literature on term premium determinants has focused on models of its second moments. Engle et al. (1987), for instance, suggest that the conditional variance of the excess holding yield on a long-term bond is a determinant of the current term premium, in addition to the information already contained in the often-used long-short yield spread. Yet Tzavalis and Wickens (1995) and Henry (1999) argue that a structural break in the unconditional variance can give rise to a spurious persistence in volatility. This suggests that conditional heteroskedasticity models may not adequately capture the time-variation in the term premium. Henry (1999), for instance, accounts for regime shifts in the U.S. monetary policy in tests of timevarying term premia and finds that conditional heteroskedasticity models appear less than adequate. On the other hand, Lee (1995) and Bekdache (2001) find that term premia should be modeled as a function of macroeconomic variables instead of as a function of mere asset covariances. In particular production, money supply, and maturity composition of federal debt appear important determinants.

Little if anything is documented about the behavior and the determinants of foreign term premia, while the behavior of international term premia can be substantially different. Hejazi et al. (2000) report that, in contrast to the U.S., the Canadian term premium is not related to the conditional variances of Canadian macroeconomic variables, like industrial production and money supply. Yet, an indepth comparative study on the presence of term premia in international interest rate deposits is still lacking in the literature. We address these issues by explicitly modeling the survey-based term premia using various techniques.

Finally, the rejection of the expectations hypothesis is particularly pronounced for longer maturity bonds, while for the shorter maturity bonds the evidence is mixed. We therefore focus in this chapter on the short end of the term structure, in an effort to obtain more clarity for this segment.

Our results are easily summarized. Although we find strong evidence for the rejection of the 'pure' version of the expectations hypothesis, we only find the null hypothesis that forward rates are biased estimates of future interest rates to be rejected for a limited number of international interest rate deposits. Nevertheless, we find some evidence that the behavior of market participants, when making predictions about the future level of interest rates, is not entirely in line with what rational behavior would suggest. We furthermore find that there is strong evidence of time-variation in the term premia. Also, while the dynamics of term premia can be accounted for by low-order members of the ARMA class models, there is clear evidence to conclude that the conditional heteroskedasticity in term premium movement plays an important role.

The remainder of the chapter is presented as follows. In section 4.2 we introduce the basic methodology. Section 4.3 presents the data and examines several important standard propositions regarding interest rate expectations. In section 4.4 we examine the validity of the expectations hypothesis and we look at the extent to which timevarying term premia are present in the term structure of interest rates and whether the behavior of market participants can be labeled rational. In section 4.5 the timeseries behavior of term premia is examined and section 4.6 models the time-variation in the term premia. Finally, section 4.7 concludes. 


\subsection{The Expectations Hypothesis of the Term Struc- ture}

The expectations hypothesis of the term structure of interest rates is presented in the literature in various basic forms. In one form, interest rates on long-term contracts are represented as an average of expected future short-term rates, plus a constant premium. A constant is allowed by the expectations hypothesis, for instance to account for the liquidity preference theory that states that investors are risk-averse and hence require an (monotonically) increasing return for bonds with longer maturities, since the latter are less liquid. An alternative form of the expectations hypothesis asserts that investors try to equalize the expected holding returns of investments strategies with various horizons, again up to a constant (see, e.g. Campbell, 1995). A final version of the expectations hypothesis asserts that forward rates should be equal to the expectation of the corresponding future interest rates, and hence forward rates can be used to forecast future rates. An advantage of this version is that it depends only on contemporaneous information. All three versions allow for a constant term premium. Shiller et al. (1983) give a clear overview of the implications of these three versions. In this article we focus on the third version of the expectations hypothesis.

The continuously compounded yield to maturity at time $t$ on an $n$-period zero coupon (or discount) bond with a normalized face value of 1 currency unit and a market price of $P_{t}^{(n)}$ equals

$$
r_{t}^{(n)}=-\frac{1}{n} \ln \left[P_{t}^{(n)}\right]
$$

for each period when held to maturity. The forward rate implied by the term structure of interest rates at time $t$ for an $(n-k)$-period contract to be delivered at time $t+k$ is the interest rate at which either holding an $n$-period bond until maturity or investing in a $k$-period bond at time $t$ and subsequently in a $(n-k)$-period bond at time $t+k$, yields the same return, defined as

$$
f_{t, t+k}^{(n-k)}=\frac{1}{n-k}\left(\ln \left[P_{t}^{(n)}\right]-\ln \left[P_{t}^{(k)}\right]\right)=\frac{n}{n-k} r_{t}^{(n)}-\frac{k}{n-k} r_{t}^{(k)},
$$

where $k<n$. In this chapter, the interest rate series used have a maturity of only 3 months. We can therefore simplify the notation where we leave the superscript $n$ out of $r_{t}^{(n)}$ and use $r_{t}$ in the remainder of this chapter to denote the 3 month spot rate and $f_{t, t+k}$ as the $k$-period ahead 3 month forward rate (since then $n-k$ equals 3 months).

The expectations hypothesis states that the implicit forward rate should equate the expected future interest rate, up to a term premium, which is defined as

$$
\varphi_{t} \equiv f_{t, t+k}-E_{t}\left[r_{t+k}\right]
$$

From this specification it can be seen that although the forward rate may contain information about future spot interest rates, it also contains a premium component. Variation through time of the term premium can therefore reduce the power of 
forward rates as predictors of future spot rates. Time-variation in term premia may arise because of changes in market participants' preferred investment horizon, so that term premia evolve over time with investors' presumed risk aversion. More general equilibrium asset pricing models, like Cox et al. (1985), imply that the term premium is a function of both investors' attitudes towards risk, so that the term premium can be interpreted as a risk premium, and the covariance of long and short rates with consumption or wealth.

A technical problem that has plagued model builders on the expectations hypothesis is that market expectations are inherently unobservable. A commonly used assumption is that expectations are formed in a rational way, such that the market forms unbiased expectations of future interest rates and that the forecast error, defined as

$$
\Xi_{t+k} \equiv r_{t+k}-E_{t}\left[r_{t+k}\right]
$$

is orthogonal to all information available at time $t$, and in fact is distributed around a zero mean and constant variance. Conditional on this assumption of rational expectations, the term premium is approximated by the ex-post forward bias

$$
\phi_{t} \equiv f_{t, t+k}-r_{t+k}=\varphi_{t}+\xi_{t+k}
$$

Fama (1984b) builds on this assumption by developing a technique based on forward rates that are implicit in the term structure of interest rates, while allowing for time-varying term premia. He assumes that premia are time-variant when their covariance with other elements from the investor's information set, such as the forward premium, is nonnegative. Therefore, the expectations hypothesis of the term structure of interest rates can be tested by means of the following equation:

$$
r_{t+k}-r_{t}=\alpha_{1}+\beta_{1}\left(f_{t, t+k}-r_{t}\right)+\epsilon_{t+k} .
$$

The null hypothesis that the implicit forward rate is an unbiased predictor of the future spot interest rate is presented by the joint hypothesis that $\alpha_{1}=0$ and $\beta_{1}=1$. In fact, this specification tests the pure version of the expectations hypothesis, where no constant premium is allowed. In a weaker version the constant is allowed to be nonzero. In the next section we introduce a survey data set that allows us to deviate from the commonly used rationality assumption. We denote $r_{t, t+k}^{e}$ as the surveybased proxy for the (unknown) market expectation $E_{t}\left[r_{t+k}\right]$.

\subsection{Survey Data and Standard Propositions Re- garding Expectations}

The interest rate data and survey data that is used in this chapter is described in detail in section 3.2. In this chapter we focus only on the 3-month ahead forecasts. We categorize the interest rate deposits in four areas based on their geographic origin. The sample primarily consists of expectations for eurodeposit rates, interbank rates, and treasury bill rates. The use of eurodeposit rates has the added advantage of 
not being affected by any possible government regulations such as capital controls and are sold in a number of national markets simultaneously, thus making the rates more comparable than national rates.

Typical concerns when using survey data, in any setting, are whether these data reflect the true market expectations, whether the expectations are biased because of strategic behavior from the panelists, or whether forecasts from surveys are of any use in an out-of-sample forecast setting - a criterion that has often been put forward to evaluate the quality of survey forecasts. It should be noted that for survey data in the present setting it is of primary concern that the survey expectations reflect the market's sentiment at the time they are formed, that is, the survey data should reflect agents' expectations, nothing more than that. While it is not the primary concern that the expectations outperform other forecasting techniques, there is general consensus that expectations from surveys in most fields perform no worse than any other forecast technique and in this respect we can also learn much from related fields.

Ang et al. (2007), for instance, provide recent evidence that aggregate expectations from various surveys on inflation consistently deliver better forecasts than time-series models, models based on the yield curve, and forecasts based on the Phillips curve, which highlights the usefulness of survey measures of expectations. Elliott and Ito (1999) find that in the foreign exchange market portfolio's based on survey expectations produce small, but positive, profits. It is therefore surprising that Hafer et al. (1992), the only study that investigates the forecast performance of survey-based interest rate expectations, find that survey forecasts for the 3-month U.S. treasury bill rate have larger root mean squared errors (RMSE) and mean absolute errors (MAE) than simple random walk (no change) forecasts.

To ascertain the quality of the survey-based forecasts, table 4.1 presents MAE's and RMSE's of the survey-based and forward rate forecasts in comparison to the benchmark forecast performance of a random walk model. In addition, the table presents Theil's $U$-statistic, which is defined as the ratio of the RMSE of the survey forecast divided by the RMSE of the random walk forecast. Several observations can be made from this table. First, for about half of the rates the errors for the survey forecasts are lower that those of the forward forecasts, indicating that the forecast performance from survey data is about equal to that of forward rate forecast. Second, and of more significance is that both in terms of MAE and RMSE the surveybased forecasts outperform the benchmark random walk model. In fact, except for U.S., Australian, Swiss and Belgium interest deposits, the $U$-statistics are below unity, which stresses the outperformance of the survey forecasts. It is interesting to compare these findings to those of Hafer et al. (1992). Generalizing their finding on the forecast performance of the U.S. treasury bill would erroneously have led to the conclusion that survey-based forecasts cannot outperform a simple random walk forecasts, where in fact we document that the failure to 'beat' the random walk for U.S. forecasts is only an exception to a much larger sample where survey forecasts do outperform their benchmark.

Another issue is that consensus measures of expectations are likely to perform better than the individual expectations that together make the consensus. Although 
Table 4.1: Forecast Performance

\begin{tabular}{|c|c|c|c|c|c|c|c|c|}
\hline \multirow{2}{*}{\multicolumn{2}{|c|}{+2}} & \multicolumn{3}{|c|}{$\begin{array}{r}\text { MAE } \\
\end{array}$} & \multicolumn{3}{|c|}{ RMSE } & \multirow[b]{2}{*}{$\begin{array}{c}\text { Theil's } \\
U \text {-statistic }\end{array}$} \\
\hline & & $\begin{array}{l}\text { forward } \\
\text { rate }\end{array}$ & $\begin{array}{c}\text { survey } \\
\text { forecast }\end{array}$ & $\begin{array}{c}\text { random } \\
\text { walk }\end{array}$ & $\begin{array}{l}\text { forward } \\
\text { rate }\end{array}$ & $\begin{array}{c}\text { survey } \\
\text { forecast }\end{array}$ & $\begin{array}{c}\text { random } \\
\text { walk }\end{array}$ & \\
\hline
\end{tabular}

$\begin{array}{llllllll}\text { Austria } & 0.182 & 0.163 & 0.148 & 0.280 & 0.236 & 0.259 & 0.912 \\ \text { Belgium } & 0.208 & 0.190 & 0.178 & 0.297 & 0.277 & 0.259 & 1.071 \\ \text { Europe } & 0.175 & 0.228 & 0.248 & 0.242 & 0.308 & 0.363 & 0.847 \\ \text { France } & 0.219 & 0.225 & 0.251 & 0.322 & 0.306 & 0.381 & 0.802 \\ \text { Germany } & 0.173 & 0.204 & 0.209 & 0.244 & 0.278 & 0.319 & 0.870 \\ \text { Ireland } & 0.339 & 0.357 & 0.350 & 0.498 & 0.530 & 0.630 & 0.841 \\ \text { Italy } & 0.338 & 0.257 & 0.389 & 0.494 & 0.343 & 0.578 & 0.594 \\ \text { Netherlands } & 0.196 & 0.216 & 0.225 & 0.267 & 0.291 & 0.324 & 0.900 \\ \text { Spain } & 0.199 & 0.254 & 0.310 & 0.281 & 0.345 & 0.436 & 0.791 \\ \text { Switzerland } & 0.307 & 0.315 & 0.298 & 0.411 & 0.430 & 0.424 & 1.015\end{array}$

b) Asia-Pacific

$\begin{array}{llllllll}\text { Australia } & 0.267 & 0.295 & 0.276 & 0.349 & 0.393 & 0.386 & 1.016 \\ \text { Hong Kong } & 1.055 & 0.809 & 0.931 & 1.870 & 1.526 & 1.827 & 0.835 \\ \text { Japan } & 0.095 & 0.089 & 0.087 & 0.145 & 0.142 & 0.152 & 0.933 \\ \text { New Zealand } & 0.493 & 0.531 & 0.550 & 0.743 & 0.738 & 0.794 & 0.929\end{array}$

c) Anglo-Saxon Countries

$\begin{array}{llllllll}\text { Canada } & 0.403 & 0.333 & 0.350 & 0.559 & 0.479 & 0.503 & 0.953 \\ \text { U.K. } & 0.254 & 0.267 & 0.280 & 0.334 & 0.369 & 0.400 & 0.924 \\ \text { U.S. } & 0.243 & 0.305 & 0.276 & 0.372 & 0.458 & 0.444 & 1.031\end{array}$

d) Scandinavia

\begin{tabular}{llllllll} 
Denmark & 0.277 & 0.201 & 0.263 & 0.391 & 0.303 & 0.401 & 0.755 \\
Norway & 0.426 & 0.513 & 0.517 & 0.669 & 0.756 & 0.786 & 0.961 \\
Sweden & 0.333 & 0.317 & 0.326 & 0.461 & 0.414 & 0.512 & 0.810 \\
\hline Notes.
\end{tabular}

Notes. MAE and RMSE are the mean absolute error and the root mean squared error, respectively. ' $U$-statistic' is Theil's $U$-statistic, which is expressed as the ratio of the RMSE of a survey-based forecast divided by the RMSE of a no-change (random walk) forecast.

some individuals' forecast performance may be better than others' in terms of criteria like root mean squared errors, it is difficult to identify a priori who these individuals are, in particular since forecast performance is not constant. Since surveys aggregate the expectations from many market participants, the information in consensus measures is usually superior, which may be due to an effect similar to Bayesian Model Averaging or due to implicitly filtering out the common components of the forecasts.

We continue the analysis by providing summary statistics for the annualized percentage realized spot interest rate, its first difference, and the survey-based expected future rate, in table 4.2. Several findings are worth noting. Over the period investigated, January 1995 through December 2004, the general level of all interest rates decreased, given the uniformly negative mean change in the interest rates. For some rates, like the Hong Kong interbank rate, the decrease is over 15 percent over a 


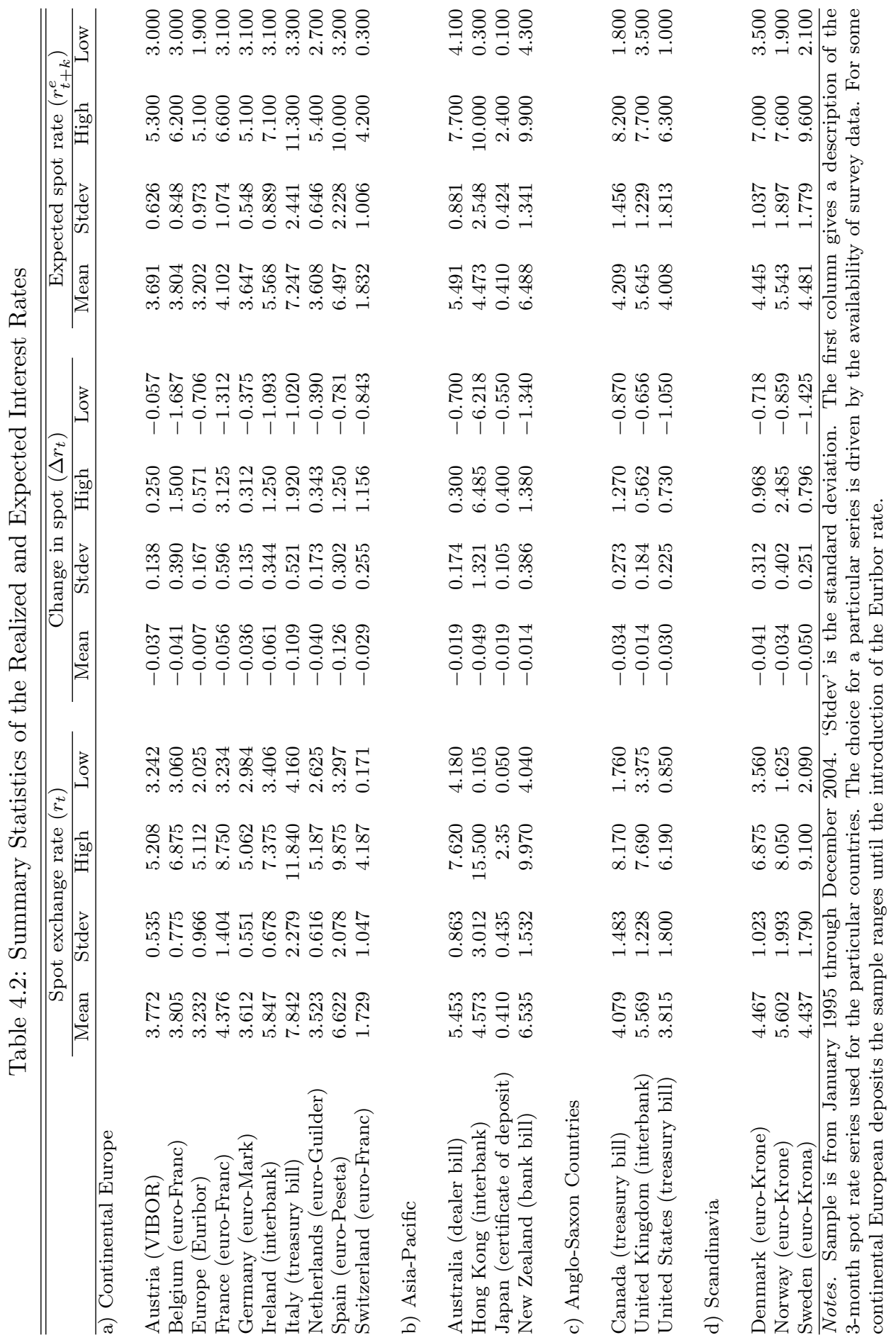


Table 4.3: Summary Statistics of the Term Premia

\begin{tabular}{|c|c|c|c|c|c|c|c|c|}
\hline & Mean & Stdev & Skew & Kurt & BJ & $\%>0$ & $\tau_{1}(\varphi)$ & $\tau_{1}\left(\varphi^{2}\right)$ \\
\hline \multicolumn{9}{|c|}{ a) Continental Europe } \\
\hline Austria & 0.194 & 0.150 & 0.56 & -0.19 & 2.58 & 89 & 0.178 & $0.320^{* *}$ \\
\hline Belgium & 0.101 & 0.240 & 0.27 & -0.42 & 0.94 & 68 & 0.177 & 0.099 \\
\hline Europe & 0.072 & 0.162 & 0.57 & 1.67 & $11.84^{* * *}$ & 67 & $0.708^{* * *}$ & $0.612^{* * *}$ \\
\hline France & 0.154 & 0.215 & -0.15 & 2.43 & $12.03^{* * *}$ & 95 & 0.141 & 0.031 \\
\hline Germany & 0.022 & 0.143 & 0.43 & 0.44 & 1.75 & 56 & $0.416^{* * *}$ & 0.106 \\
\hline Ireland & 0.092 & 0.419 & 0.04 & -0.54 & 0.59 & 54 & $0.577^{* * *}$ & $0.424^{* * *}$ \\
\hline Italy & 0.203 & 0.416 & -0.75 & 3.33 & $26.69^{* * *}$ & 75 & 0.136 & -0.034 \\
\hline Netherlands & 0.056 & 0.136 & 0.58 & -0.39 & 3.05 & 60 & 0.184 & -0.001 \\
\hline Spain & -0.009 & 0.235 & 2.40 & 8.35 & $186.07^{* * *}$ & 33 & 0.044 & 0.032 \\
\hline Switzerland & 0.051 & 0.233 & 0.90 & 1.47 & $27.14^{* * *}$ & 53 & $0.492^{* * *}$ & $0.411^{* * *}$ \\
\hline
\end{tabular}

b) Asia-Pacific

$\begin{array}{lrlrrcccc}\text { Australia } & -0.045 & 0.177 & 0.36 & -0.31 & 2.60 & 37 & 0.599^{* * *} & 0.379^{* * *} \\ \text { Hong Kong } & 0.474 & 0.869 & 2.87 & 11.97 & 530.91^{* * *} & 82 & 0.668^{* * *} & 0.417^{* * *} \\ \text { Japan } & -0.016 & 0.097 & 0.08 & 1.22 & 7.60^{* *} & 39 & 0.528^{* * *} & 0.237^{* * *} \\ \text { New Zealand } & 0.066 & 0.234 & -0.15 & 0.20 & 0.64 & 62 & 0.575^{* * *} & 0.453^{* * *}\end{array}$

c) Anglo-Saxon

$\begin{array}{lrlllllll}\text { Canada } & 0.146 & 0.234 & 0.17 & 1.64 & 14.18^{* * *} & 74 & 0.523^{* * *} & 0.284^{* * *} \\ \text { U.K. } & -0.014 & 0.180 & 0.22 & 4.11 & 85.51^{* * *} & 43 & 0.412^{* * *} & 0.037 \\ \text { U.S. } & -0.080 & 0.209 & 0.20 & 1.74 & 16.05^{* * *} & 30 & 0.397^{* * *} & 0.232^{* * *}\end{array}$

d) Scandinavia

\begin{tabular}{lrllrcccl} 
Denmark & 0.135 & 0.194 & 0.15 & -0.29 & 0.34 & 75 & $0.272^{* *}$ & 0.081 \\
Norway & -0.153 & 0.240 & 0.12 & 0.14 & 0.27 & 23 & $0.764^{* * *}$ & $0.594^{* * *}$ \\
Sweden & 0.020 & 0.222 & 1.43 & 4.72 & $153.00^{* * *}$ & 48 & $0.423^{* * *}$ & $0.500^{* * *}$ \\
\hline Notes
\end{tabular}
Notes. Sample is from January 1995 through December 2004. 'Stdev' is the standard deviation. Kurtosis is in fact excess kurtosis. 'BJ' is the Bera-Jarque statistic for normality of the distribution. $\%>0$ is a sign test statistic that gives the percentage of months the term premium is positive over the sample period. $\tau_{1}(\varphi)$ is the first order autocorrelation of the premium, and $\tau_{1}\left(\varphi^{2}\right)$ for it's squared; significance levels come from Ljung-Box $Q$-statistics. $\mathrm{A}^{*},{ }^{* *}$, and ${ }^{* * *}$ means rejection of the null hypothesis at a 10,5, and 1 percent significance level, respectively.

period of 10 years. We must therefore bear in mind that all results in this chapter should be interpreted against the background of a period of decreasing interest rates.

Furthermore, there does not seem to be a consistent difference in the variability in expectations for the various blocks of deposits in terms of their standard deviation. For instance, the standard deviation for the so-called EMS deposits (most continental European rates) is by no means lower than the variability of expected rates from other blocks of countries. This is an interesting finding, for it could reflect that the market did not believe in the stabilizing role of the EMS, and expected larger swings in the EMS' interest rates than actually occurred.

Table 4.3 presents summary statistics from the survey-based term premia, $\varphi$, following the definition in equation 4.3. The majority of the term premia have 
a positive average, indicating that forward rates, on average, are larger than the expected future levels of the interest rates. Interpreting the results, for instance for the Hong Kong interbank rate, suggests that the yield curve is priced in such a way that the total return of a longer-term contract is higher than the return participants expect when short rates are rolled over. In other words, market participants add a premium for longer-term instruments. Results from a sign test corroborate that for most interest rates the term premium is more often positive than negative, such that the finding of positive average premia is not the result of outliers. Note that premia are typically skewed to the left and show leptokurtic behavior, which results in a regular rejection of the normal distribution.

First-order autocorrelation coefficients are reported for the premia and their squares, accompanied by significance levels from Ljung-Box $Q$-statistics for firstorder serial correlation. The level premia show strong evidence of serial correlation. Modern equilibrium theory can explain this behavior. If term premia are functions of both investors' attitudes towards risk and the covariance of long and short rates with consumption or wealth, as in the Cox et al. (1985) framework, and these parameters evolve only slowly over time as is often assumed, then term premia should be partially predictable from past observations. In this framework the serial correlation in the levels of the term premia makes sense from an economic theory point of view. Serial correlation in the squares of the premia furthermore suggests the presence of at least first order autoregressive conditional heteroskedasticity.

We subsequently analyze the (non)stationarity of expected, realized, and forward interest rates. When the forward rate, realized spot rate, and expected future spot rate all contain a unit root, a linear relation between any of these variables can be spurious and hence may lead to an erroneous non-rejection of the expectations hypothesis. If, say, the forward rate contains a unit root, but the expected interest rate is stationary, the resulting term premium is not stationary, since a linear combination of a stationary and nonstationary variable is nonstationary.

The (non)stationarity of nominal interest rates remains an issue of central concern in the literature. In a seminal paper Rose (1988) investigates the stationarity of various international nominal short- and long-term interest rate measured at yearly, quarterly, and monthly data frequencies and finds that the null hypothesis of a single unit root in the levels of the series cannot be rejected. Rapach and Weber (2004) re-examine the stationarity condition of long-term government bonds as the nominal interest rates for about the same sample of international deposits as Rose, using new unit root tests with improved size and power. They find that, except for Austrian, German, and Swiss interest rates, the results conform to those in Rose (1988) in that nominal rates contain a unit root.

It remains ambiguous as to whether expected interest rates inherit the same (non)stationarity characteristics as their nominal realized counterparts. To the best of our knowledge, no previous study has attempted to investigate the stationarity of expected interest rates (or expectations series in general), by means of survey data or other techniques. When the order of integration of expected interest rate series differs than that of realized interest rate series, any linear combination of the two is nonstationary, and results of a test of time-varying term premia may then be 
spurious.

We examine the stationarity of realized, expected, and implicit forward rate series using two nonparametric unit root tests. First, we use a traditional Phillips-Perron $(\mathrm{PP})$ unit root test that is robust to a variety of serial correlation and heteroskedasticity, where the null hypothesis is that of a unit root. A criticism of such traditional unit root tests is that they cannot distinguish between a unit root and a near-unit root process, since the classical way of hypothesis testing ensures that the null hypothesis cannot be rejected unless there is strong evidence against it. Therefore, the test due to Kwiatkowski et al. (1992) (henceforth KPSS) is also considered, where the null hypothesis is that of a stationary series.

In both tests a linear trend does not seem relevant for the data at question and a constant term is included for generality; thus we check for level stationarity. Spectral estimation is performed using the Bartlett kernel and the optimal lag length is selected automatically using the Newey-West bandwidth. ${ }^{1}$

Table 4.4 presents test statistics from the unit root/stationarity tests for the forward rate, realized future spot rate, expected future spot rate, and some linear combinations hereof. The general finding that emerges from the Phillips-Perron unit root test is that nominal realized interest rates, $r_{t}$, appear to be $I(1)$ in that the null hypothesis of a unit root in the levels cannot be rejected, whilst for their first differences the null of a unit root is strongly rejected. ${ }^{2}$ Three exceptions are the German, Dutch, and Japanese interest rate deposits, for which a unit root in the level cannot be rejected. Interestingly is that for survey-based expected interest rates the null hypothesis of a unit root also cannot be rejected for most rates. This would imply that expected interest rates seem to share the stationarity properties with their realized counterparts. However, we must be careful with such an interpretation, for results on Austrian interest rates show that although realized rates can be $I(1)$, expected rates can nevertheless be $I(0)$. Finally, most forward rates appear to contain a unit root as well.

However, for the expected and implicit forward rates in excess of the contemporaneous nominal spot rate, the null hypothesis of a unit root is generally rejected, suggesting that any test of the expectations hypothesis is not influenced by a spurious relationship between $f_{t, t+k}$ and $r_{t+k}$ or $f_{t, t+k}$ and $r_{t, t+k}^{e}$. KPSS test results support these results, although for continental European deposits the results remain somewhat non-uniform. At minimum, for all non-continental European and nearly all continental European rates, the null hypothesis of stationarity can be rejected for the levels of the realized, expected, and forward interest rates.

Although it is possible that for some interest rate deposits the levels of the realized, expected, and forward interest rates contain a unit root, whereas for other deposits a unit root is absent, it is also possible that our sample size simply does not give us enough testing power to reject the unit root in the levels for a few countries.

Based on results from both tests, the general picture that emerges is that while

\footnotetext{
${ }^{1}$ Other bandwidth estimators, like the Andrews bandwidth, were considered but did not alter the general conclusions in any way.

${ }^{2}$ Statistics on the differenced series are not reported to conserve space, but are available on request.
} 


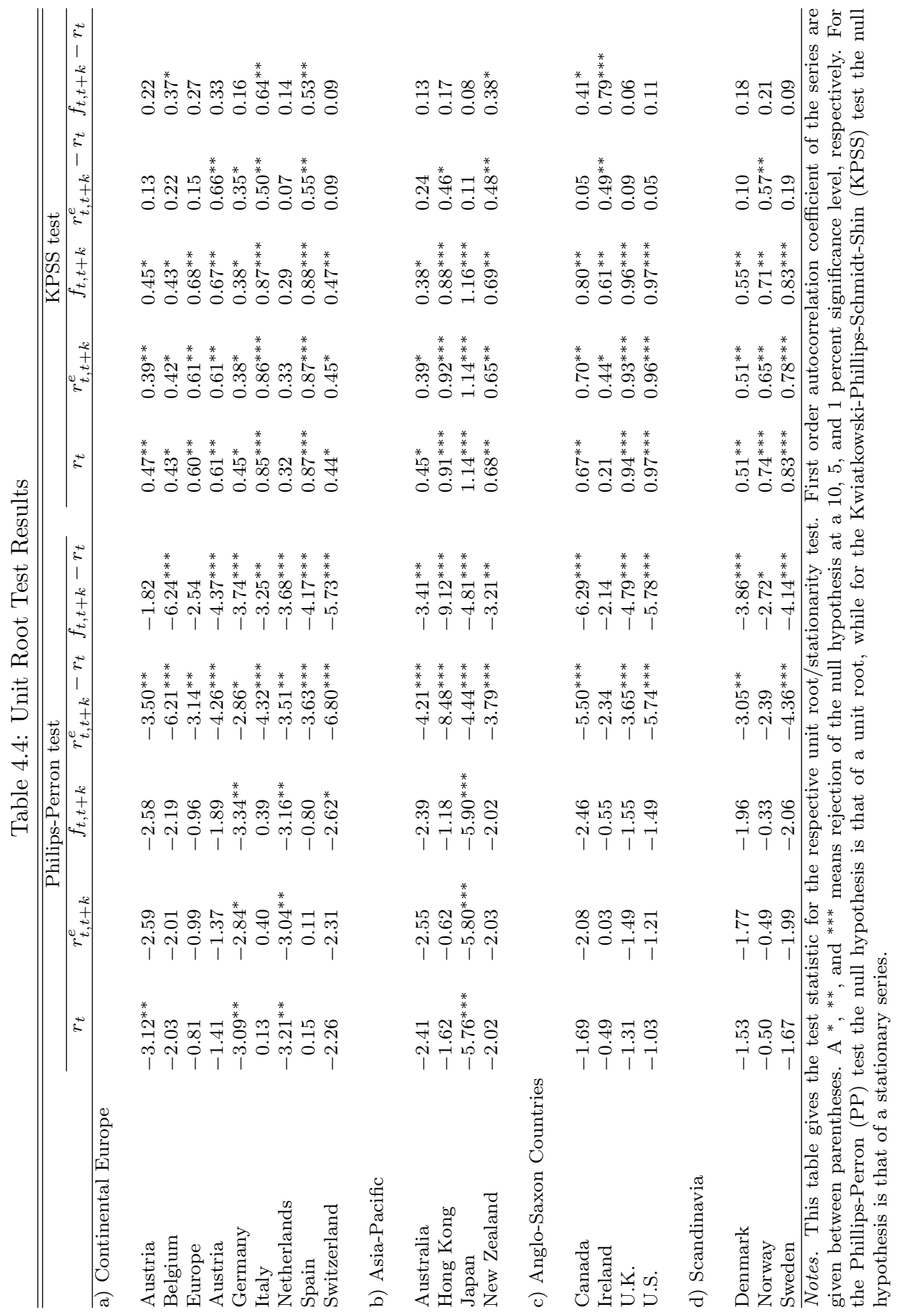


nominal realized, implicit forward, and expected interest series seem to contain a unit root, linear combinations thereof are stationary. In addition, Bekaert et al. (1997) show that traditional single-equation regression models are characterized by a positive bias in the slope coefficients, even with relatively large samples. Tests of the expectations hypothesis, rational expectations, or time-variation in the term premia should therefore be expressed in terms of these linear combinations. In the next section we examine the expectations hypothesis of the term structure of interest rates empirically and investigate to what extent expectations are rational and whether term premia are time-varying.

\subsection{Rational Expectations and Time-Varying Term Premia}

The unbiasedness specification in equation 4.6 has been used regularly as a tool to verify the validity of the expectations hypothesis, and in a comparable version to explain the forward premium behavior in the exchange rate literature (see, e.g. Engel, 1996; Hodrick, 1987, for an overview). Failure of the hypothesis that $\alpha_{1}=0$ and $\beta_{1}=1$ is interpreted as failure of the expectations hypothesis, and conditional on the assumption of rational expectations the failure is generally attributed to the existence of a time-varying term premium.

However, from the decomposition in equation 4.5 it follows that the forward premium consists of both an expectational error and a term premium component and therefore the above regression-based test is in fact a joint test of time-varying term premia and of the existence of errors in expectations. Whenever the assumption of rational expectations is invalid, rejection of the null hypothesis that $\alpha_{1}=0$ and $\beta_{1}=1$ does not automatically imply the existence of time-varying term premia, but instead can be attributed to the existence of constant or time-varying expectations errors, constant or time-varying term premia, or a combination of these. Moreover, even when one fails to reject the null hypothesis that $\alpha_{1}=0$ and $\beta_{1}=1$, this does not imply that no time-varying term premia exist, whenever the variability of term premia and expectations errors move in opposite directions, thereby dampening any movement in the ex-post forward error.

Table 4.5 reports GMM estimates for the unbiasedness test in equation 4.6, with standard errors corrected to allow for a $k$-order moving average. ${ }^{3}$ Most slope coefficients are positive and significant, indicating that the forward rates contain information about the future spot rates. Conditional on the assumption of rational expectations, the null hypothesis that the forward rate is an unbiased estimate of

\footnotetext{
${ }^{3}$ When the forecast horizon is longer than the observational frequency, the forecast error will be serially correlated up to a moving average process of order $k-1$. Since the survey forecasts are for 'approximately 3 months ahead' projections, and since panelists are known to often make their projections towards the end of a calendar month, it is expected that the $k$-month-ahead forecast is in fact a $k$-month-plus-a-few-days-ahead forecast. We have replicated all results assuming a moving average process of order $k-1$, yet these results differ only marginally from the ones reported and do not alter any of our conclusions.
} 
Table 4.5: Forward Rate Unbiasedness

\begin{tabular}{|c|c|c|c|c|}
\hline & $\alpha_{1}$ & $\beta_{1}$ & $T: \beta_{3}=1$ & $\chi^{2}$ \\
\hline \multicolumn{5}{|c|}{ a) Continental Europe } \\
\hline Austria & $\begin{array}{c}-0.1110 \\
(0.0908)\end{array}$ & $\begin{array}{c}-0.0810 \\
(0.4161)\end{array}$ & $2.59^{* * *}$ & $37.05^{* * *}$ \\
\hline Belgium & $\begin{array}{c}-0.1794 \\
(0.1105)\end{array}$ & $\begin{array}{c}-0.0154 \\
(0.2925)\end{array}$ & $3.47^{* * *}$ & $47.77^{* * *}$ \\
\hline Europe & $\begin{array}{c}-0.0707^{*} \\
(0.0415)\end{array}$ & $\begin{array}{l}1.1624^{* * *} \\
(0.1677)\end{array}$ & 0.96 & 3.45 \\
\hline France & $\begin{array}{c}-0.1383^{* * *} \\
(0.0901)\end{array}$ & $\begin{array}{l}1.2015^{* * *} \\
(0.1552)\end{array}$ & $1.11^{*}$ & $11.03^{* * *}$ \\
\hline Germany & $\begin{array}{c}-0.1138^{* * *} \\
(0.0332)\end{array}$ & $\begin{array}{c}0.9376 \\
(0.1902)\end{array}$ & -2.44 & $11.73^{* * *}$ \\
\hline Italy & $\begin{array}{c}-0.1666^{* * *} \\
(0.0539)\end{array}$ & $\begin{array}{l}0.6987^{* * *} \\
(0.1343)\end{array}$ & $-2.44^{* *}$ & $13.19^{* * *}$ \\
\hline Netherlands & $\begin{array}{c}-0.1440^{* * *} \\
(0.0384)\end{array}$ & $\begin{array}{c}0.8512 \\
(0.2180)\end{array}$ & -2.44 & $14.26^{* * *}$ \\
\hline Spain & $\begin{array}{c}-0.1472^{* * *} \\
(0.0415)\end{array}$ & $\begin{array}{l}0.9657^{* * *} \\
(0.1749)\end{array}$ & -2.44 & $13.23^{* * *}$ \\
\hline Switzerland & $\begin{array}{c}-0.2199^{* * *} \\
(0.0585)\end{array}$ & $\begin{array}{l}0.8837^{* * *} \\
(0.1923)\end{array}$ & -2.44 & $19.38^{* * *}$ \\
\hline \multicolumn{5}{|l|}{ b) Asia-Pacific } \\
\hline Australia & $\begin{array}{c}-0.0464 \\
(0.0511)\end{array}$ & $\begin{array}{l}0.7793^{* * *} \\
(0.1831)\end{array}$ & -1.20 & 2.94 \\
\hline Hong Kong & $\begin{array}{c}-0.3793 \\
(0.3023)\end{array}$ & $\begin{array}{c}0.6336 \\
(0.4523)\end{array}$ & -0.80 & $6.42^{* *}$ \\
\hline Japan & $\begin{array}{c}-0.0489 \\
(0.0330)\end{array}$ & $\begin{array}{l}0.4890^{* * *} \\
(0.1574)\end{array}$ & $-3.24^{* * *}$ & $11.53^{* * *}$ \\
\hline New Zealand & $\begin{array}{c}-0.0512 \\
(0.1248)\end{array}$ & $\begin{array}{l}0.7825^{* * *} \\
(0.2516)\end{array}$ & -0.86 & 1.56 \\
\hline \multicolumn{5}{|c|}{ c) Anglo-Saxon Countries } \\
\hline Canada & $\begin{array}{c}-0.3892^{* * *} \\
(0.0784)\end{array}$ & $\begin{array}{l}0.9439^{* * *} \\
(0.1572)\end{array}$ & 0.35 & $33.33^{* * *}$ \\
\hline Ireland & $\begin{array}{c}-0.0959 \\
(0.1110)\end{array}$ & $\begin{array}{c}0.6337^{*} \\
(0.3529)\end{array}$ & -2.44 & 1.96 \\
\hline U.K. & $\begin{array}{c}-0.0929 \\
(0.0511)\end{array}$ & $\begin{array}{l}0.7819^{* * *} \\
(0.1831)\end{array}$ & -1.04 & $7.25^{* *}$ \\
\hline U.S. & $\begin{array}{c}-0.2092^{* * *} \\
(0.0644)\end{array}$ & $\begin{array}{l}1.0845^{* * *} \\
(0.2764)\end{array}$ & 0.30 & $20.84^{* * *}$ \\
\hline \multicolumn{5}{|c|}{ d) Scandinavia } \\
\hline Denmark & $\begin{array}{c}-0.2827^{* * *} \\
(0.1038)\end{array}$ & $\begin{array}{l}1.1771^{* * *} \\
(0.2458)\end{array}$ & 0.72 & $9.34^{* * *}$ \\
\hline Norway & $\begin{array}{c}0.0975 \\
(0.1271)\end{array}$ & $\begin{array}{l}1.0075^{* * *} \\
(0.2380)\end{array}$ & 0.00 & 0.70 \\
\hline Canada & $\begin{array}{c}-0.2308^{* * *} \\
(0.0667)\end{array}$ & $\begin{array}{l}1.1469^{* * *} \\
(0.2732)\end{array}$ & 0.53 & $18.52^{* * *}$ \\
\hline
\end{tabular}
standard errors of the coefficients are given in parenthesis. $\mathrm{A}^{*},{ }^{* *}$, or ${ }^{* * *}$ denotes rejection at the 10,5 , or 1 percent significant level, respectively, of the hypothesis that $\alpha_{1}=0$ or that $\beta_{1}=1$. The $\chi^{2}$ statistic pertains to the joint hypotheses that $\alpha_{1}=0$ and $\beta_{1}=1$. 
the future spot interest rate is presented by the joint hypothesis that $\alpha_{1}=0$ and $\beta_{1}=1$.

The null hypothesis is rejected for about 75 percent of the countries, with varying degrees of significance. This implies that there is considerable evidence against at least the pure version of the expectations hypothesis. Rejection of this null is not predominantly caused by either a constant or a time-varying premia, but must be attributed to both. Estimates for $\beta_{1}$ are furthermore mostly less than unity and occasionally even negative, although when relaxing the zero constant premium, we find that the null hypothesis of $\beta_{1}=1$ can only be rejected for five interest rate deposits.

Focusing on the role of the estimate for $\beta_{1}$ alone, one could erroneously be tempted to interpret the findings in table 4.5 as evidence against time-variability of term premia. However, since the test in equation 4.6 is a joint test of rational expectations and the existence of constant or time-varying term premia, results in table 4.5 remain inconclusive as to the existence of time-varying term premia. In fact, even when time-varying term premia exist in the term structure of interest rates, $\beta_{1}$ may still be equal to unity provided that expectations are irrational. Equation 4.6 hence cannot capture the presence of time-varying term premia, nor provide evidence of irrationality of expectations in the term structure of interest rates.

Survey data can be used to decompose the forward premium into a time-varying term premium component and an irrational expectations component. It can be shown that the probability limit in equation 4.6 reduces to

$$
\operatorname{plim} \beta_{1}=1-\frac{\operatorname{cov}\left(\phi_{t}, f_{t, t+k}-r_{t}\right)}{\operatorname{var}\left(f_{t, t+k}-r_{t}\right)},
$$

which exactly measures time-variability in term premia in the Fama sense. The probability limit in equation 4.7 can be decomposed into an expectational error and time-varying term premium component as $\beta_{1}=\beta_{3}+\beta_{4}$, where

$$
\beta_{3} \equiv \frac{\operatorname{cov}\left(\epsilon_{t+k}, f_{t, t+k}-r_{t}\right)}{\left.\operatorname{var} f_{t, t+k}-r_{t}\right)}
$$

and

$$
\beta_{4} \equiv 1-\frac{\operatorname{cov}\left(\varphi_{t}, f_{t, t+k}-r_{t}\right)}{\operatorname{var}\left(f_{t, t+k}-r_{t}\right)}
$$

To test the rationality of survey-based interest rate expectations we employ an orthogonality test (see, for instance Pesaran, 1987). The orthogonality test aims to assess whether economic agents use information that is available to them efficiently to forecast future interest rates. The null hypothesis of rational expectations implies that $\alpha_{3}=0$ and $\beta_{3}=0$ in regressions of the following form

$$
\xi_{t+k}=\alpha_{3}+\beta_{3}^{\prime} X_{t}+\epsilon_{t+k},
$$

where $X_{t}$ is a vector of elements from the investor's information set, a subset from her complete, yet unobserved information set $\Omega_{t}$. When expectations are formed in 
a rational way, the survey-based forecast error should be orthogonal to all elements form the investor's information set at the time she forms her forecasts. Although the information set may be infinite and unobserved, we choose to use the forward premium, $f_{t, t+k}-r_{t}$, as the sole element for $X_{t}$. We choose this specification since under the null hypothesis of rational expectations and under the assumption that any measurement error in the survey is orthogonal to the forward discount, the $\beta_{3}$ coefficient is precisely equal to $\beta_{3}$ in equation 4.8. Equation 4.10 was estimated using GMM for each interest rate.

Table 4.6 reports parameter estimates of this orthogonality test. The null hypothesis of rational expectations is rejected for about half of the interest rates. It is interesting to note that the vast majority of estimates for $\beta_{3}$ are positive of sign, indicating that an increase in the interest rate implied by the term structure (through the implicit forward rate) leads to an underestimation of future interest rates.

These results should be interpreted with care. If conditional forecasts are formed rationally, while allowing for a small probability of a large interest rate movement, then forecasts will appear biased when judged from ex-post forecast errors. This is the familiar 'peso problem' due to Krasker (1980). Bekaert et al. (1997) find that the failure of the expectations hypothesis in the U.S. can be explained at least partly by the existence of such a peso problem effect. An alternative explanation would be that the time series process which describes the expected interest rate movement, is not ergodic as is implied in the application of the GMM procedure.

In order to discover time-variation in the term premia and to see to what extent the existence of a time-varying term premium is an economically important reason for rejection of the expectations hypothesis, the following regression test is used:

$$
r_{t, t+k}^{e}-r_{t}=\alpha_{4}+\beta_{4}\left(f_{t, t+k}-r_{t}\right)+\epsilon_{t+k}
$$

where the mathematical expectations are replaced by their survey-based counterparts. The null hypothesis of no time-varying term premia is represented by the hypothesis that $\beta_{4}=1$, where the correlation of the risk premium with the forward discount is zero. By inspection, the $\beta_{4}$ coefficient is precisely equal to $\beta_{4}$ in equation 4.9. Similarly, the hypothesis of a zero mean term premium can be tested by examining whether the $\alpha_{4}$ coefficient is significantly different from zero.

Table 4.7 reports GMM estimates for the test of time-varying term premia in equation 4.4. There is strong evidence of time-variation in the term premia, given that for all but a few deposits the null hypothesis of no time-variation, $\beta_{4}=1$, is resoundingly rejected. Although for the remaining deposits, Belgium and France, and Denmark and Hong Kong the null hypothesis of no time-variation in the term premium cannot be rejected, slope coefficients are below unity and the joint null hypothesis of no constant or time-varying premia is nevertheless rejected. All slope estimates are between zero and unity, a finding which corroborates the early finding of Froot (1989) and MacDonald and Macmillan (1994) for US and UK interest rate deposits, respectively. Whilst strong evidence of time-varying term premia, all estimates of $\beta_{3}$ are significantly positive, indicating that not all of the variation in the expectations hypothesis can be attributed to the existence of a time-varying term premium. 
Table 4.6: Error Orthogonality to Forward Premia

\begin{tabular}{|c|c|c|c|}
\hline & $\alpha_{3}$ & $\beta_{3}$ & $\chi^{2}$ \\
\hline \multicolumn{4}{|c|}{ a) Continental Europe } \\
\hline Austria & $\begin{array}{c}0.0518 \\
(0.0798)\end{array}$ & $\begin{array}{c}-0.8051^{*} \\
(0.4284)\end{array}$ & 4.37 \\
\hline Belgium & $\begin{array}{c}-0.1138 \\
(0.1115)\end{array}$ & $\begin{array}{r}-0.6548^{*} \\
(0.3367)\end{array}$ & $7.44^{* *}$ \\
\hline Europe & $\begin{array}{c}-0.0176 \\
(0.0494)\end{array}$ & $\begin{array}{l}0.7066^{* * *} \\
(0.1802)\end{array}$ & $15.43^{* * *}$ \\
\hline France & $\begin{array}{c}0.0414 \\
(0.0867)\end{array}$ & $\begin{array}{c}0.3027 \\
(0.2223)\end{array}$ & 2.32 \\
\hline Germany & $\begin{array}{c}-0.1394^{* * *} \\
(0.0491)\end{array}$ & $\begin{array}{c}-0.1698 \\
(0.2653)\end{array}$ & $9.95^{* * *}$ \\
\hline Ireland & $\begin{array}{c}0.0525 \\
(0.1248)\end{array}$ & $\begin{array}{c}-0.0654^{*} \\
(0.3693)\end{array}$ & 0.21 \\
\hline Italy & $\begin{array}{c}0.3068^{*} \\
(0.1640)\end{array}$ & $\begin{array}{c}0.3612^{*} \\
(0.2766)\end{array}$ & 3.63 \\
\hline Netherlands & $\begin{array}{c}-0.1458 \\
(0.0947)\end{array}$ & $\begin{array}{c}-0.4571 \\
(0.4587)\end{array}$ & $9.07^{* *}$ \\
\hline Spain & $\begin{array}{c}-0.2380^{* * *} \\
(0.0628)\end{array}$ & $\begin{array}{c}0.1080 \\
(0.1274)\end{array}$ & $14.42^{* * *}$ \\
\hline Switzerland & $\begin{array}{c}-0.2705^{* * *} \\
(0.0642)\end{array}$ & $\begin{array}{l}0.5669^{* *} \\
(0.2245)\end{array}$ & $18.97^{* * *}$ \\
\hline \multicolumn{4}{|l|}{ b) Asia-Pacific } \\
\hline Australia & $\begin{array}{c}-0.0845 \\
(0.0583)\end{array}$ & $\begin{array}{c}0.3728^{*} \\
(0.2076)\end{array}$ & $4.89^{*}$ \\
\hline Hong Kong & $\begin{array}{c}-0.0473 \\
(0.2852)\end{array}$ & $\begin{array}{c}0.0692 \\
(0.4488)\end{array}$ & 0.03 \\
\hline Japan & $\begin{array}{c}-0.0563 \\
(0.0338)\end{array}$ & $\begin{array}{c}0.0150 \\
(0.1841)\end{array}$ & 2.78 \\
\hline New Zealand & $\begin{array}{c}0.0102 \\
(0.1273)\end{array}$ & $\begin{array}{c}0.1126 \\
(0.2688)\end{array}$ & 0.27 \\
\hline \multicolumn{4}{|c|}{ c) Anglo-Saxon Countries } \\
\hline Canada & $\begin{array}{c}-0.3868^{* * *} \\
(0.0774)\end{array}$ & $\begin{array}{l}0.4880^{* * *} \\
(0.1560)\end{array}$ & $25.55^{* * *}$ \\
\hline U.K. & $\begin{array}{c}-0.1357^{* *} \\
(0.0578)\end{array}$ & $\begin{array}{c}0.2701 \\
(0.2056)\end{array}$ & $6.02^{* *}$ \\
\hline U.S. & $\begin{array}{c}-0.3505^{* * *} \\
(0.0679)\end{array}$ & $\begin{array}{c}0.6436^{* *} \\
(0.2785)\end{array}$ & $30.41^{* * *}$ \\
\hline \multicolumn{4}{|c|}{ d) Scandinavia } \\
\hline Denmark & $\begin{array}{c}-0.1552^{*} \\
(0.0865)\end{array}$ & $\begin{array}{c}0.2463 \\
(0.2478)\end{array}$ & 3.22 \\
\hline Norway & $\begin{array}{c}0.0554 \\
(0.1434)\end{array}$ & $\begin{array}{c}0.3722 \\
(0.2837)\end{array}$ & 1.79 \\
\hline Sweden & $\begin{array}{c}-0.2281^{* * *} \\
(0.0582)\end{array}$ & $\begin{array}{l}0.4785^{* *} \\
(0.2344)\end{array}$ & $15.33^{* * *}$ \\
\hline
\end{tabular}

Notes. Sample is from January 1995 through December 2004. A $^{*},{ }^{*}$, or $^{* * *}$ denotes rejection at a 10,5 , and 1 percent significance level. The $\chi^{2}$ statistic pertains to the joint hypothesis that $\alpha_{3}=0$ and $\beta_{3}=0$ (standard errors are given in parentheses). 
Table 4.7: Time-Variation in Term Premia

\begin{tabular}{|c|c|c|c|c|c|c|}
\hline & $\alpha_{4}$ & $\beta_{4}$ & $T: \beta_{4}=1$ & $\chi^{2}$ & BG & $\mathrm{ARCH}$ \\
\hline \multicolumn{7}{|c|}{ a) Continental Europe } \\
\hline Austria & $\begin{array}{c}-0.1629^{* * *} \\
(0.0232)\end{array}$ & $\begin{array}{l}0.7241^{* * *} \\
(0.1019)\end{array}$ & $-2.70^{* * *}$ & $66.88^{* * *}$ & $\begin{array}{r}2.62 \\
(1)\end{array}$ & $\begin{array}{r}1.68 \\
(1)\end{array}$ \\
\hline Belgium & $\begin{array}{r}-0.0656^{*} \\
(0.0363)\end{array}$ & $\begin{array}{l}0.6393^{* * *} \\
(0.2333)\end{array}$ & -1.54 & $8.75^{* *}$ & $\begin{array}{r}0.99 \\
(1)\end{array}$ & $\begin{array}{r}0.99 \\
(1)\end{array}$ \\
\hline Europe & $\begin{array}{c}-0.0493^{* * *} \\
(0.0171)\end{array}$ & $\begin{array}{l}0.4585^{* * *} \\
(0.0664)\end{array}$ & $-8.15^{* * *}$ & $80.68^{* * *}$ & $\begin{array}{l}20.71^{* * *} \\
(1)\end{array}$ & $\begin{array}{r}0.59 \\
(1)\end{array}$ \\
\hline France & $\begin{array}{c}-0.2570^{* * *} \\
(0.0360)\end{array}$ & $\begin{array}{l}0.8706^{* * *} \\
(0.1345)\end{array}$ & -0.96 & $57.75^{* * *}$ & $\begin{array}{l}7.56^{* *} \\
(2)\end{array}$ & $\begin{array}{r}0.24 \\
(1)\end{array}$ \\
\hline Germany & $\begin{array}{c}0.0132 \\
(0.0211)\end{array}$ & $\begin{array}{l}0.3833^{* * *} \\
(0.0771)\end{array}$ & $-7.99^{* * *}$ & $81.98^{* * *}$ & $\begin{array}{c}12.13^{* * *} \\
\text { (1) }\end{array}$ & $\begin{array}{c}7.79^{* * *} \\
(1)\end{array}$ \\
\hline Ireland & $\begin{array}{c}-0.1485^{* *} \\
(0.0756)\end{array}$ & $\begin{array}{l}0.6991^{* * *} \\
(0.1108)\end{array}$ & $-2.71^{* * *}$ & $13.25^{* * *}$ & $\begin{array}{l}17.24^{* * *} \\
(1)\end{array}$ & $\begin{array}{c}11.04^{* * *} \\
(1)\end{array}$ \\
\hline Italy & $\begin{array}{c}-0.4115^{* * *} \\
(0.0572)\end{array}$ & $\begin{array}{l}0.4680^{* * *} \\
(0.1006)\end{array}$ & $-5.30^{* * *}$ & $52.30^{* * *}$ & $\begin{array}{r}0.03 \\
(1)\end{array}$ & $\begin{array}{r}1.64 \\
(3)\end{array}$ \\
\hline Netherlands & $\begin{array}{c}0.0311 \\
(0.0189)\end{array}$ & $\begin{array}{l}0.3792^{* * *} \\
(0.0836)\end{array}$ & $-7.42^{* * *}$ & $70.21^{* * *}$ & $\begin{array}{r}1.91 \\
(1)\end{array}$ & $\begin{array}{r}0.00 \\
(1)\end{array}$ \\
\hline Spain & $\begin{array}{c}-0.0524 \\
(0.0423)\end{array}$ & $\begin{array}{l}0.5381^{* * *} \\
(0.1435)\end{array}$ & $-3.21^{* * *}$ & $19.94^{* * *}$ & $\begin{array}{r}0.46 \\
(1)\end{array}$ & $\begin{array}{c}11.45^{* * *} \\
\text { (1) }\end{array}$ \\
\hline Switzerland & $\begin{array}{l}0.0536^{* *} \\
(0.0260)\end{array}$ & $\begin{array}{l}0.3217^{* * *} \\
(0.0765)\end{array}$ & $-8.86^{* * *}$ & $85.86^{* * *}$ & $\begin{array}{c}20.36^{* * *} \\
(1)\end{array}$ & $\begin{array}{c}5.54^{* *} \\
(1)\end{array}$ \\
\hline \multicolumn{7}{|l|}{ b) Asia-Pacific } \\
\hline Australia & $\begin{array}{c}0.0410^{* *} \\
(0.0175)\end{array}$ & $\begin{array}{l}0.4087^{* * *} \\
(0.0654)\end{array}$ & $-9.04^{* * *}$ & $89.45^{* * *}$ & $\begin{array}{c}32.93^{* * *} \\
(1)\end{array}$ & $\begin{array}{c}12.80^{* * * *} \\
(1)\end{array}$ \\
\hline Hong Kong & $\begin{array}{c}-0.3127 \\
(0.1961)\end{array}$ & $\begin{array}{c}0.5683^{* *} \\
(0.2798)\end{array}$ & -1.54 & $28.30^{* * *}$ & $\begin{array}{l}66.82^{* * *} \\
(6)\end{array}$ & $\begin{array}{c}18.33^{* * *} \\
(2)\end{array}$ \\
\hline Japan & $\begin{array}{c}0.0080 \\
(0.0078)\end{array}$ & $\begin{array}{l}0.4735^{* * *} \\
(0.0885)\end{array}$ & $-5.94^{* * *}$ & $35.55^{* * *}$ & $\begin{array}{c}32.74^{* * *} \\
(1)\end{array}$ & $\begin{array}{c}26.44^{* * *} \\
(1)\end{array}$ \\
\hline New Zealand & $\begin{array}{c}-0.0604^{* *} \\
(0.0281)\end{array}$ & $\begin{array}{l}0.6696^{* * *} \\
(0.0855)\end{array}$ & $-3.86^{* * *}$ & $43.67^{* * *}$ & $\begin{array}{c}29.63^{* * *} \\
(1)\end{array}$ & $\begin{array}{c}30.25^{* * *} \\
\text { (1) }\end{array}$ \\
\hline \multicolumn{7}{|c|}{ c) Anglo-Saxon Countries } \\
\hline Canada & $\begin{array}{c}0.0044 \\
(0.0299)\end{array}$ & $\begin{array}{l}0.4532^{* * *} \\
(0.0544)\end{array}$ & $-10.03^{* * *}$ & $228.28^{* * *}$ & $\begin{array}{c}38.17^{* * *} \\
(1)\end{array}$ & $\begin{array}{c}5.70^{* * * *} \\
(2)\end{array}$ \\
\hline U.K. & $\begin{array}{l}0.0442^{* * *} \\
(0.0163)\end{array}$ & $\begin{array}{l}0.5116^{* * *} \\
(0.0681)\end{array}$ & $-7.17^{* * *}$ & $54.95^{* * *}$ & $\begin{array}{c}30.55^{* * *} \\
(1)\end{array}$ & $\begin{array}{r}1.59 \\
(1)\end{array}$ \\
\hline U.S. & $\begin{array}{l}0.1421^{* * *} \\
(0.0157)\end{array}$ & $\begin{array}{l}0.4530^{* * *} \\
(0.0584)\end{array}$ & $-9.36^{* * *}$ & $145.78^{* * *}$ & $\begin{array}{c}12.32^{* * *} \\
(1)\end{array}$ & $\begin{array}{c}14.26^{* * * *} \\
(1)\end{array}$ \\
\hline \multicolumn{7}{|c|}{ d) Scandinavia } \\
\hline Denmark & $\begin{array}{c}-0.1275^{* * *} \\
(0.0329)\end{array}$ & $\begin{array}{l}0.9308^{* * *} \\
(0.0889)\end{array}$ & -0.77 & $15.39^{* * *}$ & $\begin{array}{c}4.67^{* *} \\
(1)\end{array}$ & $\begin{array}{r}1.78 \\
(1)\end{array}$ \\
\hline Norway & $\begin{array}{c}0.0772^{* *} \\
(0.0354)\end{array}$ & $\begin{array}{l}0.6415^{* * *} \\
(0.0620)\end{array}$ & $-5.77^{* * *}$ & $38.83^{* * *}$ & $\begin{array}{l}48.15^{* * *} \\
\quad(2)\end{array}$ & $\begin{array}{c}42.08^{* * *} \\
(1)\end{array}$ \\
\hline Sweden & $\begin{array}{c}0.0004 \\
(0.0297)\end{array}$ & $\begin{array}{l}0.6738^{* * *} \\
(0.0919)\end{array}$ & $-3.54^{* * *}$ & $22.48^{* * *}$ & $\begin{array}{c}27.46^{* * *} \\
(1)\end{array}$ & $\begin{array}{c}36.35^{* * *} \\
(1)\end{array}$ \\
\hline
\end{tabular}

Notes. The standard errors of the coefficients are given in parentheses. $\mathrm{A}^{*},{ }^{* *},{ }^{* * *}$ denotes rejection at a 10,5 , and 1 percent significance level. $T: \beta_{4}=1$ reports the $T$-statistic and significance levels for the hypothesis that $\beta_{4}=1$. The $\chi^{2}$ statistic pertains to the joint hypothesis that $\alpha_{4}=0$ and $\beta_{4}=1$. 'BG' and ' $\mathrm{ARCH}$ ' give serial correlation and conditional heteroskedasticity statistics. 
Lagrange multiplier tests for the presence of serial correlation (Breusch-Godfrey test) and autoregressive conditional heteroskedasticity ( $\mathrm{ARCH})$ in the residuals are reported. For most rates, significant serial correlation is present up to one lag, indicating that term premia might be characterized by ARMA class models of low order. In general, evidence of serial correlation is more evident for non-continental European rates than for continental European rates. Volatility clustering furthermore appears predominantly in non-continental European term premia, indicating that the conditional variance of term premia varies over time. One noteworthy case is the Hong Kong interbank rate, for which autocorrelations up to six months is reported, and strong ARCH effects. Hong Kong interbank rates have experienced dramatic fluctuations in 1997 and 1998 and have decreased considerably.

We can question what the implications are of these results. To do so, a closer examination of time-varying term premia in the financial economics literature is required. In most financial models, time-varying term premia are essentially exogenous, like in the square root model of Cox et al. (1985), the affine term structure model of Dai and Singleton (2002), and the macro models of Ang and Piazzesi (2003) and Rudebusch and $\mathrm{Wu}$ (2004). A way to endogenize time-varying term premia is by arguing that transaction costs of entering the long-run bond market are higher and vary over time due to this segment's smaller liquidity, which can obviously explain why the yield curve is upward sloping most of the time. Alternatively, a segmented market approach may also explain why term premia vary over time when realizing that the preferred contract length of certain type of investors may change with their hedging requirements. In any case, an identification of the determinants of the time-variation in the term premia is desired, so that they can be controlled for in traditional tests of the expectations hypothesis.

On the other hand, the present findings may well present yet another challenge to the rational expectations hypothesis. Several ways to salvage the rational expectations hypothesis in the present setting are when we consider the existence of peso problems, learning behavior as introduced by Lewis (1989), or the presence of regime shifts by the monetary authority. Yet, it seems more plausible to depart, or at least redefine, the expectations hypothesis. Several theories that postulate deviations from it have recently drawn the attention. A common argument is that individual agents have limited capacity for processing information, which is in line with ordinary experience and basic behavior theory. A recent example of this line of argumentation is the rational inattention model due to Sims (2003).

In the next section we analyze various time-series properties of the term premia and look at potential explanations for the time-variation.

\subsection{Time Series Behavior of the Term Premia}

In most modern, intertemporal general equilibrium asset pricing models that describe the term structure of interest rates, for instance those of Vasicek (1977) or Cox et al. (1985), the term premium is a function of variables like expectations, investors' risk and intertemporal consumption preferences, investment alternatives, 
and interest rates' covariance with consumption. Although these determinants are extremely difficult to observe, they are commonly believed to evolve only gradually over time. This is an important assumption, for if determinants evolve gradually, so does the term premium and historical information about the term premium should therefore have at least some predictive power for future levels thereof. This argument has commonly resulted in treating it as a state variable, or unobserved component, and estimating it by means of a Kalman filter. Such state variables are commonly assumed to follow low-order versions of the ARMA class models.

The existence of low-order serial correlation in the residuals of the time-variability equation 4.11 furthermore supports the assumption that term premia evolve only gradually and that past values have predictive power. In order to examine the statistical time-series behavior of the risk premia implied by the survey-based expectations, we estimate $\operatorname{AR}(1), \operatorname{MA}(1)$, and $\operatorname{ARMA}(1,1)$ models for the term premia and present the model with the best fit in terms of the Bayesian Information Criterion (BIC) in table 4.8. The general framework in which we test these time-series models is then:

$$
\varphi_{t}=\gamma_{0}+\gamma_{1} \varphi_{t-1}+\epsilon_{t}+\gamma_{2} \epsilon_{t-1}
$$

Even though in a rare occasion a higher lag seems to improve the model in terms of the selection criterion, we do not report these results to preserve model parsimony and comparability and we select the most appropriate model from the three variations mentioned earlier. Lagrange Multiplier statistics for the presence of serial correlation that is not picked up by the models are presented, as well as a measure of $\mathrm{ARCH}$.

The low-order versions of the ARMA class models are quite capable of accounting for the variation in the term premia. For all AR or MA models, parameter estimates for $\gamma_{1}$ and/or $\gamma_{2}$ are significantly positive. These findings are consistent with the theories laid out above, in that knowledge about last month's premium provides considerable information about next month's premium. It is noteworthy that noncontinental European deposits are better characterized by these low-order ARMA models than other deposits, given the higher significance of the terms and higher adjusted $R^{2}$ statistics.

The ARMA models account for serial correlation in the term premia adequately, except for Hong Kong and Norway. We do note, however, that conditional heteroskedasticy is present in a number of cases. In the next section we look at this issue more closely.

\subsection{Determinants of the Time-Variation Present in the Term Premium}

In this section we examine the determinants of the term premia that are implied by the term structure. Although the presence of time-variation in the premia is firmly documented in the previous section, it remains a question as to what the source of this time-variation is. In this section we examine three ways to model the term 
Table 4.8: ARMA Specifications for the Term Premia

\begin{tabular}{|c|c|c|c|c|c|c|}
\hline & $\gamma_{0}$ & $\gamma_{1}$ & $\gamma_{2}$ & $R_{a}^{2}$ & LM & $\mathrm{ARCH}$ \\
\hline \multicolumn{7}{|c|}{ a) Continental Europe } \\
\hline Austria & $\begin{array}{l}0.1940^{* * *} \\
(0.0262)\end{array}$ & - & $\begin{array}{c}0.2243 \\
(0.1442)\end{array}$ & 0.02 & $\begin{array}{r}0.19 \\
(1)\end{array}$ & $\begin{array}{r}0.45 \\
(1)\end{array}$ \\
\hline Belgium & $\begin{array}{c}0.1017^{* *} \\
(0.0405)\end{array}$ & - & $\begin{array}{c}0.1789 \\
(0.1451)\end{array}$ & 0.01 & $\begin{array}{r}0.03 \\
(1)\end{array}$ & $\begin{array}{r}0.14 \\
(1)\end{array}$ \\
\hline Europe & $\begin{array}{c}0.0768 \\
(0.0482)\end{array}$ & $\begin{array}{l}0.7087^{* * *} \\
(0.0863)\end{array}$ & - & 0.49 & $\begin{array}{r}0.28 \\
(1)\end{array}$ & $\begin{array}{r}2.83 \\
(1)\end{array}$ \\
\hline France & $\begin{array}{l}0.2373^{* * *} \\
(0.0332)\end{array}$ & $\begin{array}{c}0.1445 \\
(0.1326)\end{array}$ & - & 0.00 & $\begin{array}{r}0.58 \\
(1)\end{array}$ & $\begin{array}{r}0.24 \\
(1)\end{array}$ \\
\hline Germany & $\begin{array}{c}0.0082 \\
(0.0305)\end{array}$ & $\begin{array}{l}0.4163^{* * *} \\
(0.1232)\end{array}$ & - & 0.18 & $\begin{array}{r}0.54 \\
(1)\end{array}$ & $\begin{array}{r}0.42 \\
(1)\end{array}$ \\
\hline Ireland & $\begin{array}{c}0.0692 \\
(0.1185)\end{array}$ & $\begin{array}{l}0.5773^{* * *} \\
(0.1193)\end{array}$ & - & 0.32 & $\begin{array}{r}2.15 \\
(1)\end{array}$ & $\begin{array}{r}0.62 \\
(1)\end{array}$ \\
\hline Italy & $\begin{array}{c}0.1666 \\
(0.0272)\end{array}$ & $\begin{array}{l}0.7979^{* * *} \\
(0.1025)\end{array}$ & $\begin{array}{c}0.9627 \\
(0.0295)\end{array}$ & 0.05 & $\begin{array}{r}1.61 \\
(1)\end{array}$ & $\begin{array}{r}0.10 \\
(1)\end{array}$ \\
\hline Netherlands & $\begin{array}{l}0.0568^{* *} \\
(0.0249)\end{array}$ & - & $\begin{array}{l}0.2896^{* *} \\
(0.1409)\end{array}$ & 0.03 & $\begin{array}{r}1.89 \\
(1)\end{array}$ & $\begin{array}{r}0.00 \\
(1)\end{array}$ \\
\hline Spain & $\begin{array}{c}-0.0331 \\
(0.0274)\end{array}$ & $\begin{array}{c}0.0443 \\
(0.1106)\end{array}$ & - & 0.00 & $\begin{array}{r}0.87 \\
(1)\end{array}$ & $\begin{array}{c}15.36^{* * *} \\
(3)\end{array}$ \\
\hline Switzerland & $\begin{array}{c}0.0446 \\
(0.0365)\end{array}$ & $\begin{array}{l}0.4926^{* * *} \\
(0.0792)\end{array}$ & - & 0.24 & $\begin{array}{r}1.15 \\
(1)\end{array}$ & $\begin{array}{r}1.42 \\
(1)\end{array}$ \\
\hline b) Asia-Pacific & & & & & & \\
\hline Australia & $\begin{array}{c}-0.0411 \\
(0.0341)\end{array}$ & $\begin{array}{l}0.6045^{* * *} \\
(0.0760)\end{array}$ & - & 0.36 & $\begin{array}{r}1.49 \\
(1)\end{array}$ & $\begin{array}{r}0.13 \\
(1)\end{array}$ \\
\hline Hong Kong & $\begin{array}{c}0.4497 \\
(0.2776)\end{array}$ & $\begin{array}{l}0.8547^{* * *} \\
(0.0703)\end{array}$ & $\begin{array}{c}-0.3297^{* * *} \\
(0.1262)\end{array}$ & 0.48 & $\begin{array}{c}19.22^{* * *} \\
(2)\end{array}$ & $\begin{array}{c}18.55^{* * *} \\
(2)\end{array}$ \\
\hline Japan & $\begin{array}{c}-0.0206 \\
(0.0157)\end{array}$ & $\begin{array}{l}0.5292^{* * *} \\
(0.0761)\end{array}$ & - & 0.28 & $\begin{array}{r}0.88 \\
(1)\end{array}$ & $\begin{array}{c}15.99^{* *} \\
(6)\end{array}$ \\
\hline New Zealand & $\begin{array}{c}0.0708 \\
(0.0434)\end{array}$ & $\begin{array}{l}0.5753^{* * *} \\
(0.0786)\end{array}$ & - & 0.32 & $\begin{array}{r}0.10 \\
(1)\end{array}$ & $\begin{array}{c}3.91^{* *} \\
(1)\end{array}$ \\
\hline c) Anglo-Saxol & & & & & & \\
\hline Canada & $\begin{array}{l}0.1279^{* * *} \\
(0.0371)\end{array}$ & $\begin{array}{l}0.5410^{* * *} \\
(0.0731)\end{array}$ & - & 0.31 & $\begin{array}{r}0.00 \\
(1)\end{array}$ & $\begin{array}{r}0.14 \\
(1)\end{array}$ \\
\hline U.K. & $\begin{array}{c}-0.0195 \\
(0.0254)\end{array}$ & $\begin{array}{l}0.4134^{* * *} \\
(0.0872)\end{array}$ & - & 0.16 & $\begin{array}{r}0.44 \\
(1)\end{array}$ & $\begin{array}{r}0.96 \\
(1)\end{array}$ \\
\hline U.S. & $\begin{array}{c}-0.0906^{* * *} \\
(0.0249)\end{array}$ & $\begin{array}{l}0.3953^{* * *} \\
(0.0792)\end{array}$ & - & 0.16 & $\begin{array}{r}0.05 \\
(1)\end{array}$ & $\begin{array}{c}8.44^{* * *} \\
\text { (1) }\end{array}$ \\
\hline d) Scandinavia & & & & & & \\
\hline Denmark & $\begin{array}{l}0.1354^{* * *} \\
(0.0351)\end{array}$ & - & $\begin{array}{l}0.3019^{* *} \\
(0.1407)\end{array}$ & 0.06 & $\begin{array}{r}0.02 \\
(1)\end{array}$ & $\begin{array}{r}3.33 \\
(1)\end{array}$ \\
\hline Norway & $\begin{array}{c}-0.1646^{* *} \\
(0.0747)\end{array}$ & $\begin{array}{l}0.7631^{* * *} \\
(0.0735)\end{array}$ & - & 0.58 & $\begin{array}{c}6.75^{* *} \\
(2)\end{array}$ & $\begin{array}{c}18.55^{* * *} \\
(5)\end{array}$ \\
\hline Sweden & $\begin{array}{c}0.0208 \\
(0.0269)\end{array}$ & - & $\begin{array}{l}0.4665^{* * *} \\
(0.0810)\end{array}$ & 0.17 & $\begin{array}{r}0.06 \\
(1)\end{array}$ & $\begin{array}{c}20.93^{* * *} \\
(1)\end{array}$ \\
\hline
\end{tabular}

Notes. Estimates are for an AR(1), MA(1), or ARMA(1,1) model, where $\varphi_{t}=\gamma_{0}+\gamma_{1} \varphi_{t-1}+\epsilon_{t}+$ $\gamma_{2} \epsilon_{t-1}$. 'ARCH' is a Langrange Multiplier statistic for autoregressive conditional heteroskedasticity and 'BG' the Breusch-Godfrey statistic for serial correlation in $\epsilon_{t}$ (optimal lags in parentheses). 
premium.

There is evidence in the literature that term premia are forecastable using variables such as the spread between the long and the short rates and the level of the interest rate (see, for instance, Bekdache, 2001; Campbell, 1995). This relationship is partly explainable by the preferred habitat theory of the term structure that states that risk-averse investors require a premium when investing in assets with a maturity that does not match their habitat. We verify this preferred habitat argumentation by linking the term premium to

$$
\varphi_{t}=\gamma_{0}+\gamma_{1} r_{t}+\gamma_{2} \operatorname{spread}_{t}+\gamma_{3} \operatorname{risk}_{t}+\epsilon_{t}
$$

where $\operatorname{spread}_{t}$ is defined as $r_{t}^{(n)}-r_{t}^{(k)}$. Although no particular measure of risk has consistently been found to be significant for term premia, we use the crude proxy risk $_{t}$, defined as the absolute percentage change in the yield on the $n$-period bond, or $\mid\left(r_{t}-r_{t-1}\right) / r_{t-1}$. Least squares estimates of equation 4.13 are presented in table 4.9. Consistent with other studies, such as Bekdache (2001) or Hejazi et al. (2000), we find that the yield spread is highly significant for all but two interest rates, and the relationship between the spread and the premium has the expected sign. The level of the 3-month spot interest rate is also statistically significant in a number of cases, yet the risk measure seems to be irrelevant.

It can be questioned whether the finding that risk measures are irrelevant is plausible or whether the risk proxy actually measures risk at all. The presence of strong ARCH effects in the tests of time-variation in the term premia, as well as in some of the low-order ARMA models, suggests that at least the inclusion of the second moments are relevant for explaining the time-variation of the premia. We therefore use a GARCH-M model, originally due to Engle et al. (1987), where the risk premia are heteroskedastic and the standard deviation of each observation directly affects the mean of that observation, or

$$
\varphi_{t}=\alpha_{0}+\alpha_{1} h_{t}+\epsilon_{t}
$$

where

$$
h_{t}^{2}=\beta_{0}+\sum_{i=1}^{p} \beta_{i} \epsilon_{t-i}^{2}+\sum_{i=1}^{q} \gamma_{i} h_{t-i}^{2},
$$

and where $\epsilon_{t} \sim N\left(0, h_{t}^{2}\right)$. To preserve model parsimony and keeping the summary statistics in table 4.3 in mind that show ARCH effects usually up to only lag, we select an $\operatorname{GARCH}(1,1)-\mathrm{M}$ specification.

The parameters in equation 4.14 are estimated by maximum likelihood using the $\mathrm{BHHH}$ algorithm and the standard errors are heteroskedasticity-consistent. Estimates are reported in table 4.10. The estimates for $\beta_{1}$ and $\gamma_{1}$ are both highly significant for most countries, indicating that that the GARCH specification is relevant. The inclusion of the conditional standard deviation in the mean equation results in significant parameter estimates for about half of the deposits, indicating that the variation in the term premia can be explained by a risk component. Furthermore, the conditional standard deviation has the correct sign: an upward change 
Table 4.9: Linear Model of the Term Premium

\begin{tabular}{|c|c|c|c|c|}
\hline & constant & interest & spread & risk \\
\hline \multicolumn{5}{|c|}{ a) Continental Europe } \\
\hline \multirow[t]{2}{*}{ Austria } & 0.2883 & -0.0467 & $0.7449^{*}$ & 0.9740 \\
\hline & $(0.1983)$ & $(0.0578)$ & $(0.4010)$ & $(0.7099)$ \\
\hline \multirow[t]{2}{*}{ Belgium } & -0.0961 & 0.0597 & 0.6784 & $-1.4718^{*}$ \\
\hline & $(0.1934)$ & $(0.0573)$ & $(0.4490)$ & $(0.7697)$ \\
\hline \multirow[t]{2}{*}{ Europe } & $0.0805^{*}$ & -0.0176 & $1.0798^{* * *}$ & 0.3307 \\
\hline & $(0.0427)$ & $(0.0121)$ & $(0.0970)$ & $(0.3394)$ \\
\hline \multirow[t]{2}{*}{ France } & $-0.1454^{* * *}$ & $0.0684^{* * *}$ & $0.7982^{* * *}$ & 0.5690 \\
\hline & $(0.0517)$ & $(0.0136)$ & $(0.1126)$ & $(0.3768)$ \\
\hline \multirow[t]{2}{*}{ Germany } & 0.0375 & -0.0128 & $1.1285^{* * *}$ & $0.0807^{*}$ \\
\hline & $(0.0395)$ & $(0.0110)$ & $(0.0860)$ & $(0.2789)$ \\
\hline \multirow[t]{2}{*}{ Italy } & -0.0295 & $0.0385^{* * *}$ & $0.6366^{* * *}$ & $-1.0599^{* *}$ \\
\hline & $(0.0537)$ & $(0.0083)$ & $(0.0965)$ & $(0.4823)$ \\
\hline \multirow[t]{2}{*}{ Netherlands } & $0.1188^{* * *}$ & $-0.0365^{* * *}$ & $1.1272^{* * *}$ & 0.1520 \\
\hline & $(0.0444)$ & $(0.0125)$ & $(0.0983)$ & $(0.2811)$ \\
\hline \multirow[t]{2}{*}{ Spain } & $0.0804^{* *}$ & $-0.0177^{* * *}$ & $0.7878^{* * *}$ & -0.0570 \\
\hline & $(0.0318)$ & $(0.0057)$ & $(0.0873)$ & $(0.3817)$ \\
\hline \multirow[t]{2}{*}{ Switzerland } & $-0.1422^{* * *}$ & $0.0402^{* *}$ & $1.4028^{* * *}$ & 0.0585 \\
\hline & $(0.0430)$ & $(0.0167)$ & $(0.1455)$ & $(0.1272)$ \\
\hline \multicolumn{5}{|l|}{ b) Asia-Pacific } \\
\hline \multirow[t]{2}{*}{ Australia } & 0.0263 & -0.0219 & $1.1652^{* * *}$ & 0.3081 \\
\hline & $(0.0788)$ & $(0.0139)$ & $(0.1042)$ & $(0.4578)$ \\
\hline \multirow[t]{2}{*}{ Hong Kong } & $-0.6587^{* * *}$ & $0.1967^{* * *}$ & $0.7082^{* * *}$ & $0.4947^{* *}$ \\
\hline & $(0.1161)$ & $(0.0199)$ & $(0.2223)$ & $(0.2051)$ \\
\hline \multirow[t]{2}{*}{ Japan } & -0.0107 & $0.0255^{*}$ & $1.0639^{* * *}$ & $-0.0613^{* *}$ \\
\hline & $(0.0087)$ & $(0.0143)$ & $(0.0805)$ & $(0.0288)$ \\
\hline \multirow[t]{2}{*}{ New Zealand } & $-0.2464^{* *}$ & $0.0337^{* *}$ & $0.9155^{* * *}$ & $0.8455^{*}$ \\
\hline & $(0.1044)$ & $(0.0147)$ & $(0.1282)$ & $(0.4625)$ \\
\hline \multicolumn{5}{|c|}{ c) Anglo-Saxon Countries } \\
\hline \multirow[t]{2}{*}{ Canada } & -0.0637 & 0.0078 & $1.1123^{* * *}$ & -0.0517 \\
\hline & $(0.0524)$ & $(0.0098)$ & $(0.0964)$ & $(0.2636)$ \\
\hline \multirow[t]{2}{*}{ Ireland } & -0.1080 & 0.0296 & $0.6436^{* *}$ & 1.2860 \\
\hline & $(0.5544)$ & $(0.0903)$ & $(0.2419)$ & $(1.6864)$ \\
\hline \multirow[t]{2}{*}{ U.K. } & -0.0638 & -0.0058 & $0.9739^{* * *}$ & 0.4309 \\
\hline & $(0.0576)$ & $(0.0094)$ & $(0.0858)$ & $(0.4533)$ \\
\hline \multirow[t]{2}{*}{ U.S. } & -0.0470 & $-0.0258^{* * *}$ & $0.9729^{* * *}$ & -0.2822 \\
\hline & $(0.0369)$ & $(0.0073)$ & $(0.1087)$ & $(0.2111)$ \\
\hline \multicolumn{5}{|c|}{ d) Scandinavia } \\
\hline \multirow[t]{2}{*}{ Denmark } & -0.0179 & 0.0361 & 0.0408 & -0.3208 \\
\hline & $(0.1312)$ & $(0.0307)$ & $(0.2547)$ & $(0.7703)$ \\
\hline \multirow[t]{2}{*}{ Norway } & -0.0812 & 0.0016 & $0.6731^{* * *}$ & $-0.8033^{* *}$ \\
\hline & $(0.0771)$ & $(0.0119)$ & $(0.1156)$ & $(0.3806)$ \\
\hline \multirow[t]{2}{*}{ Sweden } & -0.0104 & -0.0005 & $0.6455^{* * *}$ & -0.1441 \\
\hline & $(0.0547)$ & $(0.0110)$ & $(0.1549)$ & $(0.3333)$ \\
\hline
\end{tabular}
are given in parentheses. $\mathrm{A}^{*},{ }^{* *}$, or ${ }^{* * *}$ denotes significance at the 10,5 , or 1 percent significance level, respectively. 
Table 4.10: A GARCH-in-Mean Model of the Term Premium

\begin{tabular}{|c|c|c|c|c|c|}
\hline & $\alpha_{0}$ & $\alpha_{1}$ & $\beta_{0}$ & $\beta_{1}$ & $\gamma_{1}$ \\
\hline \multicolumn{6}{|c|}{ a) Continental Europe } \\
\hline \multirow[t]{2}{*}{ Austria } & $0.1646^{*}$ & 0.1342 & 0.0010 & 0.1393 & $0.8054^{* * *}$ \\
\hline & $(0.1000)$ & $(0.7146)$ & $(0.0032)$ & $(0.1565)$ & $(0.2631)$ \\
\hline \multirow[t]{2}{*}{ Belgium } & $-0.6782^{* * *}$ & $3.4940^{* * *}$ & $0.0293^{* * *}$ & $-0.1765^{* * *}$ & $0.5996^{* * *}$ \\
\hline & $(0.1183)$ & $(0.5166)$ & $(0.0045)$ & $(0.0347)$ & $(0.1091)$ \\
\hline \multirow[t]{2}{*}{ Europe } & $-0.0283^{* * *}$ & $0.5430^{* * *}$ & $0.0410^{* * *}$ & $0.4284^{* *}$ & $-0.5632^{* * *}$ \\
\hline & $(0.0040)$ & $(0.0878)$ & $(0.0067)$ & $(0.1929)$ & $(0.0980)$ \\
\hline \multirow[t]{2}{*}{ France } & -0.0235 & $1.6794^{* * *}$ & $0.0024^{* * *}$ & $-0.0577^{* *}$ & $0.9701^{* * *}$ \\
\hline & $(0.0422)$ & $(0.3856)$ & $(0.0000)$ & $(0.0250)$ & $(0.0537)$ \\
\hline \multirow[t]{2}{*}{ Germany } & -0.0532 & 0.4313 & 0.0071 & 0.4628 & 0.2272 \\
\hline & $(0.0557)$ & $(0.4001)$ & $(0.0053)$ & $(0.3043)$ & $(0.2273)$ \\
\hline \multirow[t]{2}{*}{ Italy } & $-0.1665^{* * *}$ & $0.9686^{* * *}$ & $-0.0009^{*}$ & $0.0470^{* *}$ & $0.9496^{* * *}$ \\
\hline & $(0.0496)$ & $(0.2000)$ & $(0.0005)$ & $(0.0196)$ & $(0.0238)$ \\
\hline \multirow[t]{2}{*}{ Netherlands } & 0.0560 & 0.0056 & 0.0038 & $0.2323^{*}$ & 0.5663 \\
\hline & $(0.1012)$ & $(0.7620)$ & $(0.0054)$ & $(0.1266)$ & $(0.3785)$ \\
\hline \multirow[t]{2}{*}{ Spain } & $-0.0599^{* * *}$ & $0.2266^{* * *}$ & 0.0010 & $1.7925^{* *}$ & 0.1152 \\
\hline & $(0.0090)$ & $(0.0790)$ & $(0.0007)$ & $(0.8892)$ & $(0.0745)$ \\
\hline \multirow[t]{2}{*}{ Switzerland } & -1.8249 & 9.8762 & $0.0098^{* * *}$ & 0.0576 & $0.6687^{* * *}$ \\
\hline & $(1.4028)$ & $(7.2771)$ & $(0.0031)$ & $(0.0431)$ & $(0.0563)$ \\
\hline \multicolumn{6}{|l|}{ b) Asia-Pacific } \\
\hline \multirow[t]{2}{*}{ Australia } & $-0.1012^{*}$ & 0.2005 & 0.0054 & $0.2812^{* * *}$ & $0.5415^{* * *}$ \\
\hline & $(0.0561)$ & $(0.3305)$ & $(0.0046)$ & $(0.1054)$ & $(0.2048)$ \\
\hline \multirow[t]{2}{*}{ Hong Kong } & $-0.1611^{* * *}$ & $0.9832^{* * *}$ & 0.0129 & 1.0806 & $0.3301^{* * *}$ \\
\hline & $(0.0524)$ & $(0.2283)$ & $(0.0084)$ & $(0.6873)$ & $(0.1066)$ \\
\hline \multirow[t]{2}{*}{ Japan } & $-0.0628^{* * *}$ & $0.5980^{* * *}$ & 0.0000 & $0.2840^{* *}$ & $0.7255^{* * *}$ \\
\hline & $(0.0017)$ & $(0.1258)$ & $(0.0000)$ & $(0.1263)$ & $(0.0916)$ \\
\hline \multirow[t]{2}{*}{ New Zealand } & $-0.1061^{* * *}$ & $0.6637^{* * *}$ & $0.0060^{* *}$ & $0.5438^{* * *}$ & $0.4035^{* * *}$ \\
\hline & $(0.0342)$ & $(0.1739)$ & $(0.0026)$ & $(0.1446)$ & (0.0919) \\
\hline \multicolumn{6}{|c|}{ c) Anglo-Saxon Countries } \\
\hline \multirow[t]{2}{*}{ Canada } & $-0.2613^{*}$ & $2.2863^{* *}$ & -0.0002 & 0.0078 & $0.9851^{* * *}$ \\
\hline & $(0.1436)$ & $(1.0076)$ & $(0.0002)$ & $(0.0115)$ & $(0.0115)$ \\
\hline \multirow[t]{2}{*}{ Ireland } & $-0.6308^{* *}$ & $1.7558^{* *}$ & $0.0414^{* *}$ & $0.4410^{* *}$ & $0.3388^{* *}$ \\
\hline & $(0.2882)$ & $(0.7524)$ & $(0.0201)$ & $(0.2046)$ & $(0.1633)$ \\
\hline \multirow[t]{2}{*}{ U.K. } & $-0.3522^{*}$ & 1.8109 & $0.0105^{* *}$ & 0.1641 & $0.4945^{* * *}$ \\
\hline & $(0.2012)$ & $(1.2894)$ & $(0.0049)$ & $(0.1256)$ & $(0.1552)$ \\
\hline \multirow[t]{2}{*}{ U.S. } & $-0.1523^{* * *}$ & 0.3191 & $0.0193^{* * *}$ & $0.5959^{* *}$ & -0.0007 \\
\hline & $(0.0494)$ & $(0.2652)$ & $(0.0051)$ & $(0.2345)$ & $(0.0462)$ \\
\hline \multicolumn{6}{|l|}{ d) Denmark } \\
\hline \multirow[t]{2}{*}{ Denmark } & $0.2914^{* *}$ & -0.9476 & 0.0044 & $0.1083^{* * *}$ & $0.9883^{* * *}$ \\
\hline & $(0.1441)$ & $(0.8924)$ & $(0.0035)$ & $(0.0269)$ & $(0.1170)$ \\
\hline \multirow[t]{2}{*}{ Norway } & $-0.1272^{* * *}$ & -0.0726 & $0.0051^{*}$ & $0.5566^{* * *}$ & $0.3996^{* *}$ \\
\hline & $(0.0325)$ & $(0.1537)$ & $(0.0027)$ & $(0.1814)$ & $(0.1588)$ \\
\hline \multirow[t]{2}{*}{ Sweden } & $-0.0444^{* *}$ & $0.3143^{*}$ & $0.0251^{* * *}$ & $0.4729^{* * *}$ & $-0.1183^{* *}$ \\
\hline & $(0.0267)$ & $(0.1562)$ & $(0.0061)$ & $(0.1395)$ & $(0.0500)$ \\
\hline
\end{tabular}

Notes. Reported are maximum likelihood estimates of a GARCH(1,1)-in-mean model. The quasimaximum likelihood heteroskedasticity-consistent standard errors of the coefficients are given in parentheses. $\mathrm{A}^{*},{ }^{* *}$, or ${ }^{* * *}$ denotes significance at the 10,5 , or 1 percent significance level, respectively. 
in the conditional standard deviation leads to an upward change in the level of the term premium.

Finally, we document that there is considerable evidence of a high degree of persistence in the volatility of term premia, given large estimates for $\beta_{1}$ and $\gamma_{1}$. Tzavalis and Wickens (1995) show that when $\beta_{1}+\gamma_{1}<1$, the conditional variance of innovations in interest rates has a direct, yet fading, effect on the slope of the yield curve, while if $\beta_{1}+\gamma_{1}>1$ the conditional variance is potentially explosive. For the majority of the interest rate deposits we find that the sum of $\beta_{1}$ and $\gamma_{1}$ is smaller than unity. However, for the remaining models, we cannot reject the null hypothesis that the model is integrated in variance.

\subsection{Conclusions}

In the current chapter we examine the expectations hypothesis using survey data for a large set of international, short-term interest rates. In contrast to commonly-cited results from U.S. studies we find that, although the 'pure' version of the expectations hypothesis can be firmly rejected for all deposits, forward rates are not biased estimates of future interest rates. Nevertheless we find some evidence of irrationality on the part of market participants, and strong evidence of the existence of a time-varying term premium in the short end of the term structure of our deposits.

Term premia furthermore are commonly positive, suggesting that the premia could be liquidity premia as proclaimed by the liquidity preference theory. A closer look at the time-varying term premia reveals a large degree of persistence, which is in line with intertemporal general equilibrium asset pricing models, such as for instance those of Vasicek (1977) or Cox et al. (1985). We find that low-order versions of ARMA models describe the term premia well, although low-order ARCH effects are also present in several interest rate deposits. Finally, we find that although continental European term premia show lower degrees of persistence than other premia, the former nevertheless are time-variant and the survey respondents did make irrational forecasts, in that not all available information to market participants was used efficiently. 



\section{Chapter 5}

\section{Dispersion of Beliefs in Foreign Exchange*}

\subsection{Introduction}

In the previous decades we have witnessed an increase in the number of studies that attempt to explain various aspects of the foreign exchange market. The interest in this area does not come as a surprise, since the large amount of foreign exchange that is traded worldwide is far in excess of what is required for trade in goods and services. It therefore seems that the foreign exchange market is a market 'on its own' and that this market, because of its large volume, is highly liquid and efficient (Froot and Thaler, 1990). For this reason, market participants are said to have equal access to information and form their expectations about future events in a uniform, rational manner.

In the academic literature, there has thus been a tendency to use a representative agent approach when modelling exchange rate expectations. That is, expectations in the foreign exchange market were assumed to be formed in a rational way where all market participants optimize all information as efficiently as possible and all market participants have similar access to all information. The assumption of homogeneous, rational expectations has been used in a variety of fields within the exchange raterelated literature. Several examples are worth noting.

A strand of the literature that has relied on the assumption of rational expectations is the forward premium puzzle discussion (see Hodrick, 1987; Engel, 1996, for an overview). Forward exchange rates have often been found to be biased predictors of future spot rates. Based on the assumption of rational, homogeneous expectations, most studies have attributed this bias to the existence of time-varying risk premia. However, Frankel and Froot (1987b) and Cavaglia et al. (1993b, 1994) have questioned to what extent these interpretations are biased by the possible false

${ }^{*}$ Part of this chapter is from a working paper with Willem F.C. Verschoor, Christian C.P. Wolff and Remco Zwinkels. 
assumption of rationality; Ito (1990) examines whether the homogeneity assumption is valid and Frankel and Froot (1990a) condition the use of information on the forecasting horizon.

Another example is the literature on foreign exchange rate exposure, popularized by the influential work of Adler and Dumas (1984) and Jorion (1990). This literature assumes that unexpected exchange rate changes affect the returns of companies, whether or not these companies have foreign operations. Based on the assumption of rationality, the unexpected changes are commonly approximated by realized changes. Yet after a few decades of research, the empirical evidence of whether domestic firms are exposed to currency risk still remains inconclusive and puzzling. It is for this reason that Gao (2000) questions the rationality assumption and explicitly tries to model the expected change in exchange rates using macroeconomic variables.

From these examples and the existence of other anomalies, such as the excess volume of trade in the foreign exchange market, it becomes clear that the notion of rational expectations is losing more and more ground. Instead, the focus is shifting in the direction of bounded rationality, and the accompanying heterogeneity of agents' expectations. New insights into how market participants form their expectations are therefore warranted.

Among the reasons of the popularity of rational expectations is the relative ease of (mathematical) modelling and, especially in empirical work, the lack of alternatives. The latter issue has been resolved by the introduction of survey datasets. The use of survey data is not uncommon in the finance literature and an increase of the use of surveys in various areas of the finance literature is observed. For example, Friedman (1979, 1980), Froot (1989) and MacDonald and Macmillan (1994) have used interest survey data in tests for identifying term premiums and examining the rationality of expectations of future interest rates and concluded that predictions were biased and respondents did not efficiently exploit the information contained in past interest movements. Similarly, Dokko and Edelstein (1989) review the usefulness of the Livingston forecasts of stock market rates of return and find evidence of adaptive behavior in the forecasts. Keane and Runkle (1990) use survey forecasts of the GNP deflator and find that expectations are rational, and MacDonald and Torrance (1988b) use survey data on expected changes in money aggregates with U.K. data and find that these survey measures of expectations are extremely useful, for, unlike statistical methods for generating estimates, they are truly exogenous.

But particularly in the foreign exchange rate literature there has been, for many years, a considerable amount of interest in the exploration of survey-based expectations in order to understand the behavior of foreign exchange market participants. For instance, Frankel and Froot (1987b) and Cavaglia et al. (1993b, 1994) use survey data on foreign exchange expectations to examine whether the failure of the forward premium puzzle can be attributed to irrational behavior on behalf of market participants or due to the existence of time-varying risk premia and Marsh and Power (1996) and Elliott and Ito (1999) examine the forecast performance of survey-based exchange rate forecasts.

In this chapter we use survey-based measures of exchange rate expectations to get new insights in the heterogeneity assumption of participants in the foreign exchange 
market. Our contribution lies in the fact that we approach the issues from a more fundamental viewpoint compared to the existing literature. Furthermore, we use a broader dataset and a richer arsenal of tests. We start with a fundamental discussion on what heterogeneity, or 'dispersed beliefs', comprise of theoretically and how one can measure and quantify dispersion of beliefs, specifically in survey datasets of individual forecasts. We focus on the question of what the source of the possible dispersion is. Next, we employ these insights to a survey dataset of individual expectations.

Typical concerns when using survey data in any setting are whether this data reflects the true market's expectations, whether the data is biased because of strategic behavior from the panel participants, or whether forecasts from surveys are of any good in an out-of-sample forecast setting-a criteria that has often been put forward to evaluate the quality of survey expectations. It should be noted that for survey data in the present setting it is most important that the survey forecasts reflect the market's sentiment at the time they are formed, that is, the survey data should reflect expectations, nothing more than that.

While it is not the primary concern that the survey-based forecasts outperform other forecasting techniques, there is a consensus view that forecasts from surveys in general perform no worse than any other forecast technique. We can learn much about the usefulness of survey-measures of expectations from related fields. Ang et al. (2007), for instance, provide recent evidence that forecasts from various surveys on inflation consistently deliver better forecasts than time-series models, models based on the yield curve, and forecasts based on the Phillips curve, which highlights the usefulness of survey measures of expectations. Elliott and Ito (1999) find that in the foreign exchange market portfolios based on survey-based forecasts produce small, but positive, profits.

We find that there are distinct periods of high and low dispersion where market participants disagree as to what will happen to the future level of the exchange rates. Furthermore, we document that the frequency at which extremist differences in expectations among market participants occurs is higher than that what would occur under normality. Dispersion of beliefs seems to occur as a result of the combined effects of market participants holding individual expectations and attaching different weights on various elements of the set of public information. Finally, we find that market volatility Granger-causes trader heterogeneity.

The remainder of the chapter is presented as follows. In section 5.2 we examine the rationale behind dispersed beliefs. In section 5.3 we introduce the data used for this analysis. Section 5.4 examines whether expectations are dispersed and in section 5.5 we try to give an answer as to what the sources of dispersion of beliefs is. Section 5.6 links dispersion of beliefs to market uncertainty. Finally, section 5.7 concludes. 


\subsection{Dispersion of Beliefs in Foreign Exchange}

In this chapter we are first and fore mostly interested in the expectations, or beliefs, that market participants, or agents, have with respect to future levels of an exchange rate and in particular to what extent and by which causes these differ from each other. When the expectations of a group of agents differ (for instance, one agent expects a higher appreciation of a currency than another agent, or one agent expects an appreciation while the other expects a depreciation), we state that their beliefs are dispersed. 'Dispersion of beliefs' therefore explicitly refers to the difference in expectations that the various market participants have with respect to the future status of the market. In related literature, the term 'heterogeneity' is often used to express similar concepts. Yet, this term is used in a much broader setting, for instance to refer to the market participants themselves (heterogeneous agents) or to the type of information they possess (heterogeneous information). In order to avoid confusion about the terminology, we prefer the term dispersion of beliefs instead of the term heterogeneity, whenever we talk about the difference in agents' expectations.

There are broadly three commonly used explanations for why dispersion of beliefs occurs in financial markets. First of all, one strand of the literature argues that dispersion of beliefs arises because of information asymmetries. Different market participants are assumed to hold different sets of information, whereby part of the information is common for all participants and part is private. Even when market participants use the same techniques in forming expectations and try to make the best forecast conditional on the information they have, their expectations will inherently be different due to the fact that all have a different information set. This asymmetry in information may arise because of several reasons. First, when the concept of asymmetric information was introduced in the New Classical Theory of the macro economy, the key reason why agents were assumed to be unable to obtain information that is public in other parts of the economy was that the transmission of public information was rigid.

Another source of asymmetric information is the natural informational advantage that some players have over others. For example, Peiers (1997) reports on how central banks regularly execute their interventionary transactions through selected large commercial, often domestic banks instead of going through the brokers' market. The central bank can thus benefit from the strong market presence and liquidity from its key intermediary, and the intermediary commercial bank has privileged information regarding the central bank's activities. Information asymmetry is therefore caused by the fact that central bank activity is revealed in multiple stages. Covrig and Melvin (2002) furthermore attribute part of the private information in the foreign exchange market to the customer order flow: large domestic banks will receive the foreign exchange business of large domestic corporations and this confers a temporary informational advantage on large domestic banks. The costs of asymmetric information to market participants can be substantial even today. By analyzing trades and quotes in the Deutschemark - U.S. Dollar market, Payne (2003) shows that asymmetric information can account for around 60 percent of the average 


\section{bid-ask spread.}

There are, on the other hand, several arguments and empirical considerations against the claim that all of the dispersion of beliefs is caused by the existence of private information. First, since financial markets and foreign exchange markets in particular are dominated by large institutions that are all competitive in the search for information, one would expect that each of them should possess essentially the same information. Second, even when a particular market participant possesses private, inside information, it is still illegal to trade on such information. Since developed financial markets are heavily monitored by a community of regulators, brokers, and governmental institutions, one would expect that trading on such private information is scarce, or at minimum it is unrealistic to assume that a significant part of the volatility in foreign exchange markets is caused by illegal trade.

A second strand of the literature therefore assumes that all market participants hold different beliefs about economic variables even when there is no difference in the information that is available to them. The difference in beliefs arises because agents disagree about how they should interpret this information. A popular approach in the discussion about why agents interpret information differently is the rational beliefs theory due to Kurz (1994). In this theory, the disagreement is caused by the fact that economic agents do not know the structural relations of the economy, such as demand and supply functions. Agents only have 'information' or 'empirical knowledge', which is readily observable from the economy, usually in the form of a large amount of data concerning the past performance of an asset or economy in general. They form their probability beliefs about the future by using the empirical distribution that is derived from the relative frequency of events in the past. Their own experience and success in forming accurate forecasts will likely play a role in selecting and valuing information. Given a set of identical data, different agents will then add different weights to the various elements of the data, to express their relative importance which they think the various elements have when forming an expectation about the future.

The rational beliefs theory therefore stands in contrast to the more commonly used theory of rational expectations, where agents are supposed to know a lot about the structure of the economy. It was argued that it is unreasonable to assume that economic agents possess skills and structural knowledge that no human being can possess. Structural knowledge can be gradually acquired by agents though, for instance through learning, but the literature on learning has thus far not been successful in justifying a fully rational agent.

An important observation in the rational beliefs theory is that market risks are determined by the individual beliefs of the various market participants and that a change in the distribution of these beliefs therefore affects the volatility of the market. Kurz and Motolese (2001, p. 497) in fact claim that the "distribution of beliefs in the market is the most important propagation mechanism of economic volatility", in other words, much of the volatility in the market is generated by the individual beliefs of the market participants and the correlation between these beliefs.

A third explanation for why market participants hold different beliefs about the 
future may be related to the existence of fundamentally different types of market participants. In the financial economics literature there have been several attempts to present models with different types of investors who in essence all have the same information. For instance, De Long et al. (1990) present a model where noise traders, with no access to inside information, act irrationally on noise as if it were information that would give them an advantage over rational arbitrageurs. These noise traders can earn higher expected returns, because of their own destabilizing influence and not because they bear more of the fundamental risk.

Frankel and Froot $(1986,1990 \mathrm{a})$ popularize the view that the foreign exchange market is dominated by two types of market participants that differ in which information they use for forming their beliefs. On the one hand, fundamentalists think of the exchange rate as the output of an economic model, while on the other hand chartists predominantly use the exchange rate's own history as input in their expectations formation process. They show that the increased use of technical analysis (chartist behavior) in the late 1980s could well explain why the U.S. Dollar was so far above its long-run equilibrium at that time, or why the volume of foreign exchange trading worldwide has grown so tremendously. Allen and Taylor (1990) and Taylor and Allen (1992) were among the first to show by means of surveys that at least 90 percent of market participants place some weight on technical advise, although this is used predominantly for shorter-term forecasts, and that the use of technical forecasting tools has increased over the past decades.

The realization that the presence of fundamentally different interacting market participants can shed new light on some of the anomalies in the financial economics literature has resulted in a strand of literature on how to model these 'heterogeneous' agents (see Hommes, 2006, for an overview of this literature). Most heterogeneous agents models are based on the simple chartists - fundamentalist distinction as well, but revolutionary is the fact that agents can switch between trader types. Switching occurs as a result of differences in forecasting performance of the different strategies.

Simulations show that heterogeneous agents models are capable of replicating the stylized facts from financial markets, see e.g. De Grauwe and Grimaldi (2006). Periods in which (extrapolating) chartists are dominating the market are characterized by high volatility, while periods dominated by (mean-reverting) fundamentalists are characterized by low volatility. This combination yields an economic intuitive explanation for the existence of volatility clustering, heavy tailed return distributions, excess volatility, and slow mean reversion. The first estimation results indicate the existence of switching heterogeneous agents in different financial markets; see Boswijk et al. (2007) for the S\&P500 and De Jong et al. (2006) for the EMS exchange rates.

The market microstructure approach uses dispersion of beliefs as well as highlights the importance of the market microstructure theory in explaining the complex short-term behavior of the exchange rate. For instance, using order flow as a proximate determinant, Evans and Lyons (2002) develop a model that is strikingly successful in accounting for realized exchange rate changes. In their analyses, they show that the order flow conveys dispersed information and that the distribution of information is an important determinant in short-run exchange rate movements. 
Moreover, the large volumes in the exchange rate market are explanatory for shortterm movements and an indication that agents have different information or process information differently. In other words, a high dispersion of beliefs causes high volatility. As shown by Fan and Lyons (2001), informative trades are mixed with uninformative trades, indicating that market efficiency crucially depends on how markets accomplish the difficult task of aggregating dispersed information.

In the next sections we attempt to deal with the first two arguments of why dispersion of beliefs occurs, namely because of asymmetry in information and/or disagreement about how information should be interpreted. In the next chapter we look at the relative role of fundamentally different types of market participants.

\subsection{Data}

To investigate the behavioral aspects of the beliefs of market participants, and in particular the dispersion thereof between participants, we use a unique database of survey forecasts. The individual forecasts are obtained from a survey conducted by Consensus Economics of London on a monthly basis among the leading market participants in the foreign exchange market, investment banks, and professional forecasting agencies. Examples of panelist companies are Morgan Stanley, Oxford Economic Forecasting, Deutsche Bank Research, and BNP Paribas. The panelists companies are located worldwide, although they are all from developed economies (notably from the U.S., Japan, U.K., France, Germany, Canada, etc.). The forecasts are point forecasts for a large set of currencies against the U.S. Dollar or the Deutschemark (later the Euro) and are available for horizons of 1, 3, 12, and 24 months ahead. The names of the panelist companies are revealed.

Although survey participants have a few days time to return their forecasts, we learned that the vast majority send their responses by e-mail on the Friday before the publication day (usually the second Monday of the month). We consider this Friday to be the day on which their beliefs are formed and assume that their beliefs are translated one-to-one in a point forecast. There may be reasons for panelists not to reveal their true beliefs, though. One motive may be that agents do not want to expose their (private) information to other market participants. This effect can be mitigated by the reputation effect that surveys can have. When the names of the forecasters are given in the survey publication, like is the case in this data set, agents have an incentive to perform well in order to attract customers.

For the Friday on which the beliefs are thought to be formed, we obtain spot and forward exchange rate series with different maturities to match with the survey data. All spot rate series are obtained through Datastream. To verify that the information sets of market participants are not too diverse, all of the analyses throughout this study were re-estimated using spot data from various days surrounding this Friday, yet the overall results remain virtually unchanged. Other data, such as interest rates, are also obtained through DataStream.

For our sample, we obtain the forecasts for the U.K. Pound, Japanese Yen and Euro against the U.S. Dollar for the period of October 1989 through December 
Table 5.1: Data Summary

\begin{tabular}{lccc}
\hline \hline & U.K. Pound & Japanese Yen & Euro (Deutschemark) \\
\hline a) Period 1989:10 - 1995:2 & & & \\
Survey frequency & Monthly & Monthly & Monthly \\
Minimum \# panelists & 89 & 94 & 99 \\
Maximum \# panelists & 112 & 120 & 127 \\
Median \# panelists & 99 & 108 & 112 \\
& & & \\
b) Period 1995:11 - 2004:12 & & & Monthly \\
Survey frequency & Bi-monthly & Monthly & 85 \\
Minimum \# panelists & 70 & 82 & 128 \\
Maximum \# panelists & 108 & 123 & 102 \\
Median \# panelists & 89 & 103 &
\end{tabular}

Notes. The medians are rounded.

2004. ${ }^{1}$ This period is of particular interest since it contains several financial crises, the introduction of a single monetary currency unit, and several large changes in the level of the exchange rates. The panel is unbalanced since the response rate of the individual market participants is less than 100 percent and since market participants left the panel and were replaced by others. Due to data unavailability we have to split the sample in two periods: October 1989 through February 1995 (Sample 1) and November 1995 through December 2004 (Sample 2). In this chapter we focus on the 3- and 12-month-ahead forecasts since these have the highest response rates.

Table 5.1 provides an overview of the survey dataset that is used and gives an indication of how many responses are obtained from the panelists per time period. We find that the median number of responding participants is over 100 per month for the Japanese Yen and Euro forecasts, while slightly less than 100 per month for U.K. Pound forecasts.

The number of methods to measure or quantify dispersion of beliefs is small because of the relatively scarcity of data on individual (survey) forecasts. We therefore follow the formal approach proposed by Shalen (1993), who claims that the theoretical relationship between market volatility, volume, and the dispersion of beliefs should be based on a squared function of the difference between the individual belief and the average belief about a particular asset. We therefore take the cross-sectional standard deviation of the individual survey-based forecasts, $\bar{\sigma}_{t}^{e}$. We then divide the cross-sectional standard deviation by the cross-sectional average, which gives us a dimensionless statistic that allows the comparison of the variability of populations that have a different mean, such as comparing two exchange rates. ${ }^{2}$ This statistic

\footnotetext{
${ }^{1}$ Prior to January 1999 we use forecasts on the Deutschemark versus the U.S. Dollar. We transform these forecasts into Euro / U.S. Dollar forecasts using the official conversion rate.

${ }^{2}$ We check to what extent our measure of dispersion is driven by either the cross-sectional standard deviation or the cross-sectional average. The correlation with the former is typically between 85 and 97 percent for all currency and forecast horizon combinations. The correlation with the latter is never more than 56 percent. Thus, the variation in our measure of dispersion is primarily driven by the volatility of the individual forecasts.
} 
is often called the coefficient of variation. If we define the individual survey-based forecast of a particular individual as $s_{i, t}^{e}$ and the cross-sectional average as $\bar{s}_{t}^{e},{ }^{3}$ then the resulting dispersion statistic is defined as:

$$
h_{t} \equiv \frac{\bar{\sigma}_{t}^{e}}{\bar{s}_{t}^{e}}
$$

where

$$
\bar{\sigma}_{t}^{e} \equiv \sqrt{\sum t \frac{1}{n}\left(d_{i, t}\right)^{2}},
$$

and where

$$
d_{i, t} \equiv s_{i, t}^{e}-\bar{s}_{t}^{e} .
$$

Figure 5.1 presents this coefficient of variation along two forecast horizons for the three currencies. In addition, high-low spreads are presented as a robustness check in figure 5.2. ${ }^{4}$ Several findings are noteworthy. First of all, the spread and coefficient of variation reveal similar patterns. This ensures us that both measures seem to be capable of capturing dispersion in beliefs, in other words, the variation in the spreads is not caused by the extremist expectations of outliers.

Second, the dispersion in beliefs increases with the forecast horizon. When one would see dispersion of beliefs as a sign of uncertainty, this would indicate that the market agrees more about what will happen in the nearby future than in the distant future. It should be mentioned though that this is not evidence that market participants can better predict short term changes over long term changes.

Third, dispersion of beliefs is not constant over time, but seems to be high in some periods of considerable length, while low in others. In particular for the U.K. Pound and for the Euro dispersion of beliefs was obviously higher in the period of early 1990 to late 1993 than in the subsequent period. Similarly, for the Japanese Yen rate beliefs became increasingly dispersed from early 1998 onwards until the end of 2001. This period is in the aftermath of the Asian crisis starting in mid1997, which would lead us to believe that market instability is a driving factor of dispersion in beliefs. This would be an interesting argument, for if would suggest that a dramatic event such as the Asian crisis may have an effect on the expectations of market participants even 2 year after date.

\subsection{Are the Beliefs of Foreign Exchange Forecast- ers Dispersed?}

One natural question is what we can learn from the distribution of the differences between the individual forecasts and the cross-sectional average, $d_{i, t}$. Under the

\footnotetext{
${ }^{3}$ In our notation we suppress a subscript that would indicate the forecast horizon to keep the algebra tractable.

${ }^{4}$ Using the spread as a measure of dispersion may be subject to one severe problem. Since the spread only depends on two contemporaneous observations, non-representative market participant who often produce extreme (outlier) forecasts directly influence the measure of dispersion. Therefore, we only use the spread as a robustness check.
} 

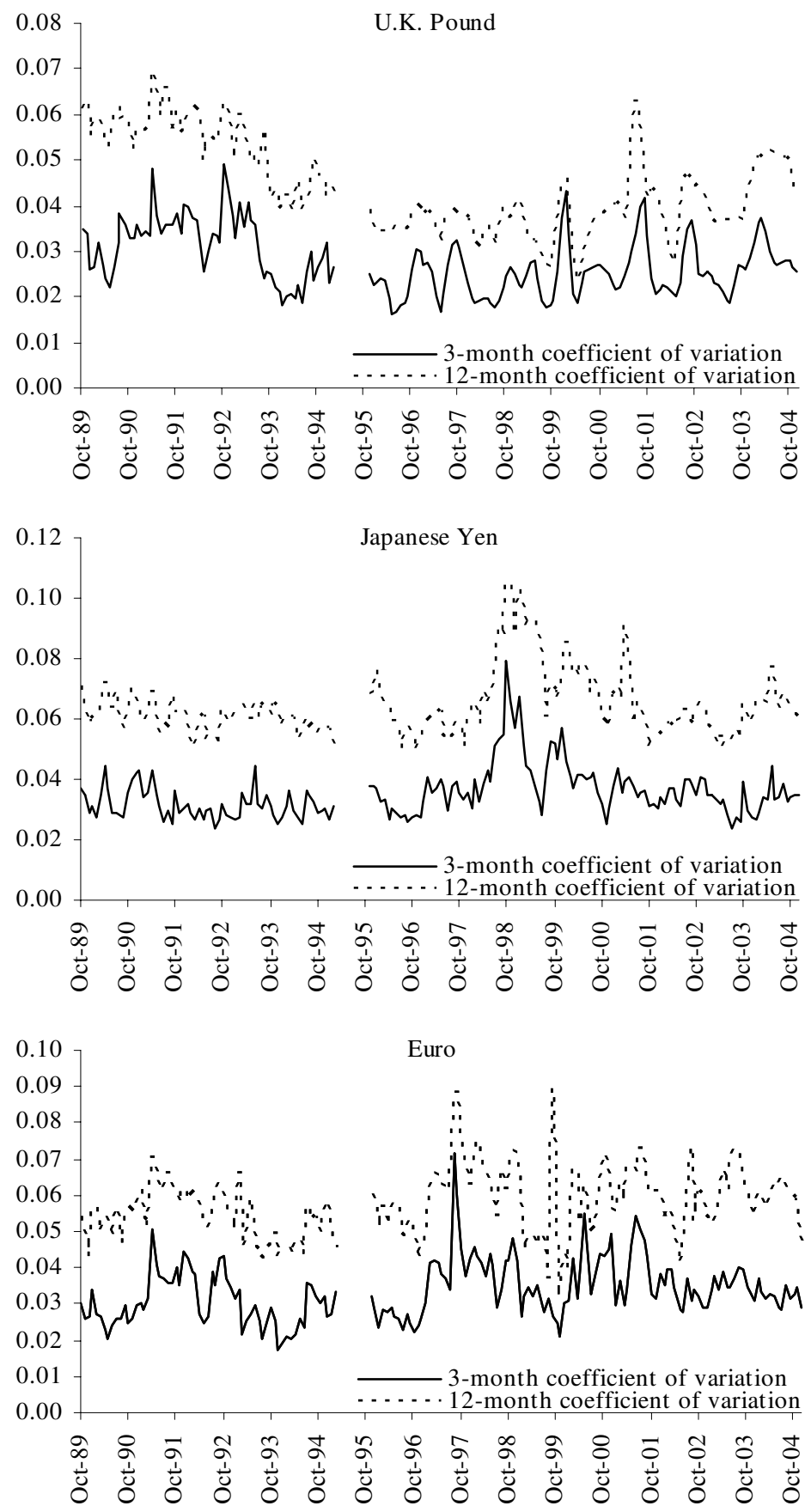

Figure 5.1: Coefficients of Variation 

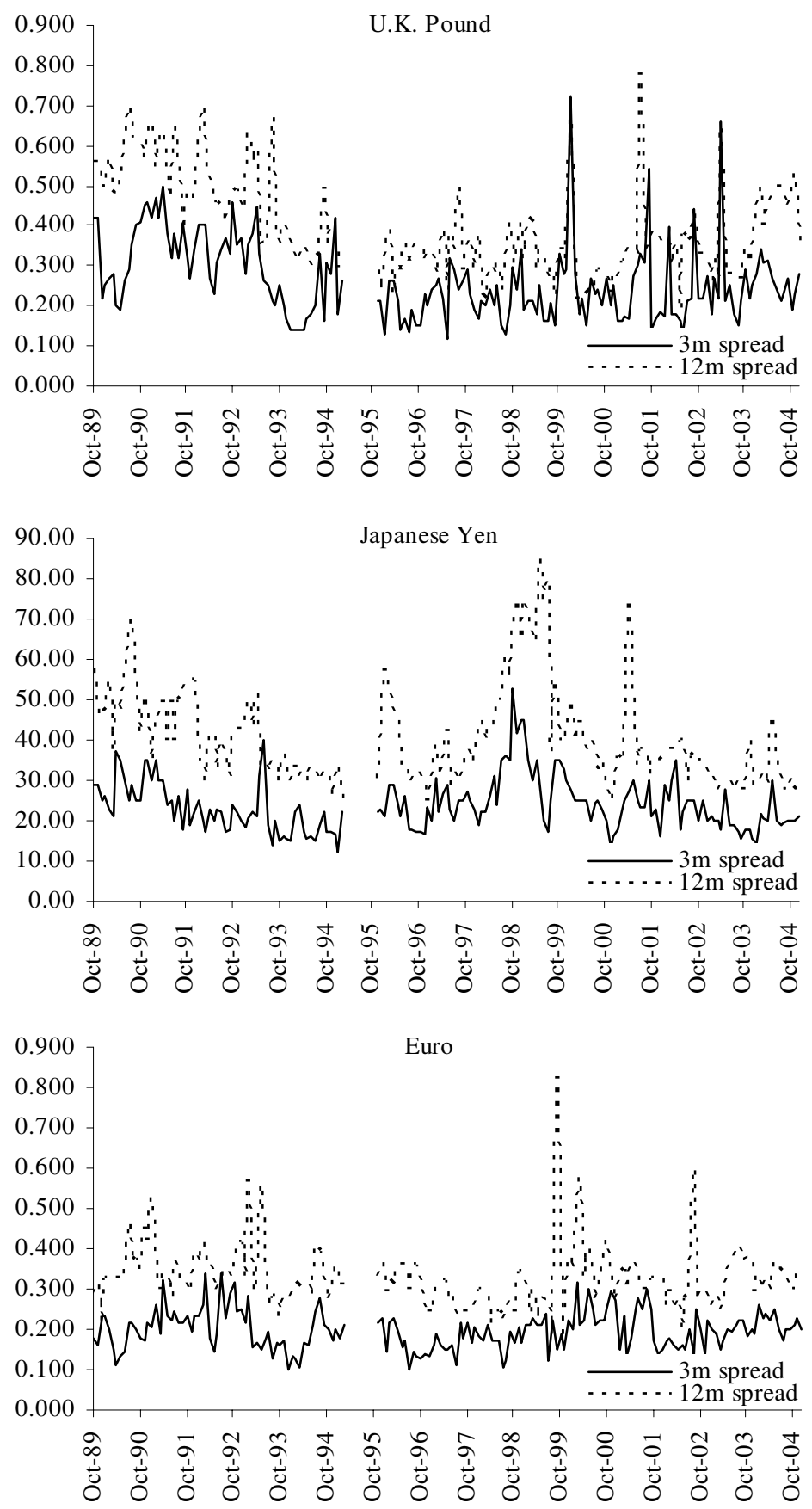

Figure 5.2: High-Low Spreads 
null hypothesis that beliefs are not dispersed, these differences (or alternatively the differences between contemporaneous individual forecasts) are independently and identically distributed (i.i.d.). This assumption is directly testable by examining the distributional properties of these differences. Of particular interest is the tail behavior of the distribution, since under the null hypothesis of no dispersed beliefs extreme differences should not occur at a rate higher than normal. Furthermore, the average difference between forecasters should be zero, and there should not be any form of autocorrelation.

We proceed by examining formally whether beliefs are dispersed. To do so we follow the methodology due to Ito (1990), who describes a way of how individual agents form their beliefs about future exchange rates. Suppose individual $i$ generates a forecast ${ }^{5}$ about the $k$-period ahead level of a particular exchange rate and that this forecast consists of a common structural part based on public information (that is common to all market participants) and an individual effect $g_{i}$. The individual forecast $s_{i, t}^{e}$ can then be described as

$$
s_{i, t}^{e}=f\left(\Omega_{t}\right)+g_{i}+\epsilon_{i, t},
$$

where $\epsilon_{i, t}$ is a pure random disturbance term (with respect to $i$ and $t$ ) that can, for instance, be the result of a measurement error. In a similar way can the crosssectional average of a set of market participants' forecasts be defined as

$$
\bar{s}_{t}^{e}=f\left(\Omega_{t}\right)+\bar{g}+\bar{\epsilon}_{t} .
$$

Suppose that a normalization such that $\bar{g}=0$ is possible (when $f\left(\Omega_{t}\right)$ contains a constant term). Subtracting the cross-sectional average from the individual forecast then gives

$$
s_{i, t}^{e}-\bar{s}_{t}^{e}=g_{i}+\left(\epsilon_{i, t}-\bar{\epsilon}_{t}\right),
$$

or

$$
d_{i, t}=g_{i}+\left(\epsilon_{i, t}-\bar{\epsilon}_{t}\right) .
$$

In this way it is not necessary to know the exact structure of $f\left(\Omega_{t}\right)$, as long as it is common to all agents. Table 5.2 presents summary statistics for the distribution of the individual expectations in excess of their cross-sectional average $d_{i, t}$, which should give us information about the individual effect $g_{i}$. The statistics are generated from the sample of pooled data.

Several observations are noteworthy. Both the high-low spread (maximum minus minimum forecast) and standard deviation increase as the forecast horizon increases. This indicates an increase in dispersion of beliefs as the forecast horizon lengthens, as we have seen in figure 1. Furthermore, the deviations are significantly and positively auto-correlated and the pattern of autocorrelation is stronger for longer forecast horizons and for the second sample period. ${ }^{6}$ Since the autocorrelation pattern does

\footnotetext{
${ }^{5}$ Recall that we made the assumption that the survey-based forecast is as close as we can get to the true, yet unknown belief of the agent.

${ }^{6}$ Except for the U.K. Pound, but this is due to the fact that forecasts are available bi-monthly in the second set.
} 
Table 5.2: Distributional Summary Statistics of the Deviations (pooled sample)

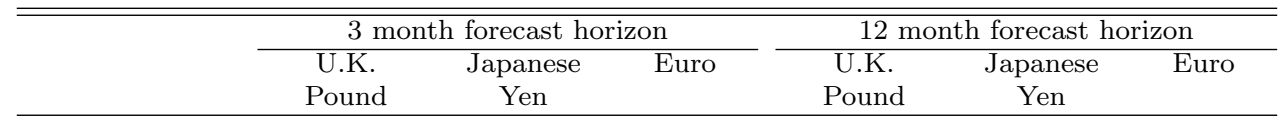

a) Period 1989:10 - 1995:2

$\begin{array}{lrrrrrr}\text { Maximum } & 0.1481 & 0.2127 & 0.1710 & 0.2563 & 0.2574 & 0.3239 \\ \text { Minimum } & -0.1934 & -0.1693 & -0.1695 & -0.3487 & -0.3044 & -0.2457 \\ \text { Stdev } & 0.0319 & 0.0317 & 0.0308 & 0.0536 & 0.0604 & 0.0536 \\ \text { Skewness } & -0.21 & 0.12 & 0.15 & -0.05 & 0.09 & 0.21 \\ \text { Kurtosis } & 5.68 & 4.91 & 4.52 & 4.28 & 3.56 & 3.92 \\ \text { Bera-Jarque } & 1961.02^{* * *} & 1071.56^{* * *} & 718.14^{* * *} & 443.08^{* * *} & 101.06^{* * *} & 313.52^{* * *} \\ \text { Autocorrelation } & 0.454^{* * *} & 0.467^{* * *} & 0.446^{* * *} & 0.610^{* * *} & 0.657^{* * *} & 0.613^{* * *}\end{array}$

b) Period 1995:11 - 2004:12

$\begin{array}{lcccrrr}\text { Maximum } & 0.1037 & 0.2287 & 0.1540 & 0.1399 & 0.3630 & 0.1371 \\ \text { Minimum } & -0.1098 & -0.1646 & -0.1471 & -0.1553 & -0.2346 & -0.3290 \\ \text { Stdev } & 0.0255 & 0.0378 & 0.0322 & 0.0400 & 0.0732 & 0.0554 \\ \text { Skewness } & -0.02 & -0.05 & 0.01 & -0.29 & 0.41 & -0.59 \\ \text { Kurtosis } & 4.54 & 4.32 & 4.40 & 4.13 & 3.76 & 3.87 \\ \text { Bera-Jarque } & 109.69^{* * *} & 162.60^{* * *} & 180.89^{* * *} & 74.96^{* * *} & 1118.22^{* * *} & 200.87^{* * *} \\ \text { Autocorrelation } & 0.303^{* * *} & 0.506^{* * *} & 0.541^{* * *} & 0.563^{* * *} & 0.738^{* * *} & 0.717^{* * *}\end{array}$

Notes. The figures are in logarithms, so they can be seen as the percentage deviations from the consensus average expectations. $\mathrm{A}^{*},{ }^{* *}$, and ${ }^{* * *}$ indicates a rejection of the null hypothesis of normality at the 10,5 , and 1 percent significant level, respectively.

not extend beyond the first lag (not reported), we can conclude that the error terms in equation 5.7 follow either an $\mathrm{AR}(1)$ or MA process with an unknown number of lags. This correlation can be explained from the overlapping pattern of the survey forecasts. Hansen (1982) and Hansen and Hodrick (1980) demonstrate that, when the forecast horizon is longer than the observational frequency (which is one month), the error term in equation 5.4 will be serially correlated up to a moving average process of order $k-1$. The error component in equation 5.7 therefore inherits this structure. In the remainder of the chapter we will correct for this moving average structure.

Although the individual forecasts do not appear to be skewed in a particular direction, the distributions are consistently leptokurtic. While high kurtosis is not analogous to fat tail behavior, we may state that an excessive number of forecasts are at enough distant from the consensus forecast that they render the distribution non-normal. Jarque-Bera statistics for the normality of the individual expectations are included and corroborate the rejection of the normality assumptions under high levels of significance.

A formal analysis of the tail behavior of the distribution of individual deviations can be given by examining a measure for the tail index. Hill (1975) defines a tail index estimate by looking at the order statistics of a series. Suppose that the surveybased forecasts for a particular exchange rate are independently and identically distributed. We then define $X$ as the set of $d_{i, t}$ for all $i$ and $t$. We define $x_{(1)} \leq$ $x_{(2)} \leq \ldots \leq x_{(n)}$ as the ascending order statistics from the sample $x_{1}, x_{2}, \ldots, x_{n}$ of 
consecutive deviations in the set $X$. In other words $x_{(n)}$ is the largest individual upward deviation and $x_{(n-m)}$ is the $m$ 'th largest individual upward deviation (the particular $d_{i, t}$ is positive) from the total set of individual expected deviations. The Hill estimator can then be defined as

$$
\gamma=\frac{1}{m} \sum_{j=1}^{m} \ln \left[\frac{x_{(n-j+1)}}{x_{(n-m)}}\right],
$$

where $m$ is the number of observations in the tail that is used for estimating the tail index and $n$ the total number of observations in the set $X$. The estimate

$$
\alpha=\frac{1}{\gamma}
$$

is called the tail index estimate and can be interpreted as the highest moment that exists from the sample. So when the tail estimates $\alpha$ are sufficiently low (or the Hill estimates $\gamma$ sufficiently high), we can question the existence of higher moments of the distribution, which is direct evidence of fatness in the tails. The specification in equation 5.9 is in fact a measure for the upper (right) side of the distribution, where we find the largest individual estimates that are above their cross-sectional average. A similar index can be generated for the lower (left) side of the distribution, by using instead descending order statistics $x_{(1)} \geq x_{(2)} \geq \ldots \geq x_{(n)}$. We distinguish these indices as $\alpha_{r}$ and $\alpha_{l}$. We choose the cutoff point $m$ by using a certain percentage of the lowest observations in $X$.

Table 5.3 provides tail index estimates for the 1, 5, and 10 percent tails of the distribution. Estimates for both upper (right) and lower (left) tails are included separately to detect any tail asymmetries. The number of tail observations $m$ that is used to estimate the tail indices is reported above the estimates. It can be seen that the distribution is fat-tailed, with indices either just above or below 4, depending on the percentile. This would even question the existence of the 4 th moment in the distribution and indicates that extreme expectations occur more often than would be normal. In other words, the number of expected changes that is extremely deviating from the mean expectation is such that we can state that market participants' beliefs are significantly dispersed and the assumption of a representative agent can be rejected.

A question that appears naturally is whether for a particular currency the market expects more upward trends than downwards trends. For instance, when a sufficiently large number of extreme expected upward changes occur relative to expected downward changes, then the right tail of the distribution should be significantly bigger than the left tail. We therefore use a two-sided $T$-test to formally test for equality of the left and right tail index estimates.

Hill (1975) shows that the statistic $\sqrt{m}(\gamma-\bar{\gamma})$ (where $\bar{\gamma}$ is the 'true', but unobservable Hill index) is asymptotically normally distributed $N\left(0, \bar{\gamma}^{2}\right)$. A two-sided test for the equality of the tail index estimates can therefore be based on the following $T$-statistic:

$$
T=\frac{\alpha_{l}-\alpha_{r}}{\sqrt{\operatorname{se}\left[\alpha_{l}\right]^{2}-\operatorname{se}\left[\alpha_{r}\right]^{2}}},
$$


Table 5.3: Hill Estimates (pooled sample)

\begin{tabular}{ccccccc}
\hline \hline & \multicolumn{2}{c}{3 month forecast horizon } & & \multicolumn{2}{c}{12 month forecast horizon } \\
\cline { 2 - 3 } \cline { 5 - 7 } & U.K. & Japanese & Euro & & U.K. & Japanese \\
Pound & Yen & & & Pound & Yen \\
\hline
\end{tabular}

a) Period 1989:10 - 1995:2

$\begin{array}{lrrrrrr}\text { 1th percentile } & m=63 & m=68 & m=71 & m=64 & m=69 & m=71 \\ \alpha_{l} & 3.682 & 5.981 & 4.917 & 4.846 & 6.383 & 5.460 \\ \alpha_{r} & 5.430 & 4.521 & 5.085 & 4.981 & 5.557 & 16.147 \\ T: \alpha_{l}=\alpha_{r} & 2.115^{* *} & -1.605 & 0.208 & 0.156 & -0.810 & 5.283^{* * *} \\ & & & & & & \\ \text { 5th percentile } & m=318 & m=344 & m=357 & m=321 & m=347 & m=357 \\ \alpha_{l} & 3.173 & 3.280 & 3.429 & 3.846 & 4.197 & 3.806 \\ \alpha_{r} & 3.372 & 3.368 & 3.274 & 4.138 & 3.823 & 5.168 \\ T: \alpha_{l}=\alpha_{r} & 0.768 & 0.348 & -0.618 & 0.925 & -1.226 & 4.009^{* * *} \\ & & & & & \\ 10 \text { th percentile } & m=636 & m=688 & m=715 & m=642 & m=695 & m=715 \\ \alpha_{l} & 2.403 & 2.837 & 2.719 & 2.908 & 3.393 & 3.136 \\ \alpha_{r} & 2.436 & 2.648 & 2.865 & 2.913 & 2.984 & 3.486 \\ T: \alpha_{l}=\alpha_{r} & 0.244 & -1.277 & 0.989 & 0.033 & -2.388^{* *} & 1.994^{* *}\end{array}$

b) Period 1995:11 - 2004:12

\begin{tabular}{|c|c|c|c|c|c|c|}
\hline 1th percentile & $m=11$ & $m=22$ & $m=22$ & $m=11$ & $m=22$ & $m=22$ \\
\hline$\alpha_{l}$ & 4.325 & 6.728 & 4.300 & 4.932 & 8.789 & 4.843 \\
\hline$\alpha_{r}$ & 3.858 & 5.989 & 6.271 & 6.557 & 3.048 & 8.794 \\
\hline$T: \alpha_{l}=\alpha_{r}$ & -0.268 & -0.385 & 1.216 & 0.657 & $-2.894^{* * *}$ & $1.846^{*}$ \\
\hline 5th percentile & $m=55$ & $m=110$ & $m=110$ & $m=55$ & $m=110$ & $m=110$ \\
\hline$\alpha_{l}$ & 3.428 & 3.487 & 3.435 & 2.958 & 5.390 & 3.992 \\
\hline$\alpha_{r}$ & 3.497 & 3.173 & 3.474 & 4.240 & 4.186 & 5.996 \\
\hline$T: \alpha_{l}=\alpha_{r}$ & 0.106 & -0.696 & 0.085 & $1.839^{*}$ & $-1.850^{*}$ & $2.917^{* * *}$ \\
\hline 10th percentile & $m=110$ & $m=221$ & $m=220$ & $m=110$ & $m=221$ & $m=220$ \\
\hline$\alpha_{l}$ & 2.568 & 2.744 & 2.949 & 2.658 & 3.270 & 3.041 \\
\hline$\alpha_{r}$ & 2.606 & 2.856 & 2.612 & 2.888 & 3.495 & 4.002 \\
\hline$T: \alpha_{l}=\alpha_{r}$ & 0.119 & 0.420 & -1.267 & 0.615 & 0.698 & $2.835^{* *}$ \\
\hline
\end{tabular}

Notes. This table gives the upper $\alpha_{r}$ and lower $\alpha_{l}$, tail index estimates for the 1, 5, and 10th percentile of the tails of the distribution of the individual expectations in excess of the crosssectional average. The $T$-statistic is for the equality of tails. $\mathrm{A}^{*}{ }^{* *}$, or ${ }^{* * *}$ refers to rejection of the null hypothesis that the tail index estimates are equal at a 10,5, or 1 percent significance level, respectively. ' $m$ ' refers to the number of tail observations that are included for the Hill estimates.

where the standard errors are approximated as follows:

$$
\mathrm{se}[\alpha]=\sqrt{\gamma^{2} / m} .
$$

Table 5.3 reports results from this $T$-test. We can only consistently reject the null hypothesis of equal tails for the 12-month-ahead forecasts of the Euro. For most other series do the tail indices look similar and hence may we assume that tails are symmetric here. The tail indices are in general also larger for the longer-term forecast horizons. In the next section we go a step further and question what the source of this dispersion is. 


\subsection{Asymmetric Information with Individual and Idiosyncratic Effects}

It remains a matter of debate whether dispersion of beliefs arise because market participants use different information sets whereby part of the information is private, whether they attach different weights to some elements of a common information set, or a combination of both. To deal with this question we should ideally look at evidence of dispersed beliefs for each market participant separately. Reconsider equation 5.7:

$$
d_{i, t}=g_{i}+\left(\epsilon_{i, t}-\bar{\epsilon}_{t}\right)
$$

Here, we assumed that the public information set $\Omega_{t}$ is common for all market participants. For this reason, it is unnecessary to know the exact structure of $f\left(\Omega_{t}\right)$. Since the random disturbance terms both have expected value equal to zero, the individual effect $g_{i}$ can be estimated from a regression of the individual forecasts in excess of the cross-sectional average on a constant. The significance of the $g_{i}$ term indicates whether individual effects are present for agent $i$, or in other words that this agent bases her forecasts on an informational set that is unique for this agent. ${ }^{7}$

We therefore estimate equation 5.7 using a least squares regression for each market participant. Since the forecast horizon is longer than the observational frequency, the error component in equation 5.7 will be serially correlated up to a moving average process of order $k-1$. While least squares estimates of equation 5.7 remain consistent in spite of the serially correlated residuals, the least squares standard errors are biased. Therefore, we adjust the standard errors nonparametrically using the procedure of Newey and West $(1987,1994)$, employing the Bartlett kernel. This correction will also be applied to all variations of this equation further on in the chapter.

Thus far this reasoning assumes that dispersion of beliefs arises due to differences in information sets, i.e. 'private' information. In addition to holding private information, it is reasonable to assume that although the remainder information may be common to all market participants, they interpret this information differently and hence attach different weights to its various elements. We call the different weights 'idiosyncratic effects.' Ito (1990) and MacDonald and Marsh (1996), for instance, regress the difference between the forecasts of agents on a set of variables that is possibly used in forming expectations, such that the difference in weight put on a certain variable in the expectation formation model is estimated directly.

We consider two models that may explain how market participants form their forecasts. First, we assume that agents follow a simple autoregressive forecasting rule, where they extrapolate the most recent trend in the exchange rate into the future. In essence this is a technical (or chartist) tool. Second, we assume that agents use an uncovered interest parity approach, where the expected change in the level of the exchange rate is related to the relative interest rate level of the

\footnotetext{
${ }^{7}$ In addition, if the difference in the individual effects of two individuals (say $i$ and $j$ ) is to be estimated, a similar method can be used: $s_{i, t}^{e}-s_{j, t}^{e}=g_{i}-g_{j}+\left(\epsilon_{i, t}-\epsilon_{j, t}\right)$. However, the estimation results are virtually identical to those of equation 5.7. These results are available on request.
} 
domestic and the foreign country. This is on its turn a more fundamentals-based approach. If the fit of a certain model of expectation formation is better for one agent compared to the other and vice versa, this is not only a direct proof of dispersion of beliefs, but it also lays bare the source of the dispersion, namely on which variables the agents put different weights. Audretsch and Stadtmann (2005) determine the optimal model for each agent by using the $R^{2}$ of these types of regressions. These statistics are informative in that they reveal to what extent the forecast is based on observable information. The remaining variance is then caused by other variables, such as psychological, experience, etc.

If market participants form forecasts in an extrapolative way, then

$$
s_{i, t}^{e}-s_{t}=g_{i}+\sum_{l=1}^{L} \beta_{l, i}\left(s_{t-l}-s_{t-l+1}\right)+\epsilon_{i, t},
$$

where $L$ is the number of lags that is used in the forecast. This equation is a specification to equation 5.4, where we have subtracted $s_{t}$ from both sides of the equality sign. In fact, we have imposed a structure for the unknown $f(\Omega)$. Following the same procedure as in equations $5.4,5.5$, and 5.7, we find that

$$
d_{i, t}=g_{i}-\bar{g}+\sum_{l=1}^{L}\left(\beta_{l, i}-\bar{\beta}_{l}\right)\left(s_{t-l}-s_{t-l+1}\right)+\epsilon_{i, t}-\bar{\epsilon}_{t} .
$$

In other words, the structural part of the information set and the values of the regressors are the same for all market participants, yet the coefficients (or weights) differ. We estimate equation 5.14 for all market participants. We use only two lags to preserve model parsimony, while still capturing most of the dynamics. Since we find that serial correlation usually does not extend beyond the second lag, we feel that this specification represents an extrapolative expectations model sufficiently.

We continue the analysis by questioning whether uncovered interest parity (UIP) has appeal as an empirical fundamental model for the formation of beliefs and whether market participants have idiosyncratic beliefs as to the importance in the relative level of interest rates. Uncovered interest parity assumes that the change in the level of the exchange rate over a period $k$ is related to the level of the $k$-period domestic interest rate relative to its foreign counterpart, such that

$$
s_{i, t}^{e}-s_{t}=g_{i}+\gamma_{i}\left(r_{t}-r_{t}^{*}\right)+\epsilon_{i, t},
$$

where $r_{t}$ is the $k$-period domestic interest rate and $r_{t}^{*}$ the $k$-period foreign interest rate. Following the same line of reasoning as under equations 5.4, 5.5, and 5.7, we can rewrite equation 5.15 as

$$
d_{i, t}=g_{i}-\bar{g}+\left(r_{t}-r_{t}^{*}\right)+\epsilon_{i, t}-\bar{\epsilon}_{t} .
$$

We measure $r_{t}$ and $r_{t}^{*}$ as the domestic and foreign interbank rates, respectively, using the 3 - and 12-month interbank rates for the two forecasting horizons. 
Table 5.4: Percentages Agents with Individual or Idiosyncratic Effects

\begin{tabular}{ccccccc}
\hline \hline & \multicolumn{2}{c}{3 month forecast horizon } & & \multicolumn{2}{c}{3 month forecast horizon } \\
\cline { 2 - 3 } \cline { 5 - 7 } & U.K. & Japanese Euro & & U.K. & Japanese Euro \\
Pound & Yen & & & Pound & Yen & \\
\hline
\end{tabular}

a) Period 1989:10 - 1995:2

Individual effect

$g_{i}-\bar{g} \neq 0$

43.33

37.01

37.87

50.00

49.69

58.29

Individual and idiosyncratic effect due to extrapolation

\begin{tabular}{|c|c|c|c|c|c|c|}
\hline$\beta_{i}-\bar{\beta} \neq 0$ & 22.00 & 9.74 & 14.20 & 32.24 & 13.21 & 29.71 \\
\hline$g_{i}-\bar{g} \neq 0$ & 44.00 & 35.71 & 39.64 & 52.63 & 42.14 & 57.14 \\
\hline$i-\bar{\beta} \neq 0$ and $g_{i}-\bar{g} \neq 0$ & 11.33 & 5.19 & 7.10 & 18.42 & 6.92 & 21.71 \\
\hline
\end{tabular}

Individual and idiosyncratic effect due to UIP

\begin{tabular}{|c|c|c|c|c|c|}
\hline$\gamma_{i}-\bar{\gamma} \neq 0$ & 24.00 & 26.62 & 26.63 & 34.87 & 38.99 \\
\hline$i-\bar{g} \neq 0$ & 33.33 & 39.61 & 30.77 & 43.42 & 55.97 \\
\hline$i-\bar{\gamma} \neq 0$ and $g_{i}-\bar{g} \neq 0$ & 19.33 & 15.58 & 9.47 & 23.02 & 27.04 \\
\hline
\end{tabular}

b) Period 1995:11 - 2004:12

Individual effect

$g_{i}-\bar{g} \neq 0$

31.03

29.03

32.26

44.83

61.29

48.39

Individual and idiosyncratic effect due to extrapolation

$g_{i}-\bar{g} \neq 0 \quad 27.59 \quad 29.03 \quad 29.03$

$\beta_{i}-\bar{\beta} \neq 0$ and $g_{i}-\bar{g} \neq 0 \quad 10.34 \quad 6.45$

48.28

35.48

48.39

9.28
0.00

61.29

54.84

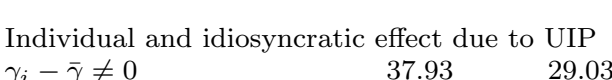

$g_{i}-\bar{g} \neq 0 \quad 31.03 \quad 35.48$

35.48

41.94

31.03

22.58

32.26

\begin{tabular}{lllllrr}
$\gamma_{i}-\bar{\gamma} \neq 0$ and $g_{i}-\bar{g} \neq 0$ & 17.24 & 19.35 & 25.81 & 20.69 & 25.81 & 25.81 \\
\hline Notes. This table presents the percentage of respondents for which we find significant individ-
\end{tabular} ual and/or idiosyncratic effects, i.e. the percentage of respondents for which we find significant coefficients from estimating equations 5.7, 5.14 and 5.16.

The results for equations 5.7, 5.14 and 5.16 are summarized in table 5.4. In this table we present the percentages of market participants for which we find individual effects, idiosyncratic effects with respect to an extrapolating model, and idiosyncratic effects with respect to uncovered interest parity, all compared to the cross-sectional average. Results are for Wald tests on the significance (on a 5 percent level) of the parameters or combinations thereof as to discriminate between the various effects.

For around 40 percent of the individual market participants we find evidence of individual effects on the short forecast horizon, that is when $g_{i}-\bar{g} \neq 0$. When the forecast horizon extends to one year, this percentage increases to around 50 percent. In the second sample period the percentages decrease to around 30 percent for the short horizon, but remain at 50 percent for the long horizon.

Furthermore, in addition to these individual effects, there is proof that a large group of market participants attach different weights on the information that is in the most recent history of the exchange rates. On average about 15 (20) percent of 
the market participants show idiosyncratic effects with respect to extrapolation (so $\beta_{i}-\bar{\beta} \neq 0$ ) in the short run for the first (second) sample period. ${ }^{8}$ This effect is more pronounced at the longer forecast horizon, for both sample periods and all exchange rates. The percentage of respondents with significant individual effects remains comparable after introducing the idiosyncratic extrapolation. The percentage of respondents that exhibit both individual and idiosyncratic extrapolation effects, so the ones for which $g_{i}-\bar{g} \neq 0$ and $\beta_{i}-\bar{\beta} \neq 0$ is in general considerably lower than the total effects, suggesting that respondents show either individual or idiosyncratic effects. The combination of both effects occurs more frequently for the longer horizon beliefs with up to 32 percent of the agents subject to both effects.

The percentage of respondents with significant idiosyncratic UIP effects is larger than extrapolation effects, implying that respondents' beliefs on the effect of the interest rate differential on the exchange rate are highly dispersed. Specifically, for the first period, we find that around 25 (40) percent of the respondents exhibit significant UIP effects for the short (long) horizon. For the second period, these percentages are both around 35 percent. The percentage of respondents with individual effects after including the idiosyncratic UIP effects is again comparable to the results without UIP effects. Contrary to the case of the idiosyncratic extrapolation effects, we find that the majority of respondents that have idiosyncratic UIP effects also have individual effects, that is the percentage of agents for which $g_{i}-\bar{g} \neq 0$ and $\gamma_{i}-\bar{\gamma} \neq 0$ is between 15 to 25 percent, also for the shorter forecast horizon.

A claim that is occasionally made with these types of expectation formation models is that when one particular model is examined in a single equation, the results may be affected by a missing variable bias. It is likely that agents use various models when forming a belief about the future instead of just one technique and therefore the omission of a set of variables in an equation with just a single explanatory variable may lead to this bias. In order to obviate this missing variable bias, we provide as a robustness test a combination of equations $5.7,5.14$ and 5.16 that contains individual effects and both technical (lags) and fundamental (interbank) information:

$$
d_{i, t}=g_{i}-\bar{g}+\sum_{l=1}^{L}\left(\beta_{l, i}-\bar{\beta}_{l}\right)\left(s_{t-l}-s_{t-l+1}\right)+\left(\gamma_{i}-\bar{\gamma}\right)\left(r_{t}-r_{t}^{*}\right)+\epsilon_{i, t}-\bar{\epsilon} .
$$

Again, we use two lags for $L$ and the standard errors are robust to the overlapping data problem. Estimation results for this equation are displayed in table 5.5.

The results for the combined test indicate that the results from the individual regressions in table 5.4 are not driven by missing variable bias: the percentages of dispersion of beliefs remain at a comparably high level. For the first period, the fraction of respondents with individual effects decreases somewhat compared to the results in table 5.4, from 40 to around 35 percent for the 3 -months horizon and from 50 to somewhat over 40 percent for the 12-months horizon. The dispersion vis-à-vis the extrapolation, on the other hand, increases, from 15 (20) to 20 (30) percent for the short (long) horizon. The same conclusion holds for the idiosyncratic UIP

\footnotetext{
${ }^{8}$ Beware that we used two lags in the specification of the extrapolation model. For the remainder of the chapter, we therefore mean with $\beta_{i}-\bar{\beta}$ a vector of both $\beta_{1, i}-\bar{\beta}_{1}$ and $\beta_{2, i}-\bar{\beta}_{2}$.
} 
Table 5.5: Percentages Agents with Individual or Idiosyncratic Effects (combined)

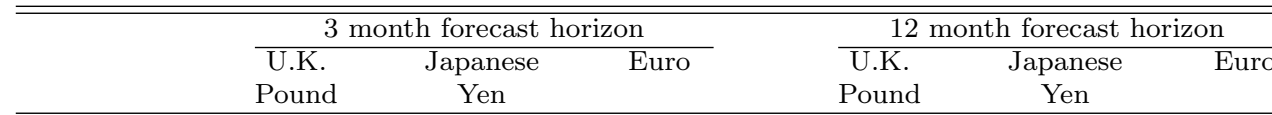

a) Period 1989:10 - 1995:2

$\begin{array}{lllllll}g_{i}-\bar{g} \neq 0 & 33.33 & 39.61 & 34.91 & 43.42 & 44.03 & 40.00 \\ \beta_{i}-\bar{\beta} \neq 0 & 25.33 & 14.29 & 20.12 & 36.84 & 22.64 & 32.57 \\ \gamma_{i}-\bar{\gamma} \neq 0 & 27.33 & 29.22 & 29.59 & 38.16 & 40.88 & 45.71\end{array}$

b) Period 1995:11 - 2004:12

\begin{tabular}{lrrrrrr}
$g_{i}-\bar{g} \neq 0$ & 17.24 & 29.03 & 35.48 & 31.03 & 41.94 & 51.61 \\
$\beta_{i}-\bar{\beta} \neq 0$ & 27.59 & 9.68 & 12.90 & 37.93 & 38.71 & 32.36 \\
$\gamma_{i}-\bar{\gamma} \neq 0$ & 34.48 & 29.03 & 38.71 & 27.59 & 48.39 & 32.26 \\
\hline
\end{tabular}

Notes. This table presents the percentage of respondents for which we find significant individual and/or idiosyncratic effects, i.e. the percentage of respondents for which we find significant coefficients from estimating equation 5.17.

effects: from 25 (40) to 30 (over 40) percent for the short (long) horizon. For the second period, we cannot draw any conclusions per effect, but we can per currency. For the U.K. Pound and the euro, we observe that all percentages decrease; for the Japanese Yen there is a positive tendency.

We look at various combinations of the hypothesis with respect to the three effects. Table 5.6 reports percentages of market participants for which at least one of the three effects has been identified and splits the sample up into subsets for which the indicated equality or inequality holds. ${ }^{9}$ The results corroborate what we found earlier. This is concluded from the fact that the highest percentages in table 5.6 can be found in the top three rows of each panel, i.e. the percentages of respondents with a single significant effect. This conclusion holds particularly for the first period, but can also be distilled for the second. Specifically, respondents that do combine two effects, combine the individual with the idiosyncratic UIP effect, or, to a lesser extent combine all three effects. Finally, in all three tables (5.4, 5.5 and 5.6) it comes forward that the individual effect is the most important source of dispersion, followed by the idiosyncratic UIP effect and, third, the idiosyncratic extrapolative effect.

We should mention two drawbacks of the above approach. First is the matter of variable selection. The exact set of variables that is commonly used to form beliefs is not known. Second, some of the variables used in forming beliefs are inherently unobservable, such as the state of mind of the agent during the expectation formation process, or even the weather condition at that particular time. Furthermore, the weight agents put on a certain variable might change through time (see, for instance, the scapegoat models in Bachetta and Van Wincoop, 2005). If beliefs are dispersed by definition, the adjustment of the weight given to a certain vari-

\footnotetext{
${ }^{9}$ For instance, $g_{i}-\bar{g} \neq 0, \beta_{i}-\bar{\beta}=0, \gamma_{i}-\bar{\gamma} \neq 0$ indicates the percentage of agents for which we find individual effects, idiosyncratic effects due to different weights for UIP, but no idiosyncratic effects with respect to different weights for the most recent change in the exchange rate (extrapolation).
} 
Table 5.6: Combinations of Effects

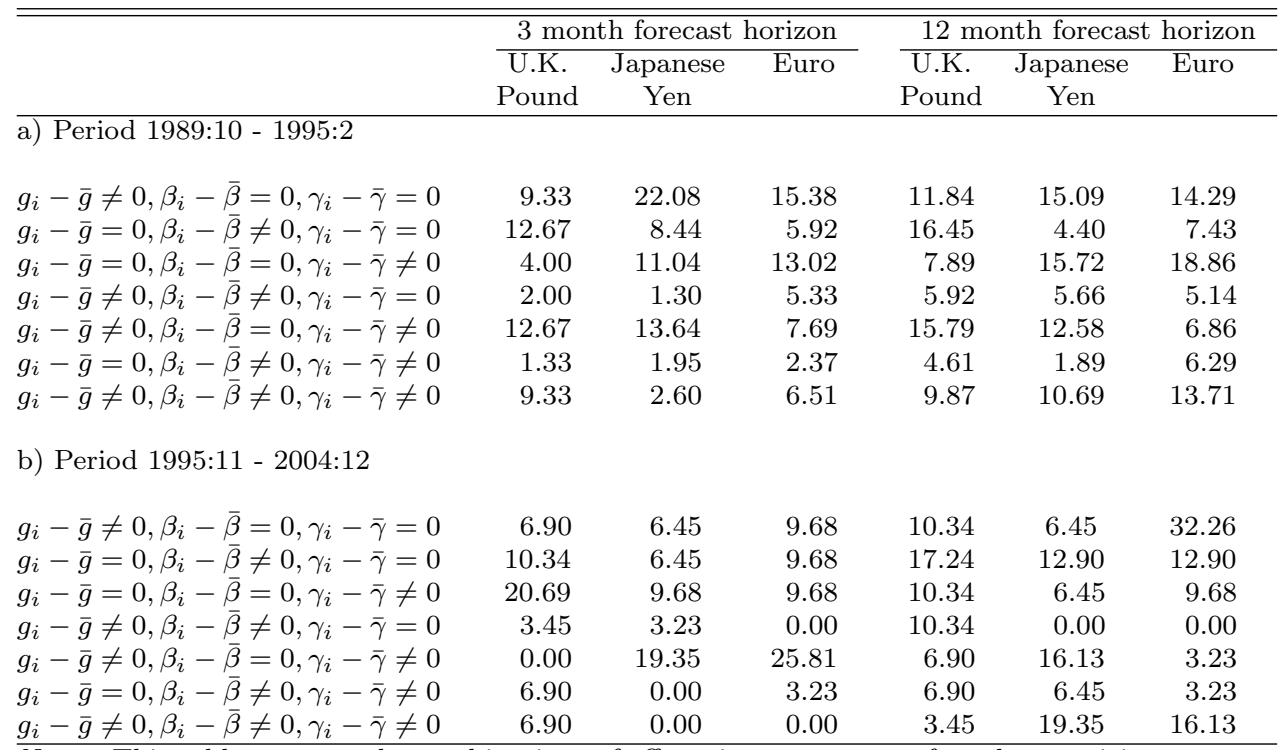

Notes. This table presents the combinations of effects in percentages of market participants.

able in the expectation formation process does not change simultaneously or equally among agents. Especially in these regression-based approaches this effect could lead to biased results, since it assumes a permanent difference in weight through time. Therefore, the question of whether beliefs are dispersed and if so, what the source of this dispersion is, should ideally be approached from various angles.

In this section we have examined the question of what the source of dispersion of beliefs is. Using various techniques we showed that the dispersion of beliefs arises both due to the existence of individual effects and idiosyncratic effects, where market participants attach different weights to variables that are observed by all market participants contemporaneously. In the next section we attempt to find a relationship between the dispersion of beliefs are certain market characteristics.

\subsection{Dispersion of Beliefs and Market Conditions}

In the previous section we have shown that the dispersion in beliefs is caused by the fact that market participants hold private information and that they attach different weights to the various elements from the set of common information. The next step is to see whether the degree of dispersion is in any way linked to market characteristics. So, contrary to the previous sections where we compared forecasts vis-à-vis each other and the consensus, we will now study the degree of dispersion vis-à-vis the market itself. To be more specific, we will examine the relation between dispersion and market uncertainty, measured by volatility and extreme values.

The heterogeneous expectations literature indicates that there is a direct causal 
relation running from dispersion of beliefs to market volatility. ${ }^{10}$ However, it also provides us with contrasting hypotheses concerning the sign of the effect. As the market price is moving away from the fundamental price, there is a negative relation between dispersion and market volatility because the expectations of the different groups are opposite to each other. ${ }^{11}$ As the market price moves more and more away from the fundamental price, the fundamentalists get driven out of the market. The technical analysts remain active, continue to push the market price away from the fundamental price and increase market volatility as the number of technical analysts increases and their expectations become self-fulfilling.

If the market price is moving towards the fundamental price, however, there is a positive relation between dispersion and volatility as the different groups expect similar directions of change. In this situation volatility is rising as all traders active on the market push the price in the same direction; there is no counter acting force which is active when the price is moving away from the fundamental price and fundamentalists are still active. Both groups remain active as both strategies are profitable.

De Grauwe and Rovira Kaltwasser (2007) illustrate the relation between dispersion of beliefs and extreme values in exchange rate returns. In their model, agents disagree on the value of the fundamental exchange rate. It is shown, in a simulation setup, that the distribution of returns exhibits heavier tails as the dispersion of beliefs about the true value of the fundamental rate is larger. This is caused by the fact that the exchange rate jumps between fundamental equilibria; as the distance between equilibria is larger, returns will automatically show more extreme values.

The market microstructure literature provides another mechanism by which dispersion of beliefs affects the volatility in the market. Evans and Lyons (2002) argue that high turnover in markets reflects great dispersion of opinions among traders. A number of authors have looked into this relation empirically. MacDonald and Marsh (1996) examine the relation between trader heterogeneity and trading volume, with the same survey dataset as us, and find a significant positive relation. Frankel and Froot (1990a) conclude, from surveys conducted by Money Market Services International and The Economist, that dispersion of opinion affects the volume of trade and thereby also market volatility.

We first study whether there is a relation between dispersion of beliefs and market conditions, and, second, in which direction the relation is causal. The relation is examined by splitting the sample in a high- and a low-dispersion sub-sample and testing the difference between the market conditions (i.e., volatility and heavy tails). Causality, on its turn, is studied by applying a (modified) Granger causality test.

First, we examine the general relation between dispersion of beliefs and volatility in table 5.7. Dispersion of beliefs is measured by the coefficient of variation; high (low) dispersion implies higher (lower) than average dispersion. Volatility is measured by the sample variance; heavy tails by the kurtosis and the Hill index. Overall, the results imply that uncertainty is significantly larger in periods with

\footnotetext{
${ }^{10}$ See Hommes (2006) for an extensive survey.

${ }^{11}$ Fundamentalists expect the price to return to the fundamental rate while technical analysts expect the price to continue to move in the direction it has been moving in the previous periods.
} 
Table 5.7: Dispersion and Market Characteristics

\begin{tabular}{|c|c|c|c|c|c|c|c|}
\hline & \multicolumn{3}{|c|}{3 month forecast horizon } & \multicolumn{3}{|c|}{12 month forecast horizon } \\
\hline & & $\begin{array}{l}\text { U.K. } \\
\text { Pound }\end{array}$ & $\begin{array}{c}\text { Japanese } \\
\text { Yen }\end{array}$ & Euro & $\begin{array}{l}\text { U.K. } \\
\text { Pound }\end{array}$ & $\begin{array}{c}\text { Japanese } \\
\text { Yen }\end{array}$ & Euro \\
\hline \multicolumn{8}{|c|}{ a) Volatility } \\
\hline \multicolumn{2}{|l|}{ Low } & 0.00039 & 0.00094 & 0.00077 & 0.00041 & 0.00092 & 0.00093 \\
\hline \multicolumn{2}{|l|}{ High } & $0.00138^{* * *}$ & 0.00128 & $0.00121^{* *}$ & $0.00135^{* * *}$ & $0.00134^{*}$ & 0.00098 \\
\hline \multicolumn{8}{|c|}{ b) Kurtosis } \\
\hline \multirow{2}{*}{\multicolumn{2}{|c|}{$\begin{array}{l}\text { Low } \\
\text { High }\end{array}$}} & 2.626 & 2.699 & 2.115 & 3.918 & 2.471 & 3.419 \\
\hline & & $5.797^{* *}$ & 4.175 & 3.714 & $6.334^{* *}$ & $4.275^{*}$ & 3.043 \\
\hline \multicolumn{8}{|c|}{ c) Tail index (Hill) } \\
\hline \multirow[t]{3}{*}{ Low } & 1st percentile & 301.058 & 42.445 & 12.164 & 3.133 & 4.187 & 10.381 \\
\hline & 5th percentile & 9.030 & 6.130 & 7.731 & 4.245 & 6.549 & 5.265 \\
\hline & 10th percentile & 4.412 & 5.177 & 7.535 & 3.374 & 4.508 & 3.961 \\
\hline \multirow[t]{3}{*}{ High } & 1st percentile & 3.303 & 15.273 & 5.661 & 3.303 & 15.272 & 6.236 \\
\hline & 5th percentile & $1.846^{*}$ & 3.089 & 3.512 & 1.619 & 3.871 & 3.105 \\
\hline & 10th percentile & 1.807 & 2.395 & 3.572 & 1.932 & 3.230 & 3.648 \\
\hline
\end{tabular}

Notes. This table displays the characteristics of the FOREX returns for sub-samples with low and high dispersion of beliefs (coefficient of variation smaller or larger than the mean coefficient of variation). The cut-off points for the Hill index are taken at the 1st, 5th, and 10th percentile. a ${ }^{*},{ }^{* *}$, and ${ }^{* * *}$ denotes a significant difference between low and high dispersion at the 10,5 and 1 percent level, respectively.

high dispersion compared to periods with low dispersion. Volatility is always higher during high dispersion periods; this is significant in four out of six cases. Kurtosis is higher during high dispersion periods in five out of six cases; three times significant. The tail index is consistently lower (i.e., tails are heavier) for all three cut-off points for high dispersion periods. ${ }^{12}$

Second, we study the causal relation between market volatility and dispersion by means of Granger causality tests. Our approach is particularly useful in that we consider a long time period, we use different measures of dispersion and volatility, and we focus on the causality question instead of correlations. In the previous sections we argued that dispersion can be measured in various ways. Similarly, volatility can be quantified by several different methods. Altogether, we examine six different dispersion-volatility measure combinations in order to check the robustness of the results. The causal relation between dispersion and extreme values could be examined by determining the conditional kurtosis. We choose not to do so, however, because Bollerslev (1987) shows that the conditional kurtosis is a constant fraction of the conditional volatility. Brooks et al. (2005) propose a model with time-varying degrees of freedom for the $T$-distribution used in a TGARCH setup. However, De Haan et al. (1989) note that ARCH-type processes generate heavy tailed

\footnotetext{
${ }^{12}$ The difference between high dispersion and low dispersion tail indices is hardly significant as a result of the relatively low number of observations on which the tail index is based.
} 
distributions, such that it is sufficient in our case to focus solely on the conditional variance.

In a standard setup, with two series $x$ and $y$ a Granger-causality test examines whether, after controlling for lagged $y$, lagged $x$ help to forecast $y_{t}$. In case the lagged $x$ are significant, $x$ is said to Granger-cause $y$, which gives an indication concerning the causality between $x$ and $y$ instead of merely the correlation. The setup of the standard Granger test is slightly altered here. In our analysis, in the case of dispersion as the dependent variable, we do not use the lagged but the contemporaneous value of market volatility. ${ }^{13}$ The reason for this is that dispersion at time $t$ is formed at the end of the month, when forecasts are submitted, and concerns forecasts for the future month(s). Volatility at time $t$, on the other hand, is formed during that past month (given that $t$ is measured in months). Therefore, including the contemporaneous value of volatility is informative in the causality question; excluding it would imply dismissing one month of information.

Since this analysis does not require a time-series in the strict sense, it is possible to use the total sample, from October 1989 to December 2004, with a gap of six months in 1995, which are 175 monthly observations. For the U.K. Pound we only use the first set (1989-1995) since the second set contains two-monthly observations. The three and twelve month forecasts are available for the total sample. We focus on the first and second lag of the Granger causality test as we assume that there is no relation between the variables over periods longer than two months. The general framework is thus:

$$
\begin{aligned}
y_{t} & =\alpha_{0}+\beta_{1} y_{t-1}+\beta_{2} y_{t-2}+\gamma_{1} x_{t-1}+\gamma_{2} x_{t-2}+\epsilon_{t} \\
x_{t} & =\alpha_{1}+\beta_{3} x_{t-1}+\beta_{4} x_{t-2}+\gamma_{3} y_{t-1}+\gamma_{4} y_{t-2}+\epsilon_{t}
\end{aligned},
$$

where we reject the null hypothesis that $x$ does not Granger-causes $y$ if the statistic from an $F$-test for joint significance of $\gamma_{1}$ and $\gamma_{2}$ is significant (and a similar reasoning for the inverse Granger-causality from $y$ to $x$ ). The dispersion measures $(x)$ are the coefficient of variation and the high-minus-low range. The volatility measures (y) are the monthly absolute returns, the monthly squared returns and a GARCH measure. ${ }^{14}$ Since all variables are not normally distributed, especially the absolute and squared returns, we apply a Box-Cox adjustment to both the left and right hand side variables.

Table 5.8 presents the results for the three exchange rates. For the Euro, looking at the absolute and squared returns for the three-month horizon, we find a significantly positive causal relation running from the variance to dispersion for both dispersion measures. The twelve months horizon gives a more mixed image. For the coefficient of variation we find similar results as for the three months expectations, but concerning the range we find positive significant results running from the heterogeneity to the variance.

The GARCH volatility measure renders a different image altogether. For the three months horizon we find, for both dispersion measures, a significant causal

\footnotetext{
${ }^{13}$ Plus lagged values of volatility (if necessary) and dispersion itself.

${ }^{14}$ The GARCH measure was constructed by estimating a $\operatorname{GARCH}(1,1)$ model for daily data and taking monthly averages of the daily conditional volatilities.
} 


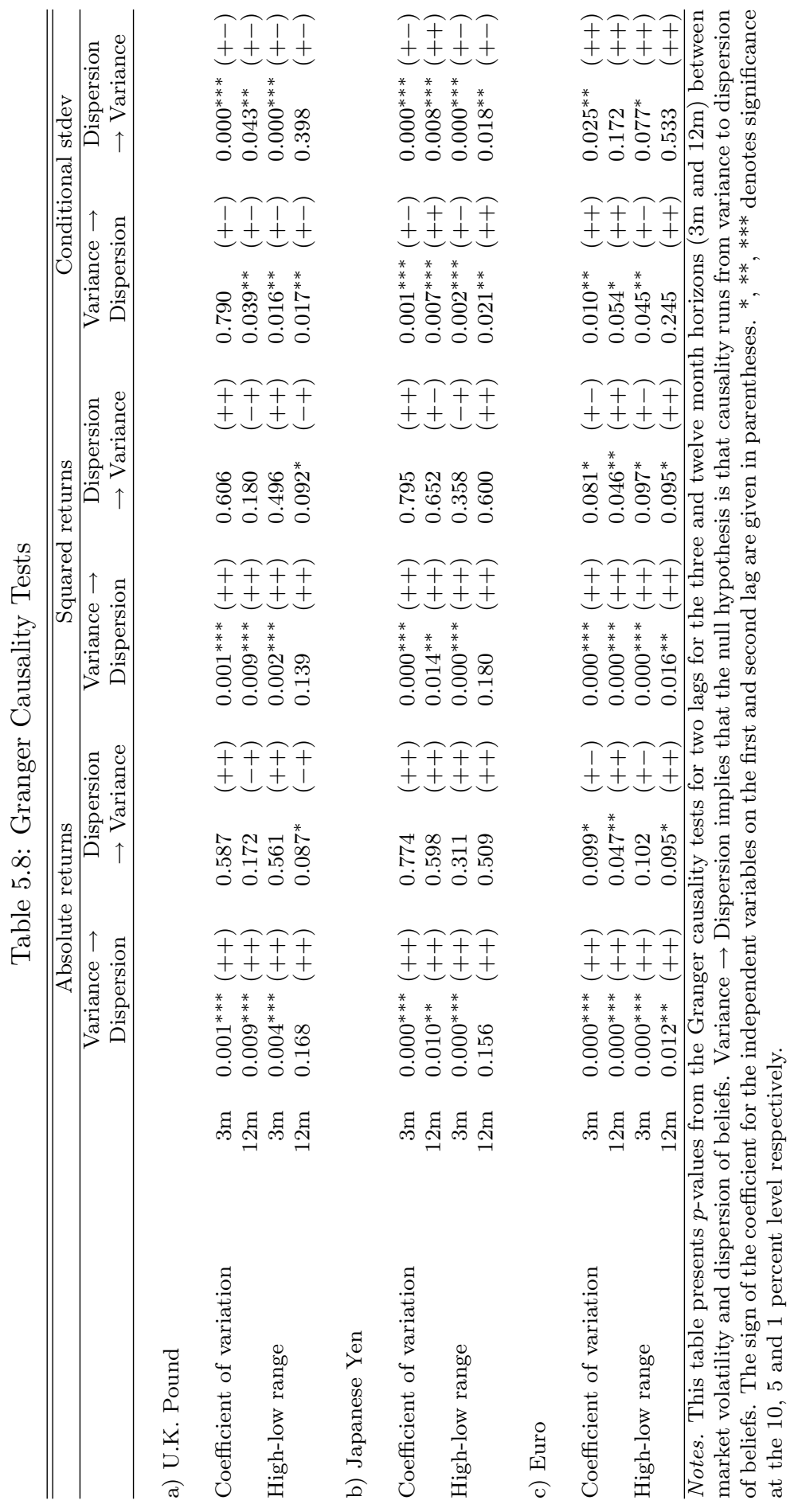


relation running from trader heterogeneity to market uncertainty; positive for the first lag, negative for the second. For the twelve months horizon we find a similar pattern, but in the opposite causal direction.

For the Japanese Yen we see a significant positive causal link from the market variance to dispersion for both dispersion variables and horizons, at least when variance is measured by absolute and squared returns. In the case of the GARCH measure we find a two-way causal relation for both dispersion measures and horizons. The signs are in general positive for the first lag, negative for the second for the three months horizon and both positive for the twelve months horizon.

The results for the U.K. Pound, finally, reflect a relatively homogeneous conclusion. For all variance and dispersion measures we find a significantly positive causal link from market uncertainty to dispersion of opinion. For a small number of combinations we find a two-way relation, but there does not seem to be a pattern.

In general we can conclude that the causal relation between market volatility and trader dispersion tends to be significant and positive for different measures of both trader heterogeneity and market volatility. This result corroborates the findings of MacDonald and Marsh (1996) but is opposite to the results of Frankel and Froot (1990a), who find causality running in the opposite direction. Furthermore, the results are not in line with the theoretical predictions that dispersion affects volatility. This might be caused by the fact that we do not have data for the total market, but only a subset of traders. Since our traders are relatively homogeneous in nature (most of them are financial institutions based in London), our observations of trader heterogeneity might be biased downward. Given that we observe a subset of the total set of traders who cannot influence the market significantly, current uncertainty can cause uncertainty concerning the future, hence relatively diverse expectations.

\subsection{Conclusions}

In this chapter we examined whether expectations of future exchange rates are dispersed in that agents have different beliefs about the future path of the exchange rates. We approach this problem using a panel of survey forecasts for the major three exchange rates along several forecast horizons. Using several measures for dispersion of beliefs we find that there are distinct periods of high and low dispersion where market participants disagree as to what will happen to the future level of the exchange rates. For the Japanese Yen versus the U.S. Dollar we even find that the Asian crisis that began in mid-1997 preceded an almost two-year period of highly increased dispersion of beliefs for this rate.

We test formally whether beliefs are dispersed using an extreme value approach by examining the tail index estimates and conclude that the frequency at which extremist differences in expectations among market participants occurs, is higher than that what would occur under normality. We furthermore attempt to answer whether dispersion of beliefs occurs because market participants hold different information sets or whether they attach different weights to commonly-held elements from their 
information sets. We find evidence for both. The extent of individual expectations seems to increase as the forecast horizon lengthens. The dispersion based on extrapolation decreases and dispersion based in interest rate differences increases as the forecast horizon lengthens. These results corroborate the fundamentalist/chartist literature.

Finally, we examine whether dispersion of beliefs is influenced by volatility in the market, as suggested earlier by the increased dispersion of beliefs in the aftermath of the Asian crisis, or that heterogeneity in expectations is causal to the volatility in the market. We find that a causal relation between market volatility and trader heterogeneity tends to be significant and positive for different measures of both trader heterogeneity and market volatility.

Several issues remain unanswered. First of all, we question what the role of different 'types' of market participants is in the above analysis. We find different weights in different forecast horizons, but when one group of market participants uses an extrapolative, or any other chartist way of forecasting, and another group uses a fundamentals-based approach, we would like to see whether the number of 'chartists' versus 'fundamentalists' is related to market uncertainty or dispersion of beliefs. Second, we question whether market participants switch between various forecasting techniques (for instance, chartist or fundamentalist approaches) when the market becomes more volatile, and hence dispersion of beliefs increases. We feel that further investigation of these issues is warranted. 



\section{Chapter 6}

\section{The Use of Fundamentalist and Chartist Techniques in Forecasting Foreign Exchange*}

\subsection{Introduction}

The role of individual market participants in the international foreign exchange market is a topic of enduring interest. For many years, the international financial economics literature has assumed that these market participants form their expectations about the future of the exchange rate in a rational way, without making consistent biases in their expectations and where all publicly available information is used in an optimal manner. All market participants were assumed to possess essentially the same information. In this literature, the typical market participant is a representative agent that uses the information in the most optimal way.

Yet, the assumption of rational representative agents has not been satisfactory in answering some of the well-known anomalies in the literature, such as the excess volume of trade. Beine et al. (2007), Chionis and MacDonald (1997), Frankel and Froot (1990a) and MacDonald and Marsh (1996) find causal relationships between, on the one hand, the volume traded, the volatility in the market and the extent of central bank intervention, and on the other hand the dispersion in the expectations of individual market participants. At the same time, the assumption of rational expectations has been refuted in many empirical studies, for example those of Cavaglia et al. (1993b), Chinn and Frankel (1994a), Dominguez (1986), MacDonald (1992), MacDonald and Marsh (1994), Marsh (1999), and Verschoor and Wolff (2002).

The use of behavioral theory in mainstream finance literature has gradually led

* Part of this chapter is from a working paper with Remco Zwinkels. 
to the assumption that market participants in the foreign exchange market are not homogeneous, but possess heterogeneous beliefs due to 1) the use of private information, 2) interpreting information in a different way and thus putting different weights on various elements in the agent's information set, or 3) by using fundamentally different types of forecast techniques. For the foreign exchange literature specifically, the distinction between chartist agents and fundamentalist agents has often been made (see, e.g. Frankel and Froot, 1987b; De Grauwe and Grimaldi, 2005, 2006; Hommes, 2006) whereby the former tries to make a forecast about the future state of the market by means of any function of past (usually macroeconomic) variables, and whereby the latter relies on forecasts based on the past history of the exchange rate itself.

Two important observations are made in the literature. First, a single agent cannot be characterized as purely chartist or fundamentalist. In a series of surveys conducted among market participants Allen and Taylor (1990), Taylor and Allen (1992), Menkhoff and Taylor (2006), Liu and Mole (1998), and Cheung and Chinn (2001) find that most agents use a combination of chartists and fundamentalists techniques when forming a belief about future exchange rates. Second, the weight that agents attach to a particular forecast technique is not constant over time. Yet, empirically there is very little known about the way agents choose among the various forecast techniques. The heterogeneous agent literature tells us for instance that agents switch between forecasting techniques according to the relative past performance of the techniques (see, e.g. De Grauwe and Grimaldi, 2005, 2006; Hommes, 2006). It has furthermore been documented that when the exchange rate deviates further away from its 'fundamental' value, market expectations are mean-reverting towards this fundamental value. However, we do not know much about how the beliefs of individual market participants are affected in times of high market volatility, or pre-crises periods. More insight into the beliefs of market participants might shed new light onto these events.

In this chapter we attempt to investigate the relative importance of the role of both chartist- and fundamentalist-based forecast techniques. In particular, we would like to know whether the weight agents attach to a certain forecast tool changes over time and why this change occurs. In contrast to all earlier work we approach this question from an empirical angle. That is, we do not take a simulation approach, nor use a qualitative approach based on sentiment surveys. Instead, we try to observe the actual use of particular techniques from the data itself. To do so, we use data from a quantitative survey of exchange rate expectations, conducted among large players in the foreign exchange market. From this survey data we attempt to distill the common time-varying weight that the market attaches to a particular forecast technique, and question what the relation between the weights on the various techniques is. We expect that although market participants use both chartist and fundamentalist rules, there will be a negative relation between the weights on chartist and fundamentalist rules.

Our results are easily summarized. We find that although both chartist and fundamentalist rules are used by the market, the chartist rules are more often significant than the fundamentalist rules, especially on the shorter spectrum of the forecast 
horizon. Furthermore, extrapolative forecast techniques have preference over moving average rules, while the market is fairly irrespective as to which fundamentalist rule is used.

The remainder of this article is organized as follows. In section 6.2 we introduce the general methodology that will be used in this chapter. Section 6.3 then looks at the various forecasting rules that are used by different types of market participants. Section 6.4 presents the data that will be used for this research and presents already basic features of the data. Section 6.5 gives the results of the various tests and section 6.6 concludes.

\subsection{Methodological Background}

We start the methodology that will be used in this chapter from the point of view of the individual agent. We hypothesize that agent $i$ forms an expectation about the $k$-period ahead level of a particular exchange rate and that this forecast consists of a structural part based on public information (that is common to all market participants) $f\left(\Omega_{t}\right)$ and an individual effect $g_{i}$. This expectation, which by itself is unobservable, can then be given as

$$
s_{i, t+k}^{E}=f\left(\Omega_{t}\right)+g_{i},
$$

Observe that in this specification the information set $f\left(\Omega_{t}\right)$ is common for all market participants. Equation 6.1 states that market participants interpret the information set that is common to them in a similar way and that the difference in their expectations is caused solely by the agent-specific individual effect, which is usually attributable to an informational asymmetry (for instance, private information). From the previous section we know that differences in expectations may not only be due to informational asymmetries, but also due to the different weight that agents attach to individual elements from this common information set, or by the presence of fundamentally different market participants; both cases in which $f\left(\Omega_{t}\right)$ should be replaced by $f_{i}\left(\Omega_{t}\right)$.

To investigate the latter possibility, assume that an agent has a set of forecast rules from which she can choose to form her expectations about the future change in the exchange rate. An agent may use only one specific rule from that set, in which case she attaches all weight to the forecast of that rule, or multiple rules at the same time, in which case the final forecast will be a weighted average of the forecasts of the multiple rules. Although we cannot determine the exact set of rules a particular agent uses at a certain point in time, we can measure whether the agent uses a particular rule in the process of forming her expectations when her expectation is related to the forecast of a particular rule. Furthermore, we can observe whether the weight that the agent attaches to that rule changes over time. The individual forecasted change by agent $i$ is determined as

$$
s_{i, t+k}^{E}-s_{t}=\omega_{i, t}^{\prime}\left(s_{t+k}^{E}-s_{t}\right),
$$


where $\omega_{i, t}^{\prime}=\left(\omega_{i, t}^{1}, \omega_{i, t}^{2}, \omega_{i, t}^{3}, \ldots\right)$ is a vector of individual weights and $s_{t+k}^{E}-s_{t}$ is a vector of the forecasted changes of the various forecast rules. The time-varying coefficients $\omega_{i, t}$ are allowed to follow a process like:

$$
\omega_{i, t}=\alpha_{i} \omega_{i, t-1}^{\prime}+\eta_{i, t},
$$

where $\eta_{i, t}$ is treated as an individual random shock.

In order to investigate how the common factor in the weights that all individual agents attach to a particular rule changes over time, we can suppress the individual agent subscript and focus on the following equation:

$$
\bar{s}_{t+k}^{E}-s_{t}=\omega_{t}^{\prime}\left(s_{t+k}^{E}-s_{t}\right) .
$$

Here, $\bar{s}_{t+k}^{E}-s_{t}$ may present an expected change in the market that is common for all market participants. An obvious candidate for this common expectation would be the principal component in all the individual expectations, or even the mere crosssectional average of median. In the next section, we will look at various ways to determine the forecasted changes $s_{t+k}^{E}-s_{t}$.

\subsection{The Forecasting Rules}

In this section we outline the various techniques that can be used by an agent to form her forecast. The list of techniques is virtually endless and therefore we focus on a few approaches that have been used in the literature regularly. We distinguish between fundamentals-based forecast rules and chartist (or technical) rules. The former uses a set of macroeconomic variables in one way or the other, while the latter uses exclusively the history of the exchange rate as the input in the forecasting process. For fundamentals-based rules we use a purchasing power parity-based technique and version of the monetary. As for the chartist rules we use an extrapolative rule and a moving average rule. The rules will be outlined below in greater detail.

We assume that fundamentalists form their expectations by comparing the current exchange rate to the fundamental exchange rate and expect that the exchange rate will eventually revert back to its fundamental value. So when the current exchange rate is above its long-run fundamental value, fundamentalists expect a future depreciation of the currency. In this sense this rule can be seen as a negative feedback rule that introduces a mean reversion in the exchange rate. We describe the general fundamentalist rule as

$$
\text { fund }_{t} \equiv-\psi\left(s_{t}-\tilde{s}_{t}\right)
$$

where fund $_{t}$ is the $k$-period ahead expected change in the exchange rate, $\psi$ is a parameter describing the speed with which the exchange rate will revert back to its fundamental value, and $\tilde{s}_{t}$ is the measure for the fundamental exchange rate.

This fundamental exchange rate is the rate that is consistent with the equilibrium in the real part of the economy. There is usually not something like 'the' fundamental exchange rate, rather it is the rate that is in line with an economic 
theory and is generally driven by the relative macroeconomic variables of at least the two economies for which the exchange rate applies. Since most macroeconomic variables only change gradually over time, it is expected that the fundamental exchange rate, being a function of these variables, also changes only gradually. It must be stressed that, in contrast to other work in the field, we do not assume that agents are able to observe the underlying value of the fundamental exchange rate. Rather, they must rely on an estimate of this value and to do so they can choose from a set of models. These will be outlined shortly.

The chartists form their forecasts by either extrapolating the most recent change in the exchange rate into the future:

$$
\operatorname{char}_{t} \equiv \beta\left(\Delta s_{t}\right)
$$

where $\beta$ indicates the degree to which chartists extrapolate and $\Delta s_{t}$ is the most recent change in the exchange rate. Alternatively, chartists follow a moving average rule, where the most recent short-run moving average in the exchange rate is compared to the moving average over a longer period ago. When the short-run moving average is above (below) its long-run moving average, agents expect the domestic currency to appreciate (depreciate) relative to the foreign currency:

$$
\operatorname{char}_{t} \equiv \gamma\left(M A_{t}^{s}-M A_{t}^{l}\right),
$$

where $M A_{t}^{s}$ denotes the short term moving average and $M A_{t}^{l}$ the moving average over a longer time period. It remains of course questionable how long the two time periods should be. In line with previous work we set $M A_{t}^{l}$ equal to the moving average over the last 6 months and for $M A_{t}^{s}$ we use the moving average over the most recent month.

The expectation of an individual agent $i$ about the future change in the exchange rate is then assumed to be formed as the weighted average of the fundamental and the chartist forecast rule:

$$
s_{i, t+k}^{E}-s_{t}=\omega_{i, t}^{f} \text { fund }_{t}+\omega_{i, t}^{c} \operatorname{char}_{t} .
$$

The weights attached to fundamentalist and chartist beliefs is often believed to be dependent on the relative success of each type of forecasting rule. When in a particular period chartists forecasts have done well, the subsequent period the weight given to chartist techniques will be increased.

These specifications of the fundamentalist and chartist rules are by far the most commonly used heuristics for modeling agents' behavior. Albeit that the rules are all simple, they are by no means unrealistic. For many years economic research has been centralized around fully rational, homogeneous representative agents, who are assumed to know a great deal about the structure of the economy. Gradually, the heterogeneous agent literature has departed from this assumption. It is argued that it is unreasonable to assume that economic agents possess skills and structural knowledge that no human being can possess. Instead, agents only have limited cognitive abilities to process information and therefore rely on these simple heuristics. Furthermore, it is argued that the beliefs of agents are dispersed because they 
all have different information sets from which they form their beliefs or that they interpret common information differently.

When we replace the unknown individual expectations by the survey-based forecasts, while allowing for a random measurement error $\epsilon_{i, t}$ such that

$$
s_{i, t+k}^{e}-s_{t}=s_{t+k}^{E}-s_{t}+\epsilon_{i, t}
$$

then we end up with the equation

$$
s_{i, t+k}^{e}-s_{t}=\omega_{i, t}^{f} \text { fund }_{t}+\omega_{i, t}^{c} \operatorname{char}_{t}+\epsilon_{i, t} .
$$

Since the fundamental exchange rate is an unobserved variable, we propose two approaches of how it can be estimated. We use a purchasing power parity-based rule where the fundamental exchange rate is related to the difference in the price level between two countries and we use a version of the monetary model where we consider a larger set of macroeconomic variables. We will describe both in greater detail later.

The common components of these time-varying weights are represented as $\omega_{t}^{f}$ and $\omega_{t}^{c}$. To extract the time-varying common weights we use two techniques. First, we take the cross-sectional average of the various $s_{i, t+k}^{e}-s_{t}$ series from the entire set of individual agents. Second, we determine the principal component from this set. Both measures we will denote as $\bar{s}_{t+k}^{e}-s_{t}$. In section 7.5 we describe these techniques in greater detail.

\subsubsection{Purchasing Power Parity}

The theory of purchasing power parity (PPP), at least in its absolute version, predicts that the exchange rate is a function of only the difference in the price levels of the home and foreign country. The debate regarding the usefulness of PPP as a way to describe the exchange rate is a long standing one. Taylor and Taylor (2004) review the PPP debate over the last decades and conclude that although the consensus view is that in the short run PPP does not hold, in the long run PPP may hold in that exchange rates do revert to a certain level that is determined by the relative price level and that the rate of reversion is slow, at best three to five years.

When exchange rates are expressed as units of foreign currency per unit of domestic currency, then the PPP-based fundamental exchange rate can be described by the following relation:

$$
\tilde{s}_{t}=p_{t}-p_{t}^{*},
$$

where $p_{t}$ is the log of the domestic country's price level in the domestic currency and $p_{t}^{*}$ denotes it's foreign counterpart (United States). ${ }^{1}$ Unfortunately, most measures of price levels that are issued by statistical agencies are of little use in constructing these PPP-based fundamental exchange rates, because they are typically reported as indexes relative to a base year and thus they do not measure the absolute price

\footnotetext{
${ }^{1}$ Throughout the rest of the chapter an asterisk always denotes the 'foreign' country; in our case this is the United States.
} 
level at a particular point in time. Therefore, we can only use the price level relative to the previous period's level. If we define $\pi_{t} \equiv p_{t}-p_{t-1}$ as the domestic inflation rate with pt as the price level in natural logarithms, and we define the foreign rate of inflation similarly, then the PPP-based fundamental exchange rate, $\tilde{s}_{t}$, can be given by the recursive equation

$$
\tilde{s}_{t}=\tilde{s}_{t-1}+\pi_{t}-\pi_{t-1} .
$$

We assume that at time $t$ agents can observe the current price level $p_{t}$ (whether or not as an index) and hence can determine what the inflation over the past period, $\pi_{t}$, was. The initial value for the fundamental exchange rate, $\tilde{s}_{0}$, is unknown and therefore has to be either estimated or imposed, in order to determine the value for the contemporaneous PPP-based fundamental spot rate in the entire sample period. We therefore proceed as follows. We take the period of January 1975 through September 1989 as the period in which we want to calibrate the fundamental series. The initial value of the fundamental rate is determined in such a way that the sum of the squared differences between the actual spot rate series and the fundamental series is minimized during this sample period. This gives us an estimate for the value of $\tilde{s}_{t}$. Instead of keeping the initial value constant for the rest of the sample period, we update the initial value for each subsequent sample period, such that we get for all values of the fundamental series using all information that is available at that time. In this way the exchange rate oscillates around its fundamental value.

Although there is no reason why the fundamental series we obtain accordingly would reflect more accurately the actual, yet unknown fundamental series, we do belief that by this approach the fundamental exchange rate we get accordingly retains the characteristics that such a fundamental value should have. For instance, it is reasonable to assume that the exchange rate oscillates around its fundamental value, provided that the time period in which we would observe this oscillating behavior is large enough, since in the long run exchange rates do revert to a certain level that is determined by the relative price level (Taylor and Taylor, 2004). It must be remarked that in the end the initial value only serves as a constant scaling factor in equation 6.12 and thus the approach described above is merely intended for a better visual comparison of the exchange rate and its fundamental counterpart.

\subsubsection{Monetary Model}

The next approach looks at a broader set of macroeconomic variables. We select four sets of macroeconomic variables that historically have been brought into context with the exchange rate. These are the price level, interest rate, money supply, and production, both for the home and foreign (U.S.) country. To give an economic meaning to these variables, we use a version of the simple flexible-price monetary model of exchange rate popularizes by Frenkel (1976) and Mussa (1976) that states that log money demand depends linearly on log real income, the log price level and the nominal exchange rate. A two-country version of this model is that for two open economies in which the money demand functions are assumed to be stable such that:

$$
m_{t}=p_{t}+\alpha_{1} r_{t}+\alpha_{2} y_{t},
$$


and

$$
m_{t}^{*}=p_{t}^{*}+\alpha_{1} r_{t}^{*}+\alpha_{2} y_{t}^{*} .
$$

One of the key assumptions of the monetary model is that purchasing parity holds. From the previous section we learned that short-run PPP does not seem to hold, but that in the long run the exchange rate reverts to a level that is determined by the relative price level. This is captured by equation 6.11. Taking equations $6.11,6.13$ and 6.14 together gives us the fundamental exchange rate in terms of the macroeconomic model:

$$
\tilde{s}_{t}=\left(m_{t}-m_{t}^{*}\right)-\alpha_{1}\left(r_{t}-r_{t}^{*}\right)-\alpha_{2}\left(y_{t}-y_{t}^{*}\right) .
$$

Before using the monetary model to generate an estimate for the fundamental exchange rate, two issues require attention. First, in related work (see Faust et al., 2003 , for instance) the set of macroeconomic variables that are of interest is often extended to include the price difference itself as well. Second, the elasticities $\alpha_{1}$ and $\alpha_{2}$ are unknown. Instead of making an assumption about the elasticities we try to estimate the weights for the various macroeconomic variables empirically using a two-step approach. In the first step the weights are estimated using a linear regression of the spot rate on the macroeconomic variables during the period of January 1975 through September 1989. The model then becomes:

$$
s_{t}=\alpha_{0}+\alpha_{1}\left(r_{t}-r_{t}^{*}\right)+\alpha_{2}\left(y_{t}-y_{t}^{*}\right)+\alpha_{3}\left(m_{t}-m_{t}^{*}\right)+\alpha_{4}\left(p_{t}-p_{t}^{*}\right)+\epsilon_{t} .
$$

The fitted values of this regression can therefore in a way be seen as a proxy for the fundamental exchange rate during the sample period. Although we learned that the actual spot rate should by no means follow the same path as the fundamental exchange rate, the exchange rate does revert to its long-run equilibrium value provided there is sufficient time. In the next step, the estimated model is used for a one-period forecast to determine the fundamental exchange rate at the first date in the second (survey) sample period of October 1989 through December 2004. ${ }^{2}$

\subsection{Data}

The foreign exchange data that will be used in this chapter is described in great detail in section 5.3. For our sample, we obtain forecasts for the U.K. Pound, Japanese Yen and Deutschemark against the U.S. Dollar for the period of October 1989 through December $2004 .^{3}$ This period is of particular interest since it contains several financial crises, the introduction of a single monetary currency unit, and several large changes in the level of the exchange rates. The panel is unbalanced since the response rate of the individual market participants is less than 100 percent and since market participants left the panel and were replaced by others. Due to

\footnotetext{
${ }^{2}$ In other words, the fundamental exchange rate at period $t$ is always estimated using all the data on the macroeconomic variables and spot exchange rate up to period $t-1$.

${ }^{3}$ Prior to January 1999 we use forecasts on the Deutschemark versus the U.S. Dollar. We transform these expectations into Euro / U.S. Dollar forecasts using the official conversion rate.
} 
data unavailability we have to split the sample in two periods: October 1989 through February 1995 (Sample 1) and November 1995 through December 2004 (Sample 2). In this chapter we focus on the 3- and 12-month-ahead forecasts since these have the highest response.

For the fundamental forecast models, we furthermore obtain data on various macroeconomic variables. The Organization for Economic Cooperation and Development's (OECD) Main Economic Indicators dataset is the source for seasonally adjusted money supply, $m_{t}$ (M4 for the United Kingdom and M1 for the other countries, all in current prices $)^{4}$ and for the non-seasonally adjusted consumer price index, $p_{t}$. The International Monetary Fund's (IMF) International Financial Statistics dataset is the source for the seasonally adjusted gross domestic production ${ }^{5}$ as a proxy for output $y_{t}$. Interest rates are three-months Euro-rates, $r_{t}$, obtained from Datastream. All macroeconomic and spot variables are obtained for the period of January 1975 through December 2004, except for the Japanese Euro-rate, which starts in August 1978. Natural logarithms are taken from all variables, except from the interest rates.

\subsubsection{Unit Root Test Results}

Before we outline the techniques that will be used, we investigate the unit root properties of the realized exchange rate and the macroeconomic variables. Since macroeconomic variables are often known to contain a unit root or are even integrated of order two, it is important to know the proper order of integration of all series prior to conducting any of the tests in the next section. We employ two different unit root tests to get a robust conclusion. First we use the augmented Dickey-Fuller test where the proper lag length is determined by the Schwarz information criterion. In addition, we use the Phillips-Perron test that uses the Bartlett kernel as the spectral estimation method. The proper lag length in this test is determined automatically using the approach by Newey and West (1994). The inclusion of a linear trend is determined by a visual inspection of the data series. Unit root tests are conducted for the series in levels and their first (or even second) difference. The sample period spans the entire period from January 1975 (if available) until December 2004 (360 observations). In principle, we define a variable to be stationary, or $I(0)$, if both tests reject the null hypothesis of a unit root at least at the 5 percent significance level. We define the variable to be $I(1)$ when the two tests cannot both reject the null of a unit root for the level at the 5 percent significance level, but can so for the first difference.

\footnotetext{
${ }^{4}$ For German money supply we use data from the OECD until December 1998 and use the German Contribution to M1 series from the Bundesbank from 1999 onwards. Both series are seasonally adjusted. Furthermore, prior to January 1980 data on the monthly money supply of the United Kingdom are only available on a quarterly basis. We generate monthly series for this period by fitting a cubic spline function trough the quarterly observations. We feel that this is appropriate to do because the seasonally adjusted money supply series are already smooth.

${ }^{5}$ Because GDP is reported only for a quarter, we create monthly series from this using a local quadratic frequency conversion function that distributes the quarterly GDP over each of the three months within that quarter.
} 


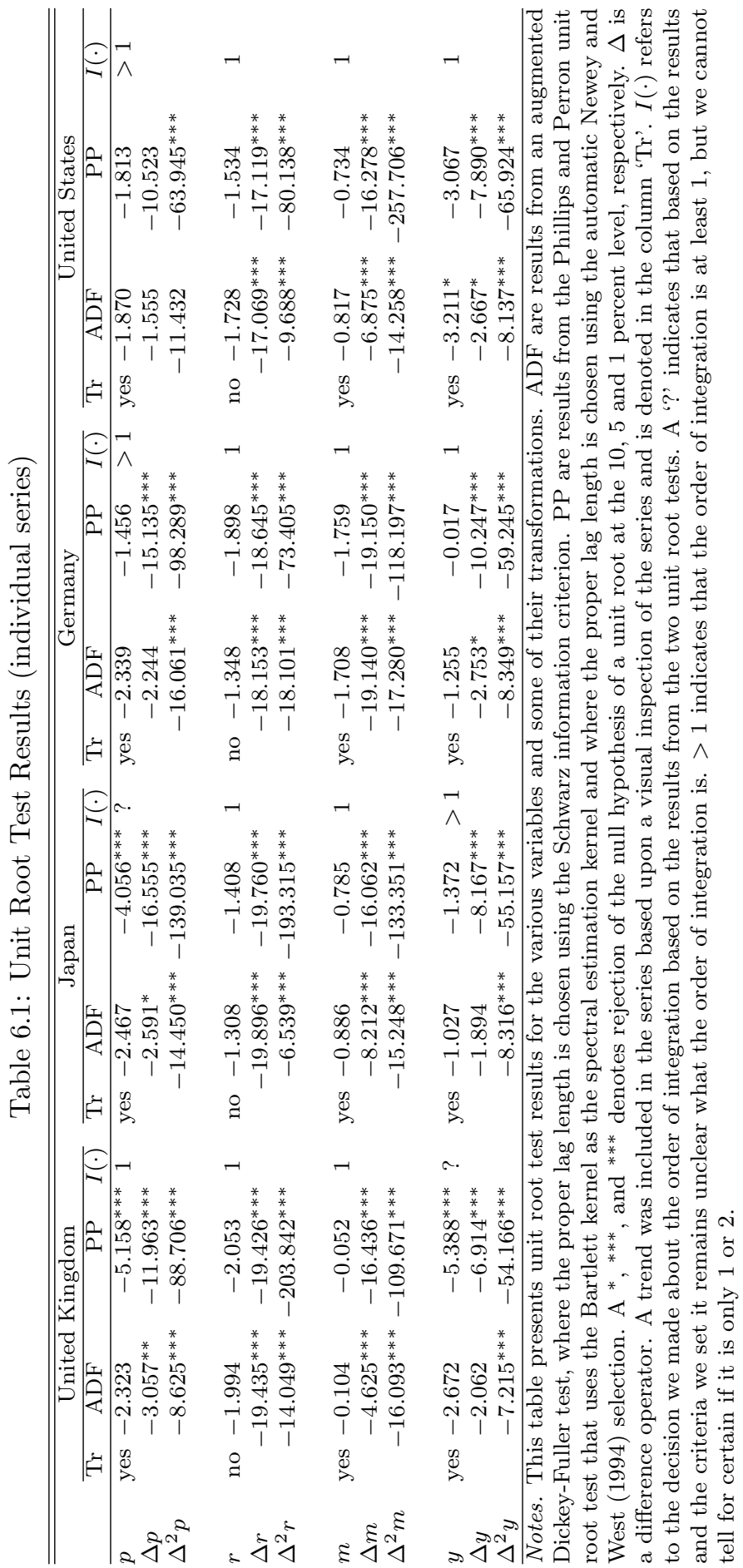




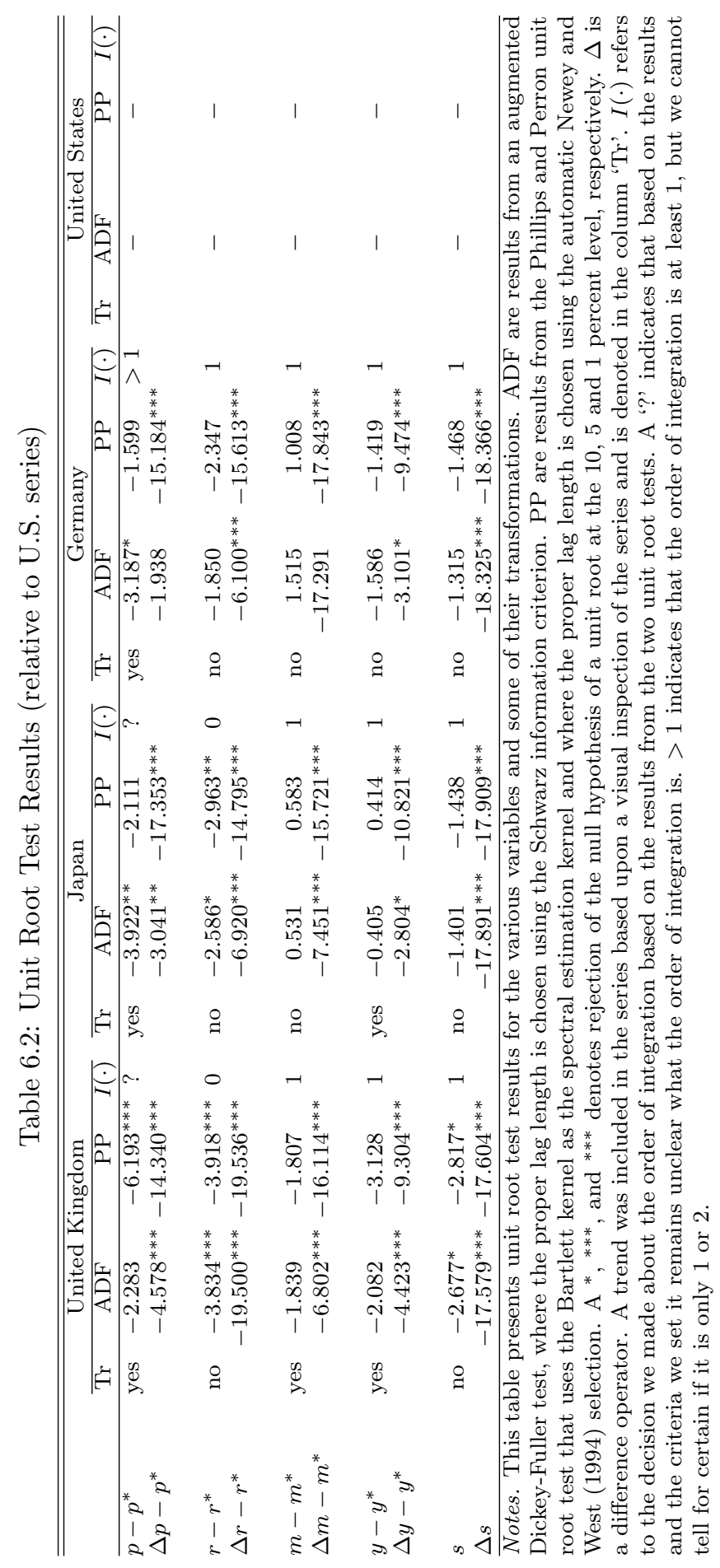


Table 6.1 and table 6.1 report results from the unit root tests. In table 6.1 , we investigate the unit root properties of the various series from the individual countries. In table 6.2, we define the macroeconomic variables relative to their counterparts in the United States (for instance, $m-m^{*}$, where an asterisk denotes the U.S. variable). Since any linear combination of $I(1)$ variables can itself be of order $I(0)$, we have to reexamine the order of integration of the relative series.

As for the individual series, several conclusions can be drawn. For the interest rates and money supply we generally cannot reject the null hypothesis of a unit root in the level series, while we can reject this for their first differences. This would suggest that these macro series are of order $I(1)$. For the price level and the production the results are less clear-cut. For the United Kingdom, Germany and the United States, consumer prices appears at least to contain a unit root, although for the latter two countries we cannot ascertain whether the appropriate order of integration is $I(1)$ or $I(2)$, as is sometimes suggested for macroeconomic variables. For Japan the results are unclear altogether. For Japan, Germany and the United States, production (GDP) also appears to contain at least a unit root, while for the United Kingdom the results are unclear altogether. For the relative series the results are more clear-cut. The relative interest series appear stationary, while the relative money supply, production and the spot exchange rate contain a unit root. Results on the relative price level does not give a clear picture.

\subsubsection{Cointegration Results}

If we find that the above macroeconomic variables are cointegrated with the spot exchange rate, we know that there is a long-term relationship between these variables, and the predictions from such a cointegration relation can then serve as proxies for the fundamental exchange rate. The analysis we pursue consists of three steps. First, we have to ascertain what the correct degree of differencing is for all the series. From the augmented Dickey-Fuller and Phillips-Perron unit root tests in the previous section we learned that most macroeconomic variables, as well as the exchange rates, are nonstationary in their levels, while stationary in their first differences. In other words, they seem to be $I(1)$ series. Only the interest rates consistently appear to be $I(0)$ series.

Second, we check whether there is any cointegrating relationship between the macroeconomic variables and the spot exchange rate. We employ the cointegration test procedure due to Johansen (1991) that assesses whether there is any linear relationship between the variables that is stationary. Following Cumperayot (2002), this linear relationship should then have the form of the following equation: ${ }^{6}$

$$
s_{t}=a_{0}+a_{1} p_{t}+a_{2} p_{t}^{*}+a_{3} r_{t}+a_{4} r_{t}^{*}+a_{5} m_{t}+a_{6} m_{t}^{*}+a_{7} y_{t}+a_{8} y_{t}^{*}+\epsilon_{t} .
$$

The Johansen approach starts by estimating an unrestricted vector autoregression (VAR) that includes all the above variables. The two interest rate series, which follow

\footnotetext{
${ }^{6}$ We use the individual country data here, i.e. not the relative series. We do this, because the cointegration analysis requires $I(1)$ variables instead of $I(0)$ variables, and the unit root tests showed that many relative series are $I(0)$.
} 
Table 6.3: Cointegration Test Results (full sample)

\begin{tabular}{|c|c|c|c|c|c|c|}
\hline \multirow{2}{*}{ 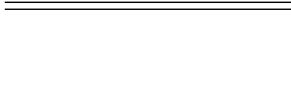 } & \multicolumn{2}{|c|}{ United Kingdom } & \multicolumn{2}{|c|}{ Japan } & \multicolumn{2}{|c|}{ Germany } \\
\hline & Trace & $\begin{array}{l}\text { Eigen- } \\
\text { value }\end{array}$ & Trace & $\begin{array}{l}\text { Eigen- } \\
\text { value }\end{array}$ & Trace & $\begin{array}{l}\text { Eigen- } \\
\text { value }\end{array}$ \\
\hline
\end{tabular}

a) Johansen cointegration test

\# cointegrating equations:

$\begin{array}{lcccccc}\text { None } & 290.499^{* * *} & 98.782^{* * *} & 228.424^{* * *} & 90.394^{* * *} & 266.811^{* * *} & 97.988^{* * *} \\ \text { At most 1 } & 191.716^{* * *} & 73.476^{* * *} & 138.029^{* * *} & 70.397^{* * *} & 168.822^{* * *} & 80.935^{* * *} \\ \text { At most 2 } & 118.241^{* * *} & 60.272^{* * *} & 67.632^{* * *} & 30.928^{* * *} & 87.888^{* * *} & 44.565^{* * *} \\ \text { At most 3 } & 57.969^{* * *} & 27.432^{*} & 36.704 & 18.767 & 43.323 & 21.611 \\ & & & & & & \\ \text { \# equations (5\% level) } & 5 & 3 & 2 & 2 & 3 & 3\end{array}$

b) Engle-Granger cointegration test

\begin{tabular}{ccccccc} 
& $\mathrm{ADF}$ & $\mathrm{DF}$ & $\mathrm{ADF}$ & $\mathrm{DF}$ & $\mathrm{ADF}$ & $\mathrm{DF}$ \\
$T$-stat & $-3.384^{* *}$ & $-3.723^{* *}$ & $-5.105^{* * *}$ & $-5.341^{* * *}$ & $-3.850^{* * *}$ & $-4.752^{* * *}$ \\
\hline Notes.
\end{tabular}

Notes. The critical values for the Trace and Maximum eigenvalue statistics are taken from MacKinnon et al. (1999) and do not assume the inclusion of exogenous series. A *, ${ }^{* *}$, or ${ }^{* * *}$ denotes rejection of the null hypothesis of no cointegration at the 10,5 or 1 percent level, respectively. The ADF test assumes 4 lags in the dependent variable and the DF test none. The critical values for the Engle-Granger cointegration test are taken from Engle and Granger (1987).

an $I(0)$ process, are treated as exogenous variables in the VAR. We use two lags in the VAR to capture most of the dynamics while still preserving model parsimony. Next, we perform two likelihood ratio tests to detect the presence of cointegrating vectors: the Trace test and the Maximum Eigenvalue test. The sample period spans the entire period from January 1975 (if available) until December 2004 (360 observations).

Panel a of table 6.3 reports the results from two likelihood ratio tests. The null hypothesis of each test is that of at most $n$ cointegrating vectors and is stated in the first column. Test results are given for various numbers of maximum cointegrating vectors, together with their significance levels. From the results, the number of cointegrating vectors is never smaller than 2 , which indicates that there is a long-term cointegrating relationship between the spot rate and the macroeconomic variables. As a robustness check we present in panel b of table 6.3 the results from the Engle and Granger (1987) cointegration test approach, which claims that if the variables from model in equation 6.16 are cointegrated, then the error terms should be stationary. We estimate equation 6.17 by least squares and use the residuals from that regression in a Dickey-Fuller (DF) or augmented Dickey-Fuller (ADF) unit root test. ${ }^{7}$ The test statistics show that the null hypothesis of a unit root in the residuals of equation 6.17 can always be rejected at least at the 5 percent significance level. This confirms the cointegrating relationship that exists between the spot exchange rate

\footnotetext{
${ }^{7}$ We estimate these tests in levels, without a trend. We use 4 lags for the ADF version of the model, although model selection criteria usually suggest that including one or two lags is already sufficient.
} 
and the macroeconomic variables in equation 6.16. In the next section we present the empirical tests together with their results.

\subsection{Results}

In this section we present results from various techniques in order to form an idea about the weights that are attached to fundamentalist and chartist techniques. We use the following three techniques: 1) a linear model where the coefficients are constant over time, 2) a state space model where the coefficients are time-varying, and 3) a heterogeneous agent model where agents are allowed to switch between the various forecast techniques. As dependent variables we use either the cross-sectional average of the survey-based expectations or the principal component from the individual expectations. ${ }^{8}$ As independent variables we always take one fundamental variable (PPP-based fundamental or monetary model-based fundamental) and one chartist variable (moving average or recent change).

\subsubsection{Linear Model}

We start by the simplest situation, where agents attach a constant weight to both the chartist and fundamentalist techniques, such that we can estimate a linear model for the entire sample period:

$$
\bar{s}_{t+k}^{e}-s_{t}=\alpha_{0}+\alpha_{1} \text { fund }_{t}+\alpha_{2} \operatorname{char}_{t}+\epsilon_{t} .
$$

Table 6.4 reports estimates from the linear model when the survey-based forecast horizon is equal to 3 months and table 6.5 reports similar estimates when the survey-based forecast horizon is equal to 12 months. In each table panel a reports results from the linear model with the cross-sectional average of the expectations as dependent variable and panel b reports results when the principal component from the individual series is used.

Several important conclusions can be drawn. First of all, the two chartist coefficients have the correct sign: they are negative, which indicates expected mean reversion of the three exchange rates. For the two fundamentalist rules the results are less clear-cut, although in the majority of the cases, and especially for the longer-term forecasts, they appear negative as well - also confirming that the markets expects the exchange rates to revert back to their long-run fundamental values.

Second, the chartist variables are highly significant, especially at the short forecast horizon, while the fundamental variables are less significant, although their significance increases with the forecast horizon. This finding confirms what is often claimed in the literature, namely that chartist rules are predominantly used at the shorter spectrum of the forecast horizon and fundamentalist rules are predominantly used at the longer spectrum of the forecast horizon. Third, the fitness of the linear model with the cross-sectional average as dependent variable is fairly good: the

\footnotetext{
${ }^{8}$ We use a standard principal component analysis that attempts to identify patterns in the data, in such a way as to highlight their similarities.
} 


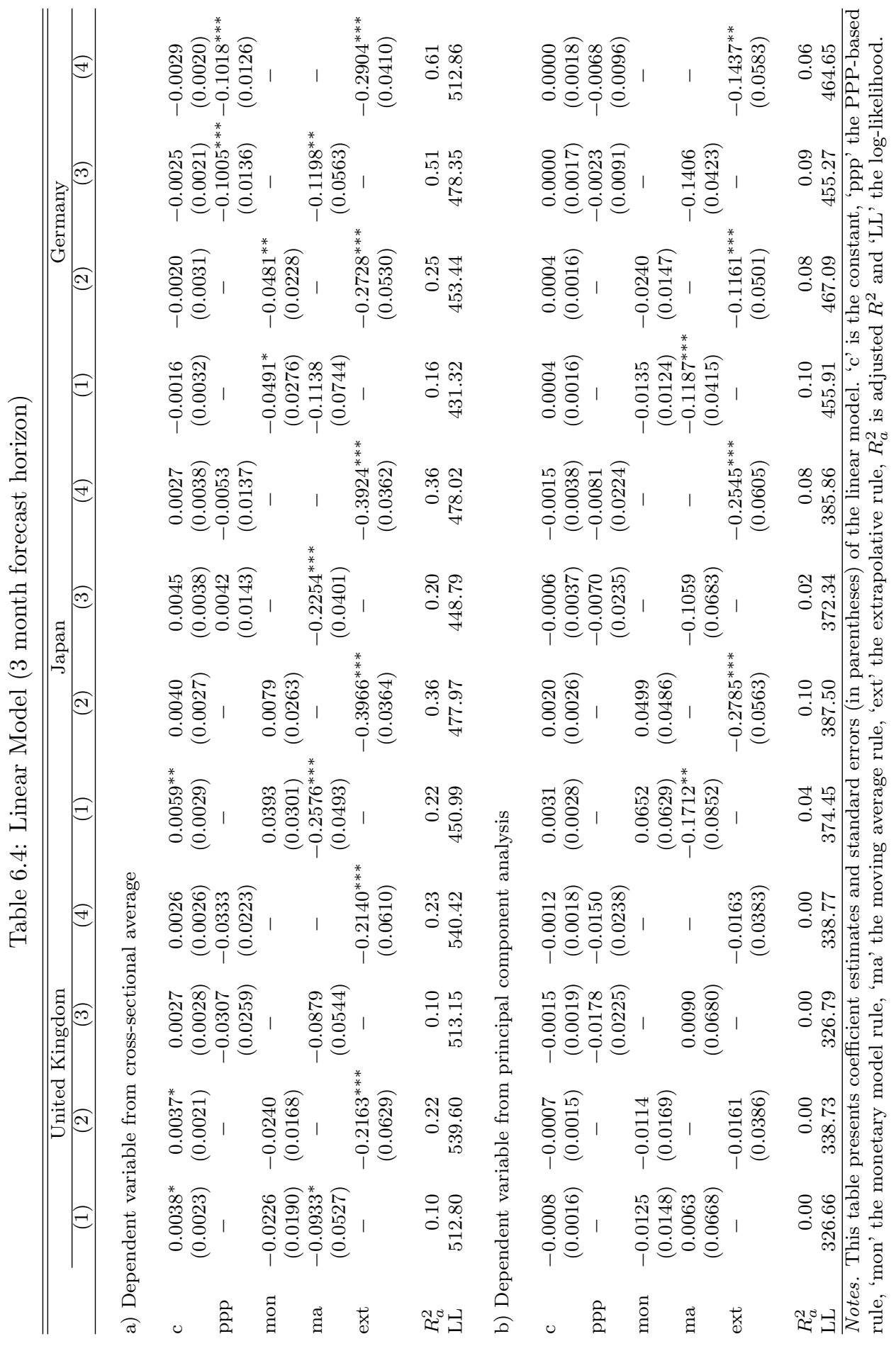




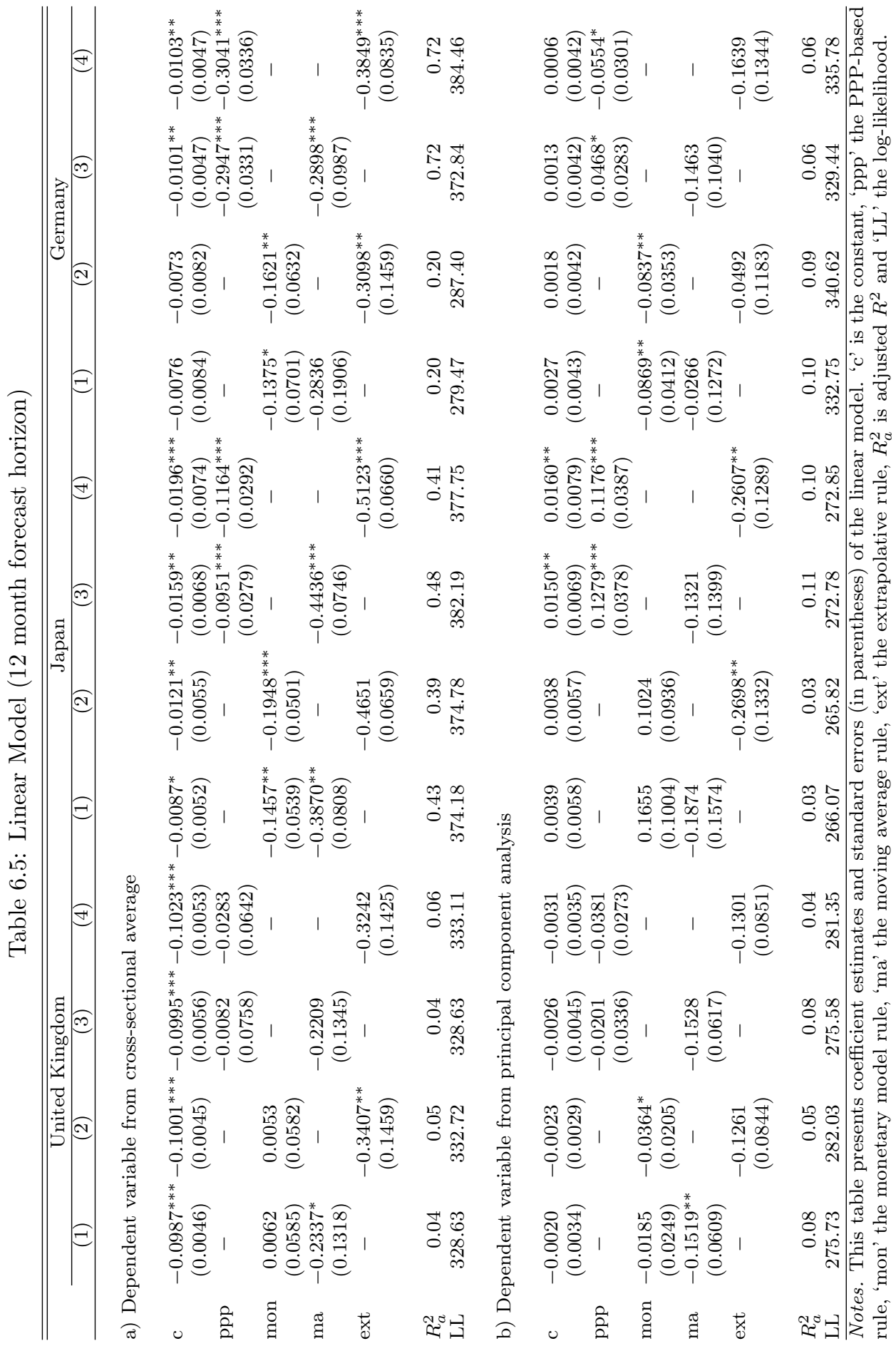


adjusted $R^{2}$ statistic is up to 72 percent. The fitness of the version where the dependent variable is determined by the principal component analysis is clearly lower, although results remain consistent between the panels a and b. Fourth, the inclusion of the extrapolative rule has clear preference over the inclusion of the moving average rule, in terms of the likelihood of the model, while there is no obvious preference for either the PPP-based fundamental rule or the monetary model-based fundamental rule.

From the above results we can conclude that both the chartist rules and fundamentalist rules have appeal when explaining the expected changes in exchange rates. In other words, in the entire sample period under investigation these rules have at least been used. In the next sections we try to address whether the weight that is attached to the rules has changed during the sample period.

\subsubsection{Heterogeneous Agent Model}

In the second empirical analysis we take as standard heterogeneous agent modeling approach and question ourselves whether agents switch between the chartist and fundamentalist techniques. This model is an extension to the previous technique in that time-varying weights are introduced now:

$$
\bar{s}_{t+k}^{e}-s_{t}=\alpha_{0}+\omega_{t} \alpha_{1} \text { fund }_{t}+\left(1-\omega_{t}\right) \alpha_{2} \operatorname{char}_{t}+\epsilon_{t},
$$

where $\omega_{t}$ is the fraction of fundamentalists present in the market. A natural choice for $\omega_{t}$ is a rule that considers the profitability or pricing error of following a fundamentalist strategy. We therefore define $\omega_{t}$ as:

$$
\omega_{t} \equiv \frac{e^{\gamma\left(\alpha_{1} \text { fund }_{t}-\Delta s_{t}\right)^{2}}}{e^{\gamma\left(\alpha_{1} \text { fund }_{t}-\Delta s_{t}\right)^{2}}+e^{\gamma\left(\alpha_{2} \text { char }_{t}-\Delta s_{t}\right)^{2}}} .
$$

In this particular setup, the weight $\omega_{t}$ is constructed in such a way that it is between 0 and 1 . The switching here depends on the relative success of either the fundamentalist or chartist rule and the parameter $\gamma$ measures the sensitivity of market participants (fundamentalists and chartists) to their respective pricing errors. The parameter $\gamma$ can take any value between infinity and minus infinity, yet the interpretation depends on the sign: when $\gamma$ is positive, agents will switch to a rule that has been successful in the past and when $\gamma$ is negative agents will switch instead to a past unsuccessful rule, for instance because they expect that the rule will become successful in the future. With $\gamma=0$ agents are distributed uniformly across the forecast techniques and do not let their choice of forecast technique be dependent on the profitability of that rule in the past. It should be noted that the absolute value of the $\gamma$ parameter is in itself meaningless.

Table 6.6 reports estimates from the heterogeneous agent model when the surveybased forecast horizon is equal to 3 months and table 6.7 reports similar estimates when the survey-based forecast horizon is equal to 12 months. In each table panel a reports results from the linear model with the cross-sectional average of the expectations as dependent variable and panel b reports results when the principal component from the individual series is used. Several conclusions can be drawn. First, 


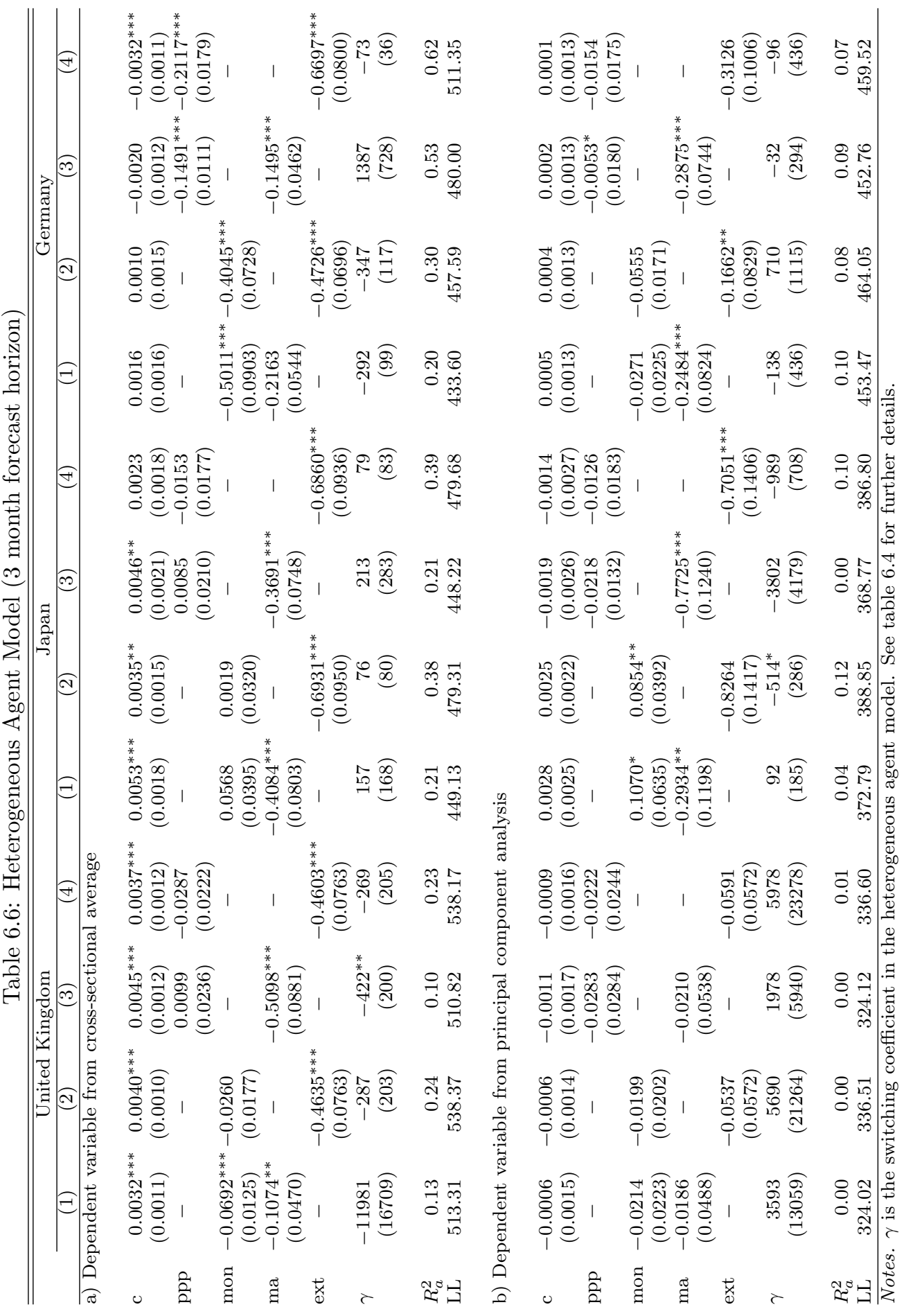




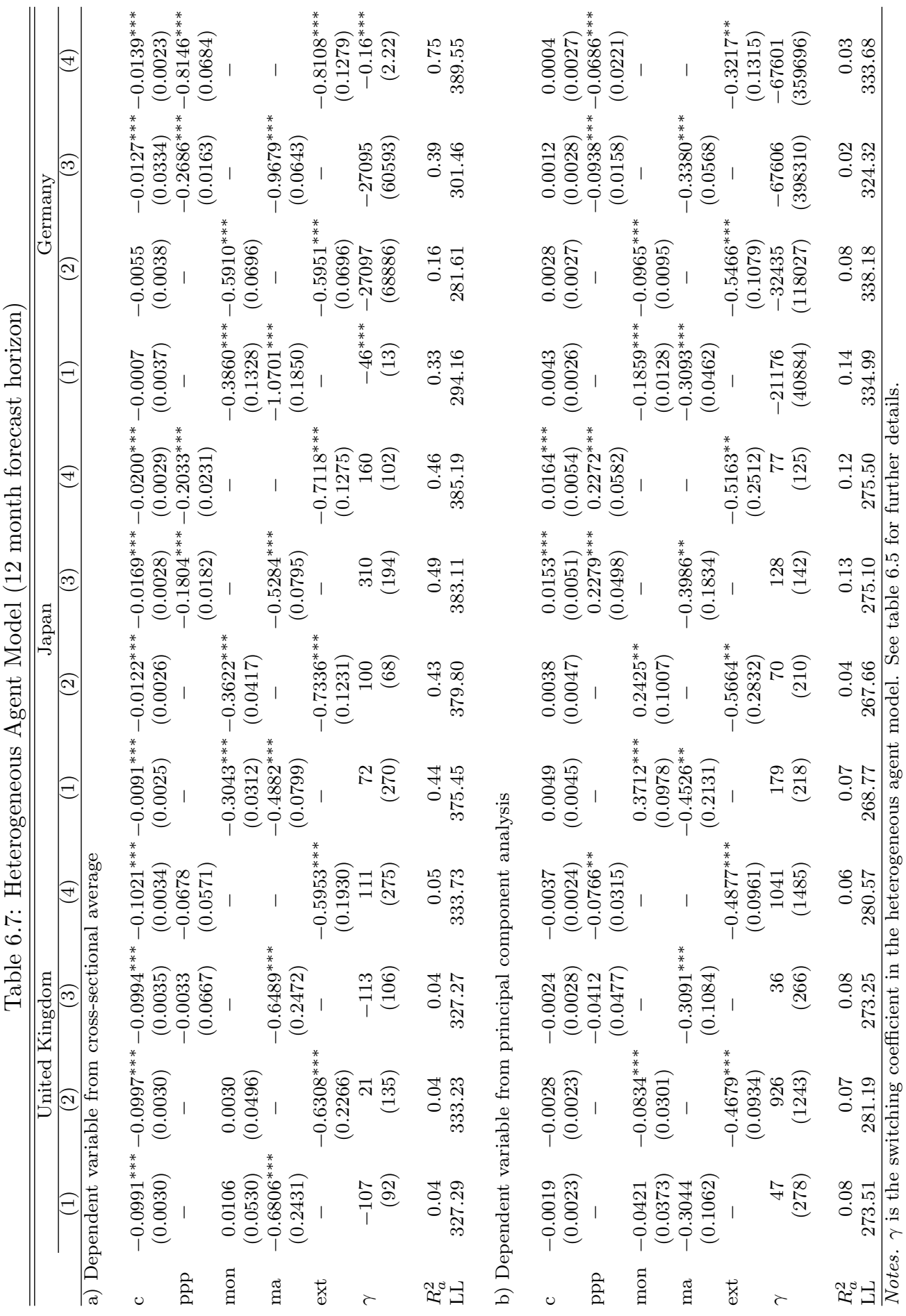


the results remain robust when compared to the linear model. For instance, the introduction of an extrapolative rule has always preference over the moving average rule, the chartist variables all have negative coefficients and are generally significant, and the fundamental variables are often (though not exclusively) negative.

Second, the switching parameter $\gamma$ is generally negative. This implies that forecasters evaluate whether the actual exchange rate has followed one of the forecasting rules in the previous month, and adapt their forecast accordingly. In other words, the forecasting rules that has the smallest forecasting error of the actual exchange rate in the previous month, receives more weight when forming the exchange rate forecast for the coming 3 and 12 months.

Third, the introduction of the switching parameter $\gamma$ does not seem to contribute to an improvement of the model at first sight since the coefficient $\gamma$ is generally not significantly different from zero. This can have several reasons. It may be that simply switching does not occur, or that switching does not occur when the only criterion for switching is the past performance of a particular forecast tool, as is the case now. However, an insignificant switching parameter is directly in line with the literature on heterogeneous agents modeling, see Boswijk et al. (2007). More important is whether the individual rules are significant, and whether the introduction of the switching mechanism improves the performance of the model. Both are the case in our results. We try to address this issue in the next section, where we let the switching variable follow a standard low-order time series process and explicitly look at how the weight variable changes over time.

\subsubsection{State Space Model}

In the last empirical test we let the time-varying loadings for the fundamental and chartist techniques directly be estimated using a Kalman filter. The general state space representation of the model is:

$$
\bar{s}_{t+k}^{e}-s_{t}=\alpha_{0}+\alpha_{1, t} \text { fund }_{t}+\alpha_{2, t} \operatorname{char}_{t}+\epsilon_{t}
$$

where the coefficients are expected to follow an $\operatorname{AR}(1)$ process: $^{9}$

$$
\begin{aligned}
& \alpha_{1, t}=\gamma_{1} \alpha_{1, t-1}+\epsilon_{1, t} \\
& \alpha_{2, t}=\gamma_{2} \alpha_{2, t-1}+\epsilon_{2, t} .
\end{aligned}
$$

The loadings $\gamma_{1}$ and $\gamma_{2}$ can be interpreted as the persistency the market attaches to the weight of the fundamentalist or chartist technique. A value close to 0 indicates that the use of that particular forecast rule can change rapidly from one period to the other, while a value close to 1 indicates strong persistence in the technique. The model is optimized using maximum likelihood with the BHHH algorithm. The starting values for the state vectors are the coefficients from the linear model in equation 6.18 .

\footnotetext{
${ }^{9}$ Similar models are often introduced with coefficients that follow a unit root process. Here, we also allow for a near unit root process by not restricting the coefficients to 1 .
} 


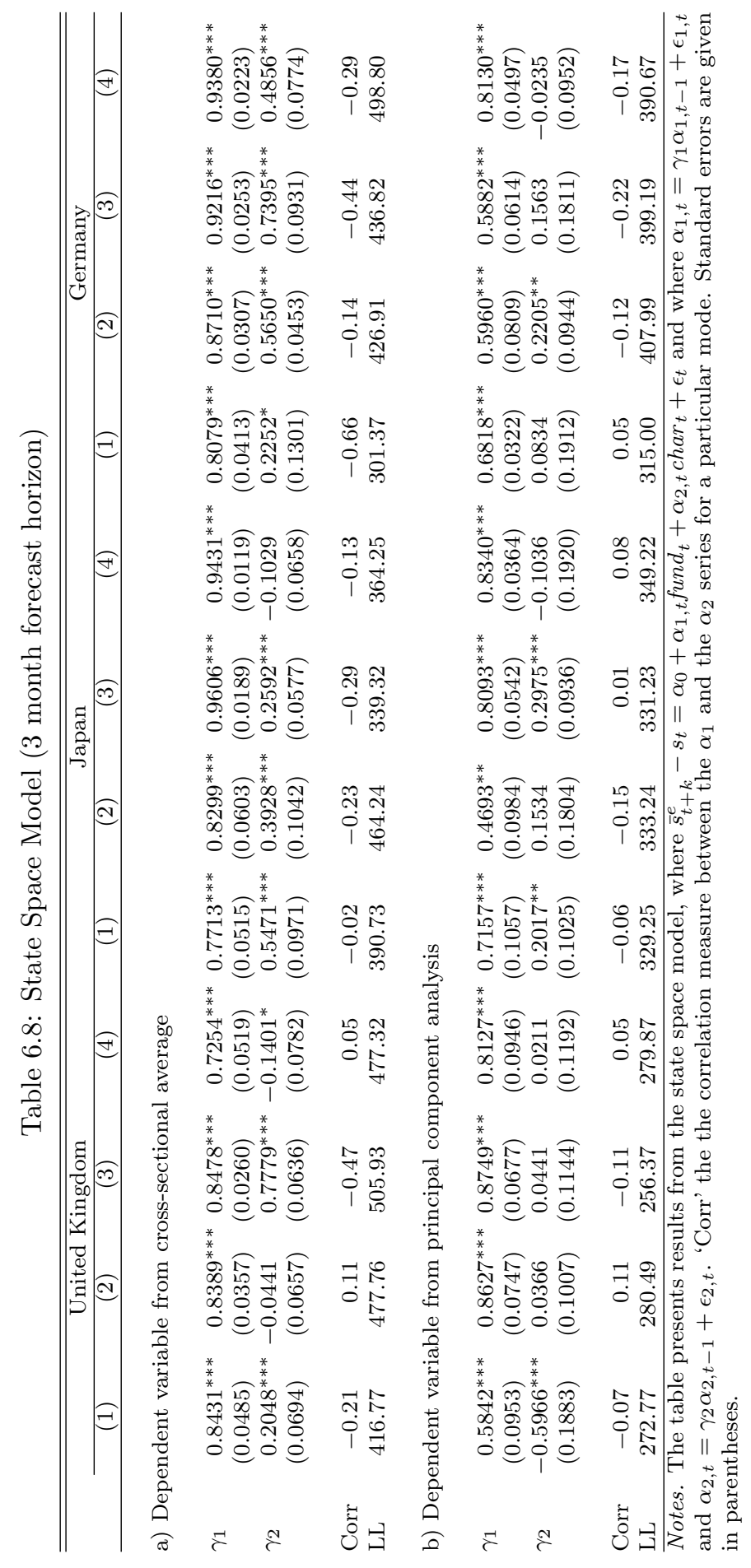




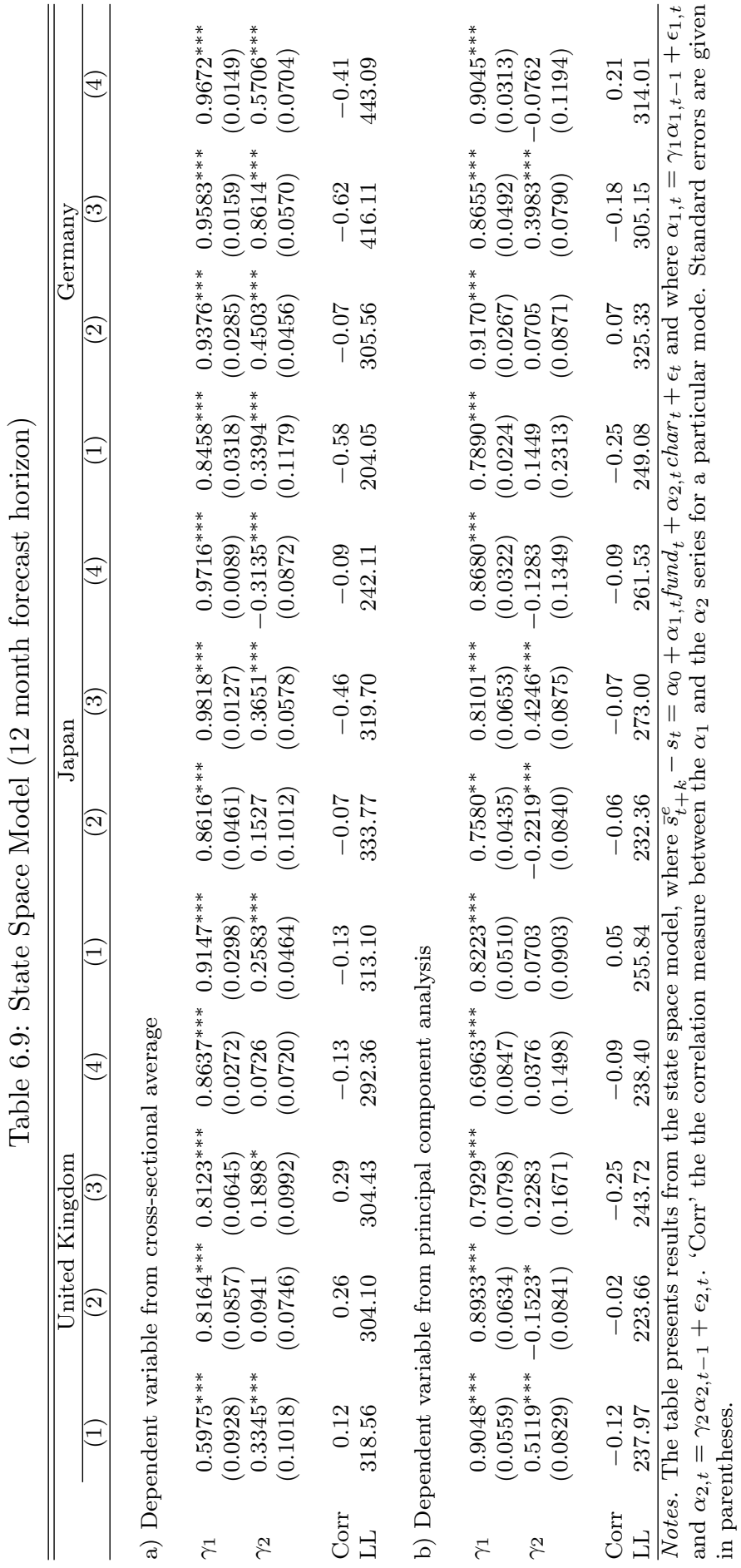


Table 6.8 reports estimates from the heterogeneous agent model when the surveybased forecast horizon is equal to 3 months and table 6.9 reports similar estimates when the survey-based forecast horizon is equal to 12 months. In each table panel a reports results from the linear model with the cross-sectional average of the expectations as dependent variable and panel b reports results when the principal component from the individual series is used.

Two conclusions can be drawn. First of all, the $\gamma_{1}$ variables are all very persistent, in that they all seem to follow a near-unit root process. This indicates that the weight on the fundamental rules is relatively persistent, or in other words, the weight the market attaches to the fundamentalist rule does not change dramatically from one period to the other. On the other hand, the significance of the $\gamma_{2}$ variables is much lower, indicating that there is much lower persistence in the weight that is attached to chartist rules and that the market is much quicker to switch from using a chartist rule from one period to the other.

We continue the analysis by filtering the series $\alpha_{1}$ and $\alpha_{2}$ for all of the Kalman filter models. So each model with a particular chartist and fundamentalist rule generates a set of and series. Next, tables 6.8 and 6.9 also present correlations of each of these sets of series, one for each model. The general result that emerges is that the correlations between the fundamentalist and chartist 'weights' are predominantly negative (and even large in absolute magnitude) for Japan and Germany, irrespective of the combination of fundamentalist or chartist rule. ${ }^{10}$ This is an interesting finding, for it shows that although the market uses both fundamentalist and chartist techniques in forecasting future foreign exchange, the use of the rules is not independent from one another: an increase in the use of a fundamentalist rule is paired with a decrease (albeit imperfect) use of a chartist rule, and vice versa. For the United Kingdom the correlations are mixed positive and negative, so that no clear conclusion can be drawn here.

\subsection{Conclusions}

This chapter has attempted to shed new light on the various forecast techniques that are used when forecasting future foreign exchange. The field of behavioral finance has documented the heterogeneity in the expectations of market participants in the foreign exchange market. The reason for this heterogeneity has generally been attributed to the existence of private information, the difference with which agents interpret common information, and the fundamental difference in forecast techniques that have been used by the market. In this article, we have attempted to investigate this last argument using a dataset of survey-based foreign exchange rate expectations for the three major exchange rates.

We found that market participants use both chartist and fundamentalist techniques at the same time when forecasting future foreign exchange, but that the

\footnotetext{
${ }^{10}$ This finding is particularly apparent for the models where the cross-sectional average is used as dependent variable. We focus primarily on these models, since they appeared to be the most successful in describing the relationships between the forecast rules and the sentiment in the market.
} 
weights attached to the various techniques is not constant over time. It seems that in general an increase of the use of fundamentalist techniques is paired with a decrease of the use of chartist techniques, but that this relationship is not a strict 'zero-sum' game. Chartist techniques seem to be especially of relevance at the short-term spectrum of the forecast horizon, while fundamentalist techniques become more relevant on longer (1-year ahead) forecasts. To be more precise: an extrapolative rule has clearly preference over a moving average rule. On the other hand, fundamentalist rules are used predominantly for longer-term forecasts.

Interestingly, there does not seem to be strong evidence at first sight for the general claim in the heterogeneous agent literature that the weight agents attach to a forecast technique is dependent on the success of that rule in the previous period. However, at closer inspection it appears that the introduction of the switching mechanism improves the performance of the model overall. This is a sign that switching between forecast rules occurs. We do find that the weight attached to fundamentalist rules is more persistent over time as compared to the weight that is attached to chartist techniques.

Finally, it appears that the weights for the fundamentalist rules are all very persistent, in that they all seem to follow a near-unit root process. In other words, the weight the market attaches to the fundamentalist rule does not change dramatically from one period to the other. On the other hand, the significance of the chartist weights is much lower, indicating that there is much lower persistence in the weight that is attached to chartist rules and that the market is much quicker to switch from using a chartist rule from one period to the other. We also find that the correlations between the fundamentalist and chartist 'weights' are predominantly negative. This is an interesting finding, for it shows that although the market uses both fundamentalist and chartist techniques in forecasting future foreign exchange, the use of the rules is not independent from one another: an increase in the use of a fundamentalist rule is paired with a decrease (albeit imperfect) use of a chartist rule, and vice versa.

As for future research, the use of advanced panel techniques should allow for more detailed analysis of the use of various forecast techniques. We belief that a better understanding of the role of forecast techniques can explain the behavior individual market participants better, and thus allowing for a better understanding on how the beliefs of market participants affects the actual behavior of exchange rates. 


\section{Chapter 7}

\section{Using Survey Data to Test Propositions Regarding Exchange Risk Exposure*}

\subsection{Introduction}

One of the most striking financial developments of recent decades is the tremendous increase in exchange rate instability following the collapse of the Bretton Woods system in 1973. While since 1973 exchange rate movements have been dramatic by almost any standard, the ongoing internationalization of trade, production and investment has intensified the concern of economists, managers and policymakers about foreign exchange risk. As it is essential to know how much wealth is at risk before defining how much effort and cost it is worth incurring to manage these risks to an acceptable level, the explicit measurement and identification of the implications of foreign exchange risk uncertainty has become one of the most crucial issues in economics, business and international finance.

While there is a general agreement that changes in exchange rates should affect the value of any physical or financial asset, empirical research on foreign exchange risk exposure - defined as the sensitivity of asset values to unanticipated exchange rate movements - hasn't been able, until now, to give a clear answer regarding the impact of foreign exchange risk. The somewhat surprising, but fairly unanimous, early results by Jorion $(1990,1991)$ and Bodnar and Gentry (1993) suggest indeed that exchange rate fluctuations influence firm very little, if at all. Today, after more than 15 years of intensive discussion on probable difficulties related to methodological issues (Bartov and Bodnar, 1994; Koutmos and Martin, 2003b,a; Bartram, 2004; Dewenter et al., 2005; Muller and Verschoor, 2006a), to the investigation field (He and Ng, 1998; Muller and Verschoor, 2006b) and to the impact of potential hedging

\footnotetext{
* Part of this chapter is from a working paper with Aline Muller and Willem F.C. Verschoor.
} 
activities (Bartov and Bodnar, 1994), empirical evidence still remains inconclusive and puzzling (Griffin and Stulz, 2001). ${ }^{1}$

Interestingly, the analysis of the extensive literature on foreign exchange exposure reveals that most empirical studies - with a few exceptions like Amihud (1994) and Gao (2000) - have based the estimation of foreign exchange exposure on the questionable assumption that unanticipated exchange rate movements may be approximated by changes in realized spot exchange rates. While some empirical studies, like Meese and Rogoff (1983, 1976), Urrutia (1992), and Smoluk et al. (1998) tend to support this assumption, the lack of consensus regarding the general outperformance of random walk forecasts over any other alternative exchange rate forecast model (Frankel and Rose, 1995; MacDonald, 1995) opens a new and promising research avenue that compares the impact of 'realized' versus 'unanticipated' exchange rate movements on shareholder wealth.

One of the reasons why the vast majority of foreign exchange risk exposure studies use realized changes in spot exchange rates as a proxy for unexpected currency movements is that it may be difficult to estimate in how far realized currency fluctuations have been anticipated. While the foreign exchange rate market literature has stirred for years a considerable amount of interest in the exploration of survey-based expectations in order to understand the behavior of foreign exchange market participants (Frankel and Froot, 1987b; Liu and Maddala, 1992a; Cavaglia et al., 1993b), surprisingly, no existing study has yet incorporated the huge amount of information contained in foreign exchange rate market expectations to distinguish between 'anticipated' and 'unanticipated' exchange rate movements and verify whether it is only to the extent that exchange rates move by more or less than had been expected that there are likely to be losses, respectively gains, in economic value.

In this study we analyze how foreign exchange market expectations and the heterogeneity of these expectations affect the valuation of U.S. multinational companies. To our knowledge such a study has not been undertaken before and should, therefore, provide useful information about key aspects dealing with foreign exchange risk. In particular, we use survey data on 1-, 3- and 12-month exchange rate forecasts related to 16 bilateral exchange rates for the period 1995-2005. These expectations allow us to distinguish between six distinctive 'realized' versus 'unanticipated' region-specific trade-weighted exchange rate indices. In order to measure in how far market participants use the information contained in these foreign exchange market forecasts when valuing U.S. multinationals, we use an extensive data set consisting of 935 U.S. companies with real operations in foreign countries and estimate the firm-specific exchange risk exposure of each company according to the geographical dispersion of its activities.

The comparison of our results with previous U.S. evidence (1) confirms that the disaggregation of the worldwide trade-weighted U.S. dollar exchange rate index into six region-specific trade-weighted indices increases the precision and significance of exposure estimates; (2) suggests that models assuming that changes in spot exchange rates are unanticipated are frequently misspecified and, thus, not able to correctly

\footnotetext{
${ }^{1}$ Muller and Verschoor (2006c) offer a detailed overview on the foreign exchange risk literature.
} 
detect the impact of currency movements on firm value; and (3) reveals that investors tend to use more the information contained in short-term exchange rate forecasts than in long-term forecasts.

The outline of the remainder of this chapter is as follows. In the next section, we discuss the motivations of this research. Section 7.3 describes the selection procedure used to form the sample of U.S. multinationals analyzed and carefully details the construction of the 'realized' and 'unanticipated' exchange rate series. In section 7.4 we describe the empirical design used to measure foreign exchange risk exposure. The foreign exchange risk exposure estimates obtained from alternative exchange risk factor specifications are presented in section 7.5 and results are analyzed when lengthening the return horizon. Section 7.6 concludes.

\subsection{Background and Motivation}

Adler and Dumas (1984) can be interpreted as defining foreign exchange risk exposure as the sensitivity of the domestic-currency value of any physical or financial asset to changes in unanticipated exchange rate movements. ${ }^{2}$ The exposure of an asset is hence estimated by regressing its domestic-currency return on the contemporaneous unexpected exchange rate change. ${ }^{3}$ Since other macroeconomic variables may nevertheless simultaneously covary with exchange rate movements and asset returns, Jorion (1990) recommends measuring the asset-specific exchange rate sensitivity (called residual exposure) in excess of the total market's reaction to exchange rate movements. Equation 7.1 describes his augmented market model that may be regarded as the traditional approach used in the literature to measure foreign risk exposure:

$$
R_{i, t}=\alpha_{i}+\beta_{i} R_{m, t}+\gamma_{i} \theta_{t}+\epsilon_{i, t},
$$

where $R_{i, t}$ designates the total return of asset $i$ in period $t,{ }^{4} R_{m, t}$ the overall stock market return in period $t, \beta_{i}$ asset $i$ 's return sensitivity to market risk, $\theta_{t}$ the movement in the exchange rate factor in period $t, \gamma_{i}$ asset $i$ 's exposure to the exchange rate independent of the effect these currency movements have on the overall market, and $\epsilon_{i, t}$ denotes the white noise error term. ${ }^{5}$

It should be emphasized that, according to the seminal definition of Adler and Dumas (1984), foreign exchange risk exposure relates to 'unanticipated' changes in exchange rates. The rationalization for this specification is that current market

\footnotetext{
${ }^{2}$ The seminal papers of Shapiro (1975) and Hodder (1982) offer a similar definition of foreign exchange risk exposure.

${ }^{3}$ As underlined in Jorion (1990), the decomposition of the value of an asset into a component correlated with the unanticipated exchange rate shock doesn't necessarily imply a casual relationship between unexpected currency movements and asset prices.

${ }^{4}$ To avoid confusion over the notation, we use an uppercase $R$ to denote stock returns and a lowercase $r$ to denote interest rates. The uppercase $R$ does not mean, however, that the stock returns are not in natural logarithms.

${ }^{5}$ A zero exposure therefore doesn't signify that the asset is not affected by currency movements. It rather means that the asset value reacts to exchange rate movements to the same degree as the market portfolio.
} 
prices are assumed to have already incorporated currency fluctuations that were anticipated. Consequently it is only to the extent that exchange rates move by more or less than had been expected that there are likely to be losses, respectively gains, in economic value.

While there is a general consensus regarding this definition of exchange risk exposure, it is striking to observe that most previous empirical studies have used realized changes in spot exchange rates to proxy for unanticipated currency movements. ${ }^{6}$ One of the reasons why realized changes in exchange rates have been used in previous studies to approximate unanticipated currency movements is that it may be difficult to estimate how much of the realized change was anticipated, respectively unanticipated. Some authors have nevertheless tried to consider alternative approaches to distinguish between anticipated and unanticipated exchange rate fluctuations. While Levi (1994) suggests the use of forward exchange rates to approximate expected future spot rates, ${ }^{7}$ Amihud (1994) recommends the use of an AR(1) model to estimate unanticipated currency movements. After having regressed exchange rate variations on their lagged values, he estimates equation 7.1 with $\theta_{t}$ being defined as the residuals of the first regression - considering, hence, the residuals of the first regression as unanticipated exchange rate changes. As this procedure only marginally increases the significance of the results, some authors have constructed the exchange rate factor to be used in equation 7.1 to be orthogonal to fundamental variables. ${ }^{8}$

Gao (2000) proposes, for instance, the regression of exchange rate movements on macroeconomic variables:

$$
\begin{aligned}
\Delta s_{t}=\gamma_{1} & +\sum_{i=1}^{n 1} \gamma_{r, i} r_{t-i}+\sum_{i=1}^{n 2} \gamma_{m, i} m_{t-i}+\sum_{i=1}^{n 3} \gamma_{y, i} y_{t-i} \\
& +\sum_{i=1}^{n 4} \gamma_{\mathrm{tb}, i} \mathrm{tb}_{t-i}+\sum_{i=1}^{n 5} \gamma_{\pi, i} \pi_{t-i}+\theta_{t},
\end{aligned}
$$

where $r_{t}$ stands for the interest rate, $m_{t}$ for the money supply, $y_{t}$ the level of industrial production, $\mathrm{tb}_{t}$ net exports and $\pi_{t}$ the rate of inflation at time period $t .{ }^{9}$ The residual term $\theta_{t}$ thus represents the unanticipated change in exchange rate at time period $t$ and should be used as input in equation 7.1 .

The implicit assumption made by Gao (2000) is that such a fundamentals-based exchange rate model is not only able to explain exchange rate movements but also able to capture the market participants' expectations concerning these currency movements. Many empirical studies, however, have pointed out that fundamental variables such as international payment situations, money supplies, interest rates, output levels and inflation rates can hardly explain exchange rate fluctuations or market participants' behavior (Frankel and Rose, 1995).

\footnotetext{
${ }^{6}$ See for instance Jorion (1990, 1991), Bodnar and Gentry (1993), Bartov and Bodnar (1994), $\mathrm{He}$ and $\mathrm{Ng}$ (1998).

${ }^{7}$ The use of forward exchange rates as a proxy for expected future spot exchange rates may be cast into doubt given the empirically documented biasness of the forward premium. Hodrick (1987) and Engel (1996) provide good overviews of the extensive literature on this topic.

${ }^{8}$ See, for instance, Choi and Prasad (1995) and Gao (2000).

${ }^{9}$ Investigating the impact of these unanticipated exchange rate changes $d \theta_{t}$ on a sample of 80 multinational firms (equation 7.2), Gao (2000) shows that they have significantly stronger effects on firm value than the original exchange rate variation series.
} 
Given the lack of consensus regarding the performance of fundamentals-based exchange rate forecasts and the limitations of previous reported approaches, this chapter offers a new empirical specification of the exchange risk factor to be used in equation 7.1. Since our focus is to understand in how far currency movements that haven't been anticipated by the market affect shareholder wealth, the easiest and straightest approach is to concentrate on the expectations of foreign exchange market participants. We define hence the 'expected' part of currency movements as the consensus average measure of foreign exchange rate expectations established on survey-based market participants' forecasts. This procedure enables us not only to distinguish between 'anticipated' and 'unanticipated' exchange rate shocks but also to get at each day of expectation formation a perception of the overall market sentiment as well as of the agreement, respectively disagreement, among market participants regarding the future path of the exchange rate.

The use of survey data is not uncommon in the finance literature and an increase of the use of surveys in various areas of the finance literature is observed. For example, Friedman (1979, 1980), Froot (1989), and MacDonald and Macmillan (1994), have used interest survey data in tests for identifying term premiums and examining the rationality of expectations of future interest rates and concluded that predictions were biased and respondents did not efficiently exploit the information contained in past interest movements. Similarly, Dokko and Edelstein (1989) review the usefulness of the Livingston forecasts of stock market rates of return and find evidence of adaptive behavior in the forecasts. Keane and Runkle (1990) use survey forecasts of the GNP deflator and find that expectations are rational. MacDonald and Torrance (1988a) use survey data on expected changes in money aggregates with U.K. data and find that these survey measures of expectations are extremely useful, for, unlike statistical methods for generating estimates, they are truly exogenous.

Particularly in the foreign exchange rate market literature there has been for years a considerable amount of interest in the exploration of survey-based expectations in order to understand the behavior of foreign exchange market participants. Frankel and Froot (1987b) and Cavaglia et al. (1993b, 1994) use survey data on foreign exchange to examine whether the failure of the forward premium puzzle is attributed to irrational behavior on behalf of market participants or due to the existence of time-varying risk premium and Marsh and Power (1996) and Elliott and Ito (1999) examine the forecast performance of survey-based exchange rate forecasts.

As no existing study has yet incorporated the huge amount of information contained in survey-based exchange rate expectations to estimate foreign exchange risk exposures, this research makes three major contributions. First, it confronts the traditional currency exposure estimation with a new empirical specification that measures the impact of the part of the exchange rate change that hasn't been anticipated by market participants - and may, hence, be legitimately regarded as a 'new' currency shock. Second, the fact that market participants' forecasts are taken into account allows us not only to measure the foreign exchange risk exposure of U.S. shareholder wealth as originally defined and specified in the literature (Hodder, 1982; Adler and Dumas, 1984) but also to compare the foreign exchange risk exposure estimates obtained using these 'unexpected' currency movements with those obtained 
using 'realized' changes in spot exchange rates. The contrast between these results is extremely informative on the way U.S. shareholders use the publicly available exchange rate forecasts when valuing multinational companies. Third, the analysis of our empirical findings across 1-, 3- and 12-month horizons offers a complete and empirically rich picture on the role played by short- and long-term foreign exchange rate expectations in the valuation of U.S. multinationals and sheds new light on the links and interactions between stock and foreign exchange rate markets.

\subsection{Sample Selection of U.S. Multinationals and Survey Data}

\subsubsection{U.S. Multinational Firms}

We begin by describing the selection of U.S. multinational firms with real operations in foreign countries. The focus on multinational companies allows us to concentrate on firms that, due to their real foreign trade and production activities, are expected to be affected by exchange rate shocks. ${ }^{10}$ The selection procedure of these firms consists of three steps. The first selection step identifies all U.S. companies that are registered in the 15th edition of the Directory of American Firms Operating in Foreign Countries. As only listed firms are included in our study, we check the firms for their daily stock market return availability in the University of Chicago Center for Research in Security Prices (CRSP) database. Companies are as well required to provide at least five years of consecutive daily returns across the entire sample period from January 1995 to December 2005. The entire procedure yields a sample of 935 U.S. multinational firms. For all these companies, the data employed are daily adjusted prices obtained from CRSP and Datastream International from November, 10th 1995 until December, 31st 2005. The use of daily prices is essential in order to extract for each company in each month the share price on that day on which the expectations for the various exchange rates are formed. ${ }^{11}$

Table 7.1 gives a brief overview on the size, debt structure and foreign sales activities of the firms included in our sample. The summary statistics of the market values and debt ratios clearly indicate the presence of some relatively large, respectively strongly leveraged companies in our sample. It should furthermore be emphasized that the selected U.S. multinationals are extensively involved in international activities as their foreign sales accounted on average for almost 50 percent of their total sales. $^{12}$

\footnotetext{
${ }^{10}$ Firms with sales and sourcing totally limited to the domestic market may as well be exposed to shifts in the competitive environment caused by changes in foreign exchange rates. As the exposure of domestic firms is primarily operating exposure - which occurs because current, and particularly, future profits from operations depend on exchange rates - and, more importantly, as investors may be less aware of the operating exposure of domestic firms, some authors argue that it may take, on average, more time to detect the impact of currency movements on domestic companies in comparison with multinational firms (Bartov and Bodnar, 1994).

${ }^{11}$ The expectation formation day is usually the Friday before the second Monday of the month (see the next section for more details on the expectation series).

${ }^{12}$ As suggested in Bartov and Bodnar (1994), the focus on firms with large foreign revenues
} 
Table 7.1: Summary Statistics of Sample of U.S. Multinational Firms

\begin{tabular}{lrrrrr}
\hline \hline & \# obs & mean & first quartile & median & third quartile \\
\hline Market capitalization & 935 & $53,358,951$ & 239,849 & 731,851 & $3,344,989$ \\
Dept/equity ratio & 890 & 1.767 & 0.556 & 1.146 & 2.275 \\
Foreign sales/total sales & 724 & 0.482 & 0.309 & 0.484 & 0.679 \\
\hline
\end{tabular}

Notes. This table reports descriptive statistics for the market value, debt structure and foreign sales of the 935 companies included in our sample. For each company the market capitalization, debt ratio and foreign sales ratio has been calculated as the average value over the entire sample period. Market capitalizations are in thousands of U.S. dollars. For some companies the debt/equity ratio, respectively the foreign sales/total sales ratio, is not made available by the Datastream International database. '\# obs' reports the number of observations.

The foreign operations of the U.S. multinationals of our sample are grouped in six geographical regions: Europe, U.K., Asia, Australia, Latin America and Africa. In table 7.2, we provide information about the geographical dispersion of these foreign trade and/or production activities. It is interesting to observe that the major international trading activities of the 935 U.S. multinationals included in our sample are located in Europe, U.K. and Asia. While all companies active in Africa-with the exception of one - seem to have trading and production relationships in the entire world, particularly in Asia, it should be stressed that on average 80 percent of the companies that have real operations in Asia, Australia, Latin America or Africa have as well trading links in Europe. Finally, only very few firms appear to be exclusively focusing on one geographical region. ${ }^{13}$

\subsubsection{Exchange Risk Factors}

The data on the unexpected exchange rate changes is obtained from a survey among market participants. Every second Monday of each calendar month Consensus Economics of London publishes results from a survey among up to 150 professional market participants and forecasting agencies for their subjective expectations of a large number of exchange rates. Forecasts are made for a variety of horizons ranging from 1 month to 24 months ahead.

For our panel, we obtain expectations on the Argentine peso, Australian dollar, Brazilian real, Chilean peso, Chinese renminbi, Hong Kong dollar, Japanese yen, Malaysian ringitt, Mexican peso, New Zealand dollar, South African rand, Singaporean dollar, South Korean won, Thai baht, euro, and United Kingdom pound versus the United States dollar, for the period of November 1995 through December $2004 .^{14}$ This period is of particular interest since it contains several financial crises, the introduction of a single monetary currency unit, and several large changes in the

doesn't necessarily favor the detection of significant foreign exchange risk exposures, as these firms are more likely to hedge (with financial or operational strategies) their foreign exposures and to be able to undertake these hedging activities at a lower cost.

${ }^{13} 35$ firms are exclusively active in Europe (excluding the U.K.), 59 in the U.K., 28 in Asia, 9 in Australia, 36 in Latin America and 1 is exclusively active in Africa.

${ }^{14}$ Prior to January 1999 we use expectations on the Deutschemark / U.S. dollar and calibrate these expectations to U.S. Dollar / euro expectations. 
Table 7.2: Geographic Dispersion of the Foreign Activities of U.S. Firms

\begin{tabular}{lccccccc}
\hline \hline & \# obs & Europe & U.K. & Asia & Australia & $\begin{array}{c}\text { Latin } \\
\text { America }\end{array}$ & Africa \\
\hline Europe & 683 & - & $81.55 \%$ & $77.16 \%$ & $51.24 \%$ & $53.00 \%$ & $22.40 \%$ \\
U.K. & 712 & $78.23 \%$ & - & $72.47 \%$ & $49.30 \%$ & $50.56 \%$ & $20.79 \%$ \\
Asia & 639 & $82.47 \%$ & $80.75 \%$ & - & $52.90 \%$ & $57.59 \%$ & $24.73 \%$ \\
Australia & 396 & $88.38 \%$ & $88.64 \%$ & $85.35 \%$ & - & $70.45 \%$ & $35.35 \%$ \\
Latin America & 461 & $78.52 \%$ & $78.09 \%$ & $79.83 \%$ & $60.52 \%$ & - & $31.89 \%$ \\
Africa & 164 & $93.29 \%$ & $90.24 \%$ & $96.34 \%$ & $85.37 \%$ & $89.63 \%$ & - \\
Total sample & 935 & $73.05 \%$ & $76.15 \%$ & $68.34 \%$ & $42.35 \%$ & $49.30 \%$ & $17.54 \%$ \\
\hline
\end{tabular}

Notes. This table gives a brief description of the geographic dispersion of the foreign activities of the U.S. multinational companies included in our sample. For instance, 78.23 percent of U.S. multinational firms that have real operations in the U.K. also have real operations in the rest of Europe. 'Total sample' give the percentage of firms that have foreign operations in any of the 6 regions. The source is the 15th edition of the Directory of American Firms Operating in Foreign Countries.

level of some of the exchange rates.

Specifically, for these currencies we obtain the consensus average expectations that are made for 1,3 , and 12 months ahead. ${ }^{15}$ Consensus measures of expectations are likely to perform better than the individual expectations that together make the consensus. Although some individuals' forecast performance may be better than others' - in terms of criteria like root mean squared errors - it is difficult to identify a priori who these individuals are, in particular since forecast performance is generally not constant through time. As surveys aggregate the expectations from many market participants, the information in consensus measures is thus usually superior, which may be due to an effect similar to the Bayesian model averaging or due to the fact that the common components of the forecasts are implicitly filtered out in the consensus value.

Although the survey participants have a few days time to return their expectations, we learned that the vast majority send their forecasts by e-mail on the Friday before the publication day (usually second Monday of the month). We consider this Friday to be the day on which the expectations are formed. On this Friday, we obtain spot exchange rate series to match with the survey data. All spot rate series are obtained through Datastream and origin from either Reuters or Barclays Bank International. To verify that the information sets of market participants are not too diverse, all of the analyses throughout this study were re-estimated using spot data from various days surrounding this Friday, yet the overall results remained virtually unchanged.

Typical concerns when using survey data in any setting are whether this data reflects the true market's expectations, whether the expectations are biased because of strategic behavior from the panelists, or whether forecasts from surveys are of any good in an out-of-sample forecast setting - a criteria that has often been put forward to evaluate the quality of survey expectations. It should be noted that for survey data

\footnotetext{
${ }^{15}$ We excluded the 24-month ahead expectations for this would considerably reduce the number of observations.
} 
in the present setting it is only important that the survey expectations reflect the market's sentiment at the time they are formed, that is, the survey data should reflect expectations, nothing more than that. While it is not the primary concern that the expectations outperform other forecasting techniques, there is general consensus that expectations from surveys in general perform no worse than any other forecast technique. In general, we can learn much about the usefulness of survey-measures of expectations from related fields. Ang et al. (2007), for instance, provide recent evidence that aggregate expectations from various surveys on inflation consistently deliver better forecasts than time-series models, models based on the yield curve, and forecasts based on the Phillips curve, which highlights the usefulness of survey measures of expectations. Elliott and Ito (1999) find that in the foreign exchange market portfolio's based on survey expectations produce small, but positive, profits.

We proceed by defining the natural logarithm of the current spot rate on a particular currency $l$ at time $t$ as $s_{l, t}$ and the natural logarithm of the $k$-period ahead survey-based consensus expectation for that particular exchange rate formed at time $t$ for delivery at time $t+k$ as $s_{l, t, t+k}^{e}$ and make the assumption that the survey-based expectations equal the unobserved 'true' market observation up to a white noise random error, such that $s_{l, t, t+k}^{e}=s_{l, t+k}^{E}+\epsilon_{l, t+k}$. The ex-post realized change in the exchange rate over the last $k$-period can then be decomposed in an 'anticipated' component and an 'unanticipated' (or noise) component:

$$
s_{l, t}-s_{l, t-k}=\left(s_{l, t-k, t}^{e}-s_{l, t-k}\right)+\left(s_{l, t}-s_{l, t-k, t}^{e}\right) .
$$

The expectations for the individual currencies are grouped together to construct 6 region-specific indices. A particular region is indicated as $j$. The indices are region-specific trade-weighted exchange rate indices ${ }^{16}$ that translate the evolution of one or more foreign currencies of the same geographical region towards the U.S. dollar. They are computed as a weighted average of spot and survey-based expected bilateral exchange rates according to the following formulas:

$$
x_{j, t}=\sum_{l=1}^{n_{j}} \frac{\exp _{l}+\operatorname{imp}_{l}}{\sum_{l=1}^{n_{j}}\left(\exp _{l}+\operatorname{imp}_{l}\right)} s_{l, t}
$$

and

$$
x_{j, t, t+k}^{e}=\sum_{l=1}^{n_{j}} \frac{\exp _{l}+\operatorname{imp}_{l}}{\sum_{l=1}^{n_{j}}\left(\exp _{l}+\operatorname{imp}_{l}\right)} s_{l, t, t+k}^{e},
$$

where $n_{j}$ is the number of countries included in a particular region $j, \exp _{l}$ is the export flow from the U.S. towards country $l$ and $\operatorname{imp}_{l}$ the import flow from country $l$ towards the U.S. The weights of the region-specific indices, updated monthly, are based on each country's proportion of trade $\left(\exp _{l}+\operatorname{imp}_{l}\right)$ in the total import and export flows of the region with the U.S. $\left(\sum_{l=1}^{n_{j}}\left(\exp _{l}+\mathrm{imp}_{l}\right)\right)$ as reported by the Foreign Trade Division of the U.S. Census Bureau.

\footnotetext{
${ }^{16}$ Following Jorion (1990) and Dominguez and Tesar (2001a,b), exchange rate indices are parsimonious representations of the effect of multiple exchange rate changes.
} 
Table 7.3: Summary Statistics of Realized and Unexpected Exchange Rate Change

\begin{tabular}{|c|c|c|c|c|c|c|c|}
\hline & Index/rate & Mean & Median & Stdev & Skew & Kurt & BJ \\
\hline \multicolumn{8}{|c|}{ a) 1 month forecast horizon } \\
\hline \multirow[t]{6}{*}{ Realized } & Euro & -0.0019 & -0.0033 & 0.0381 & 0.5132 & 2.6627 & $5.3501^{*}$ \\
\hline & U.K. Pound & 0.0047 & 0.0031 & 0.0282 & 0.2489 & 2.4854 & 2.3493 \\
\hline & Asian index & 0.0028 & 0.0013 & 0.0233 & 0.4479 & 4.9737 & $21.5328^{* * *}$ \\
\hline & Australian index & 0.0023 & 0.0048 & 0.0370 & 0.0425 & 2.7053 & 0.4313 \\
\hline & Latin American index & 0.0087 & 0.0055 & 0.0313 & 0.1827 & 4.1218 & $6.3797^{* *}$ \\
\hline & South African Rand & 0.0061 & 0.0125 & 0.0610 & 0.1431 & 4.1303 & $6.2310^{* *}$ \\
\hline \multirow[t]{6}{*}{ Unexpected } & Euro & -0.0058 & -0.0097 & 0.0433 & 0.2425 & 2.3298 & 3.1365 \\
\hline & U.K. Pound & 0.0058 & 0.0049 & 0.0293 & 0.2691 & 2.6414 & 1.9168 \\
\hline & Asian index & 0.0013 & 0.0034 & 0.0246 & 0.0899 & 5.0353 & $19.1353^{* * *}$ \\
\hline & Australian index & 0.0063 & 0.0049 & 0.0427 & 0.3359 & 2.9418 & 2.0840 \\
\hline & Latin American index & -0.0023 & -0.0080 & 0.0326 & 0.2476 & 3.8906 & $4.7590^{*}$ \\
\hline & South African Rand & 0.0024 & 0.0105 & 0.0689 & 0.0131 & 4.0840 & $5.3883^{*}$ \\
\hline
\end{tabular}

b) 3 month forecast horizon

$\begin{array}{llrrrrrc}\text { Realized } & \text { Euro } & -0.0023 & -0.0042 & 0.0578 & 0.1009 & 2.2217 & 2.9629 \\ & \text { U.K. Pound } & 0.0086 & 0.0049 & 0.0379 & 0.5456 & 2.9246 & 5.4842^{*} \\ & \text { Asian index } & 0.0046 & 0.0026 & 0.0370 & 0.3459 & 4.6231 & 14.2676^{* * *} \\ & \text { Australian index } & 0.0012 & -0.0009 & 0.0585 & 0.0435 & 2.4220 & 1.5660 \\ & \text { Latin American index } & 0.0169 & 0.0135 & 0.0407 & 0.5049 & 3.4697 & 5.6839^{*} \\ & \text { South African Rand } & 0.0152 & 0.0231 & 0.0968 & 0.1914 & 3.7619 & 3.3325 \\ & & & & & & \\ \text { Unexpected } & \text { Euro } & -0.0142 & -0.0129 & 0.0639 & -0.1225 & 2.3071 & 2.4759 \\ & \text { U.K. Pound } & 0.0100 & 0.0090 & 0.0402 & 0.1137 & 3.1200 & 0.3028 \\ & \text { Asian index } & 0.0029 & 0.0058 & 0.0396 & 0.0698 & 4.6204 & 12.1241^{* * *} \\ & \text { Australian index } & 0.0168 & 0.0075 & 0.0666 & 0.2267 & 2.4249 & 2.4575 \\ & \text { Latin American index } & -0.0088 & -0.0171 & 0.0432 & 0.7111 & 3.1778 & 9.4143^{* * *} \\ & \text { South African Rand } & 0.0049 & 0.0194 & 0.1118 & 0.0663 & 3.1121 & 0.1381\end{array}$

c) 12 month forecast horizon

\begin{tabular}{|c|c|c|c|c|c|c|c|}
\hline \multirow[t]{6}{*}{ Realized } & Euro & -0.0079 & -0.0110 & 0.1179 & 0.2720 & 2.1088 & $4.9966^{*}$ \\
\hline & U.K. Pound & 0.0201 & 0.0226 & 0.0706 & -0.1567 & 2.1635 & 3.6571 \\
\hline & Asian index & 0.0116 & -0.0114 & 0.0711 & 0.6065 & 2.8667 & $6.8259^{* *}$ \\
\hline & Australian index & 0.0030 & -0.0130 & 0.1328 & -0.0478 & 2.2094 & 2.9068 \\
\hline & Latin American index & 0.0507 & 0.0384 & 0.0759 & 0.4899 & 3.1282 & 4.4759 \\
\hline & South African Rand & 0.0480 & 0.0782 & 0.2046 & -0.6359 & 2.6804 & $7.8813^{* *}$ \\
\hline \multirow[t]{6}{*}{ Unexpected } & Euro & -0.0484 & -0.0659 & 0.1245 & 0.2015 & 2.0764 & $4.6536^{*}$ \\
\hline & U.K. Pound & 0.0226 & 0.0326 & 0.0741 & -0.5129 & 2.3636 & $6.6790^{* *}$ \\
\hline & Asian index & 0.0211 & -0.0010 & 0.0775 & 0.5422 & 2.6945 & $5.8183^{*}$ \\
\hline & Australian index & 0.0514 & 0.0222 & 0.1381 & 0.1875 & 2.1192 & 4.2001 \\
\hline & Latin American index & -0.0304 & -0.0518 & 0.0804 & 0.3895 & 2.3098 & $4.9641^{*}$ \\
\hline & South African Rand & 0.0022 & 0.0320 & 0.2273 & -0.3195 & 2.1781 & $4.9673^{*}$ \\
\hline
\end{tabular}

Notes. This table presents summary statistics for 1-, 3-, and 12-month expected and unexpected log price changes for the period of November 1995 until December 2004.

Table 7.3 provides summary statistics of these region-specific indices. Since all series are in natural logarithms, we can interpret the figures as percentage changes. 
Several consistencies emerge. First of all, the median and standard deviation of the unexpected exchange rate change are generally larger than the realized change. This implies that the role of currency changes in previous exposure literature that focus on realized changes is potentially understated. In addition, if unexpected changes are larger and more volatile than actual changes, market participants underestimated most of the change or even missed the direction of the exchange rate change, and hence most of the change comes at a surprise for investors. Finally, most changes are skewed to the right, which indicates that there are some large appreciations in the currencies over the sample period under investigation, while there is no apparent evidence of lepto- or platykurtosis.

\subsection{Empirical Design}

Following the extensive literature on foreign exchange rate exposure we measure the firm-specific exchange rate sensitivity, called firm-specific exposure, as the effect of exchange rate changes (whether anticipated or not) on the value of a firm in excess of the global market's reaction to foreign exchange rate movements ${ }^{17}$ :

$$
R_{i, t}=\alpha_{i}+\beta_{i} R_{m, t}+\gamma_{i} \theta_{t}+\epsilon_{i, t},
$$

where $R_{i, t}$ designates the total return of firm $i$ over the period $t-k$ until $t,{ }^{18} R_{m, t}$ the global stock market return over the period $t-k$ until $t, \beta_{i}$ firm $i$ 's return sensitivity to market fluctuations, $\theta_{t}$ the change in the exchange risk factor from period $t-k$ until $t, \gamma_{i}$ firm $i$ 's exposure to exchange rate changes independent of the effect these variations have on the overall market, and $\epsilon_{i, t}$ denotes the white noise error term. The proxy for the market portfolio used in this study is the CRSP value-weighted U.S. market index as provided by the CRSP database. ${ }^{19} 20$

The coefficient $\gamma_{i}$ is the so-called foreign exchange risk exposure measure. It describes the sensitivity of firm $i$ 's stock returns to changes in exchange rates. As we define foreign exchange rate movements as the evolution of one or more foreign currencies towards the U.S. dollar, the appreciation of the home currency corresponds to a positive change in the exchange risk factor $\theta_{t}$. Consequently, we expect $\gamma_{i}$ to be negative for an exporter, since a U.S. dollar appreciation causes U.S. exports to get more expensive in terms of the foreign currencies, leading potentially to a

\footnotetext{
${ }^{17}$ See Adler and Dumas (1984) and Jorion (1990) for instance.

${ }^{18}$ In contrast to work that looks at the return over only 1 period, in this chapter we match the return period with the length of the forecast period of the survey-based exchange rate forecasts.

${ }^{19}$ If $\gamma_{i}$ is zero, this doesn't imply that firm $i$ has no exposure. It implies that firm $i$ has the same exchange risk exposure as the market portfolio.

${ }^{20}$ Including the stock market return in equation 7.6 dramatically reduces the residual variances of the regression. In addition, the market return implicitly controls for the value-relevant macroeconomic factors that are correlated with the exchange rates. As suggested by Bodnar and Wong (2003) this measurement of a firm's exposure estimate improves (somewhat) the precision of the exposure elasticity estimates, but more importantly, improves the interpretation of a firm having zero firm-specific exposure. The empirical result of having zero exposure no longer implies that the firm's value is independent of exchange rates; rather, a zero firm-specific exposure implies that firm value is affected to the same degree as the market portfolio.
} 
fall in foreign demand and foreign sales revenue. On the other hand, the importing firm will benefit from an appreciation of the domestic currency, resulting hence in a positive $\gamma_{i}$ coefficient. $^{21}$ The sign of $\gamma_{i}$ becomes less distinct for companies that are both importing and exporting. These firms' sensitivity to exchange rate fluctuations depends on the elasticity of the firms' demand for foreign goods relative to the elasticity of the foreign markets' demand for the firms' goods (Adler and Dumas, 1984; He and $\mathrm{Ng}, 1998$ ).

Testing for exchange risk exposure entails taking a stand on a number of empirical issues. One of these issues addresses the relevance of the composition of the exchange rate factor. To the extent that U.S. multinationals are not uniformly involved in the international environment, the traditional approach that uses a common trade-weighted exchange rate index to measure firms' currency exposure has a major drawback: by implicitly assuming that firms are identically exposed to the exchange rates (and the relative weights) included in the index, the model is systematically misspecified for any firm whose foreign activities doesn't correspond to the specific weighting structure of the index - distorting, hence, both the measurement and the detection of foreign exchange risk exposure (Dominguez and Tesar, 2001a,b; Ihrig, 2001). To alleviate this problem, we create for each U.S. multinational a firmand region- specific exchange risk factor based on each individual firm's trading or production links with one of the six following regions: Europe (EU), United Kingdom (UK), Asia (AS), Australia (AU), Latin America (LA) and South Africa (SA). The model then becomes:

$$
r_{i, t}=\alpha_{i}+\beta_{i} r_{m, t}+\sum_{j \in J} \gamma_{j, i} D_{j, i} \theta_{j, t}+\epsilon_{i, t}
$$

for the set $J=\{\mathrm{EU}, \mathrm{UK}, \mathrm{AS}, \mathrm{AU}, \mathrm{LA}, \mathrm{SA}\} . \gamma_{j, i}$ measure firm $i$ 's exchange risk exposure towards the euro, the U.K. pound, Asian index, the Australian dollar, Latin American index and the South African rand. $D_{j, i}$ describe the presence of firm $i$ 's real activities in Europe, the U.K., Asia, Australia, Latin America and South Africa. Depending on the presence or not of firm $i$ 's real activities in region $j$,

$$
D_{j, i}= \begin{cases}1 & \text { if firm } i \text { has foreign operations in region } j \\ 0 & \text { otherwise }\end{cases}
$$

Finally, $\theta_{j, t}$ denotes the fluctuation of the price of one euro, U.K. pound, basket of Asian currencies, Australian dollar, basket of Latin American currencies and South African rand, respectively, in terms of U.S. dollars over the period $t-k$ until $t$. As outlined in section 7.3.2, a crucial question regarding the estimation of foreign exchange risk exposure is the specification of 'unanticipated' exchange rate movements. In contrast to the vast majority of the previous empirical studies that use changes in realized spot exchange rates as a proxy for 'unanticipated' currency movements, we adopt a new empirical specification and define the 'unanticipated' part of the exchange rate movement as the difference between the 'realized' exchange

\footnotetext{
${ }^{21}$ Similarly, firms with net exposed foreign denominated liabilities will gain with a strengthening home currency, while firms with net exposed foreign denominated assets lose.
} 
rate movement and the consensus average expectation of foreign exchange market participants. The exchange risk factor $\theta_{j, t}$ is therefore defined as

$$
\theta_{j, t}= \begin{cases}x_{j, t}-x_{j, t-k} & \text { for 'realized' exchange rate changes } \\ x_{j, t}-x_{j, t-k}^{e} & \text { for 'unanticipated' exchange rate changes }\end{cases}
$$

Finally, it should be mentioned that the assumption of constant variance made in the afore-mentioned models may be violated in some cases - invalidating hence the test statistics of the ordinary least squares regression. We therefore test the residuals $\epsilon_{i, t}$ of the model in equation 7.7 for the presence of time-varying heteroscedasticity using the test Engle derived from the Lagrange multiplier principle. If we do not reject the null hypothesis that the residuals $\epsilon_{i, t}$ present no heteroscedasticity we estimate the afore-mentioned models using ordinary least squares. Otherwise a $\operatorname{GARCH}(1,1)$ specification is added to the initial model and all the parameters are estimated using maximum likelihood and generated by the Berndt et al. (1974) algorithm (Bollerslev et al., 1992):

$$
\epsilon_{i, t}=\mu_{i, t} h_{i, t}
$$

where

$$
h_{i, t}^{2}=\delta_{i}+\tau_{i} \epsilon_{i, t-k}^{2}+\nu_{i} h_{i, t-k}^{2},
$$

and where $h_{i, t}$ denotes the conditional standard deeviation of the residuals over the period $t$ until $t+k, \delta_{i}, \tau_{i}$ and $\nu_{i}$ unknown parameters, and $\mu_{i, t}$ represents the white noise error term.

\subsection{Results}

Table 7.4 presents the parameter estimates of the augmented market model described in equation 7.7, where the exchange risk factor $\theta_{t}$ is determined by the 'realized' exchange rate change (see equation 7.9). In line with Muller and Verschoor (2006a), results show that the disaggregation of the worldwide trade-weighted exchange rate index into six region-specific trade-weighted currency indices improves the detection and estimation of foreign exchange risk exposures: in comparison with Jorion (1990) who finds that out of 287 U.S. multinational corporations only 5 percent exhibit significant exchange risk exposure and Choi and Prasad (1995) who detect 15 percent of 409 multinationals to be significantly exposed, our 1-month horizon estimation of foreign exposure reveals that more than 31 percent of the 935 U.S. multinationals included in our sample are significantly affected by currency fluctuations.

Table 7.4 reports, furthermore, the distribution of the firm- and region-specific exposure coefficients $\gamma_{j, i}$ for the 3 - and 12-month measurement intervals. Consistent with Chow et al. (1997b,a) and Muller and Verschoor (2006b), our findings show that there is a general increase in the number of significant positive and negative exposure coefficients when lengthening the return horizon. The number of signif- 
Table 7.4: Exposure to Realized Exchange Rate Changes

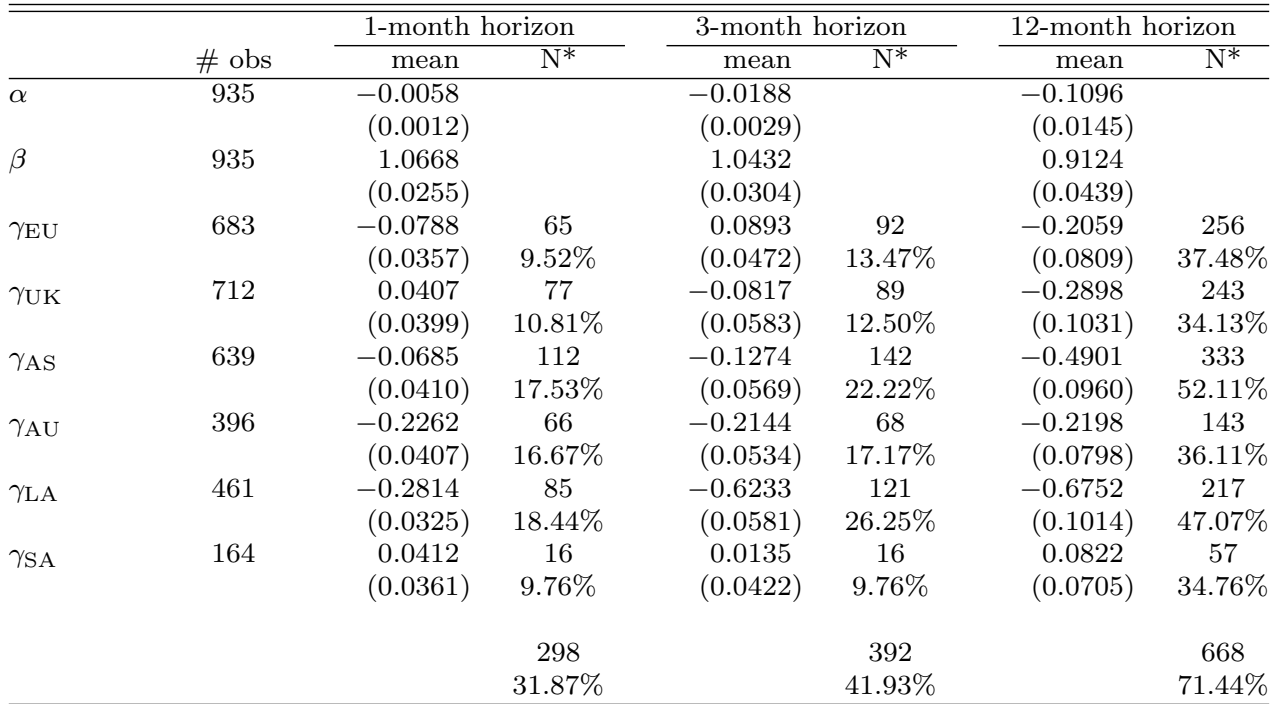

Notes. The numbers are summary statistics of the cross-sectional distribution of the ordinary least squares parameter estimates, or the maximum likelihood (using the Berndt et al., 1974, algorithm) parameter estimates of equations 7.10 and 7.11. Newey and West (1987) corrected standard deviations are in parentheses. ' $\mathrm{N}{ }^{*}$ ' designates the numbers of firms with a documented significant exchange rate exposure to the regional currency index (at least at the 5 percent significance level). '\# obs' are the numbers of firms that have activities in the corresponding geographical regions.

icantly exposed ${ }^{22}$ U.S. multinationals increases from 298 for the 1 month horizon, to 392 for the 3 month horizon and to 668 , corresponding to more than 70 percent of the total sample, for the 12 month horizon. Two arguments may explain the stronger perceptibility of long-term foreign exchange risk exposures: either financial managers ignore their shareholders' long-term exposure to foreign exchange risk in their risk-management activities - respectively are not able to properly hedge long-term economic currency exposure that is unrelated to known transactions - or investors make systematic errors when characterizing the impact of short-term exchange rate movements on firm value, rendering hence the relationship statistically and economically difficult to identify in the short-run.

In table 7.5, the sensitivity of U.S. multinationals to 'unanticipated' currency fluctuations is described. As we already expected, the use of 'unanticipated' exchange rate movements in the estimation of foreign exchange risk exposure - in line with the seminal definition of currency exposure (Shapiro, 1975; Hodder, 1982; Adler and Dumas, 1984; Levi, 1994) - strongly increases the precision and significance of U.S. multinationals' exposure estimates. Table 7.5 reports that almost 50 percent of the U.S. multinational corporations of our sample are exposed to at least one region-

\footnotetext{
${ }^{22}$ A company is defined as 'exposed' to exchange rate risk if its market-adjusted returns are statistically significantly affected by changes in currency values. Throughout the chapter the 5 percent significance level is adopted therefore.
} 
Table 7.5: Exposure to Unanticipated Exchange Rate Changes

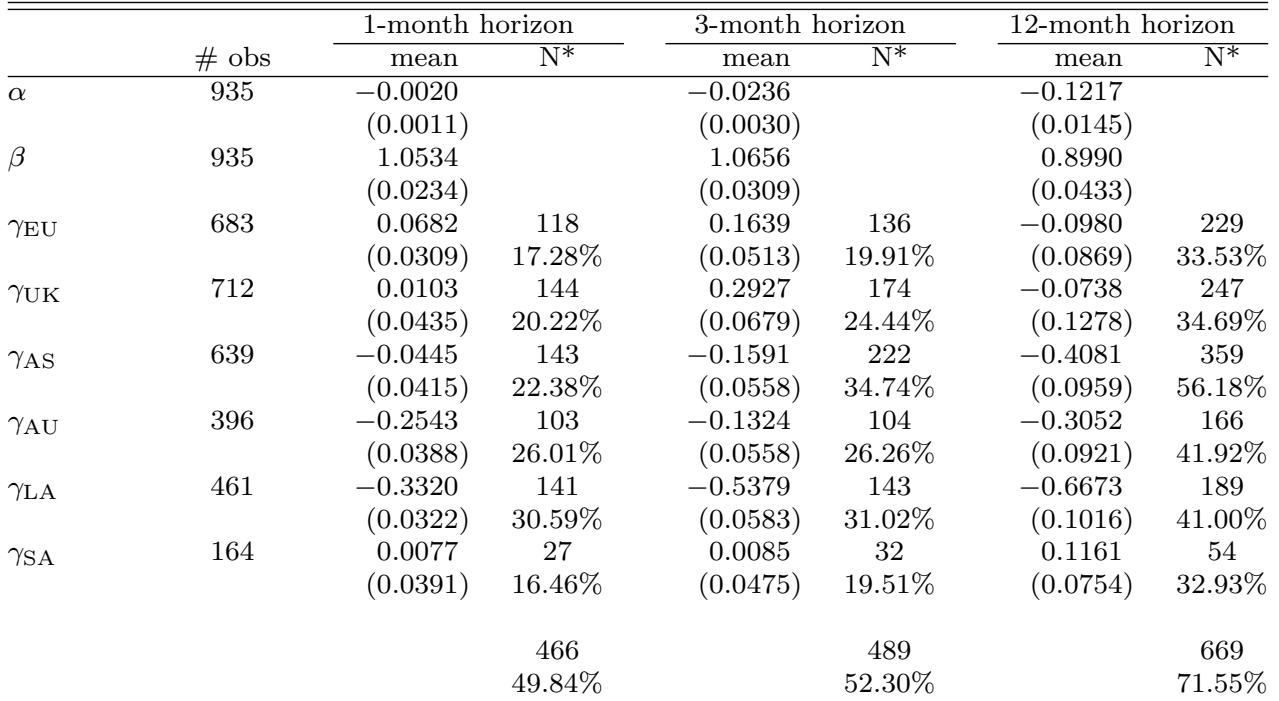

Notes. The numbers are summary statistics of the cross-sectional distribution of the ordinary least squares parameter estimates, or the maximum likelihood (using the Berndt et al., 1974, algorithm) parameter estimates of equations 7.10 and 7.11. Newey and West (1987) corrected standard deviations are in parentheses. ' $\mathrm{N}{ }^{*}$ ' designates the numbers of firms with a documented significant exchange rate exposure to the regional currency index (at least at the 5 percent significance level). '\# obs' are the numbers of firms that have activities in the corresponding geographical regions.

specific trade-weighted exchange risk factor, when forecasts are made for 1 month ahead. This result is in fierce contrast to the 30 percent of significantly exposed companies reported at the same forecast horizon of table 7.4. The exposure due to unanticipated exchange rate changes increases to over 70 percent of the firms in the sample when the forecast horizon lengthens.

The improvement of the detection of foreign exchange risk exposure reveals that U.S. shareholder wealth is less affected by movements in spot exchange rates than by the extent to which currency values change by more or less than had been expected by foreign exchange market participants. It seems therefore that foreign exchange rate expectations are reflected in the value of U.S. multinationals before their maturity and that investors make use of the publicly available forecasts of foreign exchange market participants. The stronger perceptibility of foreign exchange risk exposure may, however, as well be generated by financial managers' implemented hedging strategies. It would seem that financial managers build their hedging strategies on their perception of the overall market sentiment regarding the future evolution of exchange rates - leaving hence the company unprotected vis-à-vis unexpected currency shocks. ${ }^{23}$

\footnotetext{
${ }^{23}$ Loderer and Pichler (2000) offer empirical support to the argument that managers use their perception of future exchange rate movements for the implementation of their hedging strategies. To the extent that these perceptions are close to the consensus average value of the overall market, these strategies, that are exclusively protecting firms against expected currency fluctuations, cause
} 
Several additional points can be made from the empirical findings presented in table 7.5. The evolution of currency exposure estimates across the 1-, 3- and 12month horizon shows that, in line with our findings in table 7.4, there is a general increase in the sensitivity of U.S. companies to unexpected exchange rate movements from the 1-month to the longer 12-month horizon. It appears furthermore that most U.S. multinationals active in Asia, Australia and Latin America tend to gain (suffer) from a depreciation (appreciation) of the related currencies, indicating that they are primarily importing from these regions. On the other hand, firms with links to South Africa appear to behave like net-exporters. U.S. multinationals' foreign operations in Europe are more difficult to characterize as it appears that U.S. companies have a short-term net-exporter exposure while they have a long-term net importer exposure to both the U.K. pound and euro.

Finally, it should be emphasized that the increase in the perceptibility and precision of the exposure to 'unanticipated' versus 'realized' currency fluctuations tends to disappear when lengthening the return horizon. This would indicate that investors use more the information contained in the short-term forecasts, than in the longer-term forecasts. A question that naturally arises is whether this finding can be explained by the possibility that long-term expectations are more heterogeneousthat is, market participants disagree more about the value of the exchange rates that are farther in the future than those in the nearby future. This would be an interesting development, for it would question whether long-term expectations are mean-reverting. If expectations are mean-reverting, one would expect that these expectations are homogeneous, since the market should be aware of the underlying fundamental exchange rate or in general the rate which the exchange rate would revert to. This issue asks for a better understanding of the mechanisms behind the formation of expectations and in particular the role of dispersion of beliefs in the foreign exchange market.

Anderson et al. (2005) show that heterogeneous beliefs matter for asset pricing in that it is a priced factor in traditional factor asset pricing models and is a good predictor of return volatility in out-of-sample tests. Heterogeneity is usually a missing factor when it comes to predicting returns and volatility. Yet, little is documented about the microstructure of the foreign exchange market and the role of heterogeneous beliefs therein. Ito (1990) was the first to document the existence of heterogeneous beliefs in the foreign exchange market and finds that market participants show evidence of wishful thinking in that their expectations of future Japanese yen / U.S. dollar rates reflect what they would like to see happening to the exchange rate. ${ }^{24}$ Beine et al. (2007) furthermore find that this heterogeneity can be influenced by several market factors, like expected or unexpected official central bank intervention. Finally, there seems to be some evidence of sequential herding in the foreign exchange market in that forecasters are connected to each other through leader and imitation patterns, though the evidence is not strong (see, e.g. Beine et al., 2003).

We can learn much from the results in chapter 5 . There we showed that the

companies to be exposed to 'unexpected' exchange rate movements.

${ }^{24}$ For instance, exporters are biased towards a depreciation of the currency while importers are biased towards appreciation. 
dispersion in beliefs, as measured by the coefficient of variation, increases with the forecast horizon. Market participants obviously disagree more about the future path of the exchange rate when the horizon lengthens. Second, we showed that heterogeneity in beliefs is not constant across time. There have been periods of increased dispersion of beliefs. For example, in the aftermath of the Asian currency crisis (i.e. after 1997) there has been an obvious increase in uncertainty about the future direction of the Japanese yen, since the dispersion in beliefs increased dramatically. For these reasons, it seems plausible that the fact that on the short run the role of expected exchange rate changes is higher than on the longer run can at least be partly attributed to the fact that long-term expectations are more heterogeneous and therefore the market is more in disagreement. The lack of consensus regarding the future evolution of exchange rates may indeed cause investors to be more reluctant to incorporate these expectations in their valuation process as well as managers to be less likely to build their hedging strategies based on strongly dispersed forecasts.

\subsection{Conclusions}

This chapter is devoted to clarifying the nature, definition and estimation of foreign exchange risk exposure. While the measurement and detection of foreign exchange risk exposure has evolved and will continue to improve over time, there is no doubt that the present study offers a unique and far-reaching contribution to the existing literature. The focus on the original definition of foreign exchange risk exposure - characterized as the sensitivity of firm value to unexpected exchange rate movements - leads us indeed to confront the traditional approach used to estimate foreign exchange risk exposure (for instance in Jorion, 1990) with a new empirical specification that takes the market's perception of the future path of exchange rates into account. By explicitly testing the implications of the generally accepted assumption that unexpected currency movements may be approximated by changes in realized spot exchange rates, we do not only provide an explanation for the weak evidence reported in previous empirical work but increase as well our understanding of the economic significance and mechanism of foreign exchange risk exposuregenerating hence crucial information for any financial or political decision dealing with foreign exchange risk.

On an extensive dataset consisting of 935 U.S. multinationals with real operations in foreign countries we perform a thorough comparison of the impact of 'realized' versus 'unexpected' exchange rate movements on U.S. shareholder wealth from 1995 to 2005. Overall our results confirm the fact that the use of firm-specific trade-weighted regional exchange risk factors increases the precision and detection of foreign currency exposure estimates. The use of a unique survey-based foreign exchange rate expectations data set allows us moreover to measure in how far the extent to which exchange rates change by more or less than had been expected by foreign exchange market participants affects firm value and to verify in how far investors and managers use these publicly disclosed forecasts in their decision-making process. There is strong evidence that U.S. multinationals are less affected by actual 
currency movements than by the extent to which these movements depart from what had been expected by the market. Indeed, we find that more than 49 percent, versus less than 32 percent, of U.S. multinationals are affected by 'unexpected', versus 'realized', exchange rate movements. Investors hence seem to incorporate publicly available foreign exchange rate expectations in the valuation of U.S. multinationals before these expectations mature. The stronger perceptibility of foreign exchange risk exposure may, however, as well be caused by the fact that financial managers use market expectations to design selective hedging strategies - causing hence the company to be unprotected vis-à-vis unexpected currency shocks. 


\section{Chapter 8}

\section{Conclusions}

\subsection{Expectations in Financial Markets}

In this study we have attempted to shed new light on the role of expectations in financial markets, in particular on expectations about future exchange rates and interest rates. We have addressed several issues that so far have received only little attention. Specifically, we examined the rationality of interest rate expectations, the role of time-varying term premia in explaining the failure of the forward premium puzzle in the term structure literature, the role of dispersion of beliefs in expectations about future exchange rates, the role of time-varying weights of chartist and fundamentalist rules in forecasting future foreign exchange and the role of expected versus unanticipated exchange rate changes in generating exchange risk exposure.

The use of survey-based measures of exchange and interest rate expectations plays a central role in the entire study and hence provides an important contribution to the existing literature. Using aggregate and disaggregate measures of expectations of important players in the market allows us to get a reasonable view of the general sentiment about the future level of interest and exchange rates in the market. Although the use of survey data is not unique in the foreign exchange and interest rate literature, the topics we address are all important debates in the field and have never been approached from a survey-based point of view.

Also, the use of disaggregate measures of expectations is relatively new. Only in the past years have disaggregate measures of expectations become available and the use of these tools in financial research has opened some old discussions and has provided room for new ones. The next section gives a detailed overview of the most important findings from this research.

\subsection{Summary}

In chapter 2 we analyzed over 20 years of empirical and theoretical evidence on the role of survey-based measures of expectations in the foreign exchange market. 
First, the chapter analyzed the evidence on the failure of the forward exchange rate as an unbiased predictor of future spot exchange rates and in particular looks at whether the failure is primarily attributable to time-varying risk premiums, to the failure of the rationality assumption, or to a combination of both. The consensus emanating from the literature is that the failure of the forward premium unbiasedness is attributable both to irrational expectations and to the existence of time-varying risk premiums. Survey-based expected future spot rates are biased estimates of the true level of the future spot rate and that expectations are irrational in that agents do not use all available information efficiently.

Second, the chapter reviewed the various attempts to model the time-variation in the risk premium in foreign exchange and investigates whether the use of surveybased measures of expectations adds in this modeling. There is some support for the claim that survey-based risk premiums can be modeled by simple, low-order time series models, while most fundamentals-based models have little explanatory power overall. But the evidence also shows that aggregate measures of risk premiums average out much of the heterogeneity and richness of the individual survey expectations.

Third, chapter 2 looked at the performance of market participants when forecasting future exchange rates and tries to ascertain whether individual market participants can outperform a simple random walk forecast. While profit-based criterions to asses the forecast performance of individual market participants appear forecasters are successful in forecasting the directional change, a random walk model remains pre-eminent. Fourth, the chapter looked at the role of heterogeneity in survey-based forecasts and how this heterogeneity can shed new light on some of the puzzles in the foreign exchange market, like the excess volume of foreign exchange trade. There appears to be indeed a causal relationship that exists between the volatility in the market, the heterogeneity of expectations, and the volume in the market. And finally, the chapter reviewed the literature on fundamentalist- versus chartist-type of forecast techniques and how the interaction between these two techniques has changed over the years. It seems that over the years the role of macroeconomic fundamentals in forecasting has declined, and are only used for longer-term forecasts. Still, most market participants use a combination of these two techniques. The increased use of chartist techniques and the presence of noise traders in the foreign exchange market can, at least to some extent, explain the large trading volume in the foreign exchange market.

In chapter 3 we questioned whether expectations of future interest rates are made in a rational manner. The chapter documented one of the well-documented anomalies in the field, namely that implied forward interest rates are biased estimates of future interest rates. This is the so-called forward premium puzzle. Using a unique data set of survey-based interest rate forecast for a large set of international interest rates, where forecasts are made for several periods of different length in the future, we tried to ascertain whether the anomaly occurs because interest rate expectations are irrational. Specifically, the survey data allowed us to perform two separate tests, namely one in which we examine whether the expectations by market participants are biased and another that examines whether market participants use 
all information that is available to them in an optimal manner. While short-term interest rates sometimes appear to be rational, we corroborate the earlier finding in the literature that (longer-term) interest rate forecasts are not rational and that agents do not use all available information in an efficient manner.

The chapter also tried to find alternative approaches to the rational expectations model and investigated whether survey-based expectations are better characterized by learning behavior or mean-reversion behavior. Market participants appear to underreact to current (unanticipated) changes in the interest rate at the 3and 12-month horizons, as implied by stabilizing expectations models. Our results demonstrated that the pattern across long-term forecast horizons for foreign currency deposits corroborates the long-held view that speculation based on long-term expectations may be stabilizing.

In chapter 4 we analyzed an alternative explanation for the forward premium puzzle, namely whether the premium that market participants require for investing at a certain horizon changes over time. We called this premium the time-varying term premium. Strong evidence of the existence of a time-varying term premium in the short end of the term structure of our deposits. Term premia furthermore are commonly positive, suggesting that the premia could be liquidity premia as proclaimed by the liquidity preference theory. A closer look at the time-varying term premia reveals a large degree of persistence. Next, we turned to a novel field, namely that of trying to explain the time-variation in the premia by means of surveymeasures of expectations. We find that low-order versions of ARMA models describe the term premia well, although low-order $\mathrm{ARCH}$ effects are also present in several interest rate deposits. Finally, we find that although continental European term premia show lower degrees of persistence than other premia, the former nevertheless are time-variant and the survey respondents did make irrational forecasts, in that not all available information to market participants was used efficiently.

In chapter 5 we examined whether expectations of future exchange rates are dispersed in that agents have different beliefs about the future path of the exchange rates. We approached this problem using a panel of survey forecasts for the major three exchange rates along several forecast horizons. Using several measures for dispersion of beliefs we find that there are distinct periods of high and low dispersion where market participants disagree as to what will happen to the future level of the exchange rates. For the Japanese Yen versus the U.S. Dollar we even find that the Asian crisis that began in mid-1997 preceded an almost two-year period of highly increased dispersion of beliefs for this rate.

We tested formally whether beliefs are dispersed using an extreme value approach by examining the tail index estimates and conclude that the frequency at which extremist differences in expectations among market participants occurs, is higher than that what would occur under normality. We furthermore attempted to answer whether dispersion of beliefs occurs because market participants hold different information sets or whether they attach different weights to commonly-held elements from their information sets. We find evidence for both. The extent of individual expectations seems to increase as the forecast horizon lengthens. The dispersion based on extrapolation decreases and dispersion based in interest rate 
differences increases as the forecast horizon lengthens. These results corroborate the fundamentalist/chartist literature.

Finally, we examined whether dispersion of beliefs is influenced by volatility in the market, as suggested earlier by the increased dispersion of beliefs in the aftermath of the Asian crisis, or that heterogeneity in expectations is causal to the volatility in the market. We find that a causal relation between market volatility and trader heterogeneity tends to be significant and positive for different measures of both trader heterogeneity and market volatility.

Chapter 6 built upon the previous chapter and looked at whether dispersion of beliefs occurs because market participants use different types of rules to forecast future foreign exchange. We made the distinction between fundamentalist and chartist rules, where the former relies on various (macroeconomic) variables and the latter exclusively on the own history of the exchange rate. We developed a theoretical framework where the expected change by a particular market participant is a timevarying weighted average of a fundamentalist and chartist rule. We constructed several forecast rules that are both easy to construct and for which we know that all market participants have access to. These rules are a purchasing power paritybased rule, a rule that relies on a version of the monetary model, an extrapolative expectations rule, and a moving average rule.

These rules are then implemented in thee different models. The first model was a linear one where the weights of the various forecast techniques are assumed to be constant during the entire forecast period. We find that both chartist and fundamentalist rules are used by market participants when forecasting future exchange rates, but that the way in which the rules are used differ. Chartist rules seem, on average, be used on all forecast horizons, but the evidence is strongest at the shorter spectrum. An extrapolative rule has clearly preference over a moving average rule. On the other hand, fundamentalist rules are used predominantly for longer-term forecasts.

The second model was a heterogeneous agent model that allows for switching between the chartist and fundamentalist techniques, where switching is based on the relative success of each rule in the previous period. Although the switching parameter itself is only significant in a few number of cases, the introduction of the switching mechanism improves the performance of the model overall. This is a sign that switching between forecast rules occurs.

The last model considered was a state-space model where the weights are assumed to follow a simple, low order time-series process. It appears that the weights for the fundamentalist rules are all very persistent, in that they all seem to follow a near-unit root process. In other words, the weight the market attaches to the fundamentalist rule does not change dramatically from one period to the other. On the other hand, the significance of the chartist weights is much lower, indicating that there is much lower persistence in the weight that is attached to chartist rules and that the market is much quicker to switch from using a chartist rule from one period to the other. We also find that the correlations between the fundamentalist and chartist 'weights' are predominantly negative. This is an interesting finding, for it shows that although the market uses both fundamentalist and chartist techniques in forecasting future foreign 
exchange, the use of the rules is not independent from one another: an increase in the use of a fundamentalist rule is paired with a decrease (albeit imperfect) use of a chartist rule, and vice versa.

In chapter 7 we re-examined the existence of foreign exchange risk exposure by explicitly making the distinction between expected and unanticipated exchange rate movements. For a sample of 935 U.S. multinationals with real operations in foreign countries we performed a thorough comparison of the impact of 'realized' versus 'unanticipated' exchange rate movements on U.S. shareholder wealth from 1995 to 2005. Overall our results confirm the fact that the use of firm-specific trade-weighted regional exchange risk factors increases the precision and detection of foreign currency exposure estimates. The use of a unique survey-based foreign exchange rate expectations data set allows us moreover to measure in how far the extent to which exchange rates change by more or less than had been expected by foreign exchange market participants affects firm value and to verify in how far investors and managers use these publicly disclosed forecasts in their decision-making process. There is strong evidence that U.S. multinationals are less affected by actual currency movements than by the extent to which these movements depart from what had been expected by the market. Indeed, we find that more than 49 percent, versus less than 32 percent, of U.S. multinationals are affected by 'unexpected', versus 'realized', exchange rate movements. Investors hence seem to incorporate publicly available foreign exchange rate expectations in the valuation of U.S. multinationals before these expectations mature. The stronger perceptibility of foreign exchange risk exposure may, however, as well be caused by the fact that financial managers use market expectations to design selective hedging strategies - causing hence the company to be unprotected vis-à-vis unexpected currency shocks.

\subsection{Lessons from Expectations and Suggestions for Future Research}

We will conclude this study by discussing and interpreting several striking facts that emerge consistently from the survey data on foreign exchange and interest rate expectations. These 'facts' can be seen as a meta-analysis of the various chapters in this study. One of the most striking facts that appears consistently in this study is that the expectations by market participants are irrational in that not only market participants make consistent biases in forecasting future interest rates and exchange rates, but also miss the direction of the change and do not use all information that is available to them in an optimal way. This finding is not unique to this study, but appears consistently in the literature (see, for instance, chapters 2, 3 and 4). The rejection of the rationality assumption in the empirical corner of the financial economics literature leads to a discussion about the use of the rationality assumption in theoretical finance work. We feel that it is time to move away from this assumption and instead work towards a bounded rationality approach where we acknowledge the fact that expectations are generated under restricted conditions, by heterogeneous agents. 
A second striking fact is the apparent mean reversion in the expectations of interest rates and exchange rates. It appears that expectations eventually revert back to a long-term equilibrium rate, provided that the time between the the current situation and the moment of reversion is sufficiently large. Although the exact details around the mean reversion are still open for debate, in our study we already document evidence of mean-reversion at a forecast horizon of 1 year. Interestingly, the use of macro-economic techniques like a purchasing power parity-based rule and variables like money supply, production and interest rates are still incorporated in these meanreverting exchange rate expectations. Thus, although the failure of macro-economic techniques in forecasting future foreign exchange is well documented, market participants still use the information in these variables when forming their beliefs about future rates.

A third issue that appears in this study is the importance of the role of heterogeneity in the expectations of future exchange rates. For many years the literature has taken a single representative agent approach. In this study we have shown empirically that the expectations of market participants are significantly dispersed. Moreover, we showed that there is a relationship between this dispersion in expectations and the volatility in the market that runs in both directions. This is an important finding, for it implies that dispersion of beliefs is not a stand-alone feature, but is embedded in the day-to-day operations of the market, and is likely reflected in the exchange rates (or at minimum the volatility thereof). A better understanding of the beliefs of individual market participants therefore should help us understanding some of the anomalies presently in the market and should also help in understanding the changes in volatility, volume, and in the end a better understanding of why financial instability (and ultimately, financial crises) occurs. The relationship between dispersion and the condition in the market, like volatility and volume is complex, though, and we belief that more research in this matter is warranted. The availability of survey-based measures of expectations should be an important tool in this research.

A fourth striking issue in this study is the large 'understatement' in the literature about how multinational corporations are exposed to foreign exchange risk. There is a vast literature the extent to which multinational corporations are exposed to foreign exchange risk, when they have part of their operations or sales in foreign countries. The mainstream literature focuses on the realized changes in exchange rates as a starting point for the measurement of foreign exchange exposure. Yet, the use of survey-data allows us to truly measure exposure in the correct way, namely by looking at that part of the change in exchange rate that is unexpected. Only when an unexpected change in the exchange rate is related to the profitability of the multinational company can we truly speak about foreign exchange risk exposure. This study reports an amazing increase in the number of U.S. companies that are exposed to currency risk. The use of survey data has also in this field, once again, proven its usefulness. We therefore suggest that future research in the field of exposure should focus much more on this 'unexpected' component and suggest the use of survey data as an extremely useful tool in this debate.

A fifth fact that we would like to document is the presence of time-variation in 
many functions of interest rate and exchange rate expectations. From a methodological point of view the assumption of, for instance, constant foreign exchange risk exposure, constant term premia, and constant weights on fundamentalist and chartist forecast rules, has been very appealing. Constant parameters are easy to estimate and often directly originate from the theory. Yet, this study has shown by various different ways that the assumption of constant behavior does not hold. We find, for instance, evidence of time-varying term premia and time-varying weights of the use of various forecast rules. Therefore, we belief that future empirical research should focus much more on the role of time-varying parameters. Not only does this add more flexibility to models, it also is much more in line with the actual situation in the various market and is in line with the behavior of actual market participants.

Several issues still remain unanswered and should provide an interesting avenue for future research. First, this research has not touched upon the important area of disaggregate interest rate expectations. Important lessons may be learned in this unexplored field. For instance, Chionis and MacDonald (2002) show that the use of aggregate measures of the interest rate risk premium average out much of the heterogeneity and richness of the individual survey expectations. Much more can be learned from the individual behavior of market participants. Similarly, it should be noted that we do not address several other important topics in the field, such as the role of expectations of stock prices, inflation rates, and other macroeconomic variables. Individual survey-based expectations on most macroeconomic variables is available nowadays, yet has not been used in academic literature. We feel that this is an important and promising avenue for future research.

Also, the increased availability of disaggregate survey-based measures of foreign exchange, interest rate, and macro-economic expectations prompts for a better set of tools than have been used so far. We feel that there is plenty of opportunities for research when advanced panel data techniques are combined with the information in these disaggregated databases. This study has not been written from a panelbased point of view, but we do acknowledge that there is definitely room for future research.

Finally, we believe that the combination of various types of expectations should allow a discussion about some of the well-established financial and economic rules and parities. For instance, combining expectations data on interest rates and exchange rates can shed new light on, for instance, the uncovered interest parity debate. 



\section{Bibliography}

Adler, M. and Dumas, B. (1984). Exposure to currency risk: Definition and measurement. Financial Management, 13(2):41-50.

Allen, H. and Taylor, M. P. (1990). Charts, noise and fundamentals in the London foreign exchange market. The Economic Journal, 100(400):49-59.

Amihud, Y. (1994). Exchange rates and the valuation of equity shares. In Amihud, Y. and Levich, R. M., editors, Exchange Rates and Corporate Performance, pages 49-59. Irwin, New York.

Anderson, E. W., Ghysels, E., and Juergens, J. L. (2005). Do heterogeneous beliefs matter for asset pricing. Review of Financial Studies, 18(3):875-924.

Ang, A., Bekaert, G., and Wei, M. (2007). Do macro variables, asset markets or surveys forecast inflation better? Journal of Monetary Economics, forthcomming.

Ang, A. and Piazzesi, M. (2003). A no-arbitrage vector autoregression of term structure dynamics with macroeconomic and latent variables. Journal of Monetary Economics, 50(4):745-787.

Audretsch, D. B. and Stadtmann, G. (2005). Biases in FX-forecasts: Evidence from panel data. Global Finance Journal, 50(4):745-787.

Avraham, D., Ungar, M., and Zilberfarb, B.-Z. (1987). Are foreign exchange forecasts rational? An empirical note. Economics Letters, 24(3):291-293.

Bachetta, P. and Van Wincoop, E. (2005). Rational inattention: A solution to the forward discount puzzle. NBER Working Paper, 11633.

Baillie, R. T. and Bollerslev, T. (1990). A multivariate generalized ARCH approach to modeling risk premia in forward foreign exchange rate markets. Journal of International Money and Finance, 9(3):309-324.

Barro, R. J. (1976). Rational expectations and the role of monetary policy. Journal of Monetary Economics, 2(1):1-32.

Bartov, E. and Bodnar, G. M. (1994). Firm valuation, earnings expectations, and the exchange rate exposure effect. Journal of Finance, 49(5):1755-1785. 
Bartram, S. (2004). Linear and nonlinear foreign exchange rate exposure of German nonfinancial corporations. Journal of International Money and Finance, 23(4):673-699.

Beine, M., Bénassy-Quéré, A., and Colas, H. (2003). Imitation amongst exchangerate forecasters: Evidence from survey data. CEPII Working Paper, 2003-08.

Beine, M., Bénassy-Quéré, A., and MacDonald, R. (2007). The impact of central bank intervention on exchange-rate heterogeneity. Journal of the Japanese and International Economies, 21(1):38-63.

Bekaert, G., Hodrick, R. J., and Marshall, D. A. (1997). On biases in tests of the expectations hypothesis of the term structure of interest rates. Journal of Financial Economics, 44(3):309-348.

Bekaert, G., Hodrick, R. J., and Marshall, D. A. (2001). Peso problem explanations for term structure anomalies. Journal of Monetary Economics, 48(2):241-270.

Bekdache, B. (2001). Term premia and the maturity composition of the federal debt: New evidence from the term structure of interest rates. Journal of Forecasting, 20(7):519-539.

Bénassy, A. and Raymond, H. (1994). The heterogeneity of exchange rate expectations according to survey data. THEMA Working Paper, 9418.

Bera, A. K. and Jarque, C. M. (1982). Model specification tests: A simultaneous approach. Journal of Econometrics, 20(1):59-82.

Berk, J. M. and Knot, K. H. W. (2001). The term structure of UIP: Evidence from survey data. Applied Economics Letters, 8(7):459-462.

Berndt, E. K., Hall, H. B., Hall, R. E., and Hausman, J. A. (1974). Estimation and inference in nonlinear structural models. Annals of Economic and Social Measurement, 4:653-666.

Bhattacharya, D. (2007). Inference on inequality from household survey data. Journal of Econometrics, 137(2):674-707.

Blake, D., Beenstock, M., and Brasse, V. (1986). The performance of UK exchange rate forecasters. The Economic Journal, 96:986-999.

Bodnar, G. M. and Gentry, W. M. (1993). Exchange rate exposure and industry characteristics: Evidence from Canada, Japan and the USA. Journal of International Money and Finance, 12(1):29-45.

Bodnar, G. M. and Wong, M. H. F. (2003). Estimating exchange rate exposures: Issues in nonlinear structural models. Financial Management, 32(1):35-67.

Bollerslev, T. (1987). A conditional heteroskedastic time series model for speculative prices and rates of return. Review of Economics and Statistics, 69(3):542-547. 
Bollerslev, T., Chou, R. Y., and Kroner, K. F. (1992). ARCH modeling in finance. Journal of Econometrics, 52(1):5-59.

Boswijk, H. P., Hommes, C. H., and Manzan, S. (2007). Behavioral heterogeneity in stock prices. Journal of Economic Dynamics and Control, forthcoming.

Branch, W. A. (2004). The theory of rationally heterogeneous expectations: Evidence from survey data on inflation expectations. The Economic Journal, 114(497):592-621.

Branch, W. A. (2007). Sticky information and model uncertainty in survey data on inflation expectations. Journal of Economic Dynamics and Control, 31(1):245276.

Brooks, C., Burke, S. P., Heravi, S., and Persand, G. (2005). Autoregressive conditional kurtosis. Journal of Financial Econometrics, 3(3):399-421.

Campbell, J. Y. (1995). Some lessons from the yield curve. Journal of Economic Perspectives, 9(3):129-152.

Cavaglia, S., Verschoor, W. F. C., and Wolff, C. C. P. (1993a). Asian exchange rate expectations. Journal of the Japanese and International Economies, 7(1):57-77.

Cavaglia, S., Verschoor, W. F. C., and Wolff, C. C. P. (1993b). Further evidence on exchange rate expectations. Journal of International Money and Finance, 12(1):78-98.

Cavaglia, S., Verschoor, W. F. C., and Wolff, C. C. P. (1994). On the biasedness of forward foreign exchange rates: Irrationality or risk premia. Journal of Business, $67(3): 321-343$.

Cavaglia, S. M. F. G. and Wolff, C. C. P. (1993). Sobre el sesgo de los tipos de cambio forward: El caso de la peseta. Cuadernos Economicos de ICE, 53(1):31-43.

Cheung, Y.-W. and Chinn, M. D. (2001). Currency traders and exchange rate dynamics: A survey of the US market. Journal of International Money and Finance, 20(4):439-471.

Chinn, M. and Frankel, J. (1994a). Patterns in exchange rate forecasts for twenty-five currencies. Journal of Money, Credit, and Banking, 26(4):759-768.

Chinn, M. D. and Frankel, J. A. (1994b). More survey data on exchange rate expectations: More currencies, more horizons, more tests. University of California Working Paper.

Chionis, D. and MacDonald, R. (1997). Some tests of market microstructure hypotheses in the foreign exchange market. Journal of Multinational Financial Management, $7(3): 203-229$. 
Chionis, D. and MacDonald, R. (2002). Aggregate and disaggregate measures of the foreign exchange risk premium. International Review of Economics and Finance, 11(1):57-84.

Choi, J. J. and Prasad, A. M. (1995). Exchange risk sensitivity and its determinants: A firm and industry analysis of U.S. multinationals. Financial Management, 24(3):77-88.

Chow, E. H., Lee, W. Y., and Solt, M. E. (1997a). The economic exposure of U.S. multinational firms. Journal of Financial Research, 20(2):191-210.

Chow, E. H., Lee, W. Y., and Solt, M. E. (1997b). The exchange-rate risk exposure of asset returns. Journal of Business, 70(1):105-123.

Christiansen, C. (2003). Testing the expectations hypothesis using long-maturity forward rates. Economics Letters, 78(2):175-180.

Covrig, V. and Melvin, M. (2002). Asymmetric information and price discovery in the FX market: Does Tokyo know more about the Yen. Journal of Empirical Finance, 9(3):271-285.

Cox, J. C., Ingersoll, J. E., and Ross, S. A. (1985). A theory of the term structure of interest rates. Econometrica, 53(2):385-407.

Cumperayot, P. (2002). Dusting off the perception of risk and returns in FOREX markets. CESifo Working Paper, 904.

Dahlquist, M. and Jonsson, G. (1995). The information in Swedish short-maturity forward rates. European Economic Review, 39(6):1115-1131.

Dai, Q. and Singleton, K. J. (2002). Expectations puzzles, time-varying risk premia, and affine models of the term structure. Journal of Financial Economics, $63(3): 415-441$.

De Grauwe, P. and Grimaldi, M. (2005). Heterogeneity of agents, transactions costs and the exchange rate. Journal of Economic Dynamics and Control, 29(4):691719 .

De Grauwe, P. and Grimaldi, M. (2006). Exchange rate puzzles: A tale of switching attractors. European Economic Review, 50(1):1-33.

De Grauwe, P. and Rovira Kaltwasser, P. (2007). Modeling optimism and pessimism in the foreign exchange market. Katholieke Universiteit Leuven mimeo.

De Haan, L., Resnick, S. I., Rootzén, H., and De Vries, C. G. (1989). Extremal behaviour of solutions to a stochastic difference equation with applications to ARCH-processes. Stochastic Processes and their Applications, 32(2):213-224.

De Jong, E., Verschoor, W. F. C., and Zwinkels, R. C. J. (2006). Behavioural heterogeneity and shift-contagion: Evidence from the Asian crisis. NiCE Working Paper. 
De Long, J. B., Shleifer, A., Summers, L. H., and Waldmann, R. J. (1990). Noise trader risk in financial markets. Journal of Political Economy, 98(4):703-738.

Dewenter, K. L., Higgins, R. C., and Simin, T. T. (2005). Can event study methods solve the currency exposure puzzle? Pacific-Basin Finance Journal, 13(2):119144.

Di Tella, R. and MacCulloch, R. (2005). The consequences of labor market flexibility: Panel evidence based on survey data. European Economic Review, 49(5):12251259.

Dokko, Y. and Edelstein, R. H. (1989). How well do economists forecast stock market prices? A study of the Livingston surveys. American Economic Review, $79(4): 865-871$.

Domínguez, E. and Novales, A. (2000). Testing the expectations hypothesis in Eurodeposits. Journal of International Money and Finance, 19(5):713-736.

Dominguez, K. M. (1986). Are foreign exchange forecasts rational? New evidence from survey data. Economics Letters, 21(3):277-281.

Dominguez, K. M. and Frankel, J. A. (1993). Does foreign-exchange intervention matter? The portfolio effect. American Economic Review, 83(5):1356-1369.

Dominguez, K. M. and Tesar, L. L. (2001a). A re-examination of exchange rate exposure. American Economic Review, 91(2):396-399.

Dominguez, K. M. and Tesar, L. L. (2001b). Trade and exposure. American Economic Review, 91(2):367-370.

Domowitz, I. and Hakkio, C. S. (1985). Conditional variance and the risk premium in the foreign exchange market. Journal of International Economics, 19(1):47-66.

Dornbusch, R. (1976). Expectations and exchange rate dynamics. Journal of Political Economy, 84(6):1161-1176.

Dutt, S. D. and Ghosh, D. (1997). Are experts' expectations rational? A multicurrency analysis. Applied Economics, 29(6):803-812.

Elliott, G. and Ito, T. (1999). Heterogeneous expectations and tests of efficiency in the yen/dollar forward exchange rate market. Journal of Monetary Economics, $43(2): 435-456$.

Engel, C. (1996). The forward discount anomaly and the risk premium: A survey of recent evidence. Journal of Empirical Finance, 3(2):123-192.

Engle, R. F. and Granger, C. W. J. (1987). Co-integration and error correction: Representation, estimation, and testing. Econometrica, 55(2):251-276.

Engle, R. F., Lilien, D. M., and Robins, R. P. (1987). Estimating time varying risk premia in the term structure: The ARCH-M model. Econometrica, 55(2):391-407. 
Evans, M. D. D. and Lyons, R. K. (2002). Order flow and exchange rate dynamics. Journal of Political Economy, 110(1):170-180.

Fama, E. F. (1984a). Forward and spot exchange rates. Journal of Monetary Economics, 14(3):319-338.

Fama, E. F. (1984b). The information in the term structure. Journal of Financial Economics, 13(4):309-528.

Fan, M. and Lyons, R. K. (2001). Customer trades and extreme events in the foreign exchange. In Mizen, P., editor, Monetary History, Exchange Rates and Financial Markets. Edward Elgar, Northampton.

Faust, J., Rogers, J. H., and Wright, J. H. (2003). Exchange rate forecasting: The errors we've really made. Journal of International Economics, 60(1):35-59.

Fernandez-Villaverde, J. and Krueger, D. (2007). Consumption over the life cycle: Facts from consumer expenditure survey data. Review of Economics and Statistics, $89(3): 552-565$.

Fischer, A. M. (1989). Unit roots and survey data. Oxford Bulletin of Economics and Statistics, 51(4):451-463.

Frankel, J. A. (1982). A test of perfect substitutability in the foreign exchange market. Southern Economic Journal, 49(2):406-416.

Frankel, J. A. and Chinn, M. D. (1993). Exchange rate expectations and the risk premium: Tests for a cross section of 17 currencies. Review of International Economics, 1(2):136-144. NBER Working Paper no. 3806.

Frankel, J. A. and Froot, K. A. (1986). Understanding the US dollar in the eighties: The expectations of chartists and fundamentalists. The Economic Record, 62(supplement):24-38.

Frankel, J. A. and Froot, K. A. (1987a). Short-term and long-term expectations of the yen/dollar exchange rate: Evidence from survey data. Journal of the Japanese and International Economies, 1(3):249-274.

Frankel, J. A. and Froot, K. A. (1987b). Using survey data to test standard propositions regarding exchange rate expectations. American Economic Review, $77(1): 133-153$.

Frankel, J. A. and Froot, K. A. (1988). Chartists, fundamentalists and the demand for dollars. Greek Economic Review, 10(1):49-102.

Frankel, J. A. and Froot, K. A. (1990a). Chartists, fundamentalists, and trading in the foreign exchange market. American Economic Review, 80(2):181-185.

Frankel, J. A. and Froot, K. A. (1990b). Exchange rate forecasting techniques, survey data, and implications for the foreign exchange market. NBER Working Paper, 3470. 
Frankel, J. A. and Rose, A. K. (1995). Empirical research on nominal exchange rates. In Grossman, G. and Rogoff, K., editors, Handbook of International Economics, volume 3, chapter 33, pages 1689-1729. North-Holland, Amsterdam.

Frenkel, J. A. (1976). A monetary approach to the exchange rate: Doctrinal aspects and empirical evidence. Scandinavian Journal of Economics, 78(2):200-224.

Friedman, B. M. (1979). Interest rate expectations versus forward rates: Evidence from an expectations survey. Journal of Finance, 34(4):965-973.

Friedman, B. M. (1980). Survey evidence of the 'rationality' of interest rate expectations. Journal of Monetary Economics, 6(4):453-465.

Froot, K. A. (1989). New hope for the expectations hypothesis of the term structure of interest rates. Journal of Finance, 44(2):283-305.

Froot, K. A. and Frankel, J. A. (1989). Forward discount bias: Is it an exchange risk premium? Quarterly Journal of Economics, 104(1):139-161.

Froot, K. A. and Thaler, R. H. (1990). Anomalies: Foreign exchange. Journal of Economic Perspectives, 4(3):179-192.

Gan, W. B. and Wong, K. S. (1993). Exchange rate expectations and risk premium in the Singapore/US dollar exchange rate: Evidence from survey data. Applied Financial Economics, 3(4):365-373.

Gao, T. (2000). Exchange rate movements and the profitability of U.S. multinationals. Journal of International Money and Finance, 19(1):117-134.

Gerlach, S. and Smets, F. (1997). The term structure of Euro-rates: Some evidence in support of the expectations hypothesis. Journal of International Money and Finance, 16(2):305-321.

Giorgianni, L. (1997). Foreign exchange risk premium: Does fiscal policy matter? Evidence from Italian data. IMF Working Paper, WP/97/39.

Griffin, J. M. and Stulz, R. M. (2001). International competition and exchange rate shocks: A cross-country industry analysis of stock returns. Review of Financial Studies, 14(1):215-241.

Hafer, R. W., Hein, S. E., and MacDonald, S. S. (1992). Market and survey forecasts of the three-month treasury-bill rate. Journal of Business, 65(1):123-138.

Hansen, L. P. (1982). Large sample properties of generalized Methods of Moments estimators. Econometrica, 50(4):1029-1054.

Hansen, L. P. and Hodrick, R. J. (1980). Forward exchange rates as optimal predictors of future spot rates: An econometric analysis. Journal of Political Economy, 88(5):829-853. 
Harris, R. D. F. (2001). The expectations hypothesis of the term structure and time-varying risk premia: A panel data approach. Oxford Bulletin of Economics and Statistics, 63(2):233-245.

He, J. and Ng, L. K. (1998). The foreign exchange exposure of Japanese multinational corporations. Journal of Finance, 53(2):733-753.

Hejazi, W., Lai, H., and Yang, X. (2000). The expectations hypothesis, term premia, and the Canadian term structure of interest rates. Canadian Journal of Economics, 33(1):133-148.

Henry, O. T. (1999). The volatility of US term structure term premia 1952-1991. Applied Financial Economics, 9(3):263-271.

Hicks, J. R. (1939). Value and Capital: An Inquiry into Some Fundamental Principles of Economic Theory. Clarendon Press, Oxford.

Hill, B. M. (1975). A simple general approach to inference about the tail of a distribution. Annals of Statistics, 3(5):1163-1174.

Hodder, J. E. (1982). Exposure to exchange-rate movements. Journal of International Economics, 13(3-4):375-386.

Hodrick, R. J. (1987). The Empirical Evidence on the Efficiency of Forward and Futures Foreign Exchange Markets. Harwood Academic Publishers, Chur, Switzerland.

Hommes, C. H. (2006). Heterogeneous agents models in economics and finance. In Tesfatsion, L. and Judd, K. L., editors, Handbook of Computational Economics, volume 2: Agent-Based Computational Economics. North-Holland, Amsterdam.

Hsieh, D. A. (1984). Tests of rational expectations and no risk premium in forward exchange markets. Journal of International Economics, 17(1-2):173-184.

Ihrig, J. E. (2001). Exchange-rate exposure of multinationals: Focusing on exchangerate issues. Federal Reserve Board International Finance Discussion Papers, 709.

Ito, T. (1990). Foreign exchange rate expectations: Micro survey data. American Economic Review, 80(3):434-449.

Ito, T. (1994). Short-run and long-run expectations of the yen/dollar exchange rate. Journal of the Japanese and International Economies, 8(2):119-143.

Johansen, S. (1991). Estimation and hypothesis testing of cointegration vectors in Gaussian vector autoregressive models. Econometrica, 59(6):1551-1580.

Jondeau, E. and Ricart, R. (1999). The expectations hypothesis of the term structure: Tests on US, German, French, and UK Euro-rates. Journal of International Money and Finance, 18:725-750. 
Jorion, P. (1990). The exchange rate exposure of U.S. multinationals. Journal of Business, 63(3):331-345.

Jorion, P. (1991). The pricing of exchange rate risk in the stock market. Journal of Financial and Quantitative Analysis, 26(3):363-376.

Keane, M. P. and Runkle, D. E. (1990). Testing the rationality of price forecasts: New evidence from panel data. American Economic Review, 80(4):714-735.

Kim, S.-J. (1997). Testing the rationality of exchange rate and interest rate expectations: An empirical study of Australian survey-based expectations. Applied Economics, 29(8):1011-1022.

Koutmos, G. and Martin, A. D. (2003a). Asymmetric exchange rate exposure: Theory and evidence. Journal of International Money and Finance, 22(3):365383.

Koutmos, G. and Martin, A. D. (2003b). First- and second-moment exchange rate exposure: Evidence from U.S. stock returns. Financial Review, 38(3):455-471.

Krasker, W. S. (1980). The 'peso problem' in testing the efficiency of forward exchange markets. Journal of Monetary Economics, 6(2):269-276.

Kurz, M. (1994). On the structure and diversity of rational beliefs. Economic Theory, $4(6): 877-900$.

Kurz, M. and Motolese, M. (2001). Endogenous uncertainty and market volatility. Economic Theory, 17(3):497-544.

Kwiatkowski, D., Phillips, P. C. B., Schmidt, P., and Shin, Y. (1992). Testing the null hypothesis of stationarity against the alternative of a unit root. Journal of Econometrics, 54(1-3):159-178.

Lee, S.-S. (1995). Macroeconomic sources of time-varying risk premia in the term structure of interest rates. Journal of Money, Credit, and Banking, 27(2):549-569.

Levi, M. D. (1994). Exchange rates and the valuation of firms. In Amihud, Y. and Levich, R. M., editors, Exchange Rates and Corporate Performance, pages 37-48. Irwin, New York.

Lewis, K. K. (1989). Changing beliefs and systematic rational forecast errors with evidence from foreign exchange. American Economic Review, 79(4):621-636.

Lim, G. C. and McKenzie, C. R. (1998). Testing the rationality of expectations in the Australian foreign exchange market using survey data with missing observations. Applied Financial Economics, 8(2):181-190.

Liu, P. C. (1996). The effects of the fundamentalists' and chartists' expectations on market survey. Applied Financial Economics, 6(4):363-366. 
Liu, P. C. and Maddala, G. S. (1992a). Rationality of survey data and tests for market efficiency in the foreign exchange markets. Journal of International Money and Finance, 11(4):366-381.

Liu, P. C. and Maddala, G. S. (1992b). Using survey data to test market efficiency in the foreign exchange markets. Empirical Economics, 17(2):303-314.

Liu, Y.-H. and Mole, D. (1998). The use of fundamental and technical analyses by foreign exchange dealers: Hong Kong evidence. Journal of International Money and Finance, 17(3):535-545.

Loderer, C. and Pichler, K. (2000). Firms, do you know your currency risk exposure? Journal of Empirical Finance, 7(3-4):317-344.

Lucas, R. E. (1972). Expectations and the neutrality of money. Journal of Economic Theory, 4(2):103-124.

Lucas, R. E. (1976). Econometric policy evaluation: A critique. In Brunner, K. and Meltzer, A. H., editors, The Phillips Curve and Labor Markets. North-Holland, Amsterdam.

Lucas, R. E. (1982). Interest rates and currency prices in a two-country world. Journal of Monetary Economics, 10(3):335-359.

Lutz, F. A. (1940). The structure of interest rates. Quarterly Journal of Economics, $55(1): 36-63$.

MacDonald, R. (1990). Are foreign exchange market forecasters "rational"?: Some survey-based tests. The Manchester School, 58(3):229-241.

MacDonald, R. (1992). Exchange rate survey data: A disaggregated G-7 perspective. The Manchester School, 60(supplement: Papers in Money, Macroeconomics and Finance):47-62.

MacDonald, R. (1995). Long-run exchange rate modeling. IMF Staff Papers, $42(3): 437-489$.

MacDonald, R. (2000a). Expectations formation and risk in three financial markets: Surveying what the surveys say. Journal of Economic Surveys, 14(1):69-100.

MacDonald, R. (2000b). Is the foreign exchange market 'risky'? Some new surveybased results. Journal of Multinational Financial Management, 10(1):1-14.

MacDonald, R. and Macmillan, P. (1994). On the expectations view of the term structure, term premia and survey-based expectations. The Economic Journal, 104(425):1070-1086.

MacDonald, R. and Marsh, I. W. (1994). Combining exchange rate forecasts: What is the optimal consensus measure? Journal of Forecasting, 13(3):313-332. 
MacDonald, R. and Marsh, I. W. (1996). Currency forecasters are heterogeneous: Confirmation and consequences. Journal of International Money and Finance, $15(5): 665-685$.

MacDonald, R. and Torrance, T. S. (1988a). Exchange rates and the "news": Some evidence using U.K. survey data. The Manchester School, 56(1):69-76.

MacDonald, R. and Torrance, T. S. (1988b). On risk, rationality and excessive speculation in the Deutschmark-US dollar exchange market: Some evidence using survey data. Oxford Bulletin of Economics and Statistics, 50(2):107-123.

MacDonald, R. and Torrance, T. S. (1989). Some survey-based tests of uncovered interest parity. In MacDonald, R. and Taylor, M. P., editors, Exchange Rates and Open Economy Macroeconomics, pages 239-248. Basil Blackwell, Oxford.

MacDonald, R. and Torrance, T. S. (1990). Expectations formation and risk in four foreign exchange markets. Oxford Economic Papers, 42:544-561.

MacKinnon, J. G., Haug, A. A., and Michelis, L. (1999). Numerical distribution functions of likelihood ratio tests for cointegration. Journal of Applied Econometrics, 14(5):563-577.

Maddala, G. S. (1991). Survey data on expectations: What have we learnt? In Nerlove, M., editor, Issues in Contemporary Economics: Proceedings of the Ninth World Congress of the International Economic Association, volume 2 (Macroeconomics and Econometrics), pages 319-344. MacMillan Academic and Professional Ltd., London.

Madsen, E. S. (1996). Inefficiency of foreign exchange markets and expectations: Survey evidence. Applied Economics, 28(4):397-403.

Marsh, I. W. (1999). An analysis of the performance of European foreign exchange forecasters. City University Business School Working Paper.

Marsh, I. W. and Power, D. M. (1996). A note on the performance of foreign exchange forecasters in a portfolio framework. Journal of Banking and Finance, 20(3):605-613.

Meese, R. (1990). Currency fluctuations in the post-Bretton Woods era. Journal of Economic Perspectives, 4(1):117-134.

Meese, R. A. and Rogoff, K. (1976). The out-of-sample failure of empirical exchange rate models: Sampling errors or misspecification? In Frenkel, J., editor, Exchange Rates and International Macroeconomics. University of Chicago Press, Chicago.

Meese, R. A. and Rogoff, K. (1983). Empirical exchange rate models of the seventies: Do they fit out of sample? Journal of International Economics, 14(1):3-24.

Meese, R. A. and Singleton, K. J. (1982). On unit roots and the empirical modeling of exchange rates. Journal of Finance, 37(4):1029-1035. 
Menkhoff, L. and Taylor, M. P. (2006). The obstinate passion of foreign exchange professionals: Technical analysis. Journal of Economic Literature, forthcoming.

Mitchell, J. (2007). Uncertainty in UK manufacturing: Evidence from qualitative survey data. Economics Letters, 94(2):245-252.

Modigliani, F. and Shiller, R. J. (1973). Inflation, rational expectations, and the term structure of interest rates. Economica, 40(157):12-43.

Muller, A. and Verschoor, W. F. C. (2006a). Asymmetric foreign exchange risk exposure: Evidence from U.S. multinational firms. Journal of Empirical Finance, $13(4-5): 495-518$.

Muller, A. and Verschoor, W. F. C. (2006b). European foreign exchange risk exposure. European Financial Management, 12(2):195-220.

Muller, A. and Verschoor, W. F. C. (2006c). Foreign exchange risk exposure: Survey and suggestions. Journal of Multinational Financial Management, 16(4):385-410.

Mussa, M. M. (1976). The exchange rate, the balance of payments, and monetary and fiscal policy under a regime of controlled floating. Scandinavian Journal of Economics, 78(2):229-248.

Muth, J. F. (1961). Rational expectations and the theory of price movements. Econometrica, 29(3):315-335.

Newey, W. K. and West, K. D. (1987). A simple, positive semi-definite, heteroskedasticity and autocorrelation consistent covariance matrix. Econometrica, 55(3):703708 .

Newey, W. K. and West, K. D. (1994). Automatic lag selection in covariance matrix estimation. Review of Economic Studies, 61(4):631-653.

Nieuwland, F. G. M. C., Verschoor, W. F. C., and Wolff, C. C. P. (1998). EMS exchange rate expectations and time-varying risk premia. Economics Letters, $60(3): 351-355$.

Nieuwland, F. G. M. C., Verschoor, W. F. C., and Wolff, C. C. P. (2000). Exchange risk premia in the European monetary system. Applied Financial Economics, $10(4): 351-360$.

Payne, R. (2003). Informed trade in spot foreign exchange markets: An empirical investigation. Journal of International Economics, 61(2):307-329.

Peel, D. A. and Pope, P. F. (1989). Empirical evidence on the properties of exchange rate forecasts and the risk premium. Economics Letters, 31(4):387-391.

Peiers, B. (1997). Informed traders, intervention, and price leadership: A deeper view of the microstructure of the foreign exchange market. Journal of Finance, 52(4):1589-1614. 
Pesaran, M. H. (1987). The Limits to Rational Expectations. Basil Blackwell, Oxford.

Porto, G. G. (2006). Using survey data to assess the distributional effects of trade policy. Journal of International Economics, 70(1):140-160.

Rapach, D. E. and Weber, C. E. (2004). Are real interest rates really nonstationary? New evidence from tests with good size and power. Journal of Macroeconomics, 26(3):409-430.

Rose, A. K. (1988). Is the real interest rate stable? Journal of Finance, 43(5):10951112 .

Rudebusch, G. D. and Wu, T. (2004). A macro-finance model of the term structure, monetary policy, and the economy. Federal Reserve Bank of San Francisco Working Paper, 2003-17.

Sargent, T. J. and Wallace, N. (1975). "Rational" expectations, the optimal monetary instrument, and the optimal money supply rule. Journal of Political Economy, 83(2):241-254.

Shalen, C. T. (1993). Volume, volatility, and the dispersion of beliefs. Review of Financial Studies, 6(2):405-434.

Shapiro, A. C. (1975). Exchange rate changes, inflation and the value of multinational corporations. Journal of Finance, 30(2):485-502.

Shiller, R. J. (1990). The term structure of interest rates. In Friedman, B. M. and Hahn, F. H., editors, Handbook of Monetary Economics, volume 1, chapter 33, pages 627-722. North-Holland, Amsterdam.

Shiller, R. J., Campbell, J. Y., and Schoenholtz, K. L. (1983). Forward rates and future policy: Interpreting the term structure of interest rates. Brookings Papers on Economic Activity, 1:173-223.

Sims, C. A. (2003). Implications of rational inattention. Journal of Monetary Economics, 50(3):665-690.

Smoluk, H. J., Vasconcellos, G. M., and Kramer, J. K. (1998). Random walks in the U.K. Pound/U.S. Dollar exchange rates. International Review of Financial Analysis, 7(1):65-82.

Sobiechowski, D. (1996). Rational expectations in the foreign exchange market? Some survey evidence. Applied Economics, 28(12):1601-1611.

Strong, N. and Xu, X. (2003). Understanding the equity home bias: Evidence from survey data. Review of Economics and Statistics, 85(2):307-312.

Takagi, S. (1991). Exchange rate expectations: A survey of survey studies. IMF Staff Papers, 38(1):156-183. 
Taylor, A. M. and Taylor, M. P. (2004). The purchasing power parity debate. Journal of Economic Perspective, 18(4):135-158.

Taylor, M. P. (1989). Expectations, risk and uncertainty in the foreign exchange market: Some results based on survey data. The Manchester School, 57(2):142153.

Taylor, M. P. and Allen, H. (1992). The use of technical analysis in the foreign exchange market. Journal of International Money and Finance, 11(3):304-314.

Thornton, D. L. (2005). Predictions of short-term rates and the expectations hypothesis of the term structure of interest rates. Federal Reserve Bank of St. Louis Working Paper, 2005-010A.

Tzavalis, E. and Wickens, M. R. (1995). The persistence in volatility of the us term premium 1970-1986. Economics Letters, 49(4):381-389.

Urrutia, J. L. (1992). Variance ratio tests of random walk for foreign exchange rates. Economics Letters, 38(4):457-465.

Vasicek, O. (1977). An equilibrium characterization of the term structure. Journal of Financial Economics, 5(2):177-188.

Verschoor, W. F. C. (1993). Forward Exchange Market Dynamics: An Empirical Analysis of Expectations, Risk and Innovations in Forward Foreign Exchange. PhD thesis, Rijksuniversiteit Limburg, Maastricht, The Netherlands.

Verschoor, W. F. C. and Wolff, C. C. P. (2001a). Exchange risk premia, expectations formation and "news" in the Mexican peso/U.S. dollar forward exchange rate market. International Review of Financial Analysis, 10(2):157-174.

Verschoor, W. F. C. and Wolff, C. C. P. (2001b). Scandinavian forward discount bias risk premia. Economics Letters, 73(1):65-72.

Verschoor, W. F. C. and Wolff, C. C. P. (2002). Scandinavian exchange rate expectations. Applied Economics Letters, 9(2):111-116.

Wolff, C. C. P. (1987a). Forward foreign exchange rates, expected spot rates, and premia: A signal-extraction approach. Journal of Finance, 42(2):395-406.

Wolff, C. C. P. (1987b). Time-varying parameters and the out-of-sample forecasting performance of structural exchange rate models. Journal of Business and Economic Statistics, 5(1):87-97.

Wolff, C. C. P. (2000). Forward foreign exchange rates and expected future spot rates. Applied Financial Economics, 10(4):371-377. 


\section{Nederlandse Samenvatting}

In financiële markten spelen verwachtingen een bijzonder belangrijke rol. Het gedrag dat personen vertonen die deelnemen aan financiële markten, de zogenaamde 'marktparticipanten', wordt vaak gedreven door wat deze marktparticipanten verwachten van de toekomst. Veel theoretische modellen en theorieën in de financiële literatuur veronderstellen een relatie tussen de huidige stand van zaken en de verwachte toekomstige situatie.

Dit proefschrift probeert bij te dragen aan een vernieuwende kijk op de rol van deze verwachtingen en in het bijzonder aan wat we kunnen leren van verwachtingen. Het domein van dit onderzoek beperkt zich tot twee markten: de markt voor vreemde valuta's en de kapitaalmarkt. Binnen dit domein stellen wij ons de volgende kernvragen: 1) In hoeverre worden verwachtingen binnen de rentemarkt op een rationele manier gevormd?, 2) Zijn termijnpremies, die doorgaans aanwezig zijn binnen rentecontracten, tijdsvariërend en wat is de oorzaak hiervan?, 3) In hoeverre verschillen de verwachtingen van marktparticipanten over de toekomstige stand van wisselkoersen en waar is dit verschil aan te wijten?, 4) In hoeverre gebruiken marktparticipanten verschillende technieken om toekomstige wisselkoersen te voorspellen?, 5) Wat is de invloed van verwachte wisselkoersveranderingen op het risico dat bedrijven lopen, wanneer ze aan wisselkoersrisico worden blootgesteld?

Een kernpunt van dit proefschrift is dat we deze vijf vragen proberen te analyseren aan de hand van verwachtingsdata die door enquetes zijn verzameld. Verwachtingsdata worden verkregen door aan verschillende marktparticipanten te vragen naar hun subjectieve mening ten aanzien van de toekomstige stand van een variabele, bijvoorbeeld een vreemde valuta of een rente. Door meerdere van deze individuele verwachtingen te bundelen hopen we een beter idee te krijgen over hoe marktparticipanten 'denken', wat hun algemene verwachting is, maar ook hoe de verschillen die optreden, een invloed hebben op de huidige ontwikkelingen in de markt.

Hoofdstuk 2 bekijkt de rol van verwachtingsdata binnen de markt voor vreemde valuta, waarbij empirische en theoretische studies over een tijdspanne van ruim 20 jaar worden geanalyseerd. Het hoofdstuk behandelt vijf vraagstukken. Ten eerste wordt bekeken waarom de prijs van termijncontracten een consistent slechte voorspeller is van de prijs van toekomstige vreemde valuta's, ondanks dat dit theoretisch wel het geval zou moeten zijn.

Ten tweede wordt gekeken naar verschillende technieken om tijdsvariatie in risicopremies te verklaren en te modelleren en in hoeverre het gebruik van verwach- 
tingsdata hierbij een rol kan spelen. Eenvoudige tijdreeksmodellen (zoals die van de ARMA-klasse en de GARCH-klasse) blijken redelijk goed deze tijdsvariatie te kunnen verklaren, terwijl macro-economische modellen gebaseerd op fundamentele variabelen dit niet kunnen. Er moet echter wel een kanttekening worden geplaatst: wanneer geaggregeerde verwachtingsdata (een gemiddelde van de verwachtingen van meerdere marktparticipanten) worden gebruikt, gaat veel van de heterogeniteit en voorspelkracht van de individuele verwachtingen verloren. Het gevolg hiervan is dat de door ons bekeken modellen nooit echt goed presteren in het verklaren van deze tijdsvariatie.

Als derde wordt gekeken naar de mate waarin marktparticipanten toekomstige wisselkoersen kunnen voorspellen. Alhoewel voorspeltechnieken gebaseerd op de winst die marktparticipanten kunnen behalen, adequaat zijn in het voorspellen van de richting van de wisselkoersverandering (toename of afname), blijkt de meest basale voorspeltechniek (die van geen verandering) nog steeds moeilijk te overtreffen door meer geavanceerde technieken.

Ten vierde wordt gekeken naar de rol van heterogeniteit in de verwachtingsdata (ofwel: de mate waarin verwachtingen van marktparticipanten van elkaar verschillen) en hoe deze heterogeniteit een nieuw licht kan werpen op bestaande onregelmatigheden, zoals het bijzonder hoge volume van vreemde valuta's die dagelijks wereldwijd worden verhandeld. Er blijkt ruimte te zijn voor een complex causaal verband tussen de mate waarin verwachtingen van elkaar verschillen, de volatiliteit van de markt en het verhandelde volume van vreemde valuta's.

Tenslotte bekijkt hoofdstuk 2 de literatuur over de verschillen in voorspeltechnieken die worden gebruikt door marktparticipanten die als 'fundamentalist' worden getypeerd (marktparticipanten die voornamelijk gebruik maken van macroeconomische variabelen) en 'technische' analisten (marktparticipanten die hun analyse voornamelijk baseren op het verleden van de wisselkoers) en hoe de interactie tussen deze technieken door de jaren heen is veranderd. Macro-economische variabelen hebben de laatste jaren aan belang ingeboet en worden voornamelijk gebruikt voor langetermijnvoorspellingen. Toch geven marktparticipanten aan van beide technieken gebruik te maken. De toename van het gebruik van technische analyse en aanwezigheid van handelaren die vanwege puur speculatieve doeleinden deelnemen aan de markt voor vreemde valuta's, kan ten dele verklaren waarom het dagelijks verhandelde volume van vreemde valuta's zo groot is. De bevindingen in hoofdstuk 2 geven de aanzet voor de vijf empirische hoofdstukken die hierop volgen.

Enkele technieken die in hoofdstuk 2 bekeken zijn, passen we in hoofdstuk 3 toe op het gebied van rentecontracten. Centraal in het hoofdstuk staan de geconstateerde systematische voorspelfouten in de prijsvorming van termijncontracten, zoals die al jaren worden beschreven in de literatuur. We stellen ons de vraag in hoeverre renteverwachtingen op een rationele manier worden gevormd en in hoeverre verwerping van deze rationaliteit de de slechte voorspelkracht van termijnkoersen kan verklaren. Door gebruik te maken van een unieke dataset van renteverwachtingen kunnen we twee criteria voor rationeel gedrag toetsen, namelijk of verwachtingen voorspelfouten bevatten en of marktparticipanten alle informatie gebruiken die voor hen beschikbaar is bij het vormen van hun verwachtingen. Beide criteria zijn maat- 
staven voor rationeel gedrag. Alhoewel kortetermijnverwachtingen op een rationele wijze gevormd worden, wordt voor langetermijnverwachtingen geen optimaal gebruik gemaakt van alle beschikbare informatie en kunnen deze verwachtingen derhalve ook niet als rationeel worden bestempeld.

In dit hoofdstuk wordt ook gekeken naar alternatieve manieren om verwachtingen te modelleren. Twee mogelijke karakteristieken van verwachtingen staan hierin centraal, namelijk of marktparticipanten leergedrag vertonen (het leren van eerdere fouten bijvoorbeeld) en of verwachtingen uiteindelijk convergeren naar een langetermijnniveau. We tonen aan dat kortetermijnverwachtingen in beperkte mate en langetermijnverwachtingen in hoge mate stabiel zijn, omdat zij gemiddeld genomen nooit boven een toekomstig niveau uitschieten en omdat marktparticipanten waarde hechten aan hun eigen fouten in het verleden.

In hoofdstuk 4 bekijken we een alternatieve verklaring voor de termijncontracten anomalie (zoals beschreven in hoofdstuk 3), namelijk of de systematische voorspelfouten in de prijsvorming van termijncontracten mede ontstaan doordat de premie die marktparticipanten doorgaans verlangen wanneer ze voor langere termijn in de toekomst investeren, varieert met de tijd. Deze premie wordt derhalve ook een tijdsvariërende termijnpremie genoemd. We constateren niet alleen dat deze premies positief aanwezig zijn (wat erop zou kunnen duiden dat deze premies ontstaan doordat rentecontracten met een korte looptijd veel liquider zijn dan rentecontracten met een lange looptijd), maar ook dat de premies sterk tijdsvariërend zijn en erg persistent.

Het hoofdstuk probeert daaropvolgend een verklaring voor deze tijdsvariatie te geven, door middel van een aantal tijdreeksmodellen. We beschrijven dat ondanks het feit dat eenvoudige modellen van de ARMA-klasse in staat zijn om de tijdsvariatie na te bootsen, volatiliteitsclusters in de data aanleiding geven te veronderstellen dat GARCH-modellen het meest geschikt zijn om deze tijdsvariatie te modelleren. Dit betekent dat de tijdsvariatie in de termijnpremies ontstaat door de verandering in risicoperceptie van de marktparticipanten.

In hoofdstuk 5 maken we de overstap naar het gebied van de wisselkoersen. We bekijken de mate waarin de verwachtingen van marktparticipanten fundamenteel van elkaar verschillen. We noemen dit 'heterogeniteit' in de verwachtingen. De vragen die in dit hoofdstuk centraal staan zijn: 1) Hoe dient heterogeniteit statistisch gezien aangetoond te worden?, 2) Wat is de verklaring voor deze heterogeniteit?, 3) Hoe kan de heterogeniteit in causaal verband worden gebracht met de volatiliteit in de markt? Door opnieuw gebruik te maken van verwachtingsdata voor de drie belangrijkste wisselkoersen tonen we aan dat er specifieke perioden zijn waarin deze heterogeniteit hoog is en specifieke perioden waarin zij laag is en dat de mate van heterogeniteit toeneemt met de voorspelhorizon. Zo heeft de Aziëcrisis binnen de wisselkoersliteratuur een aanzienlijk effect gehad op de heterogeniteit van wisselkoersverwachtingen in de daaropvolgende periode.

We tonen de heterogeniteit van wisselkoersverwachtingen aan door middel van een concept uit de literatuur over extreme waarden, te weten de staartindex van de verdeling van de verwachtingen. De mate waarin extreme verschillen in verwachtingen voorkomen, is vele malen hoger dan wat normaal gezien het geval zou moeten 
zijn. We tonen aan dat deze heterogeniteit niet alleen te verklaren is doordat marktparticipanten informatie gebruiken in hun voorspelproces die uniek is voor ieder van hen, maar ook doordat zij gezamenlijke informatie verschillend interpreteren. Ook tonen we aan dat bij verschillende voorspeltermijnen marktparticipanten de nadruk leggen op andere technieken: als de voorspeltermijn toeneemt, nemen de verschillen tussen marktparticipanten die gebruik maken van fundamentele voorspeltechnieken (bijvoorbeeld aan de hand van macro-economische data) af. Tenslotte bekijkt hoofdstuk 5 het causale verband tussen de heterogeniteit in de verwachtingen enerzijds en de volatiliteit in de wisselkoersmarkt anderzijds. Wanneer er goede maatstaven worden gebruikt om zowel de heterogeniteit als de marktvolatiliteit te meten, dan blijkt er een complexer, in twee richtingen werkend causaal verband te bestaan. Heterogeniteit beïnvloedt de volatiliteit in de markt, maar door een 'feedback'-regel wordt de heterogeniteit ook weer beïnvloed door de volatiliteit in de markt.

Hoofdstuk 6 bouwt verder op de materie in hoofdstuk 5 door te analyseren of heterogeniteit wellicht ontstaat doordat er twee fundamenteel verschillende soorten marktparticipanten opereren in de markt voor vreemde valuta's. We maken het onderscheid tussen fundamentalisten en technische analisten. We ontwikkelen een theoretisch kader waarbij elke verwachting een gewogen gemiddelde is van de voorspelling van een fundamentalistische en technische voorspeltechniek. De fundamentalistische voorspeltechnieken zijn gebaseerd op de koopkrachtpariteittechniek en een techniek gebaseerd op het monetaire model. De technische voorspeltechnieken zijn een extrapolerende techniek en een techniek gebaseerd op het voortschrijdend gemiddelde van de wisselkoers in het verleden.

Deze technieken worden vervolgens geïmplementeerd in drie modellen. Het eerste model is een lineair model waarbij de gewichten van de verschillende voorspeltechnieken constant worden gehouden. Het blijkt dat zowel fundamentele als technische analyse wordt gebruikt door marktparticipanten, maar dat de manier waarop deze gebruikt worden, verschilt. Ondanks het feit dat technische analyse wordt gebruikt voor zowel korte- als langetermijnvoorspellingen, ligt de nadruk met name op het gebruik op de korte termijn. Een extrapolerend voorspelmodel heeft in ieder geval altijd de voorkeur boven een model gebaseerd op het voortschrijdend gemiddelde van de wisselkoers in het verleden. Voorspelmodellen gebaseerd op macro-economische variabelen worden echter hoofdzakelijk gebruikt voor langetermijnvoorspellingen.

Het tweede model is een 'heterogene agenten model' dat de mogelijkheid toelaat dat 'agenten' (in dit geval de marktparticipanten) wisselen van de ene naar de andere voorspeltechniek, waarbij de mate van wisselen bepaald wordt door het relatieve succes van elke techniek in het verleden. Alhoewel de parameter die de mate van wisselen in dit model beschrijft, niet altijd significant is, leidt de introductie ervan wel tot een verbetering van de kwaliteit van dit model ten opzichte van het lineaire model. Dit is een bewijs dat het wisselen van voorspeltechnieken daadwerkelijk plaatsvindt in de praktijk.

Tenslotte bekijken we een 'state-space' model waar de gewichten tijdsvariërend zijn en deze gewichten een eenvoudig tijdreeksproces worden verondersteld te volgen. De gewichten voor de fundamentele technieken blijken alle persistent te zijn, aangezien deze een bijna-eenheidswortelproces volgen. Met andere woorden, het 
gewicht dat marktparticipanten geven aan een fundamentele voorspeltechniek verandert niet aanzienlijk in de ene periode ten opzichte van de andere. Anderzijds blijken de gewichten voor de technische voorspeltechnieken aanzienlijk minder persistent te zijn, een teken dat marktparticipanten niet 'trouw' blijven aan een technische voorspeltechniek en sneller geneigd zijn deze niet te gebruiken, ondanks dat men deze technieken wellicht eerder wel gebruikt heeft. Ook tonen we aan dat de correlatie tussen fundamentele en technische gewichten voornamelijk negatief is. Dit is een interessante bevinding: beide typen voorspeltechnieken worden gebruikt, in die zin dat een toename in het gebruik van de ene techniek doorgaans leidt tot een (gedeeltelijke) afname in het gebruik van de andere techniek en vice versa.

Tenslotte bekijken we in hoofdstuk 7 de materie van wisselkoersrisico opnieuw aan de hand van verwachtingsdata door expliciet gebruik te maken van het verschil tussen gerealiseerde en onverwachte wisselkoersveranderingen. Gebruik makende van een steekproef van 935 Amerikaanse multinationals met activiteiten in het buitenland onderzoeken we het effect van een gerealiseerde en een onverwachte wisselkoersverandering op de waarde van deze bedrijven gedurende de periode 1995-2005. Onze resultaten tonen aan dat het gebruik van bedrijfsspecifieke en regio-gewogen maatstaven voor wisselkoersrisico de precisie en aantoonbaarheid van wisselkoersrisico significant verhoogt. Verder leidt het gebruik van verwachtingsdata tot de mogelijkheid om de invloed van zowel gerealiseerde als onverwachte wisselkoersveranderingen op de waardeverandering van deze multinationals te vergelijken. Bovendien kunnen we met verwachtingsdata bekijken in hoeverre marktparticipanten deze verwachte veranderingen als informatie hebben meegenomen in hun prijsvormingsproces.

Er is statistisch sterk bewijs dat de waardeverandering van de multinationals minder beïnvloed wordt door gerealiseerde wisselkoersveranderingen dan door onverwachte veranderingen. Van meer dan 40 procent (ten opzichte van 32 procent) van deze bedrijven wordt de waarde beïnvloed door onverwachte (ten opzichte van gerealiseerde) wisselkoersveranderingen. Bij het totstandkomen van de waarde van multinationals gebruiken investeerders dus de informatie die publiekelijk beschikbaar is betreffende de verwachte verandering van wisselkoersen. 



\section{Curriculum Vitae}

Ron Jongen was born on March 28, 1980 in Heerlen, The Netherlands. He studied International Business Studies and Econometrics at Maastricht University and graduated in 2002 with a Master's degree (with honours) in International Business Studies, majoring in finance.

In 2003 he joined the Department of Finance at Maastricht University to write his doctoral dissertation on expectations in financial markets, in particular for the interest rate market and the foreign exchange market, under the supervision of Prof. dr. Christian Wolff and Prof. dr. Willem Verschoor. During this period he also lectured various courses in the field of international and corporate finance. He completed his dissertation in 2007.

Ron Jongen has presented his work at numerous leading international conferences, among which the Annual Meetings of the European Finance Association and the American and European Financial Management Association meetings, and has been invited to present his work at various academic and professional institutions. His work is published or forthcoming in various international refereed academic journals.

As of 2008 he is employed as a policy advisor at the quantitative risk management department of the Dutch Central Bank's supervision directorate. Part of his job is devoted to fundamental research. In his ongoing research, he keeps a keen interest in international finance, banking, and the role of the behavior of individual market participants. 